\title{
TOWARDS DIGITAL SOIL MAPPING OF THAILAND
}

Ruamporn Moonjun 



\title{
TOWARDS DIGITAL SOIL MAPPING OF THAILAND
}

\author{
DISSERTATION
}

to obtain

the degree of doctor at the University of Twente, on the authority of the rector magnificus,

Prof.dr. T.T.M. Palstra,

on account of the decision of the Doctorate Board, to be publicly defended on Friday 21 June 2019 at $10.45 \mathrm{hrs}$

by

Ruamporn Moonjun

born on 7 June, 1976

in Nan, Thailand 
This thesis has been approved by:

Prof.dr. V.G. Jetten, supervisor

Dr. D.B.P. Shrestha, co-supervisor

ITC dissertation number 356

ITC, P.O. Box 217, 7500 AE Enschede, The Netherlands

ISBN 978-90-365-4806-9

DOI 10.3990/1.9789036548069

Cover designed by Benno Masselink

Printed by ITC Printing Department

Copyright (C) 2019 by Ruamporn Moonjun

TUC FACULTY OF GEO-INFORMATION SCIENCE AND EARTH OBSERVATION 
Graduation committee:

Chairman/Secretary

Prof.dr.ir. A. Veldkamp University of Twente

Supervisor

Prof.dr. V.G. Jetten University of Twente

Co-supervisor

Dr. D.P. Shrestha University of Twente

Members:

Prof.dr.ir. A. Veldkamp University of Twente

Prof.dr.ir. A. Stein University of Twente

Prof.dr. S.M. de Jong Utrecht University

Prof.dr.ir. G.B.M. Heuvelink Wageningen University

Prof.dr. K. Stahr Universität Hohenheim, Germany 



\section{Acknowledgements}

Firstly, I would like to express my sincere gratitude to my promoter Prof. Victor Jetten, for the continuous support of my Ph.D study, for his patience, motivation, and immense knowledge. His guidance helped me in all the time of research and writing of this thesis

I would like to express my special appreciation and thanks to my co-promoter and advisor, Dr. Dhruba Pikha Shrestha, who has been a great mentor for me. I would like to thank you, Dhruba, for motivating me in learning new things and encouraging me in doing research. Your advices on both research as well as on my professional career have been priceless. I could not have imagined having a better advisor and mentor for my Ph.D. study.

Besides my advisor, I would like to thank the rest of my thesis examination committee: Prof.dr.ir. A. Veldkamp, Prof.dr.ir. A. Stein, Prof. dr. S.M. de Jong, Prof.dr.ir. G.B.M. Heuvelink and Prof.dr. K. Stahr for their insightful comments and encouragement, but also for the hard questions which incented me to widen my research from various perspectives.

My sincere thanks goes to Dr. Abbas Farshad, who was my MSc supervisor and being my PhD. supervisor during the initial period of proposal writing. He was the one who taught me the geopedologic approach, which I always use during soil survey activity in Thailand.

My sincere thanks also goes to Dr. David Rossiter, who helped me in the initial stages of my $\mathrm{PhD}$ research. I am indebted to his valuable comments. I would also like to thank Dr. Frank Ruitenbeek, who taught me how to use gamma-ray imagery for soil survey perspective.

The Department of Mineral Resources is acknowledged for providing me the gamma-ray data. Mr. Apichart Paiyarom (geologist and senior professional) is thanked for helping me in image interpretation.

I would like to thank Dr. Ard Somrang, Mrs. Parida Kuneeping, Mr. Anukul Suchinai and Mr. Satira Udomsri for their continuous support in my work. I would also like to thank the soil surveyors and staffs from LDD who supported me in the field survey and laboratory analysis for this research project: [Mr. Tawil, Mr. Chaturong Laorpansakul, Mr. Chaturong Pechsuit, Mr. Chakrapan, Mr. Mahitthorn, Mr. Tanatkrit, Mr. Kridsophon, Mr. Panlop, Mr. Ninnat, Mr. Danai, Mr. Monton, Mr. Akkrasit, Ms. Thanyathorn, Ms. Wipawan, Ms. 
Wanwisa, Mr. Supicha and Ms. Suwapat]. Without their support, field data collection could not be successful.

I gratefully acknowledge the Agricultural Research Development Agency (ARDA) for providing me with financial support and the Land Development Department (LDD), Ministry of Agriculture and Cooperatives for allowing me to carry out my study. Without their support, my Ph.D. work cannot be successful.

Finally, I must express my very profound gratitude to my parents for providing me with unfailing support and continuous encouragement throughout my years of study and through the process of researching and writing this thesis. This accomplishment would not have been possible without them. It is a pity that my dad could not see me having this achievement, since he passed away in the fourth year of my Ph.D. research. I will always miss you and remember your teachings in my heart forever. 


\section{Table of Contents}

List of figures .......................................................................................................................iv

List of tables ........................................................................................................................ vii

Chapter 1 Introduction ......................................................................................................... 1

1.1 Purpose of mapping soils and needs for soil data in Thailand ............ 2



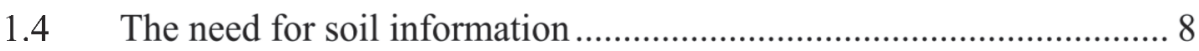

1.5 Digital soil mapping (DSM)/Predictive soil mapping (PSM) as a new approach for soil surveys ................................................. 10



1.5.2 Geomorphometry and terrain analysis.......................................... 11

1.5.3 Application of gamma-ray data in soil survey ............................. 12

1.5.4 Soil spatial predictions - Soil factorial models ............................. 13

1.6 Research objectives and questions .................................................. 14

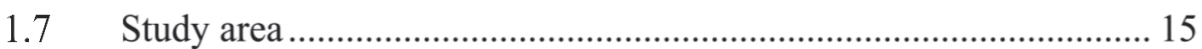

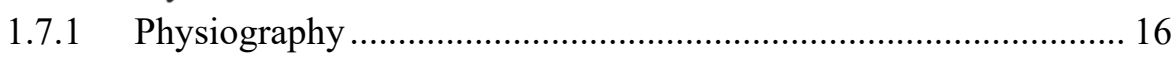

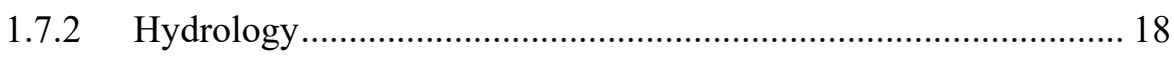



Chapter 2 Digital terrain analysis for fine-scale digital soil mapping in Thailand ...... 21

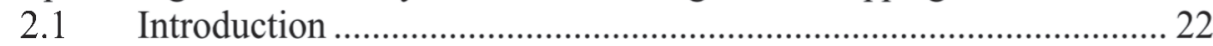

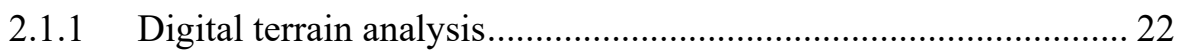

2.1.2 Soil mapping in Thailand ............................................................. 23

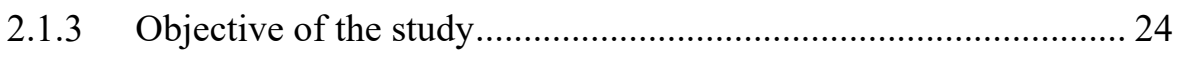

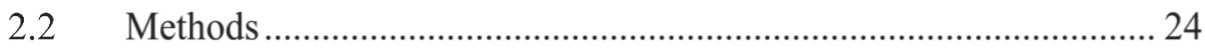

2.2.1 Digital elevation model and terrain analysis ................................. 25

2.2.2 Geopedological map and soil sampling........................................ 29

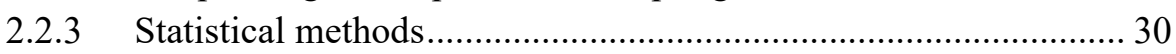

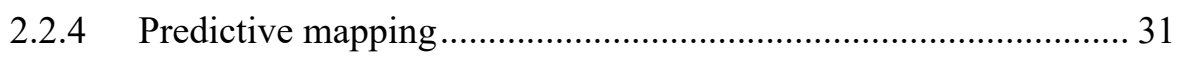

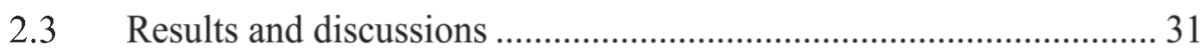

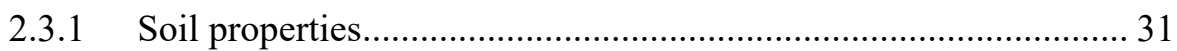

2.3.2 Terrain attributes .......................................................................... 34

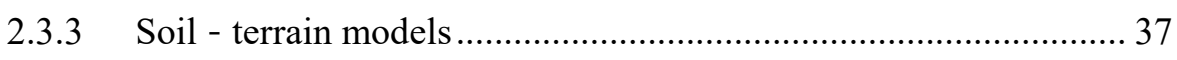

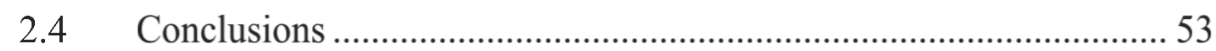

Chapter 3 Application of Airborne Gamma-Ray Imagery to Assist Soil Survey ....... 55

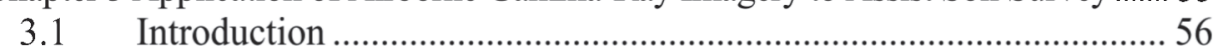

3.2 Materials and methods.................................................................. 58

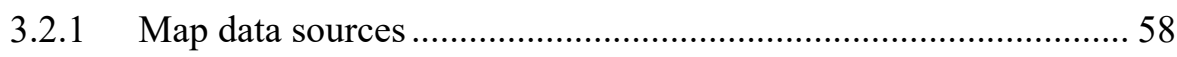




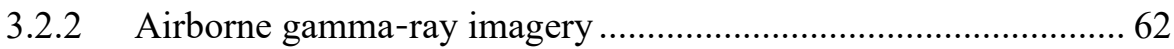

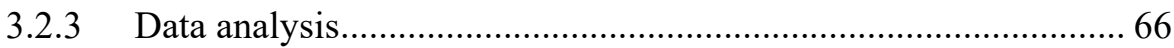



3.3.1 Relationships between gamma-ray data and geological units....... 67

3.3.2 Relationships between gamma-ray data and soils developed

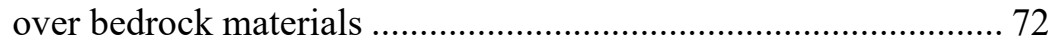

3.3.3 Relationships between gamma-ray data and soils developed

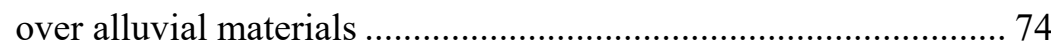

3.3.4 Comparison of gamma-ray imagery and the geopedologic map... 80

3.3.5 Comparison of gamma-ray imagery and the soil series map ........ 82

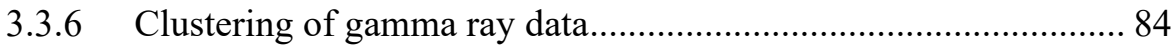

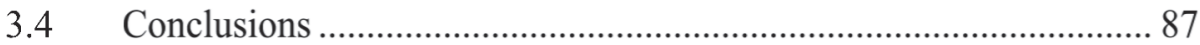

3.5 Recommendations for using gamma ray data in soil survey

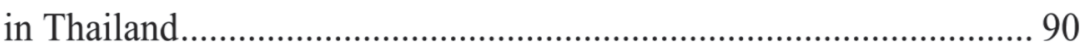

Chapter 4 Fuzzy logic for fine-scale digital soil mapping ............................................... 91

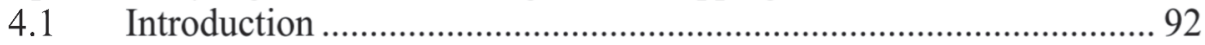

4.2 Materials and methods............................................................... 94

4.2.1 Map data sources as predictor variables ......................................... 94

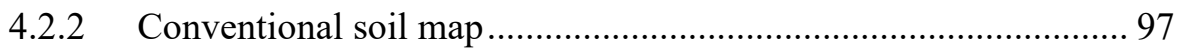

4.2.3 Soil observations based on geopedological map units ................... 98

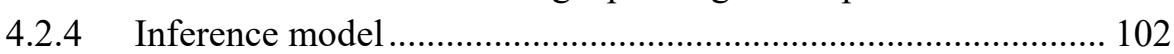

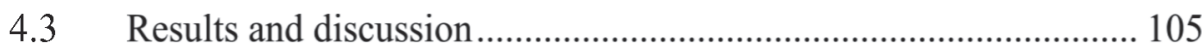

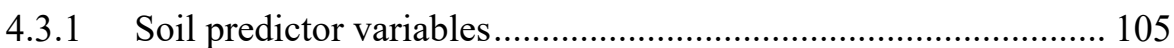

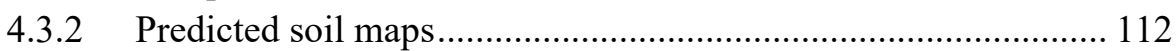

4.3.3 Accuracy and uncertainty assessments....................................... 115

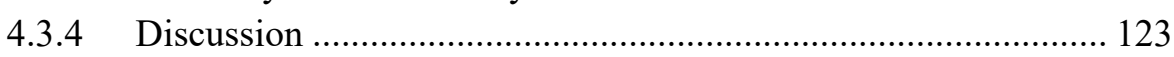

4.4 Conclusions and recommendations ............................................... 125

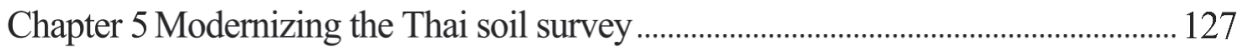

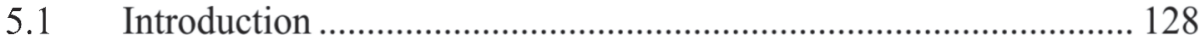

5.2 Product generation from soil maps................................................... 130

5.3 New challenges to the Thai soil survey .......................................... 132

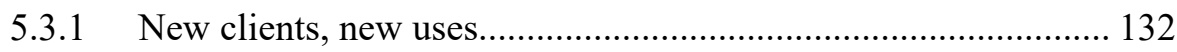

5.3.2 New survey activities by the LDD ............................................. 133

5.3.3 Challenges in applying modern soil survey concepts.................. 134

5.3.4 Human resource and budget constraints ...................................... 135

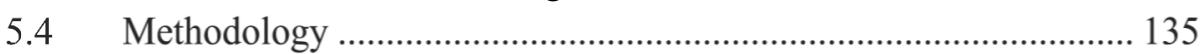

5.4.1 Introducing DSM at medium scales ....................................... 136 


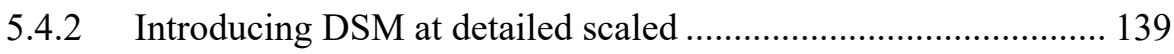

5.4.3 Quality control / adequacy assessment ...................................... 139

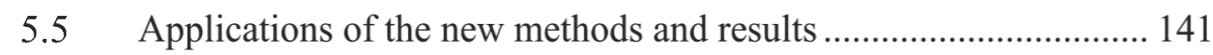

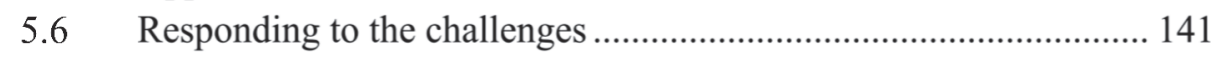

5.6.1 Communication with and identification of new clients............... 141

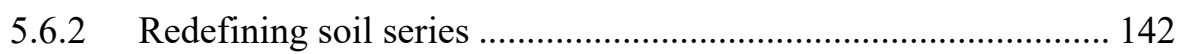

5.6.3 Organization and human resources .............................................. 143

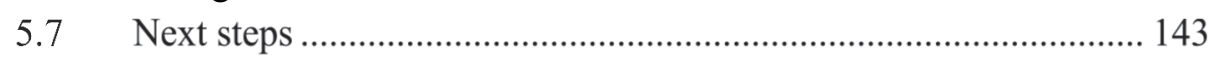

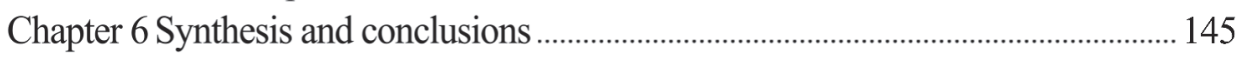

6.1 Potential for digital soil mapping in Thailand ..................................... 146

6.1.1 Using high resolution DEMs and digital terrain analysis

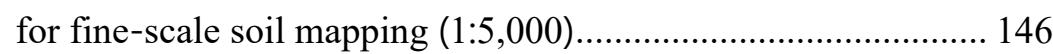

6.1.2 Investigating the use of airborne gamma-ray data to

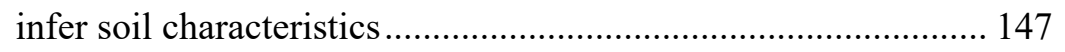

6.1.3 Investigate a combined fuzzy logic predictive method with parameters of soil forming factors, and evaluate its success in mapping soil series and properties............................. 148

6.1.4 The state of soil survey, current needs and application perspectives, and establishing a digital soil survey framework for environment.................................................... 149

6.2 Suggestions for further research................................................... 150

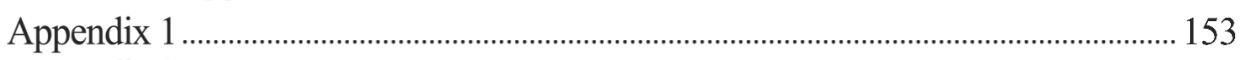

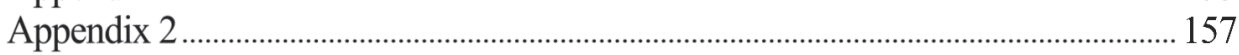

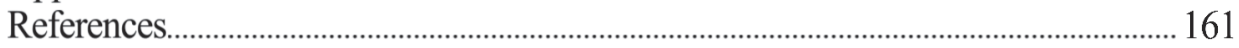

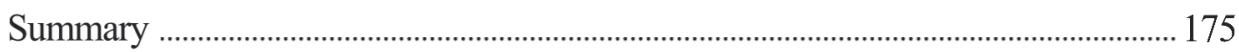

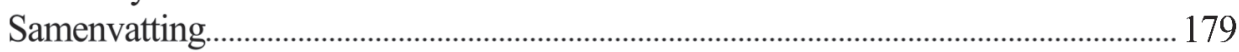

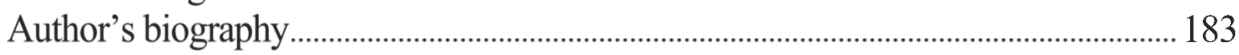




\section{List of figures}

Figure 1.1 Landuse change data of Thailand (2006-2016) (Land Development Department, 2016)

8

Figure 1.2 Schematic representation of the times needed to attain various properties of soils (A) and orders of soils, as recognized by the 'Soil Conservation Service' of the US Department of Agriculture (B) (Retallack, 2001)... 13

Figure 1.3 Upper Pa Sak watershed, a) 3D views of the Upper Pa Sak watershed and b) the study area within the watershed is demarcated by the purple line. .. 16 Figure 2.1 Terrain attributes derived from 5- $\mathrm{m}$ and 10-m DEM in difference

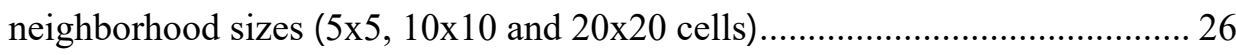
Figure 2.2 Square-grid showing a 3x3 moving window.................................. 27 Figure 2.3 (a) Geopedological landscapes with observation points and areas of interest; (b) Soil series map (1:50,000) by updating the geopedological map. For a description of the legend see Appendix 1 and 2. 30 Figure 2.4 Bivariate scatterplot of soil properties, the strong correlation showing in the black circle 34

Figure 2.5 Pairwise scatterplot for the terrain attributes for the 5- $\mathrm{m}$ resolution DEM with $5 \times 5$-widow combination, the strong correlation showing in black circles.

Figure 2.6 Success of predicted soil series and evaluating models using ROC curve; (a) Tn series vs CTI derived from 5-m DEM with 10x10 neighborhoods size, (b) Li series vs CTI derived from 5-m DEM with 10x10 neighborhoods, (c) Tn series vs PCA from 10-m DEM with 5x5 neighborhoods size, (d) Li series vs PCA derived from 10-m DEM with 5x5 neighborhoods. 44

Figure 2.7 Predicted soil-landscape model in 5 sample areas (a, b, c d, and e) implemented from subsoil bulk density with DTM in five areas; A) 5-m DEM with 20x20 neighborhoods size and B) 10-m DEM with 10x10 neighborhood sizes. Dark color refers to high bulk density... 46

Figure 2. 8 Predicted soil- landscape model in 5 sample areas (a, b, c, d and e) implemented from subsoil $\mathrm{pH}$ with DTM in five areas; A) 5-m DEM with 20x20 neighborhoods size and B) 10-m DEM with 10x10 neighborhoods size. Dark color refers to high soil $\mathrm{pH}$. 47

Figure 2.9 The spatial pattern and concentration on predicted area, differentiation between predictions (subtraction) from 5-m DEM with 20x20 neighborhoods size 
and 10-m. DEM with 10x10 neighborhoods size in 5 sample areas (a, b, c and d); A) subsoil bulk density: and $\mathrm{B}$ ) subsoil $\mathrm{pH}$. Positive value means prediction is better in 5-m. DEM and negative value means prediction is better in 10-m. DEM. Positive value means prediction is better in 5-m DEM and negative value means prediction is better in 10-m DEM.

Figure 2.10 Predicted soil- landscape model in 5 sample areas (a, b, c, d and e) implemented from soil series ( $\mathrm{Li}$ ) in five areas; A) 5-m DEM with10x10 neighborhoods size and B) 10-m DEM with $5 \times 5$ neighborhoods size. 50

Figure 2.11 Predicted soil- landscape model in 5 sample areas (a, b, c, d and e) implemented from soil series ( $\mathrm{Tn}$ ) in five areas; A) 5-m DEM with10x10 neighborhoods size $\mathrm{Bb}$ ) and 10- $\mathrm{m}$ DEM with $5 \times 5$ neighborhoods size. Positive value means prediction is better in $5 \mathrm{~m}$ DEM and low value means prediction is better in $10 \mathrm{~m}$ DEM. 51

Figure 2.12 The spatial pattern and concentration on predicted area, differentiation between predictions (subtraction) from 5-m DEM with 20x20 neighborhoods size and 10-m DEM with 10x10 neighborhoods size in 5 sample areas (a, b, c, d and e) ; A) Li series and B) Tn series. Positive value means prediction is better in $5 \mathrm{~m}$ DEM and negative value means prediction is better in $10 \mathrm{~m}$ DEM.

Figure 3.1 A landscape map showing boundary of geological formations and the location of soil profiles 61

Figure 3. 2 An enhanced ternary image fused with hill- shaded DEM, also indicated the locations of 15 flight lines. 65

Figure 3.3 Box and whisker plots showing the radioelement contents of lithological units 70

Figure 3.4 Radio element maps of Upper Pa Sak watershed map; (a)\%K, eTh, (c) eU, eU/K, (e) eTh/K and (f) eU/K ...................................... 71 Figure 3.5 Concentration of $\mathrm{K}$, eTh and eU of 11 soil profile observations ... 78 Figure 3.6 3D landscape perspective of ternary image and geology (Description of the geological map units are shown in Table 1) with (a) rock samples: A1, andesite\& rhyorite\&tuff; A2, diorite; A3, andesite; B, calcareous sandstone\&sandstone; C, greenish coarse pebblish sandstone; D, sand stone; E, diorite\&andesite\&volcanic grass; F1, shale in Ps: F2, shale in Trhl; G, shale\&silt stone; $\mathrm{H}$, silt stone; I, residual quartz and accumulation of oxides and resistant materials; J, mixed-fine material; K1, mixed-coarse material, quartz and quartzite gravels and K2, laterite. (b) Soil characteristic formed over gresidual material in 
upland and alluvial material in flood plain. (c) Two topographic profiles along Pasak river (R), mixed recent alluvial soil (A1), two cross lines from left to right; A2. 1 = old alluvium material formed extremely gravelly soil and A2.2 = old alluvium formed lateritic soil.

Figure 3.7 Geopedologic map over lay on a ternary image draped over digital elevation, showing the four geopedologic levels to gamma- ray response. (a) Landscape level. (b) Lithologic level, 1; Alluvio-colluvium, 2; Alluvium, 12; Residual/ Alluvio- colluvium, 13; sandstone\& siltstone \& shale and17; shale sandstone\& mudstone \& andesite. (c) Relief types, in red circles show distribution of radioelement on higher terraces- $\mathrm{Pi} 2$ and lower terraces $-\mathrm{Pi} 3$ and (d) Landform map units (coded to soil classification at great soil group)......... 81 Figure 3.8 Overlay of soil series map on gamma-ray ternary image. Red circles show good matching of soil series to radioelement and yellow circles show missmatching. Black circles with unit SC mean slope complex. 83

Figure 3.9 Clustering of gamma ray and elevation (DEM) for differentiating soil

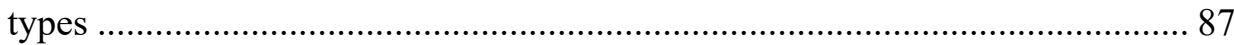

Figure 4.1: Clustering of gamma ray and elevation (DEM) for differentiating soil Lithology map of the study area 95

Figure 4. 2: Compound topographic index calculated from 10x10 m DEM indicating level of topographic wetness.

Figure 4.3: Conventional soil map at scale 1.50,000 (see also Appendix 2).... 98 Figure 4.4: Geopedological units with soil observation points (see appendices 1 and 2 for the description of the legend). .99

Figure 4.5: Distribution of soil series observations in 7 lithological units, the first bar represents the number of observations and the second bar the percentage of occurrences 105

Figure 4.6: Boxplot showing the relation of 17 soil series and Rock land (RL), a) Compound topographic index (CTI) and b) slope with a 10x10 m grid cell... 106 Figure 4.7: Boxplot showing the relation of topsoil texture with: a) slope percent and b) compound topographic index. Where $\mathrm{cl}=$ clay loam, $\mathrm{gcl}=$ gravelly clay loam, $1=$ loam, $\mathrm{RL}=$ Rock land + Rock out crop, $\mathrm{scl}=$ sandy clay loam, $\mathrm{sgcl}=$ slightly gravelly clay loam, sic=silty clay, sicl=silty clay loam, sil=silt loam and $\mathrm{sl}=$ sandy loam and $\mathrm{rl}=$ Rock land. 
Figure 4.8: Examples of normalized membership to individual soil series derived from fuzzy logic: the values show the degree of membership to a given soil series.

Figure 4.9: Soil series map derived from hardening (defuzzification) with a) hardened map at 1:120,000 map scale and b) enlarged view of area in red box with 1:10,000 map scale

Figure 4.10: The representative of individual topsoil texture units derived from fuzzy logic: the value is the fuzzy membership to the topsoil texture class (0-1)

Figure 4.11: Topsoil texture map derived from fuzzy method with a) hardened map enlarged view at 1:1,000,000 map scale and b) enlarged view of area in red box with 1:15,000 map scale 115

Figure 4.12: Soil series maps based on: a) fuzzy logic, and b) conventional soil mapping 118

Figure 4.13: Ignorance uncertainty map (a) where low values indicate a low uncertainty, and a high membership to one of the given soil series, and the exaggeration uncertainty map (b) 120

Figure 4.14: Example of image fragments of result of hardening of three soil serie; Ds, So and Ws (a) uncertainties ignorance uncertainty (b) and exxageration uncertainty (c). 120

Figure 4.15: Ignorance uncertainty map of topsoil texture map (a) with light tones indicating low ignorance uncertainty value and exaggeration uncertainty map (b) with light tone is low exaggeration uncertainty 122 Figure 4.16: a) Three variation of topsoil texture map units which also includes a miscellaneous rockland unit (RL), b) spacial variation of ignorance uncertainty and c) spatial variation of exageration uncertainty.... 123

Figure 5. 1 Historical soil maps of Thailand: a) general soil map 1953 at 1:2,500,000 scales, b) general soil map 1964 at 1:1,000,000 scales and c) revised soil map 1979 at 1:1,000,000 scales 130 Figure 5.2: Modernizing soil survey with GIS and RS environment: a) GPS device, b) GIS application for digitizing and storing soil map, c) ortho-photography with 2-m contour interval, d) 3D perspective of ortho-photography, e) 3D of high resolution $\operatorname{DEM}(5-\mathrm{m})$ and f) 3D perspective generated from 5-m DEM. 136 
Figure 5.3:Simplification of digital soil mapping framework for Thai soil survey

\section{List of tables}

Table 1.1 The category of soil classification and required dominant soil properties

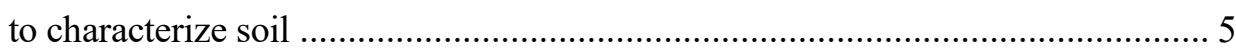

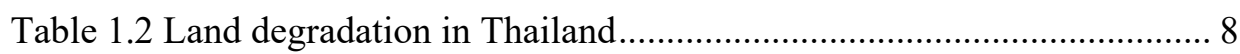

Table 2.1 Descriptive statistics of selected soil properties ................................ 32

Table 2.2 Correlation matrix of selected soil properties .................................. 33

Table 2.3 Descriptive statistics for trimmed terrain attributes for two combinations of

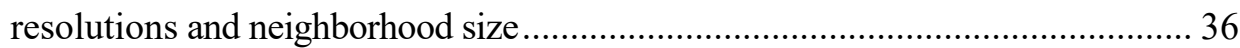

Table 2.4 Pairwise partial linear correlation coefficients between subsoil bulk density and trimmed terrain variables ......................................................... 38

Table 2.5. Pairwise partial linear correlation coefficients between soil properties and trimmed terrain attributes, with $5-\mathrm{m}$ resolution DEM and $5 \times 5 \mathrm{~m}$

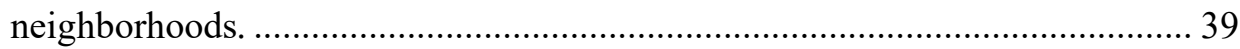

Table 2. 6 Goodness- of- fit of linear models of soil properties by standardized principal components of terrain parameters …………………………............ 39

Table 2. 7 Goodness- of- fit of logistic regression models (in section 2.2.3) for prediction of three soil series ( $\mathrm{Li}, \mathrm{Tn}$ and Ws series)

Table 2. 8 Comparison of logistic regression model performance between three soil series and standardized principal components of terrain attributes ............ 42

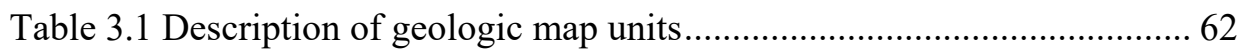

Table 3.2 Summary statistics of radioelements .............................................. 70

Table 3.3 Major mineral components, soil analyses and soil classifications for 11

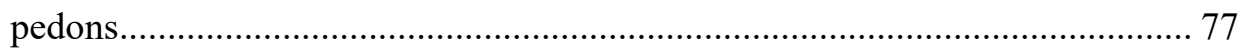

Table 3.4 Main soil characteristics and relative contents of Th, $\mathrm{K}$ and $\mathrm{U}$......... 82

Table 3.5 Clustering of gamma ray and DEM for soil differentiation .............. 84

Table 3.6 Classification accuracy assessment for soil differentiation............... 85

Table 3. 7 Classification accuracy assessment for soil parent material

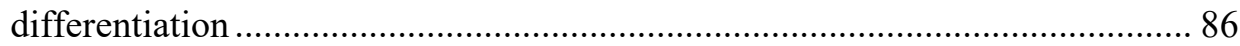

Table 4.1 Observation data, soil series and lithology ...................................... 100

Table 4.2 Fuzzy membership function construction...................................... 103

Table 4.3 Statistics of terrain parameters of soil series .................................. 108

viii 
Table 4.4 Similarity/dissimilarity between soil series in topographic parameter 109

Table 4.5 The error matrix for 17 soil series and one rock land unit derived from fuzzy logic 116

Table 4.6 The error matrix for conventional soil map with 8 soil series 117 Table 4.7 The error matrix for topsoil texture classes and one miscellaneous unit (RL) derived from fuzzy logic. The first column contains topsoil texture classes from inference results and the first row contains topsoil texture specified by field observation data. 119

Table 4.8 Example of three locations showing membership value of 17 soil series with their final classification and their uncertainty values. 121

Table 4.9 The variation of soil occurrence probability of 12 topsoil texture in three locations and with their uncertainty values. 
Chapter 1 Introduction 


\subsection{Purpose of mapping soils and needs for soil data in Thailand}

Apart from a few industrial countries, most of the developing nations depend on subsistence agriculture, for which soil is a valuable resource. But availability of soil data and soil maps varies from country to country. Examples vary from the Netherlands where very detailed information about soils is available (Hartemink, 2008) to Bhutan, where soil mapping started only in 1992 (http://www.austinhutcheon.com/bss.html, site visited on 23 Nov 2017), and soil survey activities still need to be continued to map the whole country. Soil mapping was initiated in Thailand as early as 1941. In 1953 the first soil map at the scale of 1:2,500,000 was produced by the Department of Agriculture and Fisheries. Since 1991 soil map coverage for the whole country at the scale of 1:50,000 is available, although it covers only cultivated areas below $35 \%$ slope. So, soil data is still lacking in Thailand in the hilly and the mountainous areas, which make up approximately 30 percent of the country.

In Thailand, large scale soil survey maps are in demand to support the planning and management of agricultural and environmental projects undertaken by government/semi-government agencies because the existing maps do not provide adequate information. Currently, soil surveys at detailed scale are carried out only in small areas for specific purposes (Moonjun et al., 2008). Since soil maps are produced following the traditional method (Soil Survey Staff, 1993) it depends on the experience of surveyors and thus it includes some degree of subjectivity. It is also not easily retrievable and it is usually low in accuracy. Since it is manual it is time consuming and the production costs are high (Zhu et al., 2001).

Since Thailand is basically an agricultural country with 70 percent of the population directly involved in it, soil resources have been considered very important for livelihood. In addition to its use for crop production, importance of soil data have also been recognized in a variety of applications e.g. for land use planning, military purposes (troop movement, i. e. traffic ability of soils), engineering use (road and building construction), natural hazard assessments and for watershed management. The main responsible authority for providing soil information is the 'Land Development Department' (LDD) which belongs to the Ministry of Agriculture \& Cooperatives.

The LDD is responsible for providing information about soil geography and its properties at various levels. Very detailed soil maps at farm level show phases of soil series and soil properties (see also in section 1.2). Fine scaled and very detailed soil maps (scales from 1: 4,000 to 1:5,000) are used for land use planning 
at farm level, at sub-district levels and within watershed management projects. Soil survey projects for detailed soil mapping started in Thailand in 2005, using conventional techniques, which are slow and expensive, and yet these resulted in large scale soil maps which are now well suited for multipurpose applications.

The multiple uses mentioned above demand fine scaled soil maps and corresponding soil information, in order to solve problems related to soil and land resources. Currently the soil survey products (maps) are inadequate, both in terms of their information content (soil properties) and also in terms of cartography (i.e. cartographic detail and poorly defined map units and boundary criteria).

\subsection{Soil survey and mapping in Thailand}

A soil survey is the systematic description and a detailed report of soils in the field. In soil survey, soils are grouped into similar types and well- defined mapping units with soil boundaries, description and table of soil properties and features.

In general, soil surveys in Thailand can be divided in to main categories: basic or general purpose and specific purposes soil surveys.

1) Basic soil surveys

These might also be called "general purpose soil survey. The basic soil survey takes into account all observable soil characteristics in determining the taxonomic models, which form the nucleus of the survey. Each taxonomic unit represents the modal concept and is evaluated on the basis of topographic position, association with other kinds of soil, size or area of extent, climate and relief, to determine the mapping unit. Each mapping unit is defined and its location and extent delineated on the bass map to form the soil map. The basic soil survey may be made at any of several levels of intensity. Taxonomic units on which the mapping units are based may be soil series, soil variants, families or great groups. These may be mapped individually or as geographic associations or complexes phases of any taxonomic unit may be recognized depending on conditions of relief, stoniness, depth etc., that are important to the use and management requirements.

Each taxonomic model, whether a soil series or a great group, is a natural body with a distinct set of soil characteristics which are combinations of all observable features relevant to the nature and behavior of the soil. Because of this, selected interpretations of soil conditions may be drawn from a basic soil survey. Such interpretations may need to be changed as changes occur in agricultural 
technology and the cultural environment. This does not require another soil survey, just a different interpretation of the information.

Soils are generally classified at series level following the UDSA soil taxonomy system (Soil Survey Staff, 1993) and the mapping units are described as complexes or associations consisting of the soil pedon properties. A soil classification system has proven to be a useful concept in the past when the general purpose soil survey data was used for a variety of applications often with a qualitative, descriptive character (Soil Survey Staff, 1993). The soil properties required for soil classification in each level are given in (Table 1.1). The Land Development Department (LDD) has established almost 300 series in the whole country as of 2016 .

The soil map units are based on series and can be found in four kinds: 1) soil consociations, 2) soil associations, 3) soil complexes and 4) undifferentiated soil groups. A consociation map unit consist of a homogeneous or single soil unit (series), which covers more than half of the units area and the rest is called "inclusion". As such, the soil component in a consociation may be identified at any taxonomic level and soil series is the lowest taxonomic level.

Complexes and association units consist of two or more dissimilar components that occur in a regularly repeating pattern. The total amount of other dissimilar components is minor in extent. The following arbitrary rule determines whether "complex" or "association" is used in the name: the major components of a complex cannot be delineated separately at the scale of mapping, or the major components of an association can be delineated separately at the scale of mapping. In a complex unit more than two soil series may occur which cannot be separated even at a larger map scale than the one under consideration because of the complexity or uncertainty of landscape units. An example of the complex soil unit is "Banchong-Li" which consists of soil series Banchong and Li. An example of an association unit is "Korat/Roiet" indicating the presence of the soil series Korat and Roiet. An associated unit can be separated into consociations when the map scale is larger.

The group "Undifferentiated soil groups" is a mapping unit within the boundary that has two or more component soils. They are included in the same map unit because they produce similar responses from the point of view of land use and management. The symbol "\&" will be used to separates and displays the proportion of soil, for example, A \& B at $60 \%$ \& $40 \%$ or A \& B \& C at $40 \%$ \& $30 \% \& 30 \%$. 
Since the traditional soil maps have soil map units defined as associations and complexes of soil series, their usability has often limitations due to their lack of spatial definition. In order to make these maps useful, the dominant soil series present in the unit is often considered. With the understanding of the soil-forming environment of the dominant soil series, the soil surveyors recognize soil forming factors and the potentially associated soil types.

Table 1.1 The category of soil classification and required dominant soil properties to characterize soil

\begin{tabular}{|c|c|}
\hline Level & $\operatorname{Rec}$ \\
\hline Order & $\begin{array}{l}\text { \% BS, CEC, \% clay, OM/OC, pH, CaCo3, Phosphate, n- value, } \\
\text { ESP/SAR, Ex.Mg, Ex. Na, Ex. Ca, Ex, acidity, gypsum, Fe, Al, bulk } \\
\text { density, water- soluble sulfate, particle size classes*, hydraulic } \\
\text { conductivity, EC }\end{array}$ \\
\hline Suborder & Soil moisture, $\%$ clay, $\mathrm{CaCO} 3, \mathrm{EC}, \mathrm{t}$ \\
\hline Great & $\begin{array}{l}\mathrm{Al}, \mathrm{Fe}, \% \text { Clay, } \mathrm{CaCO} 3, \% \mathrm{BS}, \% \mathrm{OC}, \mathrm{EC}, \mathrm{CEC}, \mathrm{SAR} \mathrm{ESP} \text {, texture, } \\
\text { sulfides }\end{array}$ \\
\hline Subgroup & CEC, \%BS pH, EC, SAR. ESP, CaCO3, \%OC, Al, \%clay, \\
\hline Family & Particle size, mineral, soil temperature, depth, coating of sand, crack \\
\hline Series $/ \mathrm{r}$ & $\begin{array}{l}\text { Horizon: color, texture* } * \text {, structure, swelling, } \mathrm{pH} \text {, thickness, } \\
\text { consistency, moisture, Landform/relief, parent material }\end{array}$ \\
\hline \multicolumn{2}{|c|}{$\begin{array}{l}\text { Particle size classes refers to the grain size distribution of the whole soil including the } \\
\text { coarse fraction }(>2 \mathrm{~mm}) \\
* \text { Texture classes are based on the proportion of sand, silt and clay in line earth fraction } \\
(<2 \mathrm{~mm})\end{array}$} \\
\hline
\end{tabular}

2) Special purpose soil surveys

A special purpose soil survey, unlike a basic soils survey, may result in soil maps showing single soil characteristics, such as texture, slope, depth etc., or any combination of two or more characteristics. Such maps may show soil qualities or individual soil genetic factors or combinations of genetic factors; but they do not delineate natural bodies based on all observable soil characteristics as is the case with basic soil surveys. Special purpose surveys may be proposed with a narrow objective in mind, such as the determination and location on map of areas having soil characteristics suitable for growing a specific crop. Special purpose soil survey may be made at any of several levels of intensity (the scale of soil map) and may be made quicker and at lower costs than basic soil surveys. However, theirs usefulness is always limited to their objective, which is often narrow, and they may become obsolete in a short time when changes in technology or social environment 
In most instances it is advisable to invest a little more time and money in making a basic soil survey which, if made well, will stand the test of time and serve a variety of purpose. Special purpose surveys may provide a shortcut for a specific purpose but only retain their value as long as social, economic and technical factors remain unchanged.

In the recent years, there is the increasing of soil properties maps, as many models (hydrological, crop growth models, etc.) require specific soil properties e.g. water holding capacity, porosity, hydraulic conductivity of soil etc. for a particular grid cell/location or area. But in only the polygon based are available not in the raster format and available in only specific project area such as the Royal project station, which the data is not available in general.

\subsection{Problem statement}

To date, all soil maps in Thailand have been produced using conventional methods, and they have been applied for various purposes, yet the quality of these maps has never been established as a known quantity. In combination with conventional soil survey methods the LDD plans to make revisions of the soil maps using DEM and ortho-photos in order to increase their accuracy.

Soil- landscape relationships are key to soil mapping (either conventional or digital), but so far these have only been studied at coarse scales (using USDA taxonomy scales at a maximum of 1:50,000) for soil mapping in Thailand. Until recently, soil survey projects in Thailand have not used digital terrain data for developing soil- landscape models, and thus soil survey and landscape classifications are still based on manual interpretations of aerial-photos. Recently the use of digital terrain data for automatic landscape classifications is under investigation (Land Development Department, 2009b).

At the very detailed scales envisioned for projects related to watershed management and on-farm planning, there is great demand for continuous (raster) soil properties mapping rather than mapping soil classes with discrete polygons. This requires a paradigm (concept and model) shift in soil survey methods, but also raises questions about the hierarchical relationships between area-class maps at $1: 50,000$ and soil property maps at fine-scales $(1: 5,000)$. The lack of high quality soil maps and soil property information on a fine scale has become a serious issue in sloping areas, because without soil data no land degradation assessment and/or land use planning can be successfully achieved. However, soil mapping has been derived from conventional soil survey techniques used in flat 
terrain, utilizing a topographical map of scale 1: 50,000 and aerial photo interpretation. As such the meso-relief and micro-relief are invisible and therefore cannot be differentiated, which makes this method unsuitable for detailed or very detailed soil mapping, where the soil information is general, and thus cannot be applied at farm-level or for other purposes.

Soil survey in Thailand, until recently, has focused mainly on mapping soil in the low land areas for soil fertility and suitability assessment for crop production (e.g. rice). Mountainous and hilly (slope $>35 \%$ ) areas were simply mapped as slope complexes (complex terrain and complex of slope facet). In High land area, crops are often grown on steep marginal lands without considering any conservation measures, which results in catastrophic land degradation as well as flash flood problems in the lowlands in case of extreme rainfall. The type of land degradation of Thailand was reported by Anusontpornperm et al. (2012) ( see Table 1.2). Trisurat et al. (2010) studied the forest cover loss in northern of Thailand. The result shown that, the trend scenario was developed based on a continuation of the trends of land-use conversion of recent years. The existing forest cover of $57 \%$ of the region in 2002 was expected to decrease to $45 \%$ by 2050 .

Then data on soils has to be collected based on project objectives such as "the longest-standing development project in the Thai highland project", of the of the Royal project foundation, to promote the suitable land use for hill-tribe which need more some of soil information (soil chemical, physical for landuse planning) and as shown in soil and land degradation management project (Shrestha et al., 2016; Trisurat et al., 2010). This is because increasing population requires more farmland (Land Development Department, 2016) or due to other reasons ( tourism development, political developments, shifting cultivation, etc.) substantial deforestation has taken place in the recent past in the mountainous areas (Figure 1.1). 
Table 1.2 Land degradation in Thailand

\begin{tabular}{crrrrrr}
\hline & \multicolumn{5}{c}{ Intensity classes } \\
\cline { 2 - 7 } Land degradation & \multicolumn{2}{c}{ Slight } & \multicolumn{1}{c}{ Moderate } & \multicolumn{1}{c}{ Severe } \\
\cline { 2 - 7 } & \multicolumn{1}{c}{$\mathrm{km}^{2}$} & \multicolumn{1}{c}{$\%$} & $\mathrm{Km}^{2}$ & \multicolumn{1}{c}{$\%$} & $\mathrm{Km}^{2}$ & \multicolumn{1}{c}{$\%$} \\
\hline Water erosion & 1,911 & 0.37 & 27,173 & 5.26 & 309,591 & 59.89 \\
Physical deg. & 20,238 & 3.92 & 44,121 & 8.54 & 61,009 & 11.8 \\
Chemical deg. & 10,395 & 2.01 & 6,591 & 1.27 & 20,899 & 4.04 \\
Biological deg. & 10,169 & 1.97 & 3,087 & 0.6 & 1,751 & 0.34 \\
\hline
\end{tabular}

* Approximate total land area of Thailand $=511,770 \mathrm{~km}^{2}$

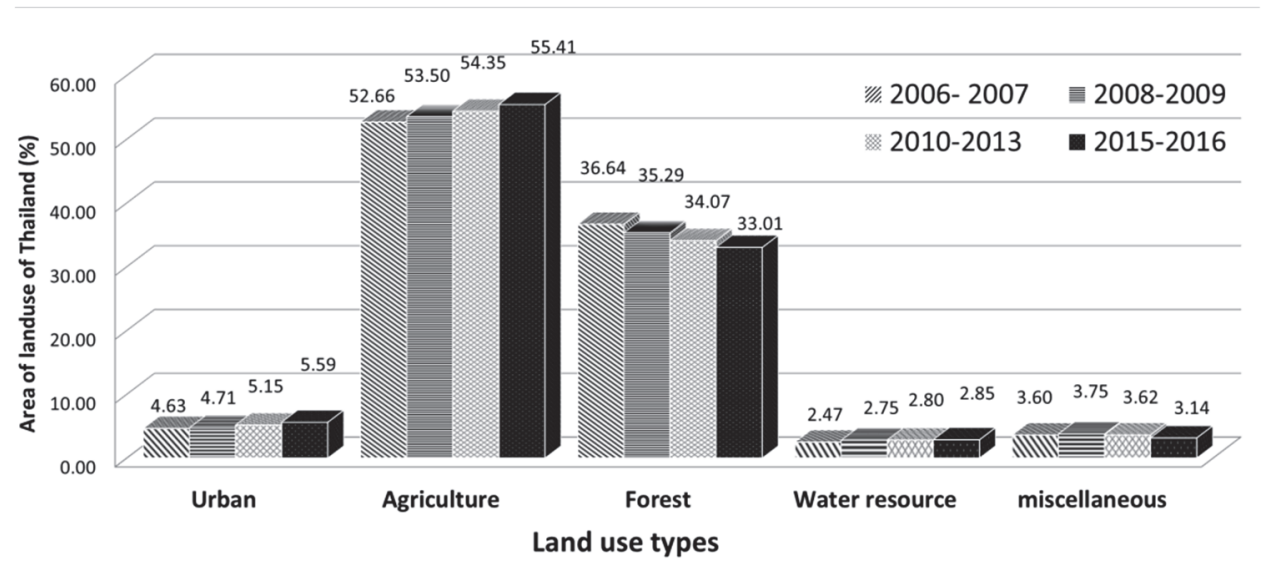

Figure 1. 1 Landuse change data of Thailand (2006-2016) (Land Development Department, 2016)

\subsection{The need for soil information}

Within the context of the growing demand for high-resolution spatial soil information accurate prediction methods are required to provide high-quality digital soil maps at finer scales (Behrens et al., 2005b), covering large areas for watershed projects in Thailand.

As in conventional soil maps, soil surveyors are often focus on delineating of soil series boundaries, is said high cost and time consuming. Thus soil property maps are rarely produced. In Thai traditional soil maps, does not provide information for modeling the dynamics of soil conditions. The maps are flexible to quantitative studies on the function of soils. Therefore, new techniques and methodologies are required which can help soil surveyors in the production of fine scaled soil series high accuracy, high precision and up to date. 
Fine-scale soil series and properties mapping are not only needed for agriculture, but also for other purposes, such as land degradation assessment and erosion modeling (Sanchez-Moreno et al., 2014). The application for flood hazard, there is also need of the assessment of soil properties (such as texture, bulk density, organic matter, drainage, Ksat) (Nikhil and Venkatesh, 2015). Nearinga et al.(2005) used soil texture and soil drainage in soil erosion and runoff modeling in southeastern Arizona, USA.

Other problems faced in traditional soil mapping comprise: high costs, high subjectivity, poor documentation and low accuracy and precision (Shi et al., 2004). Digital soil mapping (DSM) has become a new framework for many soil survey projects such as the formation of a special working group on digital soil mapping of the European Soil Bureau Network (Dobos et al., 2006), a collaborative workspace for researchers working on digital soil mapping in Australia (Federation Univeristy, 2017) and an initiative of the digital soil mapping working group of the International Union of Soil Sciences IUSS (Arrouays et al., 2014b). For the concept and approaches, Jenney's equation (Jenny, 1941) and the SCORPAN method (McBratney et al., 2003) have been applied to digital soil surveys, by representing soil-forming factors with GIS layers of environmental covariates and point soil observations.

Because of advances in computer hardware and software, access to internet and their increased affordability in many countries in the recent past, there is an increased demand of digital soil maps for making better decisions in a range of global issues like food security, climate change and environmental degradation (Arrouays et al., 2014a; Sanchez et al., 2009). In 2008, the GlobalSoilMap consortium was formed, by the International Union of Soil Sciences, that aimed to make a new digital soil map of the world using state of the art and emerging technologies for soil mapping and predicting soil properties at fine resolution. Following this initiative SoilGrids (global soil gridded information system) was made for automated soil mapping based on global soil profile and covariate data (Hengl et al., 2014). The SoilGrids predictions are based on globally fitted models using soil profile and environmental covariate data. The first production of the SoilGrids maps was at $1 \mathrm{~km}$ spatial resolution. It consists of soil properties at six standard depths, i.e. soil organic carbon $\left(\mathrm{g} . \mathrm{kg}^{-1}\right)$, soil $\mathrm{pH}$, sand, silt and clay fractions $(\%)$, bulk density $(\mathrm{kg} / \mathrm{m} 2)$, cation-exchange capacity $\left(\mathrm{cmol}^{+} / \mathrm{kg}\right)$, coarse fragments (\%), soil organic carbon stock $\left(\mathrm{t} \mathrm{ha}^{-1}\right)$. Furthermore, there are site characteristics such as depth to bedrock $(\mathrm{cm})$, the World Reference Base Soil 
Groups class and the USDA Soil Taxonomy at Suborders level class (expressed as the probability belonging to a class).

Currently, SoilGrids. org serves a collection of updatable soil property and class maps of the world at $250 \mathrm{~m}$ spatial resolutions (June 2016 update). The $250 \mathrm{~m}$ SoilGrids data was generated using automated soil mapping based on machine learning algorithms. The SoilGrids products are now available in public domain under the Open Database License (Hengl et al., 2017b). Since SoilGrids data is generated based on globally fitted models using soil profile and covariates it remains to be seen how good it is especially in hilly and mountainous areas. The predictive quality also depends on the density of the data points available in an area. While the $250 \mathrm{~m}$ resolution would be beneficial to the needs of Thailand, where it concerns the parameters needed for land use management and soil conservation modelling, the authors warn against the use at detailed scales. For the moment, using Soilgrids as a replacement for a detailed soil survey would need much more investigation. This is beyond the scope of this research.

\subsection{Digital soil mapping (DSM)/Predictive soil mapping (PSM) as a new approach for soil surveys}

\subsubsection{DSM/PSM and their applications}

DSM or PSM is the computer-assisted production of digital maps of soil types, soil properties, where the soil information from soil observation and knowledge and related environmental variables are needed. The environmental variables or the soil covariates are the spatial data available over area will be used as a predictor variables, such as climate, organisms (including land cover and natural vegetation), topography, parent material (including lithology) and age or the time factor (Hartemink, 2008).

A map with soil type classes and their attributes can be produced by conventional soil mapping or digital soil mapping (DSM) techniques (McBratney et al., 2003; Scull et al., 2003). Several soil survey techniques and approaches have been applied and used in recent times, which includes: soil landscape modeling, digital soil mapping (DSM) or predictive soil mapping (PSM), and also using Geoinformation system (GIS) and remote sensing techniques.

DSM uses mathematical and statistical models, which combine information from soil observations, with such information being contained in correlated environmental variables and remote sensing images, such as for instance Landsat Thematic Mapper (TM) or gamma-ray images. To map soil units and the natural 
characteristics of soils, different soil types need to be established including their corresponding sets of interrelated soil properties, e.g. base saturation, CEC, $\mathrm{pH}$, texture, moisture holding characteristics, etc. (Soil Survey Staff, 1993).

\subsubsection{Geomorphometry and terrain analysis}

Geomorphometry is a sub-discipline of geomorphology used to characterize land surfaces, also known as terrain analysis, and is the quantitative use of digitally elevated models (grid data) (Dehn et al., 2001; Hengl and Reuter, 2009). It can be applied to many aspects of watershed modeling e.g. fluvial systems modeling, landslide/hazards analysis, estimating soil erosion, dune geometry and windenergy potential, etc.

Geomorphometry is the science of quantitative land-surface analysis (Pike, 2000), or the science of topographic quantification, and its operational focus is based upon the extraction of land-surface parameters and objects from digitally elevated models. Digitally elevated (land surface) models or digital land surface models (DEM and DLSM) are the usual input used in geomorphometric analysis (Hengl and Reuter, 2009). They are also known as the science of 'digital terrain modeling and analysis' (Geomorphometry.org, 2009).

Geomorphometrics have been applied to activities within soil surveys and land surface models in a new digital soil mapping era, whereby DEM and land-surface parameters can be used as digital inputs for soil mapping, in four ways: to update existing soil maps, to extract soil-landscape units or landform, for the direct estimation of soil parameters and to optimize soil sampling strategies (Carvalho Junior et al., 2008; Dobos and Hengl, 2009; Dobos and Montanarella, 2007; Thwaites, 2007). These applications in soil mapping can be used to map soil attributes or properties, such as soil depth, organic carbons, $\mathrm{pH}$ values, and textures etc. (Bell et al., 2000; Boer et al., 1996; Gessler et al., 2000; Lark, 1999; Thompson et al., 2006; Walker et al., 1968; Young and Hammer, 2000; Ziadat, 2005), plus soil classes and soil types (Bell et al., 1992; Bell et al., 1994; Dobos et al., 2000; Hengl et al., 2007; Thomas et al., 1999).

Terrain attributes can be grouped into two main types: primary terrain attributes, calculated from the directional derivatives of a topographic surface (DEM) and secondary terrain attributes, which are computed from two or more primary attributes to describe pattern as a function of process (Grunwald, 2006a; Hengl and Reuter, 2009; Wilson and Gallant, 2000). 
Digital elevation models are thus increasingly being used in soil- landscape modeling applications. To derive a digital terrain model, the quality and resolution of DEMs on derived terrain variables (Kienzle 2004, Dehvari and Heck 2013) and the actual precision of the terrain correction depends on the precision of the DEM data (Dimitrios Tsoulis, Pavel Novák et al. 2009). The efficiency of using high resolution DEM for soil- landscapes and digital soil mapping has already been demonstrated (Burt, Zhu et al. 2006, Minasny, McBratney et al. 2006, Valladares and Hott 2008, Barker, Lawler et al. 2009).

\subsubsection{Application of gamma-ray data in soil survey}

Remote sensing imageries (aerial photos, ortho- photographs, satellite images, etc. ) have been commonly used as base maps in soil surveys and GIS as a tool for storing and managing the soil data. Thus remote sensing, GIS and soil information systems serve as integrators for managing and analyzing soils and other environmental datasets concerning soil-landscape modeling.

Apart from using conventional remote sensing data the use of radiometric survey or the use of gamma rays can detect and map natural radioactive emanations from rocks and soil. They are capable of detecting the presence of $\mathrm{U}$, Th and $\mathrm{K}$ on the surface of the ground (Rawlins et al., 2009). Typically, from such measurements activity concentrations are determined for ${ }^{238} \mathrm{U},{ }^{232} \mathrm{Th}$, ${ }^{40} \mathrm{~K}$ ( Sini et al., 2007). To discover the advantages of using gamma- ray spectrometry, Wilford and Minty (2007) studied mineralogy and geochemistry and the weathering characteristics of bedrock for soil mapping using gammaray data.

Gamma-ray radiometric data displays a relationship with lithology as alteration minerals. Cook et al. (1996) found gamma radiometric data useful in soil surveys, whereby such data could provide valuable insights into the spatial distribution of soil-forming materials. This data also clearly discriminated between the doleritic, lateritic and granitic soil parent materials throughout associated catchments. Wilford and Minty (2007) studied mineralogy and geochemistry and the weathering characteristics of bedrock for soil mapping using gamma-ray data.

Radiometric data also show evidence of soil ages, in that soils form over different time scales ranging from the ecological (days, years) to the geological (millions of years) (Retallack, 2001), as shown in Figure 1.2. Fortunately, several methods for determining ages in years have been devised as a supplement, and calibrations 
of these relative time scales use methods such as radioactive decay (carbon isotope-14), uranium dating, and etc.
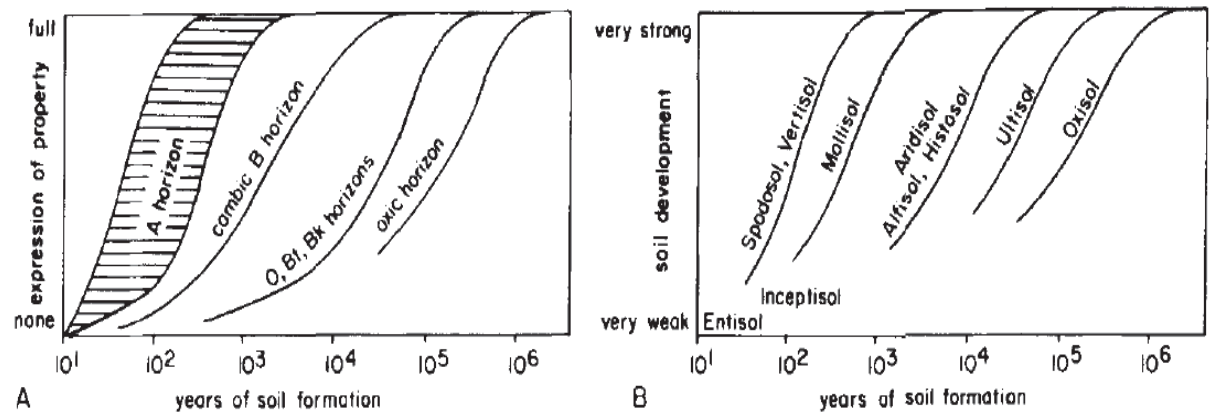

Figure 1.2 Schematic representation of the times needed to attain various properties of soils (A) and orders of soils, as recognized by the 'Soil Conservation Service' of the US Department of Agriculture (B) (Retallack, 2001)

\subsubsection{Soil spatial predictions - Soil factorial models}

Soils have been formed through the interaction of five major factors (time, climate, parent material, topography and relief, and organisms). In predictive soil mapping, emphasis is placed upon the soil forming factors (of both 'Jenny' and its modified version 'SCORPAN'), and how to parameterize them. Any given point, at any degree of resolution, can be described in terms of a set of environmental characteristics, when placed in the CLORPT (Jenny, 1941).

The problem remains though is how to parameterize each of the factors, including: climate $(\mathrm{cl})$, organism $(\mathrm{O})$, relief $(\mathrm{R})$, parent material $(\mathrm{P})$, and time $(\mathrm{T})$. Once the soil of a given point is known, the next question will be concerned with how to move from the known point to many unknown points, in order to arrive with the finalized soil mapping unit (surface area).

Several of the aforementioned soil forming factors (clorpt), such as climate, organism, and relief are not so difficult to parameterize see e.g. McBratney (2003). The difficulty lies in parameterizing the two remaining factors (Grunwald, 2006b; McBratney et al., 2003), namely the parent material (lithology), particularly in fine scale mapping, and time (soil age), which are very challenging and one of the main topics of this research.

Whatever method is used to obtain soil information from the field, it has to be represented at a given scale, and hard boundaries are drawn between soil series or soil classes that are not hard in reality. While certain soil properties that are continuous variables can be predicted with geostatistical methods based on spatial 
correlation, classified information (soil series) are depicted as uniform areas. To assist in deciding where boundaries are drawn, a fuzzy logic based model called SoLIM model (Zhu et al., 1997) can be used as a predictive approach. The advantages and disadvantages to employing a fuzzy model is that such models are robust when expressing explicit knowledge and dealing with subject uncertainty (i.e. expert knowledge).

Recognizing the concept of partial truth, alternatively to the subjective rigidity imposed on soil, expert systems using SoLIM model is investigated in this research as an alternative method to represent the uncertainty in predicted soil series and properties maps, effectively.

Soils can be seen as the result of spatial variations operating over several scales, indicating that factors influencing spatial variability differ with scale (Logsdon et al., 2008). Soils are an essential part of, and are basically controlled by, landscape, and soil-landscape is very dependent upon scale (Schoorl and Veldkamp, 2006), and scale is an important issue in digital terrain modeling ( $\mathrm{Li}$ et al., 2005). To imply fine scale soil surveys, there is strong demand for detailed soil attribute information for understanding natural systems and landscape modeling (e.g. soil erosion models) (Claridge and Grundy, 2004). Recently, fine scale soil maps have been in great demand, which is well suited for multi-purposes applications (Schargel, 1994). Therefore, high resolution DEM for DTM derivation in soil fine scale mapping. The optimal pixel and neighborhood sizes were assessed for mapping soil properties and soil series for fine scale soil mapping.

\subsection{Research objectives and questions}

The main objective is to investigate if Digital Soil Mapping provides soil series information and soil property information at a level detailed enough for land management related applications.

This focus leads to the following objectives:

1 To investigate which terrain parameters from high-resolution DEMs and digital terrain analysis can be used for fine-scale digital soil mapping ) 1:5,000 (in the first order watersheds .

2 To investigate the use of airborne gamma-ray data )AGRI (to infer parent material and soil characteristics )in the context of soil forming factors(, as an input layer to Digital Soil Mapping . 
3 To investigate a combined use of fine resolution DEM and the SoLIM fuzzy logic model as a predictive method for mapping soil series and properties .

Finally, although not strictly a research objective, at the request of the LDD we investigated if the Digital Soil Mapping can actually be implemented in the context if the organization of the Thai Soil Survey, to go beyond general suggestions based on the scientific findings.

\subsection{Study area}

The study area is located in the Upper Pa Sak watershed, Lom Kao and Lom Sak districts, Thailand, bounded by $101^{\circ} 30^{\prime \prime}-101^{\circ} 45^{\prime} \mathrm{E}$ and $16^{\circ} 45^{\prime}-17^{\circ} 15^{\prime} \mathrm{N}$, with an approximate area of $750 \mathrm{~km}^{2}$ (Figure 1.3). This area was selected for the research because it is also the pilot area for watershed management projects of the Land Development Department of the Ministry of Agriculture and Cooperatives for the period 2018-2021, and also because much background information has already been collected from the area.

This region has a complex physiography, mainly composed of hills, strongly incised plateaus and piedmonts, all found at varying levels from approximately $300 \mathrm{~m}$ to $1,200 \mathrm{~m}$ above msl within several different units of valleys, of which the Pa Sak River valley is the most important one. The plateau areas are undulating to rolling and the intervening hilly areas are steep, with some very steep areas of craggy limestone buttresses. The nearly level to flat part consists of flood plain, alluvial terraces and an adjacent surface along the Huai Num Phong River, with slopes between 1 to 5 percent. The Pa Sak River is quite narrow, and locally hard to map on a large scale in large areas, from the low relief passing through the mountainous area, which forms a portion of the watershed. The climate is humid tropical, influenced by north-eastern and south-western monsoons, with dry, hot and wet seasons. There is a distinct variation between the dry and wet seasons. The present geomorphic configuration of the Pa Sak and Huai Nam Phung River areas is a result of tectonic processes, denudation and sedimentation. 


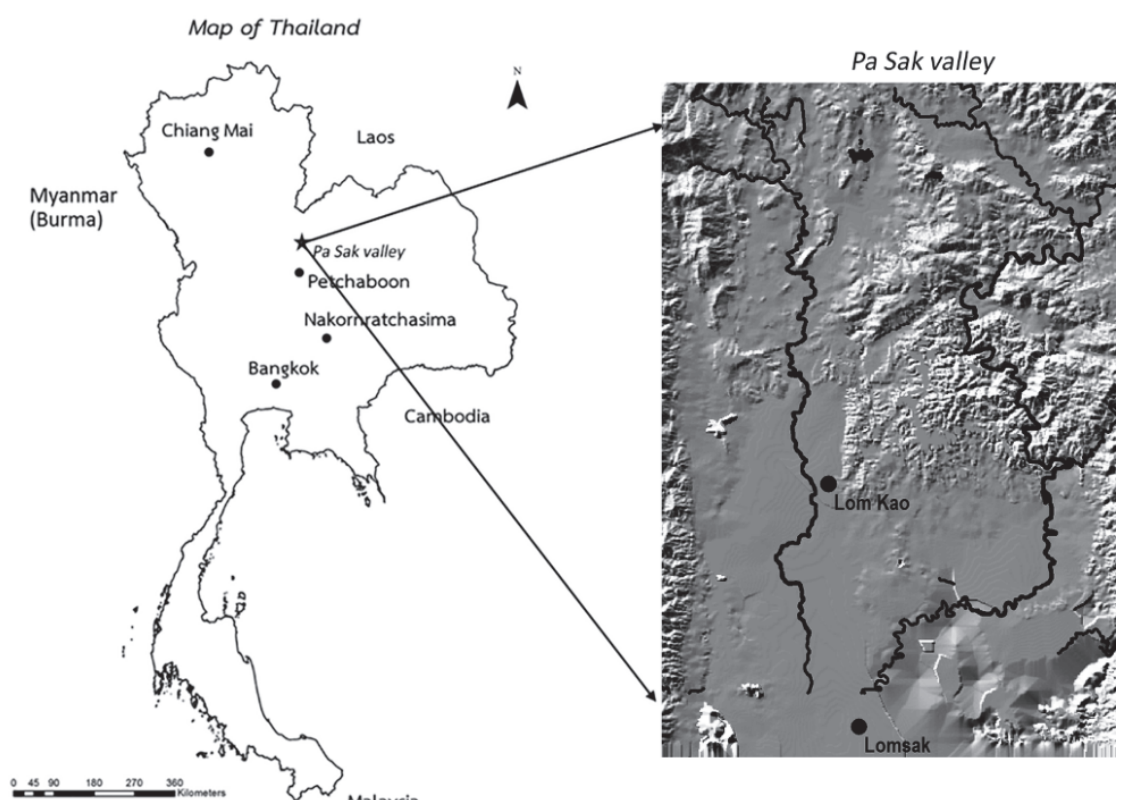

a)

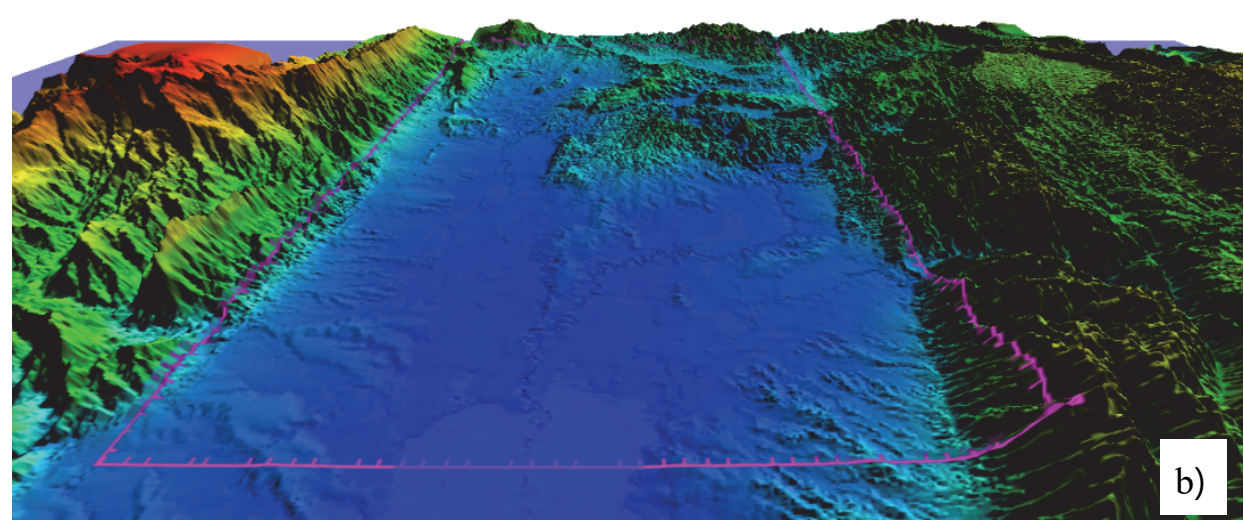

Figure 1.3 Upper Pa Sak watershed, a) 3D views of the Upper Pa Sak watershed and b) the study area within the watershed is demarcated by the purple line.

\subsubsection{Physiography}

The area is characterized by having low mountains, hill-land, isolated hills, piedmont and valley. General descriptions of these landscapes are as follows:

Low mountains

The low mountainous areas occur mainly in the west, as well as along the eastern border of the study area with elevation varying from 230-590 above msl. Here, 
soil is formed mostly from material derived from igneous rocks, which belong to lithological formation from the Carboniferous age.

\section{Hill-land}

This landscape lies between the mountains and piedmont area. Elevation varies from $170-230 \mathrm{~m}$ above msl. The hill land is diverse genetically, as well as lithologically. The relief is probably a result of tectonics and denudation processes. The summits of the hills or hillocks are local and at the same level. In other parts, erosion and deposition mainly control relief forms.

\section{Isolated low hills}

This is an elevated and often isolated land surface, elevation rising up to $200 \mathrm{~m}$, and quite prominently above the surrounding areas, and is generally considered to be less than $50 \mathrm{~m}$ from the local base level to the summit.

\section{Piedmont}

The piedmont landscapes include inclined surfaces lying at the foot of mountains or hills, with elevation ranges between $150-170 \mathrm{~m}$. By origin, some parts of these units are primarily depositional, which have been later dissected and thus turned into denudation relief forms. Due to tectonic activities, some portions of piedmont landscape have undergone some uplift to higher topographic positions. On the other hand, there are also erosional levels of glacis terrace, formed on various bedrock types (e.g. sandstone, shale and limestone). The piedmont consists of glacis, swales and vales.

\section{Valley}

This landscape forms a narrow zone between the mountains on both the western and eastern sides, with elevation ranges of $140-150 \mathrm{~m}$. This landform is composed of terraces where levees overflow mantles (or splay), and basins are distinguished. This depositional type of relief results from a fluvial transport of sediments. Erosional landforms may occur in the high and middle terraces. Soils formed in these units are normally deep and different in their degrees of development, depending upon their level and age. The soils of a higher terrace have had a longer time to undergo horizon differentiation, hence are better developed as compared to the soils of the lower terraces and the floodplain. 


\subsubsection{Hydrology}

The complex mountainous area in the north serves as the catchment basin of several important rivers, such as: the Pa Sak and the Nam Phung, originating from the highest points of the Dan Sai district, Loei province.

The Pa Sak River flows north south along a steep cliff, where the river changes into a streamlet, which overflows its banks in the rainy season.

The Nam Phung does not overflow its bank every year during the rainy season, and recorded floods are rare. During the dry months (Nov. -Feb.) of each year, the river loses volume or even dries up completely. The Nam Phung River is considered to be the natural boundary between the Lom Kao district of Phetchabun province and the Dan Sai district of Loei province. This city has a tropical climate. In winter, there is much less rainfall than in summer. This climate is considered to be Aw according to the Köppen- Geiger climate classification. The average annual temperature in Phetchabun is $27.4{ }^{\circ} \mathrm{C}$ and the average annual rainfall is $1193 \mathrm{~mm}$.

Geologic structure and topography control the drainage patterns of the area. A dendritic drainage pattern, together with tributaries, forms a crooked shape. On the other hand, seasonal climatic conditions and topography control the drainage conditions. The rainy season causes flooding in the low glacis terrace, and the wide valleys are used for paddy cultivation. To alleviate water storage problems in the dry season, farmers pump the groundwater to supplement irrigation of their crops, if necessary. Wells are dug, ranging in depths from $3 \mathrm{~m}$ to $6 \mathrm{~m}$. On higher glacis terraces, used for field crops and orchards, the groundwater table is deeper. The Pa Sak River and the Huai Khon Kaen waterway govern the drainage system at the eastern part of the area. Recently, the Huai Khon Kaen Dam was constructed for irrigation purposes and also to control flooding.

\subsection{Thesis Outline}

Chapter 1: provides the research background, motivation and specific objectives, including research questions, description of the study area, and outlines the structure of the dissertation.

Chapter 2: quantifies the effects of high resolution DEM for DTM derivation in fine scale soil mapping. The optimal pixel and neighborhood sizes were assessed for mapping soil properties and soil series. 
Chapter 3: explores the application of airborne gamma-ray imagery in response to soil parent materials (lithological class) and soil ages (based upon the pedogenic process). The solution of appropriate radio- elements and soils was identified and assessed, using two existing soil maps

Chapter 4: assesses the potential of fuzzy logic for mapping soil series and topsoil texture

Chapter 5: proposes a digital soil survey framework, based upon specific Thai needs, which could be suitable to modernizing a soil survey of Thailand.

Chapter 6: provides conclusions, reflections, on the use of SoilGrids map and further recommendations 


\section{Chapter 2 Digital terrain analysis for fine-scale digital soil mapping in Thailand}




\subsection{Introduction}

\subsubsection{Digital terrain analysis}

Digital soil mapping (DSM) is the computer-assisted production of digital maps of soil types or soil properties (McBratney et al., 2003). Most operational DSM has been done at medium map scales, i.e., 1:100,000 to 1:25,000, with an effective resolution $500 \times 500$ to $125 \times 125 \mathrm{~m}$ (Dobos et al., 2006), while the few studies at finer scales have been in small areas such as individual fields (Simbahan et al., 2006) or very small sub-catchments (Park and van de Giesen, 2004).

Digital terrain analysis, also known as geomorphometry (Hengl and Reuter, 2009; Pike, 2002; Wilson and Gallant, 2000), is a mathematical representation of the continuous surface of the earth surface. A digital terrain model (DTM) is a model of the actual topographic surface, (Hengl et al., 2003; Hengl and Reuter, 2009), whereas a digital elevation model (DEM) is only the elevation. The utility of DTA for soil survey has been extensively reviewed (Gobin et al., 2001; Grunwald, 2006a; Park and van de Giesen, 2004; Wilson and Gallant, 2000).

Terrain attributes are very much affected by DEM resolution (Arnold, 2006; Bishop and Minasny, 2006; Chaplot et al., 2000; Deng et al., 2007): higher resolutions provide a more detailed representation of the terrain. Similarly, the neighborhood size used to compute DEM derivatives affects calculated terrain attribute values: in general larger neighborhoods lead to smoothed derivatives (Smith et al., 2006). Thompson et al. (2001) provide an overview of the combined effects of DEM resolution and neighborhood size on terrain derivatives; these differences are expected to extend to the relation between soil properties or classes and these derivatives.

Several studies have examined the use of high resolution DEMs to define landform elements and their relation to soil properties over small areas (Smith et al., 2006; Thompson et al., 2001; Wu et al., 2008b). Chaplot et al.(2000) used different resolution DEMs (10 to $50 \mathrm{~m}$ ) to compute topographic measurement for prediction of soil hydromorphy at a 2 ha site, and concluded that coarser resolutions resulted in poorer prediction. Burt et al. (2006) used a one-foot vertical resolution Lidar-derived DEM as input to the expert-based SoLIM model in a 400 ha low-relief study area and were well able to represent topography and its relation to the soil pattern. Bishop and Minasny (2006) used 5 and $25 \mathrm{~m}$ horizontal resolution DEM to map clay proportion over 74 ha, obtaining better correlation between clay proportion and slope at the finer resolution. Valladares 
and Hott (2008) used a $4 \mathrm{~m}$ horizontal resolution DEM to model topography and from that map soil type over 59 ha, with moderate success. Wu et al. (2008b) investigated the effect of DEM horizontal resolutions from 4 to $30 \mathrm{~m}$ on the simple correlation between chemical soil properties and terrain attributes on 100 ha in a hilly landscape of Chongqing City, China, and concluded that there is no single best resolution, nor best terrain derivative, to correlate with all soil properties Smith et al.(2006) investigated effect of combined DEM resolution and neighborhood size for mapping soil series with the SoLIM approach in a 65 ha hillside, concluding that optimum neighborhood size ranges from $24 \mathrm{~m}$ in strongly-sloping areas, to $48 \mathrm{~m}$ in gently-rolling areas. Fine-resolution DEM was in no case necessary for accurate mapping.

These studies all suffer from one or both of the following shortcomings: (1) very small study area with restricted soil variability, (2) simple models of soil-terrain relations. In addition, none is in tropical areas.

\subsubsection{Soil mapping in Thailand}

Prediction of soil series and properties in the SCORPAN approach to DSM relies on finding relationships between the soil and covariables that represent soil forming factors (McBratney et al., 2003). The most useful relationship is usually between soil and terrain (Mendonça-Santos et al., 2006), especially within a restricted area where climate and natural vegetation are not too variable. In a DSM context this relation is expressed as a multivariate model of soil properties based on terrain variables extracted from a DEM by digital terrain analysis. This approach has been refined and successfully applied in many different contexts for the past two decades (Bishop and Minasny, 2006; Brown et al., 2004).

In Thailand the Land Development Department (LDD), Ministry of Agriculture is the agency responsible for soil survey for agricultural development. It has recently been tasked with mapping all agricultural areas in Thailand at 1:5,000, corresponding to an effective resolution to support watershed- level farm planning. To date, all soil maps in Thailand have been produced using conventional soil survey method at medium $(1: 50,000)$ and small $(1: 100,000)$ scales, with mapping units named by broadly-defined series, classified into a modified USDA Soil Taxonomy (Soil Survey Staff, 2006). Computer systems are used for ortho-photograph rectification, digitizing, and map production, but not yet for mapping. Despite the mandate to map at fine scale, no special methodology has yet been developed. Operationally, the broad series maps are simply converted to slope phase maps using the DEM; however, the categorical 
level of the map units is not adjusted, and the maps are still of polygonal classified map units. DTA involves several choices; one is the resolution of the source DEM - the focus of this article. We had access to a high-resolution DEM ( $5 \times 5 \mathrm{~m}$ horizontal, $+0.3 \mathrm{~m}$ vertical); the question is whether this finer resolution of the DEM source translates to finer resolution of the resulting soil map. Previous research (e.g., Smith et al., 2006) has established that DTA based on the highest resolution DEM does not always best correspond to detailed soil maps. These authors also show that the optimum resolution and neighborhood size is landscape-dependent, thus we could not directly use their results. Full utilization of DEM and digital terrain analysis techniques still need to be explored for fine scale soil mapping in Thailand.

\subsubsection{Objective of the study}

The main objective of the study is to utilize high-resolution DEMs and digital terrain analysis techniques for fine- scale soil mapping (1:5,000) over subwatersheds. Research questions related to this objective will be:

1) which terrain parameters are most useful to model fine-scale soil-landscape relations in a complex survey area?

2) how successfully can soil properties and series be explained by terrain modeling?

3) what is the optimum DEM resolution and neighborhood size for these models? Does this vary by landscape?

\subsection{Methods}

The methodologies used in this chapter are for the investigation of mapping soil series and soil properties. The high resolution DEMs are used to calculated primary and secondary terrains. Soil observations are collected based on geopedological map units. The statistical models ( Principal Components Analysis: PCA) of soil properties explained by terrain parameters, using an information-theoretic approach to ensure maximum predictive power and linear regression model was used for a prediction of soil properties map. The logistic regression was used to map soil series from observed locations and Kiake's Information Criterion (AIC) was used to the success of logistic regression models in separating series occurrences and non-occurrences. 


\subsubsection{Digital elevation model and terrain analysis}

The base DEM used for this study has a spatial resolution of $5 \times 5 \mathrm{~m}$ and with $95 \%$ horizontal accuracy of $<2 \mathrm{~m}$ in flat and $<4 \mathrm{~m}$ in sloping areas and relative vertical accuracy of $\pm 0.3 \mathrm{~m}$. It was produced using digital photogrammetry technique using aerial photographs at scale 1:4 000 to 1:25 000, and stored in SDTS format according to the USGS DEM standard (ESRI-Thailand, 2006). In order to see the effect of different resolutions, a DEM with $10 \mathrm{~m}$ resolution was also prepared from $5 \mathrm{~m}$ DEM, for which bilinear interpolation was used. From both the DEMs $(5 \mathrm{~m}$ and $10 \mathrm{~m})$ primary and secondary terrain attributes were derived. The primary attributes were slope, profile curvature, plan curvature, total curvature and local relief and the secondary attributes, selected for their presumed relation to soil properties, were compound topographic index ( CTI), terrain characterization index ( TCI) and topographic position index (TPI), explain below.

In order to analyze the effect of neighborhood size, three window sizes were defined: $5 \times 5,10 \times 10$ and $20 \times 20$. From these neighborhood sizes average values were estimated for the processing cell within the window. The location $(x, y$ position) of the processing cell is defined by the following:

$$
\begin{aligned}
& \mathrm{x}=(\text { width of the neighborhood }+1) / 2 \\
& y=(\text { height of the neighborhood }+1) / 2
\end{aligned}
$$

If the input number of cells is even, the $x, y$ coordinates are computed using truncation. For example in $\mathrm{s} 5 \mathrm{x} 5$ cell neighborhood, the $\mathrm{x}$ - and $\mathrm{y}$ - location values for the processing cell will be in cell with relative coordinates [3,3]. In a 10x10 neighborhood, the $x$ - and $y$-values will be in [5,5], and for 20x20 neighborhood, it will be in $[10,10]$.

The terrain attributes, computed for both resolutions ( $5 \mathrm{~m}$ and $10 \mathrm{~m}$ ) at different neighborhood sizes, are shown in Figure 2.1. 


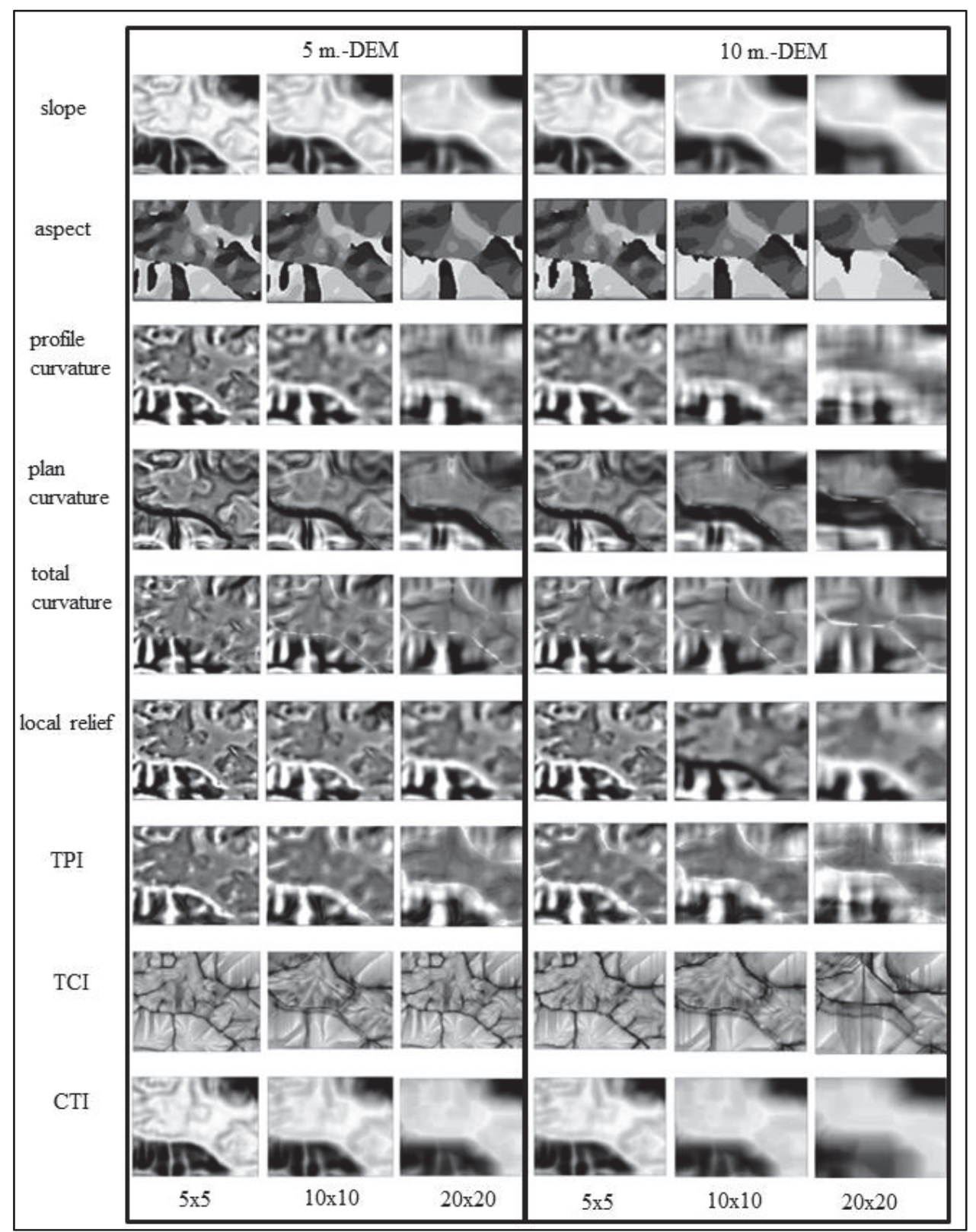

Figure 2. 1 Terrain attributes derived from $5-\mathrm{m}$ and 10- $\mathrm{m}$ DEM in difference neighborhood sizes $(5 \times 5,10 \times 10$ and $20 \times 20$ cells $)$ 
Slope was calculated from DEM using the following equation )Burrough and McDonell, 1998:(

$$
\text { Slope percent }=\left(\sqrt{ }\left([\mathrm{dz} / \mathrm{dx}]^{2}+[\mathrm{dz} / \mathrm{dy}]^{2}\right) / \text { grid size }\right) * 100
$$

Where, $\mathrm{dz} / \mathrm{dx}$ is height change in $\mathrm{x}$ direction and $\mathrm{dz} / \mathrm{dy}$ is the height change in $\mathrm{y}$ direction in a window of $3 \times 3$.

Curvature is the local surface related to erosion, water content and runoff processes (Moore et al., 1991; Zeverbergen, 1987). The extraction algorithms of the curvature types e.g. plan curvature and profile curvature is based on a DEM. Figure 2.2 shows the $3 \times 3$ moving window, and $W$ denotes the grid resolution, which is equal to 5 and 10 meters in this study. $Z=f(x, y)$ is a given point in DEM surface while $Z_{i}(1 \leq i \leq 9)$ denotes the elevation at each cell of the $3 \times 3$ moving window.

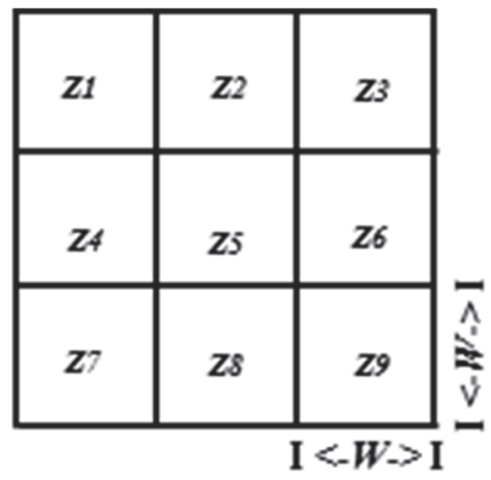

Figure 2.2 Square-grid showing a $3 \times 3$ moving window.

Plan curvature, a curvature in a horizontal plane, describes slope forms along the contour line. It shows the convergence and divergence of flow across the surface. It is derived using the following equation:

$$
\text { Plan curvature }=((\mathrm{Z} 4+\mathrm{Z} 6) / 2-\mathrm{Z} 5) / 2 \mathrm{w}
$$

Profile curvature is the curvature of the surface in the direction of the steepest slope. The profile curvature affects the flow velocity of water draining the surface and influences erosion and deposition processes. In locations with convex slope form (negative) erosion will prevail while depositions occur in locations with concave slope (positive). The profile curvature is calculated using the following equation:

$$
\text { Profile curvature }=((Z 2+Z 8) / 2-Z 5) / 2 \mathrm{w}
$$


Local relief (LoR), is defined as the difference between maximum and minimum elevation with a neighborhood (Aili, 2008) as:

$$
\text { LoR }=Z_{n} \max -Z_{n \min }
$$

where, $Z$ stands for the elevation; $\mathrm{n}$ is a natural number and represents the statistical unit over which LoR is measured.

The secondary attributes, selected for their presumed relation to soil properties, were compound topographic index (CTI), terrain characterization index (TCI) and topographic position index (TPI).

CTI, also known as topographic wetness index (TWI), is computed from local slope gradient and upslope catchment area. It quantifies the control of local topography on hydrological processes. It indicates the spatial distribution of soil moisture and surface saturation (Moore et al., 1993; Moore et al., 1991). The topographic wetness index is defined as:

$$
\mathrm{CTI} \text { or } \mathrm{TWI}=\ln (A s / \tan \beta)
$$

where ' $A s$ ' is the local upslope area draining through a certain gridcell and $\tan \beta$ is the local slope of that cell.

TCI is an estimate of the transport capacity of water flowing across a cell (Park et al., 2001; Park and van de Giesen, 2004). It is calculated as follows:

$$
\mathrm{TCI}=\mathrm{Cs} \log _{10}(A s)
$$

Where, Cs is the three-dimensional surface curvature index and defined as:

$\mathrm{Cs}=\left(\sum_{i=1}^{n}\left(z_{i}-z_{n}\right) / d_{i n}\right) / n=g(x, y)$

Where $Z_{i}$ is the elevation of the current $i$ cell, $Z_{n}$ is the elevation of a surrounding point, $d$ is the horizontal distance between the two points, and $n$ is the total number of surrounding points employed in the evaluation. The upslope contributing area is:

$$
\mathrm{As}=(1 / b) \sum_{i=1}^{n} \rho_{i} A_{i}
$$

where $A_{i}$ is the area of grid cell, $n$ is the number of cells draining into the grid cell $i, \rho_{i}$ is the weight depending on the runoff generation mechanisms, and $b$ is the contour width approximated by the cell resolution.

TPI is defined as the difference between the elevation at a cell and the average elevation in its neighborhood, and quantifies the local gravitational potential energy in the neighborhood (Jenness, 2005; Jenness et al., 2011; Tagil and 
Jenness, 2008; Weiss, 2001). The TPI is an adaptation of this method, which compares the elevation of each cell in a DEM to the mean elevation of a specified neighborhood around that cell. Local mean elevation is subtracted from the elevation value at center of the local window as follows:

$$
T P I_{i}=Z_{0}-\frac{\sum_{1-n} Z_{n}}{n}
$$

$Z_{0}=$ elevation of the model point under evaluation, $Z_{n}=$ elevation of grid within the local window and $n=$ the total number of surrounding points employed in the evaluation.

Terrain attributes were all trimmed by $2 \%$ of the cumulative frequency distribution at both extremes, i.e., extreme values were replaced by the lowest $2 \%$ or highest $98 \%$ quartile. Thus, highly unusual sites are not modeled. None of the field observations was from locations where any attribute was trimmed. Three terrain attributes were transformed to more- or- less symmetric distributions before analysis: slope and local relief using square root, and CTI using logarithms.

\subsubsection{Geopedological map and soil sampling}

As background to the DSM project, a semi-detailed $(1: 50,000)$ soil-landscape map was available, based on the geopedological approach (Farshad et al., 2006; Zinck, 1988/1989) The map units are landform elements (facets) within a fourlevel hierarchy, each associated with one or more Soil Taxonomy subgroups. This area had been mapped by Hansakdi (1998) and was revised during field observation, resulting in six major landscapes (Mo- $\mathrm{J}$ : Mountainous in Jurassic, Mo-PTrv : Mountainous in Permian and Triassic, Mo-Ps : Mountainous in Permian, Mo- Trhl : Mountainous in Triassic Huai Hin Lat formation, Pi:Piedmont and Va:Valley). These were used as the basis for stratified sampling. Five sample areas of interest (AOI) totaling $187 \mathrm{~km}^{2}$, about a quarter of the whole study area, were selected to cover the most important geopedologic units. The sample AOI were all rectangles crossing maximum landscape variability (Figure 2.3 )a) Geopedological landscapes with observation points and areas of interest; )b) Soil series map ) 1:50,000( by updating the geopedological map. For a description of the legend see Appendix 1 and 2.

Updating the geopedological map proceeded as follows: Ortho- photographs $(1: 25,000)$ and a contour map $(1: 4,000,2 \mathrm{~m}$ contour interval) were matched with a topographic map; visualization of the landscape was enhanced by hill-shading 
with adjusted transparency. The existing map of (Hansakdi, 1998) was overlaid on this visualization. It was obvious that the existing map had serious geometric problems, likely due to being compiled on a semi-controlled photomosaic. The orthophotographs were then interpreted to a so-called geoform map based on relief, drainage, photographic texture, land use and photographic tonality (Zinck, 1988/1989). These are assumed to be related to (yet unknown) soil types. The photo-interpretation was compared to the existing map; where concepts appeared similar, the geometry of the latter was used to adjust the polygons of the former; where the concepts were not similar, the new interpretation was used to define polygons.

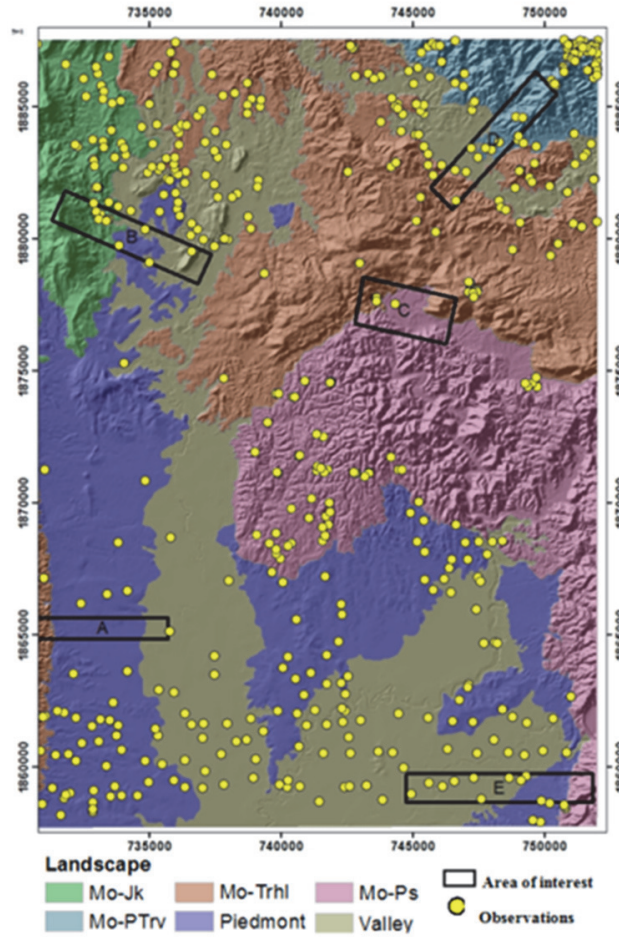

a

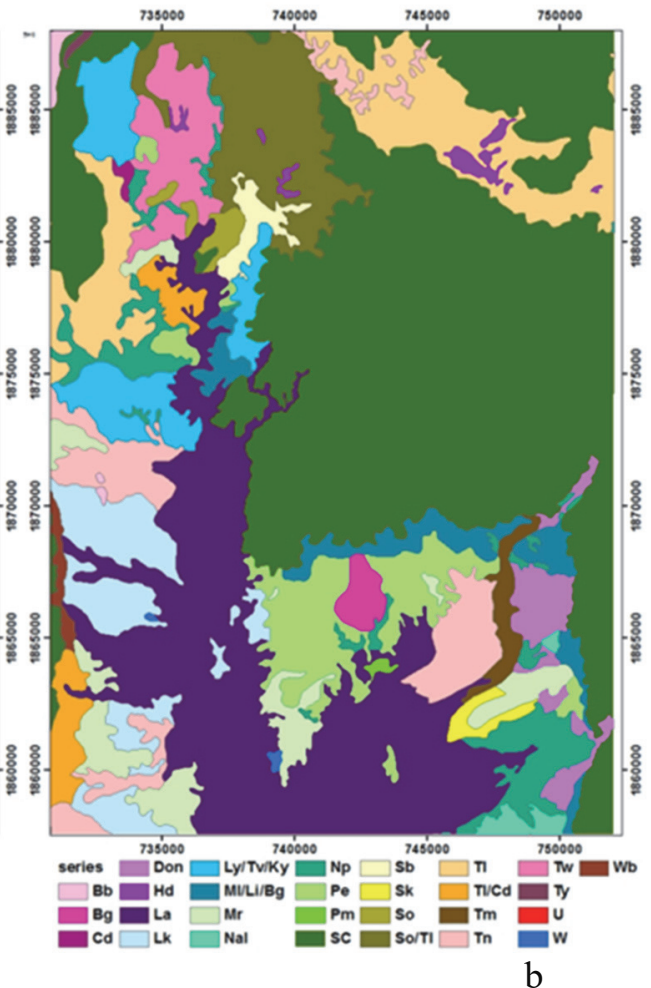

$b$

Figure 2.3 (a) Geopedological landscapes with observation points and areas of interest; (b) Soil series map $(1: 50,000)$ by updating the geopedological map. For a description of the legend see Appendix 1 and 2.

\subsubsection{Statistical methods}

All exploratory data analysis, data manipulation and statistical inference was carried out in the $\mathrm{R}$ environment for statistical computing (R Development Core Team, 2011). Besides conventional calculations of descriptive statistics and 
Pearson's correlations, we also developed statistical models of soil properties explained by terrain parameters, using an information- theoretic approach to ensure maximum predictive power. For this Principal Components Analysis (PCA) was used. First, the terrain parameters were converted to standardized principal components with $\mathrm{R}$ function 'prcomp'. These were then used as regressors in a linear model ( $\mathrm{R}$ function ' $\mathrm{lm}$ ') for each soil property as regression. Finally, the model was reduced by backwards stepwise regression to obtain the highest adjusted $\mathrm{R}^{2}$ as a measure of goodness- of- fit. Since the principal components are orthogonal, this is a deterministic procedure (Everitt and Hothorn, 2011).

Logistic regression was used to model the probabilistic relationship between occurrence of soil series and terrain variables, using each series' observed locations as presence points, and all other series' observed locations as absence points, using both single predictors and standardized principal components of the terrain variables (Hosmer and Lemeshow, 2000). We used AKiake's Information Criterion (AIC) to determine the relationship and the goodness- fit of the model, and the area under the Receiver Operating Characteristic (ROC) curve (AUC) to evaluate the success of logistic regression models in separating series occurrences and non-occurrences.

\subsubsection{Predictive mapping}

The best statistical models were applied to all grid cells in the five AOI. The predictors were converted to standardized principal components required as model predictors using the loadings derived by PCA on the point observations, and these were then used to compute the soil property or probability of series occurrence per cell. These were displayed over a hillshaded DEM and the landscape polygons were interpreted.

\subsection{Results and discussions}

\subsubsection{Soil properties}

Table 2.1 shows the descriptive statistics of the selected soil properties. Bulk densities are on average higher and but somewhat less variable in the subsoil. Clay proportion and $\mathrm{pH}$ are only slightly higher, but more variable, in subsoil. A horizon thickness is strongly right skewed, and so was square-root transformed before further analysis. 
Bulk density on topsoil (A-horizon) is lower than subsoil, this might be due to a loose soil on the top, mainly due to its higher organic matter content and to plowing (or hoeing). With respect to agricultural activity, the topsoil is usually about 15-25 $\mathrm{cm}$ thick, where, topsoil depth is about equal to tillage depth since this determines how deep organic matter and fertilizers have worked into the soil.

The average clay content in subsoil is slightly higher than topsoil, this might be due to the downward movement of water which might have transported some of the clay particles from the topsoil into the subsoil. In some cases, the subsoil is located between the topsoil and the parent rock (or material) below, therefore in some places clay content in subsoil is lower than topsoil, e.g. parent material is sandstone.

Soil $\mathrm{pH}$, subsoil $\mathrm{pH}$ is higher than topsoil, this is most likely influenced by leaching process. The study area has extreme rainfall which could be the reason for the transportation of cations from the topsoil into the subsoil.

Table 2.1 Descriptive statistics of selected soil properties

\begin{tabular}{lcccccc}
\hline $\begin{array}{c}\text { Soil } \\
\text { properties }\end{array}$ & $\mathrm{n}$ & Min & Mean & Max & $\begin{array}{c}\text { Std. } \\
\text { D. }\end{array}$ & skew \\
\hline A_THICK $(\mathrm{cm})$ & 517 & 5.00 & 15.71 & 55.00 & 8.83 & 1.49 \\
BD-T op $\left(\mathrm{g} / \mathrm{cm}^{3}\right)$ & 177 & .96 & 1.39 & 1.82 & .17 & -.07 \\
BD-Sub $\left(\mathrm{g} / \mathrm{cm}^{3}\right)$ & 160 & .84 & 1.47 & 1.80 & .14 & -.19 \\
C - T op $(\%)$ & 174 & 5.52 & 32.29 & 66.58 & 11.12 & -.51 \\
C - Sub $(\%)$ & 157 & 5.53 & 33.79 & 64.71 & 11.81 & .09 \\
pH - T op & 112 & 4.80 & 6.24 & 7.70 & .57 & .05 \\
pH - Sub & 104 & 5.00 & 6.30 & 8.10 & .64 & .04 \\
\hline
\end{tabular}

Remark: A_THICK $=$ A horizon thickness; $\mathrm{BD}=$ Bulk density and $\mathrm{C}=$ Percent clay, Top soil is defined as $0-25 \mathrm{~cm}$ and $\mathrm{Sub}$ soil as $25-50 \mathrm{~cm}$. 
Table 2.2 shows the inter-property linear correlations, which is also shown graphically in Figure 2.4. The only strong correlations are between top and subsoil for the same property as clay, $\mathrm{pH}$ and bulk density with $0.73,0.69$ and 0.47 , respectively.

Table 2.2 Correlation matrix of selected soil properties

\begin{tabular}{|c|c|c|c|c|c|c|c|}
\hline & $\begin{array}{c}\text { A } \\
\text { Thickness }\end{array}$ & $\begin{array}{c}\text { BD } \\
\text { Topsoil }\end{array}$ & $\begin{array}{c}\text { C } \\
\text { Topsoil }\end{array}$ & $\begin{array}{c}\mathrm{pH} \\
\text { Topsoil }\end{array}$ & $\begin{array}{c}\text { BD } \\
\text { Subsoil }\end{array}$ & $\begin{array}{c}\text { C } \\
\text { Subsoil }\end{array}$ & $\begin{array}{c}\mathrm{pH} \\
\text { Subsoil }\end{array}$ \\
\hline A_THICK(sqrt) & 1 & & & & & & \\
\hline BD-Top & .103 & 1 & & & & & \\
\hline Top- C & .054 & -.276 & 1 & & & & \\
\hline pH Top & .195 & -.071 & .024 & 1 & & & \\
\hline BD-Sub & .155 & .505 & -.218 & -.071 & 1 & & \\
\hline Sub- C & .024 & -.208 & .733 & -.075 & -.324 & 1 & \\
\hline $\mathrm{pH}$ Sub & .255 & -.144 & .085 & .692 & .168 & -.093 & 1 \\
\hline
\end{tabular}

Remark:_THICK(sqrt) $=$ A horizon thickness, $\mathrm{BD}=$ Bulk density, $\mathrm{C}=$ Percent clay ,Topsoil is defined as $0-25 \mathrm{~cm}$ and Subsoil as $25-50 \mathrm{~cm}$. Highest correlations with value $>0.5$ are in bold. 


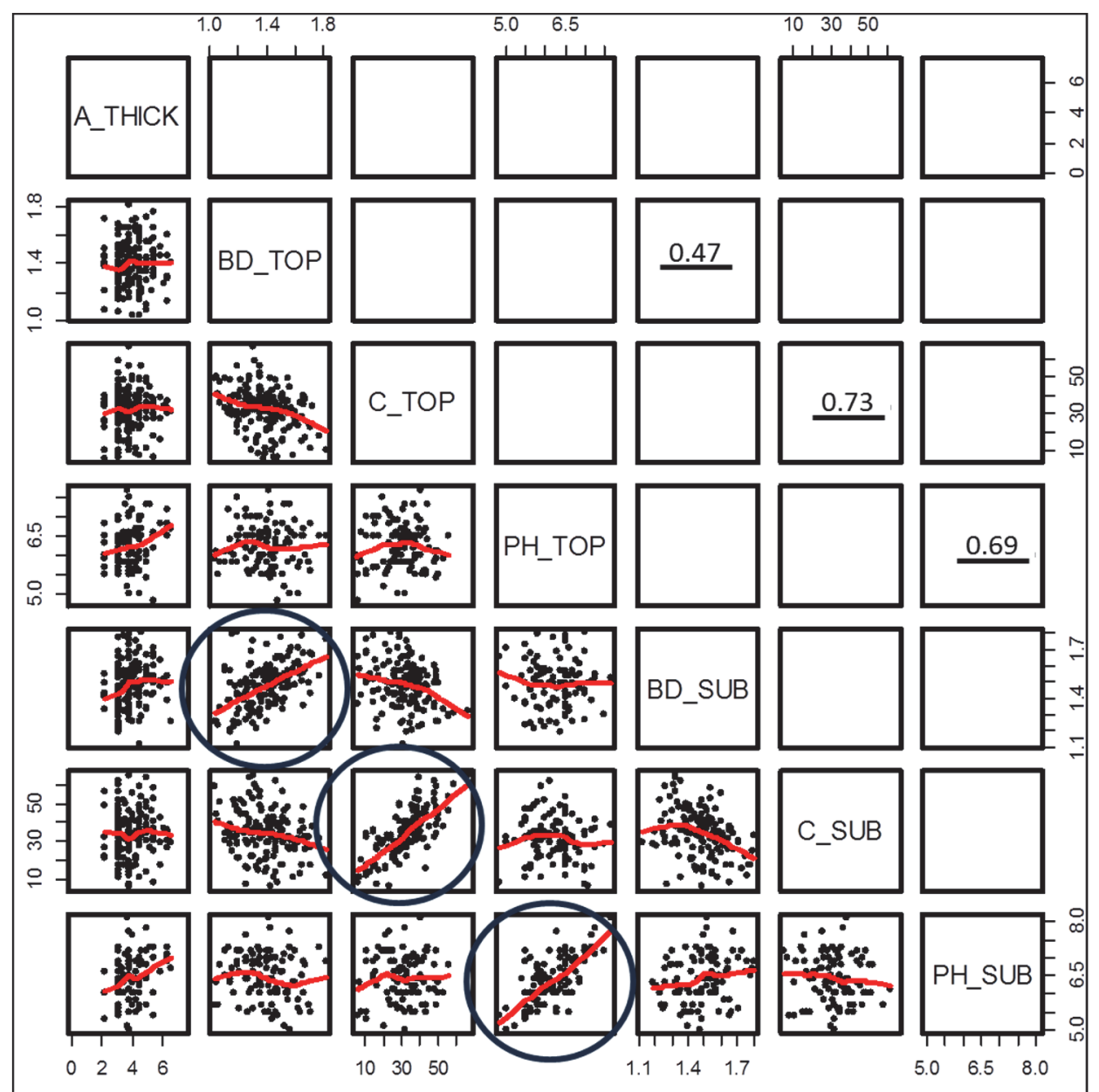

Figure 2.4 Bivariate scatterplot of soil properties, the strong correlation showing in the black circle

\subsubsection{Terrain attributes}

The descriptive statistics for the primary and secondary terrain attributes show in Table 2.3. The primary terrain attributes, mean values in both resolution and neighborhood size are varied. Analysis of the effect of neighborhood size shows that for both resolutions, increasing neighborhood size reduces mean values of slope, total curvature, profile curvature and plan curvature but increasing in mean value of local relief, this is due to the smoothing effect of increasing neighborhood (Table 2.3). The exception is the local relief, where the larger window covers more area, which leads to more relief.

The effect of DEM resolution on derived terrain attributes from fine to coarser results in the averaging of elevation values and also the averaging of derived 
terrain attributes. The descriptive statistics for the secondary terrain attributes vary by resolution and neighborhood size. One reason for this may be that we computed terrain across multiple landscapes. However, increasing DEM resolution and neighborhood size produced lower values of TCI, but larger in TPI and CTI.

Terrain derivation using coarser resolution DEMs (resampling from original 5-m DEM) increases in mean values of LoR, TPI and CTI and reduces other terrain parameters, this clearly prove that there is non-constant variance for 5-m DEM and the changes in the topographic characteristics result more from discretization effects than from terrain-smoothing effects (Wolock and McCabe, 2000).

When DEM resolution and neighborhood size are increased the effect is increasing mean value of CTI and decreasing value of TCI. This due to the effect of " $A S$ ", the estimates of upslope contributing area tend to increase along with the grid size increase, considering multiplied coverage area of each grid cell. The increase of mean contributing area is roughly in linear relationship to grid size under fair DEM resolutions (Wu et al., 2008a). The impacts will also be affected to secondary or compound topographic derivatives, which may be used as spatial input of a hydrologic model, thus resulting in uncertainty with prediction output. The result is also confirmed by Sørensen and Seibert (2007).

The inter-property linear correlations are shown graphically in Figure 2.5. The strong correlations are between terrain attribute as slope and LoR (0.99), ToC and TCI (0.92), ToC and TPI (0.90), TPI and TCI (083), ToC and plan curvature $(0.82)$, and $\mathrm{ToC}$ and profile curvature (-0.82).

Slope has a high positive correlation with LoR, this due to both terrain attributes, which are directly calculated from DEM and represent landscape surface (formula 2 and 5), especially in the areas with the high altitude, where the slopes are the dominant morphometric features of the landscape. ToC has high positive correlation with TCI, TPI, plan curvature and negative correlation with profile curvature. 
Table 2.3 Descriptive statistics for trimmed terrain attributes for two combinations of resolutions and neighborhood size

\begin{tabular}{|c|c|c|c|c|c|c|c|c|c|c|}
\hline DTM & DEM (m) & NS* & Min & $1^{\text {st }} \mathrm{Qu}$. & Med & Mean & $3^{\text {st }}$ & $\operatorname{Max}$ & Std. & Skew. \\
\hline \multirow{4}{*}{$\begin{array}{l}\text { Slope } \\
\text { (sqrt) }\end{array}$} & \multirow{2}{*}{5} & 5 & 0.00 & 1.44 & 4.42 & 9.20 & 12.12 & 81.89 & 12.17 & 2.58 \\
\hline & & 20 & 0.00 & 1.48 & 3.99 & 7.40 & 9.15 & 74.22 & 9.91 & 3.09 \\
\hline & \multirow{2}{*}{10} & 5 & 0.00 & 1.57 & 4.36 & 8.51 & 10.93 & 78.28 & 11.27 & 2.75 \\
\hline & & 20 & 0.00 & 1.41 & 3.31 & 5.95 & 7.55 & 52.06 & 7.57 & 2.78 \\
\hline \multirow{4}{*}{$\begin{array}{c}\text { Total } \\
\text { curvature }\end{array}$} & \multirow{2}{*}{5} & 5 & -2.23 & -0.01 & 0.06 & 0.18 & 0.38 & 3.10 & 0.52 & 0.63 \\
\hline & & 20 & -2.14 & -0.01 & 0.02 & 0.09 & 0.19 & 1.61 & 0.27 & -0.33 \\
\hline & \multirow{2}{*}{10} & 5 & -1.55 & -0.01 & 0.04 & 0.16 & 0.31 & 2.94 & 0.43 & 1.10 \\
\hline & & 20 & -0.66 & -0.01 & 0.00 & 0.03 & 0.06 & 3.02 & 0.19 & 8.29 \\
\hline \multirow{4}{*}{$\begin{array}{l}\text { Profile } \\
\text { curvature }\end{array}$} & \multirow{2}{*}{5} & 5 & -1.76 & -0.17 & -0.01 & -0.07 & 0.02 & 1.62 & 0.32 & -0.27 \\
\hline & & 20 & -0.88 & -0.07 & 0.00 & -0.03 & 0.02 & 0.96 & 0.16 & -0.31 \\
\hline & \multirow{2}{*}{10} & 5 & -2.45 & -0.12 & 0.00 & -0.06 & 0.02 & 1.47 & 0.28 & -1.45 \\
\hline & & 20 & -2.79 & -0.03 & 0.00 & -0.01 & 0.02 & 0.64 & 0.15 & -12.26 \\
\hline \multirow{4}{*}{$\begin{array}{l}\text { Plan } \\
\text { curvature }\end{array}$} & \multirow{2}{*}{5} & 5 & -1.47 & -0.01 & 0.02 & 0.11 & -0.18 & 2.12 & 0.32 & 1.28 \\
\hline & & 20 & -2.27 & 0.00 & 0.01 & 0.06 & 0.11 & 0.88 & 0.20 & -3.72 \\
\hline & \multirow{2}{*}{10} & 5 & -1.32 & 0.00 & 0.02 & 0.10 & 0.16 & 1.65 & 0.26 & 1.29 \\
\hline & & 20 & -0.32 & -0.01 & 0.01 & 0.02 & 0.03 & 0.43 & 0.08 & 1.22 \\
\hline \multirow{4}{*}{$\begin{array}{l}\text { Locl } \\
\text { relief }\end{array}$} & \multirow{2}{*}{5} & 5 & 0.00 & 0.40 & 1.20 & 2.42 & 3.18 & 21.05 & 3.17 & 2.58 \\
\hline & & 20 & 0.00 & 2.46 & 7.36 & 10.91 & 14.32 & 91.25 & 13.85 & 2.59 \\
\hline & \multirow{2}{*}{10} & 5 & 0.00 & 0.91 & 2.70 & 4.77 & 6.09 & 41.50 & 6.01 & 2.64 \\
\hline & & 20 & 0.00 & 5.48 & 12.87 & 20.00 & 26.59 & 112.62 & 21.51 & 1.95 \\
\hline \multirow{4}{*}{ TPI $^{1}$} & \multirow{2}{*}{5} & 5 & -0.58 & 0.00 & 0.02 & 0.05 & 0.10 & 1.46 & 0.16 & 1.88 \\
\hline & & 20 & -6.01 & -0.02 & 0.20 & 0.66 & 1.34 & 11.15 & 1.77 & 1.05 \\
\hline & \multirow{2}{*}{10} & 5 & -1.83 & -0.01 & 0.05 & 0.18 & 0.36 & 5.39 & 0.55 & 2.10 \\
\hline & & 20 & -20.22 & -0.11 & 0.50 & 1.58 & 3.10 & 27.13 & 4.31 & 1.07 \\
\hline \multirow{4}{*}{$\mathrm{TCI}^{2}$} & \multirow{2}{*}{5} & 5 & -4.04 & -0.01 & 0.08 & 0.13 & 0.42 & 2.30 & 0.72 & -1.76 \\
\hline & & 20 & -4.97 & -0.02 & 0.04 & 0.08 & 0.23 & 1.90 & 0.43 & -3.59 \\
\hline & \multirow{2}{*}{10} & 5 & -4.67 & -0.02 & 0.06 & 0.14 & 0.40 & 2.84 & 0.66 & -1.53 \\
\hline & & 20 & -1.52 & -0.03 & 0.01 & 0.02 & 0.09 & 3.02 & 0.28 & 1.79 \\
\hline \multirow{4}{*}{$\mathrm{CTI}^{3}$} & & 5 & 2.98 & 5.94 & 6.99 & 7.64 & 8.98 & 18.29 & 2.48 & 1.12 \\
\hline & & 20 & 3.42 & 6.18 & 7.41 & 8.00 & 9.16 & 17.83 & 2.49 & 0.99 \\
\hline & \multirow{2}{*}{10} & 5 & 4.19 & 6.24 & 7.35 & 7.98 & 9.13 & 19.16 & 2.50 & 1.35 \\
\hline & & 20 & 4.19 & 6.90 & 8.19 & 8.66 & 10.06 & 18.16 & 2.40 & 0.89 \\
\hline
\end{tabular}

Remark: NS*=Neighborhood size, $\mathrm{TPI}^{1}=$ =Topographic position index, $\mathrm{TCI}^{2}=$ Terrain characterization index, $\mathrm{CTI}^{3}=$ Compound topographic position index 


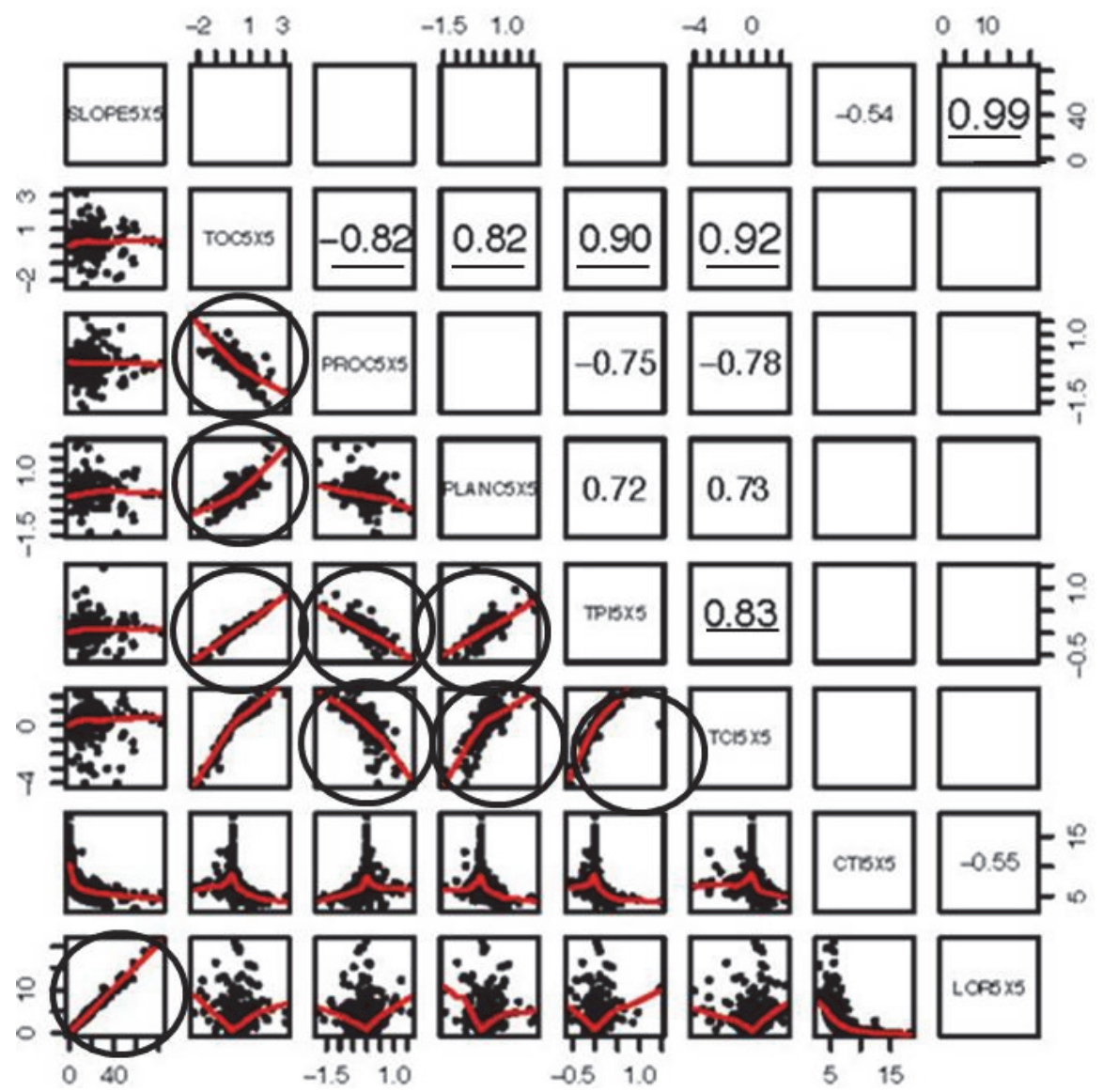

Figure 2.5 Pairwise scatterplot for the terrain attributes for the 5-m resolution DEM with $5 \times 5$-widow combination, the strong correlation showing in black circles.

\subsubsection{Soil - terrain models}

Table 2.4 shows the partial Pearson's correlation coefficients between subsoil bulk density, as a representative of the soil properties, and single terrain variables, for all combinations of DEM resolution and neighborhood size. None are very high ( at most $+/-0.23$ ), and there is no clear trend with respect to either factor. Table 2. 5 shows the partial Pearson's correlation coefficients between soil properties and terrain attributes for the $5-\mathrm{m}$ resolution and $5 \times 5$ window size. None are very strong, the highest being 0.3 (i.e., $9 \%$ of variance explained), relating CTI with subsoil $\mathrm{pH}$ and thickness of the A-horizon. Thus, there is no useful predictive relation between soil properties and single terrain attributes. This table was produced for all resolutions and window sizes; others differ in detail and in 
which relations are best, but in no case is the relations strong enough for prediction.

Table 2.6 shows the goodness- of-fit of the stepwise linear regression models of soil properties based on the standardized principal components of terrain parameters, for all resolutions and neighborhood sizes. Most models are quite poor; the only property that is consistently somewhat well-modeled (about $25 \%$ of the variance explained) is subsoil bulk density; in addition subsoil $\mathrm{pH}$ is poorly but consistently modeled (about $15-20 \%$ of variance explained). For these two properties, there is no consistent relation with neighborhood size. The topsoil properties, including A-horizon thickness, are poorly modeled, probably because the surface is affected by other factors, e.g., land use. For all properties and neighborhood sizes, the 10-m DEM gives slightly better results than the original $\operatorname{DEM}(5-\mathrm{m})$, indicating that these soil properties are somewhat the result of an averaging process on the landscape.

Table 2.4 Pairwise partial linear correlation coefficients between subsoil bulk density and trimmed terrain variables

\begin{tabular}{|c|c|c|c|c|c|c|c|c|c|}
\hline $\begin{array}{c}\text { DEM } \\
(\mathrm{m})\end{array}$ & $\begin{array}{c}\mathrm{NS}^{* *} \\
(\mathrm{~m})\end{array}$ & (sqrt)Slope & $\mathrm{ToC}^{1}$ & $\operatorname{ProC}^{2}$ & PlanC $^{3}$ & (sqrt) $L_{o R}^{4}$ & $\mathrm{TPI}^{5}$ & $\mathrm{TCI}^{6}$ & ${ }_{(\log )} \mathrm{CTI}^{7}$ \\
\hline \multirow{3}{*}{5} & $5 \times 5$ & 014 & 004 & 417 & 843 & 326 & .0159 & -.2331 & -.0314 \\
\hline & $10 \times 10$ & .0825 & -.0376 & -.1091 & -.0569 & .0426 & -.1338 & .0683 & .0315 \\
\hline & $20 \times 20$ & -.1883 & -.2070 & .0370 & -.2023 & .1193 & -.2100 & -.2271 & .0951 \\
\hline \multirow{3}{*}{10} & $5 \times 5$ & -.0237 & .0400 & .1020 & .0014 & -.0287 & .0064 & 27 & .0497 \\
\hline & $10 \times 10$ & -.0055 & .2454 & -.0727 & .2196 & -.0106 & .1740 & .0705 & -.0723 \\
\hline & $20 \times 20$ & -.0736 & -.1350 & .1702 & -.0233 & -.0705 & -.0735 & .0361 & .0132 \\
\hline
\end{tabular}

Remark: $\mathrm{NS}^{*}=$ Neighborhood size, $\mathrm{ToC}^{1}=$ Total curvature, $\mathrm{ProC}^{2}=$ Profile curvature, PlanC ${ }^{3}=$ Plan curvature, $\mathrm{LoR}^{4}=$ Local relief, $\mathrm{TPI}^{5}=$ Topographic position index, $\mathrm{TCI}^{6}=$ Terrain characterization index, and $\mathrm{CTI}^{7}=$ Compound topographic position index, where the highest correlation coefficients are in bold. 
Table 2.5. Pairwise partial linear correlation coefficients between soil properties and trimmed terrain attributes, with 5-m resolution DEM and $5 \times 5 \mathrm{~m}$ neighborhoods.

\begin{tabular}{|c|c|c|c|c|c|c|c|c|}
\hline Soil properties & (sqrt)Slope & ToC $^{1}$ & ProC $^{2}$ & PlanC $^{3}$ & (sqrt) $\mathbf{L o R}^{4}$ & TPI $^{5}$ & $\mathrm{TCI}^{6}$ & $(\log ) \mathrm{CTI}^{7}$ \\
\hline BD-Topsoil (g/cm³) & .1430 & .0894 & .0909 & -.1100 & -.1758 & .0096 & $\begin{array}{r}- \\
.0200\end{array}$ & -.0020 \\
\hline BD-Subsoil (g/cm3) & .0259 & .0034 & .0817 & -.1100 & -.0577 & .1437 & .0292 & -.1690 \\
\hline Clay-Topsoil (\%) & -.0842 & .1021 & .0705 & -.0030 & .0886 & -.1089 & .0208 & .0481 \\
\hline Clay-Subsoil (\%) & -.1012 & .0142 & .0555 & .0703 & -.0970 & .0206 & .0117 & .0666 \\
\hline pH-Topsoil & .0271 & .0297 & .0299 & -.0300 & -.0265 & -.0005 & .0627 & .3160 \\
\hline pH-Subsoil & .0242 & -.0250 & -.0230 & .0061 & -.0420 & .0495 & -.027 & -.0510 \\
\hline $\begin{array}{l}\text { A horizon } \\
\text { thickness }\end{array}$ & -.0073 & .0192 & .0197 & -.0200 & .0234 & .1420 & .0323 & .3088 \\
\hline
\end{tabular}

Remark: $\mathrm{ToC}^{1}=$ Total curvature, ProC $^{2}=$ Profile curvature, PlanC $\mathrm{C}^{3}=$ Plan curvature, $\mathrm{LoR}^{4}=$ Local relief, $\mathrm{TPI}^{5}=$ Terrain characterization index, $\mathrm{TCI}^{6}=$ Topographic position index and $\mathrm{CTI}^{7}=$ Compound topographic position index, where the highest correlation coefficients with value more than 0.10 are in bold

Table 2. 6 Goodness- of- fit of linear models of soil properties by standardized principal components of terrain parameters

\begin{tabular}{llllllll}
\hline \multicolumn{1}{c}{$\begin{array}{c}\text { Soil } \\
\text { properties }\end{array}$} & \multicolumn{1}{c}{ DEM $(\mathrm{m})$} & \multicolumn{3}{c}{5} & & \multicolumn{3}{c}{10} \\
\hline BD - Topsoil $\left(\mathrm{g} / \mathrm{cm}^{3}\right)$ & .0717 & .0709 & .0821 & .0499 & .0772 & .0753 \\
BD - Subsoil $\left(\mathrm{g} / \mathrm{cm}^{3}\right)$ & $\mathbf{. 2 4 2 3}$ & $\mathbf{. 2 4 2 3}$ & $\mathbf{. 2 5 9 0}$ & $\mathbf{. 2 1 8 2}$ & $\mathbf{. 2 4 5 3}$ & $\mathbf{. 2 5 3 9}$ \\
Clay - Topsoil $(\%)$ & .0481 & .0182 & .0368 & .0388 & .0345 & .0636 \\
Clay - Subsoil $(\%)$ & .0716 & .0886 & .0769 & .1254 & .0619 & .0993 \\
pH - Topsoil & .0296 & .0332 & .0279 & .0429 & .0424 & .0499 \\
pH - Subsoil & .1392 & .1518 & .1675 & .1655 & .2238 & .2113 \\
A_THICK $(\mathrm{cm})$. & .1057 & .1003 & .0954 & .0969 & .0971 & .1149 \\
\hline
\end{tabular}

Remark: NS $*$ Neighborhood size, $\mathrm{ToC}^{1}=$ Total curvature, ProC $^{2}=$ Profile curvature, $\mathrm{PlanC}^{3}=$ Plan curvature, $\mathrm{LoR}^{4}=$ Local relief, $\mathrm{TPI}^{5}=$ Terrain characterization index, $\mathrm{TCI}^{6}=$ Topographic position index and $\mathrm{CTI}^{7}=$ Compound topographic position index, where the highest adjusted $\mathrm{R}^{2}$ values are in bold. . Top soil is defined as $10-25 \mathrm{~cm}$ and Sub soil is defined as $25-50 \mathrm{~cm}$. 


\section{Soil Series}

Table 2.7 shows the results of the logistic regressions of soil series occurrence on single terrain variables. Only CTI had any explanatory power for two of the series ( $\mathrm{Li}$ and $\mathrm{Tn}$ ), however the third series (Ws) was poorly explained. This might be due to the effect of soil moisture, where CTI is strongly correlated with soil moisture, as Li and $\mathrm{Tn}$ are clearly different in moisture conditions and landforms. The Li series is characterized by low moisture conditions with very well drained soils in hill land or mountains, thus lower CTI values represent crests and ridges. The Tn series is characterized by having high moisture condition and very poorly drained soils in flood plain, thus higher CTI values represent drainage depressions. The Tn series is somewhat explained by CTI in all resolutions and neighborhood sizes. Li series is somewhat explained in all neighborhood sizes of 5-m DEM but less in 10-m DEM.

Both Li and Tn series have the best models based CTI from 5-m DEM with 10x10 neighborhood size showing in Figure 2.6 (a) and (b) (Tn : AIC 203 and area of ROC is about 0.91 and $\mathrm{Li}: \mathrm{AIC}=514$ and AUC is about 0.75). This indicates that CTI is highly correlated to many soil properties (Moore et al., 1993; Moore, 1993) which are used to define soil series, thus soil series are much better predicted by CTI than by primary terrain attributes. As the CTI correlated with several soil attributes such as horizon depth, silt percentage, organic matter content, and phosphorus, it can be used to quantify topographic control on hydrological processes. The hydrological processes which define as soil drainage, this play a critical role in differential transport and deposition of eroded material and leaching, translocation and re-deposition of mobile chemical constituents affecting soil properties. In particular, the role of topography on the movement of water and the consequent redistribution of materials carried within the water can influence or control the type and intensity of soil processes within a landscape. This is also confirmed by the research of (Sangchyoswat and Russel, 2002).

Table 2.8 and Figure 2.6 (c)-(d) show the goodness-of-fit of the stepwise logistic regression models of three soil series based on the standardized principal components of terrain parameters, for all resolutions and neighborhood sizes. Here the Li series was best explained in 5-m DEM with 10x10 neighborhood size (AUC 0.79) whereas Tn series was best explained in $10 \mathrm{~m}$ DEM with $5 \times 5$ neighborhood size (AUC 0.92). 
Li series is found in the narrow range of elevations in this study area (200 to 250 $\mathrm{m})$ in hilly land with slope of $12-20 \%$ and high CTI values, all these variables control soil properties ( $\mathrm{pH}, \mathrm{BS} \%$, texture and $\mathrm{OM})$. This is in contrast to the Tn series, which are mainly in wide range of flat or nearly flat topographic positions with alluvium parent material. Here the CTI and the slope gradient are lower.

Ws series was poorly predicted (AUC 0.7 ). In this case the DEM resolutions and neighborhood size made little difference. These results are far superior to models using single terrain variables. No clear trend was found for topographical aspect across different DEM resolutions for Ws series. Since the Ws and Li series are located close to each other, the difference is only the color (redder) and deeper soil (50-100 deep).

Table 2.7 Goodness-of-fit of logistic regression models (in section 2.2.3) for prediction of three soil series ( $\mathrm{Li}, \mathrm{Tn}$ and Ws series)

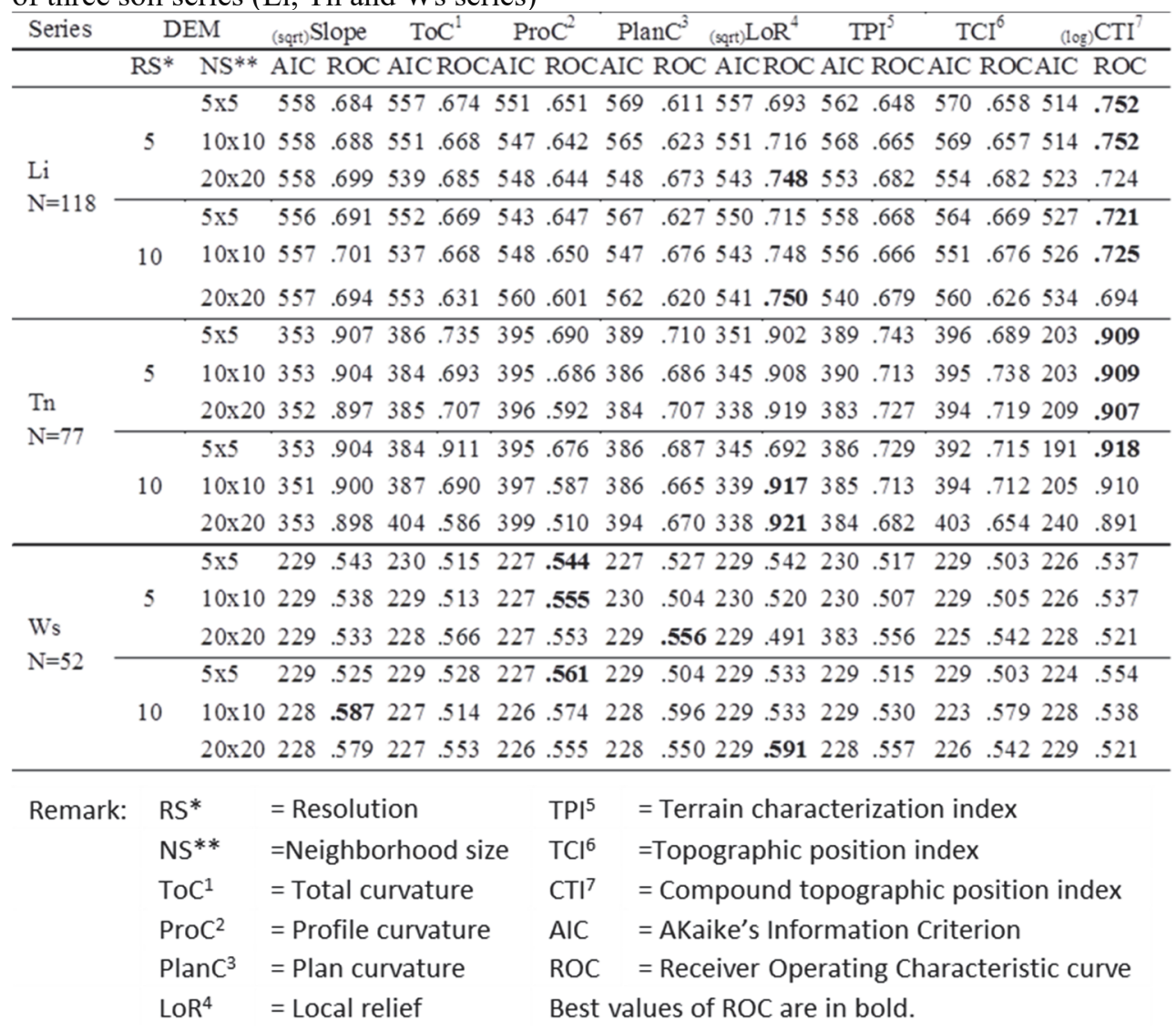


Digital terrain analysisi for fine-scale digital soil mappig in Thailand

Table 2.8 Comparison of logistic regression model performance between three soil series and standardized principal components of terrain attributes

\begin{tabular}{cccccccc}
\hline \multirow{2}{*}{ Series } & DEM & \multicolumn{3}{c}{5} & & \multicolumn{3}{c}{10} \\
\cline { 2 - 8 } & NS* & $5 \times 5$ & $10 \times 10$ & $20 \times 20$ & $5 \times 5$ & $10 \times 10$ & $20 \times 20$ \\
\hline \multirow{2}{*}{ Li } & AIC & 487 & 473 & 499 & 486 & 500 & 509 \\
& ROC & .775 & .785 & .774 & .762 & .785 & .767 \\
\hline \multirow{2}{*}{ Tn } & AIC & 203 & 209 & 210 & 190 & 203 & 238 \\
& ROC & .908 & .908 & .908 & .915 & .912 & .900 \\
\hline \multirow{2}{*}{ Ws } & AIC & 222 & 224 & 220 & 222 & 207 & 223 \\
& ROC & .646 & .633 & .679 & .626 & .703 & .626 \\
\hline
\end{tabular}

Remark: *NS = Neighbourhood size

AIC = AKaike's Information Criterion

ROC = Receiver Operating Characteristic curve

Best values of ROC are in bold. 

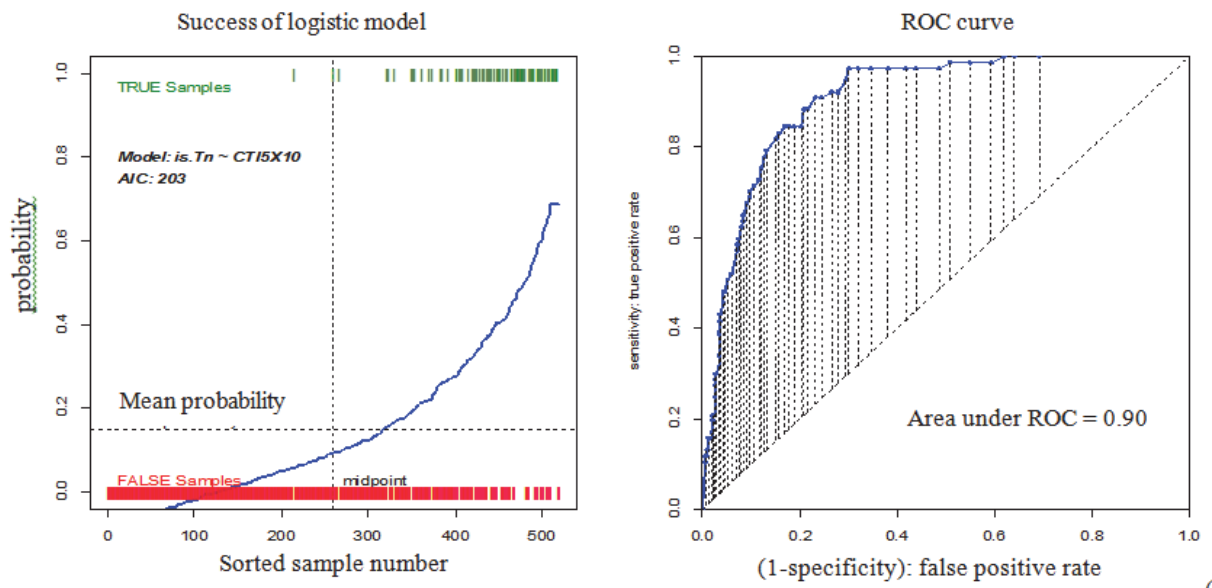

(a)
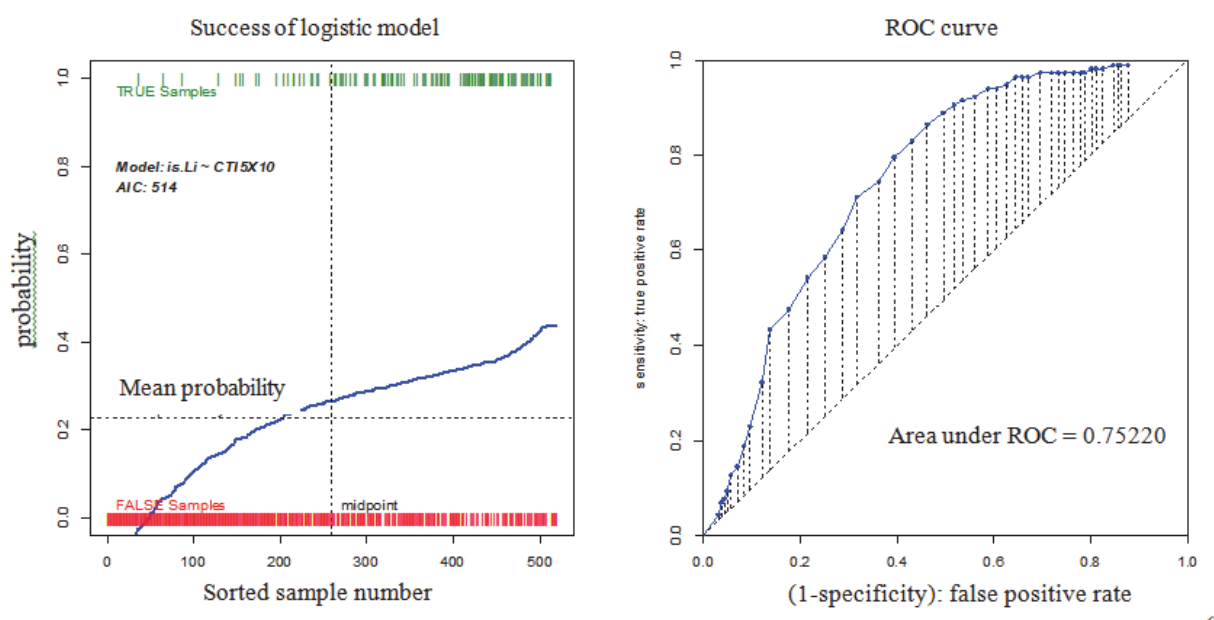

(b) 

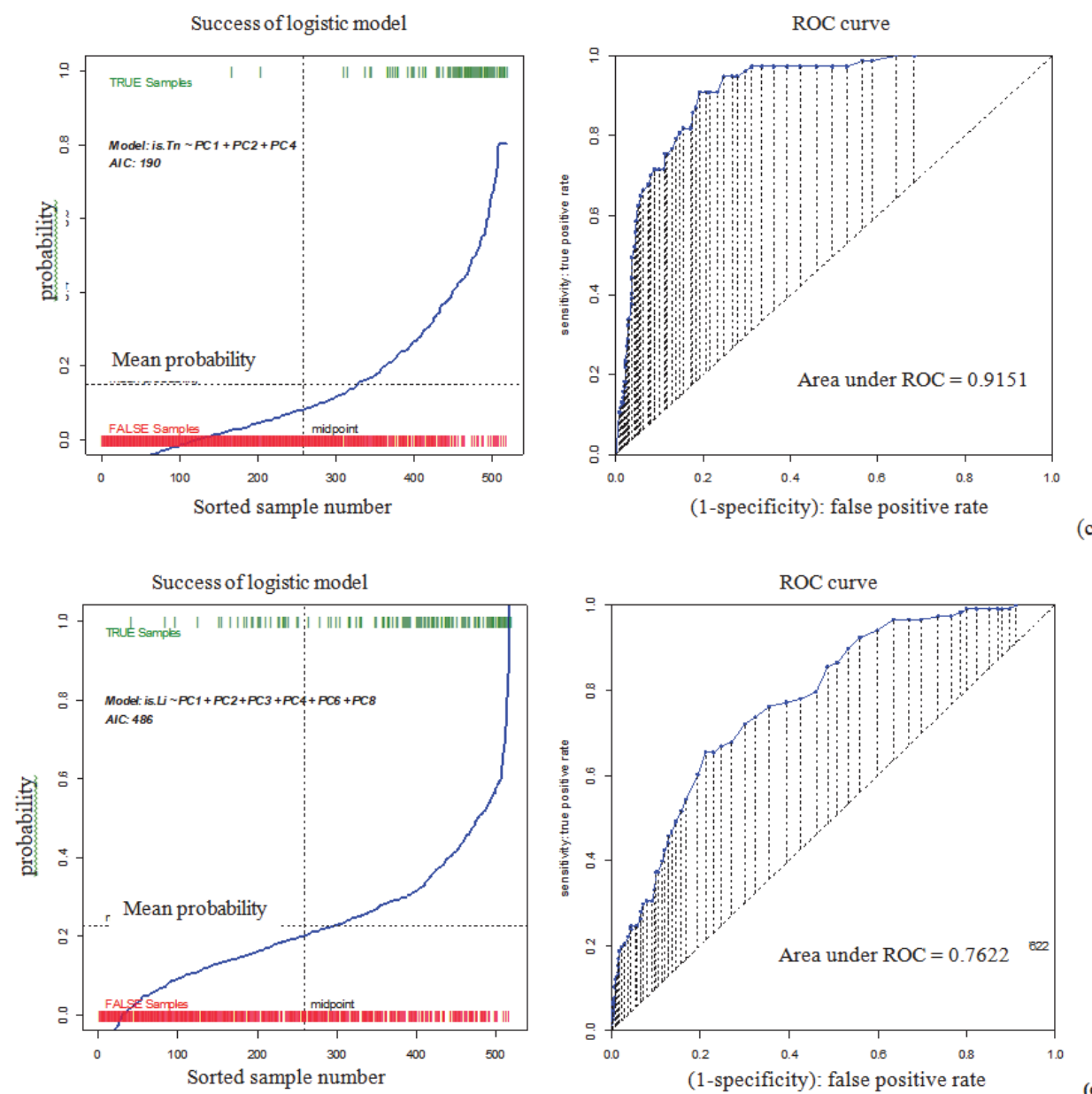

(c)

Figure 2. 6 Success of predicted soil series and evaluating models using ROC curve; (a) Tn series vs CTI derived from 5-m DEM with 10x10 neighborhoods size, (b) Li series vs CTI derived from 5-m DEM with 10x10 neighborhoods, (c) Tn series vs PCA from 10$\mathrm{m}$ DEM with $5 \times 5$ neighborhoods size, (d) Li series vs PCA derived from 10-m DEM with $5 \times 5$ neighborhoods.

\section{Predictive maps of soil properties}

For the comparison between resolutions, we compared predictions using 1 ha windows: a 20x20 neighborhood' $\mathrm{s}$ for the 5-m resolution DEM, and a 10x10 neighborhoods for the 10-m DEM. Figure 2.7and 2.8 show the predicted subsoil bulk density and $\mathrm{pH}$, respectively, for these two combinations, in all five areas. We evaluated these qualitatively by expert field knowledge of soil- landscape relations in the area, especially considering the fine-scale patterns known to the surveyor but not shown on medium-scale maps. 
Figure 2.7 shows the predicted subsoil bulk density for the two 1 ha areas, in general the maps seem realistic, but there are some regions of the map where the predictions are quite different. The patterns derived from the 5-m DEM and 20x20 window show finer features.

Figure 2.9 shows a complex pattern in hilly areas as compared to the 10-m DEM with 10x10 window: lower BD on ridge tops and higher in accumulation positions. However, the very high BD areas in the valley landscape (Figure 2.9 in area b, a and e) seem exaggerated in the 10-m DEM. With both models the subsoil bulk density was generally higher at lower elevations. Very high bulk densities $(>1.5)$ are found along the river or stream where fine sand has been deposited. High BD also appears in paddy fields, where subsoils are compacted by tillage operations. Medium bulk density (1.3-1.5) is found in middle terrace, which is influenced by accumulation of silt under the influence of soil parent material rich in silt content. The lowest bulk densities $(<1.3)$ were found in the highland, because of finegrained parent rock (shale and mudstone).

The subsoil bulk density was higher in sloping area (representing in mountain landscape), but lower in flat area (representing in valley). Meanwhile, the subsoil $\mathrm{pH}$, predicted from 5-m DEM (20x20) is higher in low-land (representing mainly in valley and piedmont), but lower in the highland (mountain landscape).

Figure 2.8 shows the predicted subsoil $\mathrm{pH}$ for the two window sizes, and Figure $2.9 \mathrm{~b}$ their difference. This also seems realistic. There are some regions of the map where the predictions were different (Figure 2.9b); the pattern of predicted results of subsoil $\mathrm{pH}$ from the 10-m DEM and 10x10 neighborhoods size was smoother, for $\mathrm{BD}$; here this artifact is more striking; this effect is especially seen on the highland landscapes. The subsoil $\mathrm{pH}$ was generally high in lowland which tends to be highest in valley and concave landscape position. High $\mathrm{pH}$ was found in lower positions where $\mathrm{Ca}_{2} \mathrm{Co}_{3}$ is transported from uplands to depressions or lower positions in flood plains and valleys, where alkaline soil is found. 

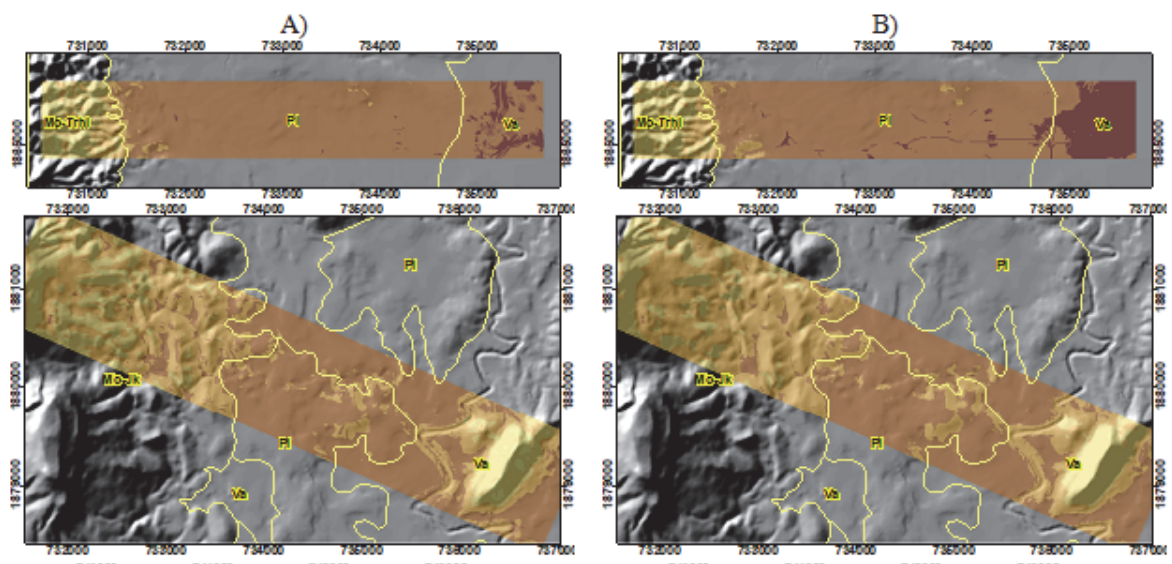

(a)
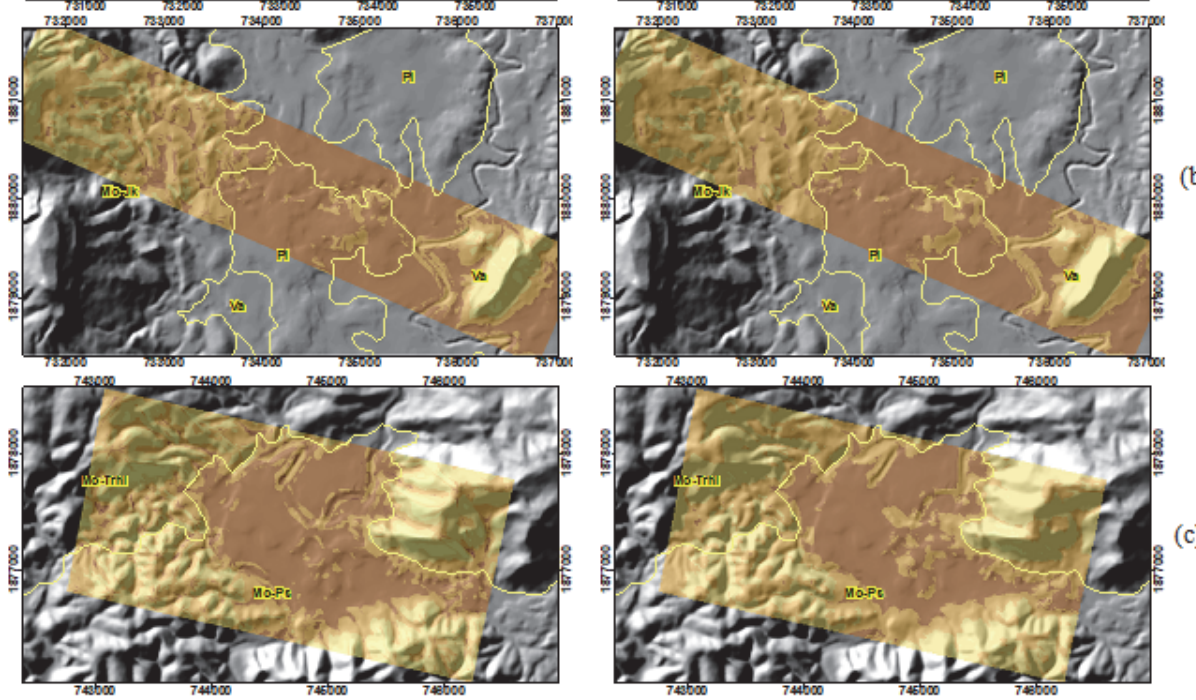

(b)
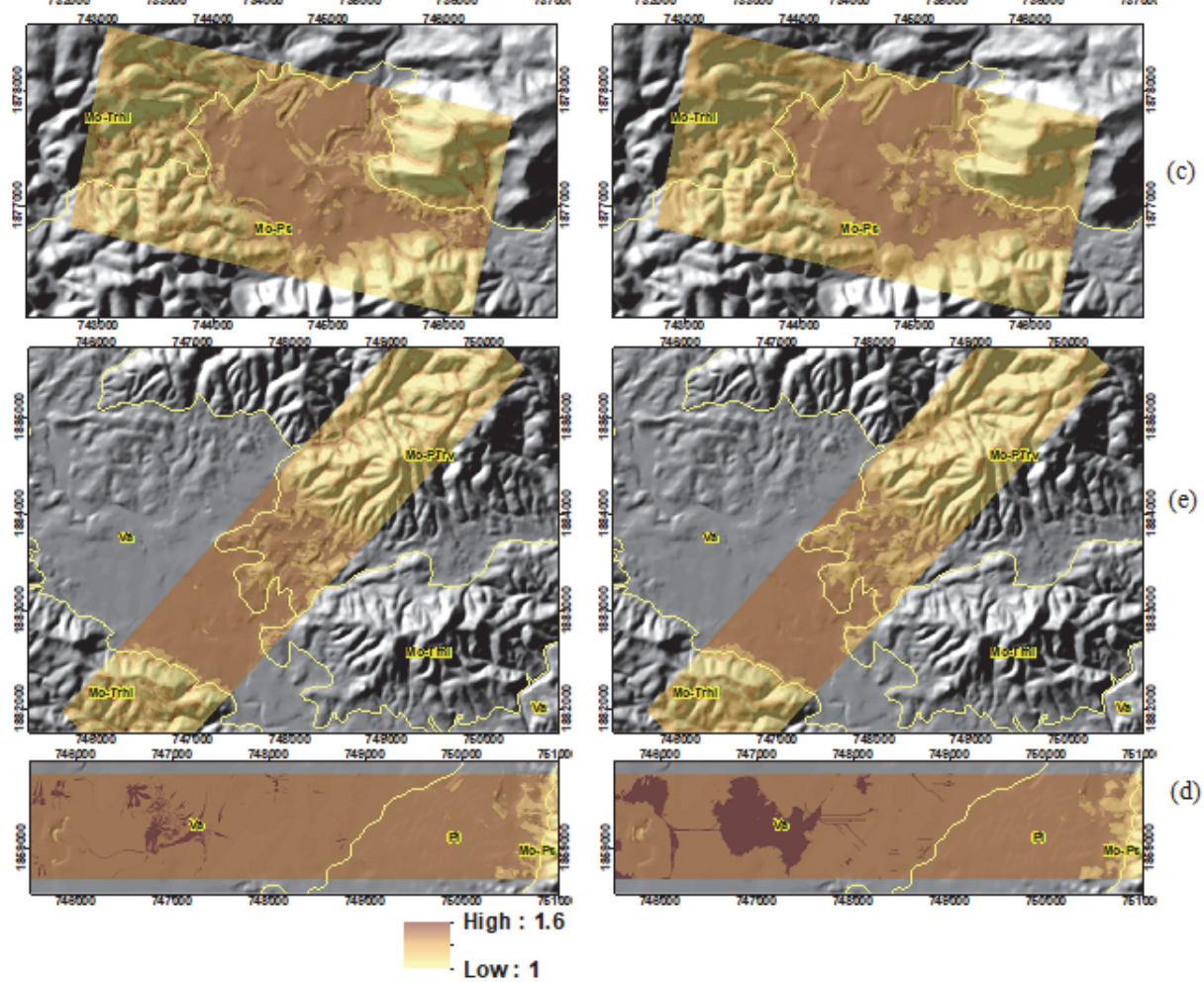

Figure 2.7 Predicted soil-landscape model in 5 sample areas (a, b, c d, and e) implemented from subsoil bulk density with DTM in five areas; A) 5-m DEM with 20x20 neighborhoods size and B) 10-m DEM with 10x10 neighborhood sizes. Dark color refers to high bulk density 

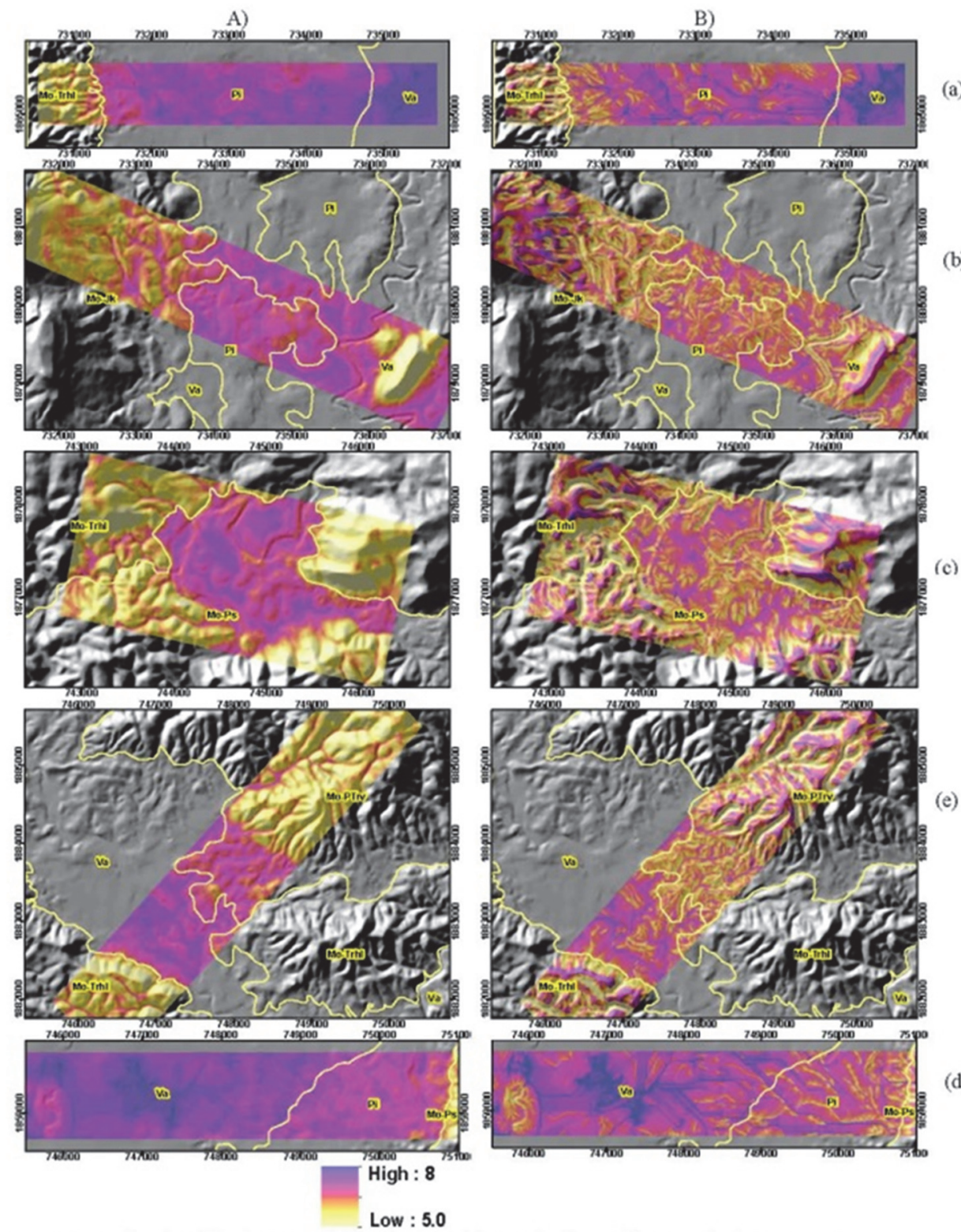

(d)

Figure 2.8 Predicted soil-landscape model in 5 sample areas (a, b, c, d and e) implemented from subsoil pH with DTM in five areas; A) 5-m DEM with 20x20 neighborhoods size and B) 10-m DEM with 10x10 neighborhoods size. Dark color refers to high soil pH. 

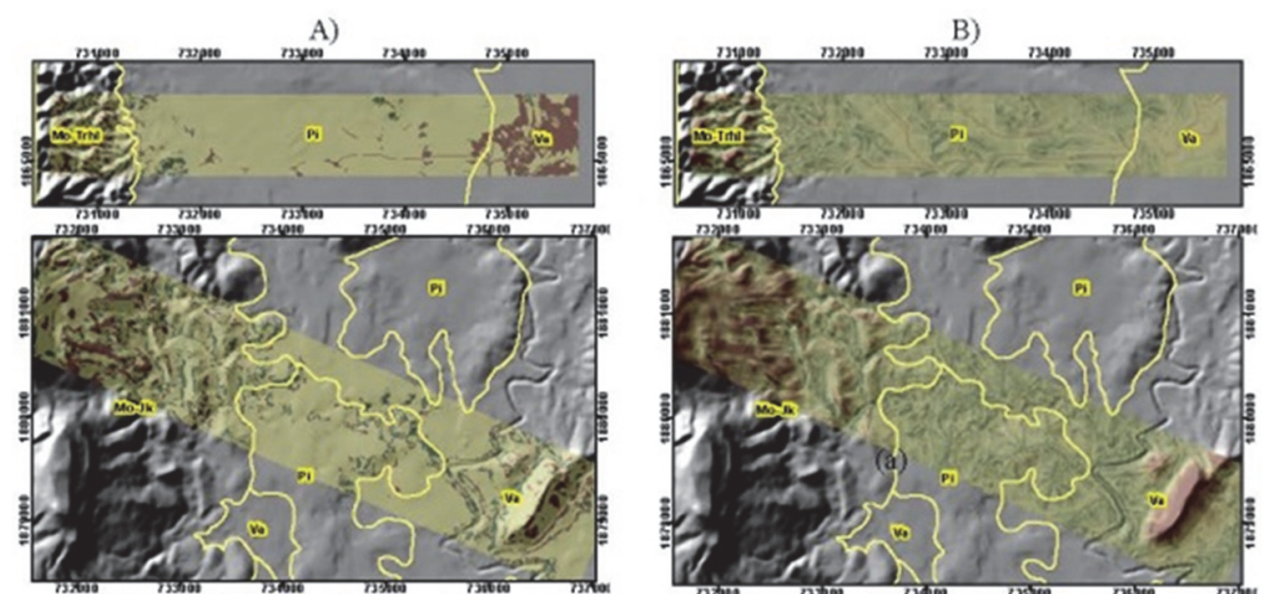

(a)
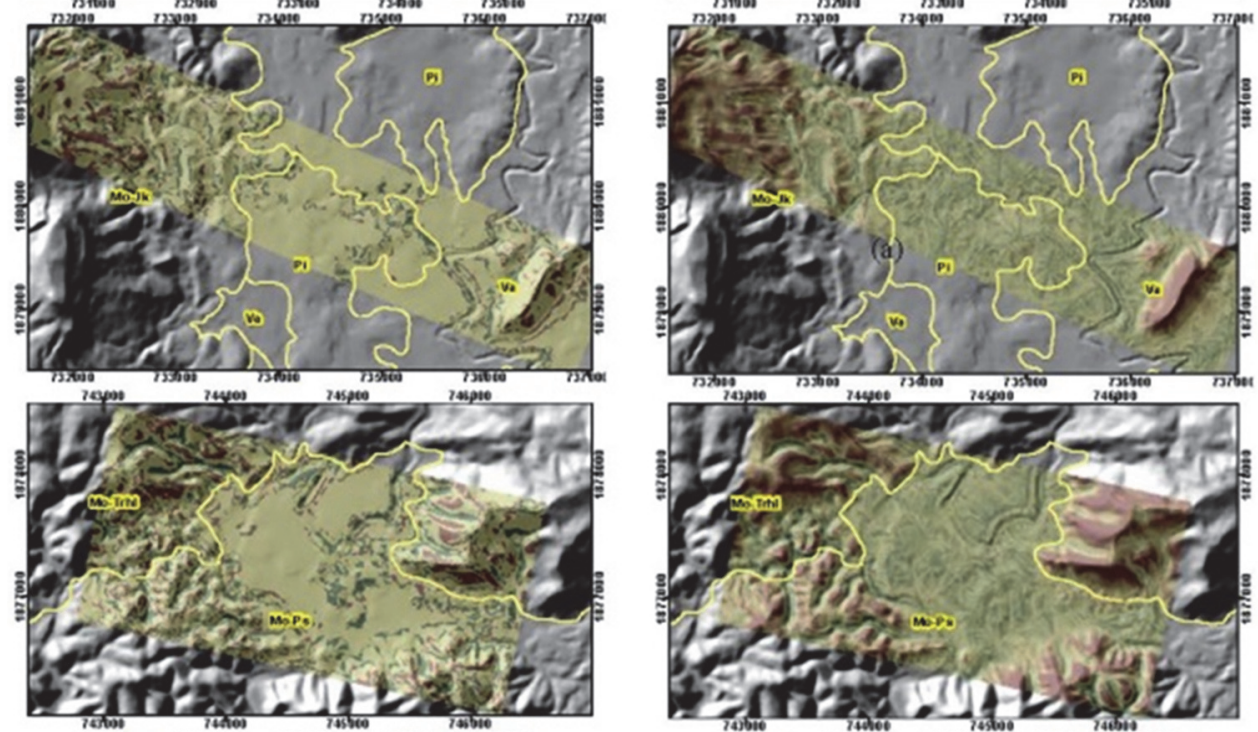

(b)
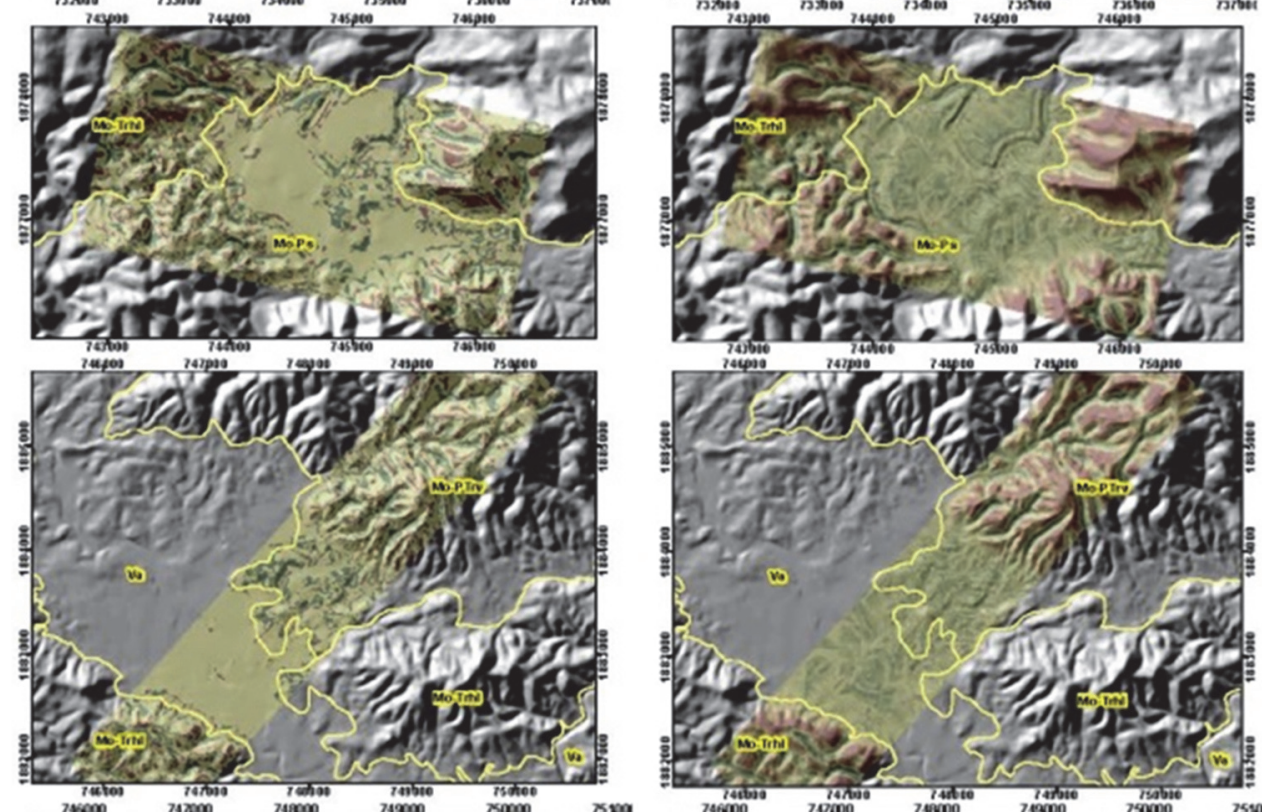

(c)
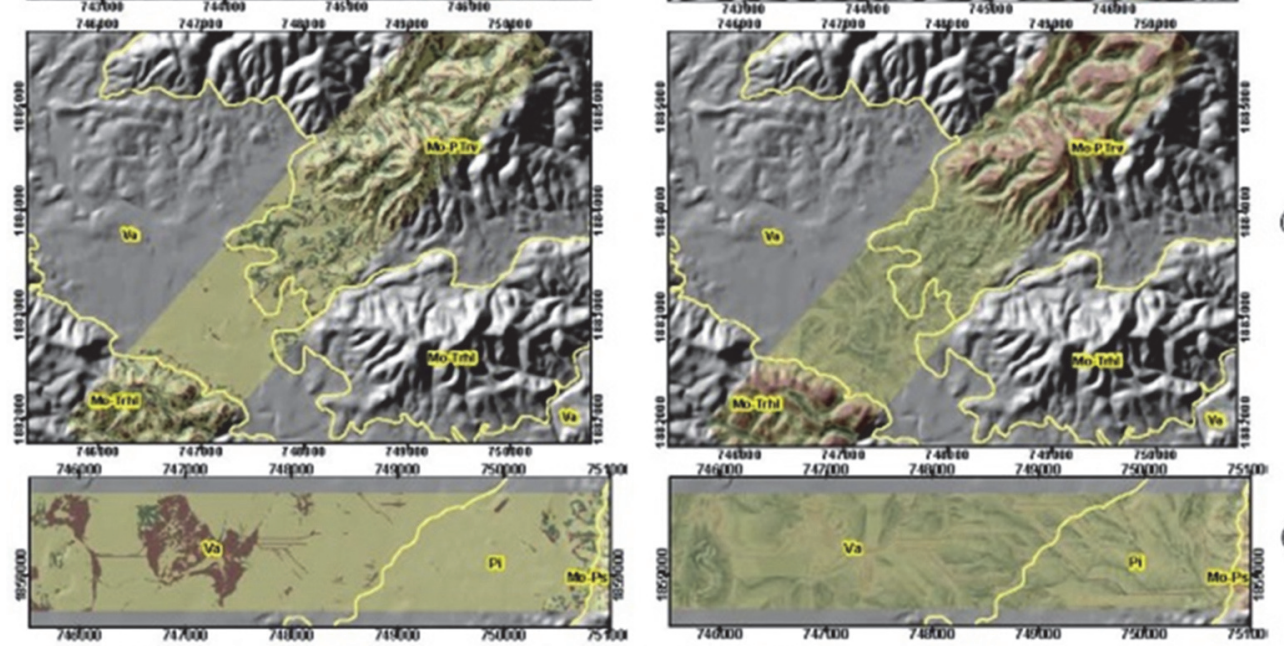

High : 0.3

Low : -0.3

High : 1.4

Low : -2.2

Figure 2.9 The spatial pattern and concentration on predicted area, differentiation between predictions (subtraction) from 5-m DEM with 20x20 neighborhoods size and 10-m. DEM with 10x10 neighborhoods size in 5 sample areas (a, b, c and d) ; A) subsoil bulk density: and $\mathrm{B}$ ) subsoil $\mathrm{pH}$. Positive value means prediction is better in 5-m. DEM and negative value means prediction is better in 10-m. DEM. Positive value means prediction is better in 5-m DEM and negative value means prediction is better in 10-m DEM. 


\section{Predictive maps of soil series}

Soil series maps from logistic regression show good result (Li in Figure 2. 10; Tn, in Figure 2. 11 with only small difference between the two resolution and neighborhoods combinations (Figure 2.12). Ws series is poorly modeled, which indicates that this series is too broadly defined and hence identified in heterogeneous landscape positions, so that terrain analysis cannot find typical occurrences.

These predictive maps are more acceptable to the expert soil mapper than to the predictive maps of individual soil properties. They show far fewer apparent artifacts; in addition, the maps from the two combinations are much more consistent. Tn series show high probabilities in valley where flat areas are used for growing rice. This series is probable in low relief areas defined as vales. These are flat to nearly flat and in the locally lowest-positions as Tn series is established mostly in areas with slopes less than $2 \%$. Li series shows high probabilities in the upland areas, mainly mountainous and hilly. There are some occurrences of $\mathrm{Li}$ series in valley, there is because this series has established as in quite wide range of slope, especially where slopes exceed $4 \%$. 

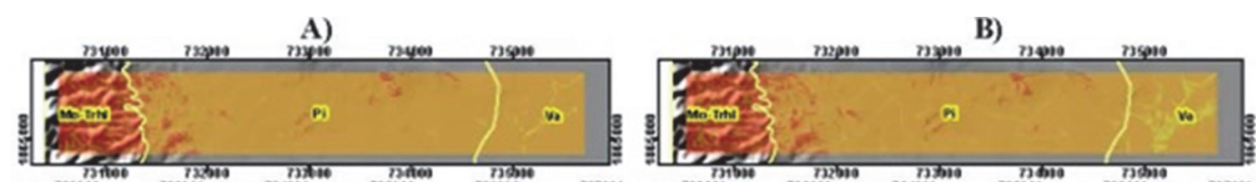

(a)
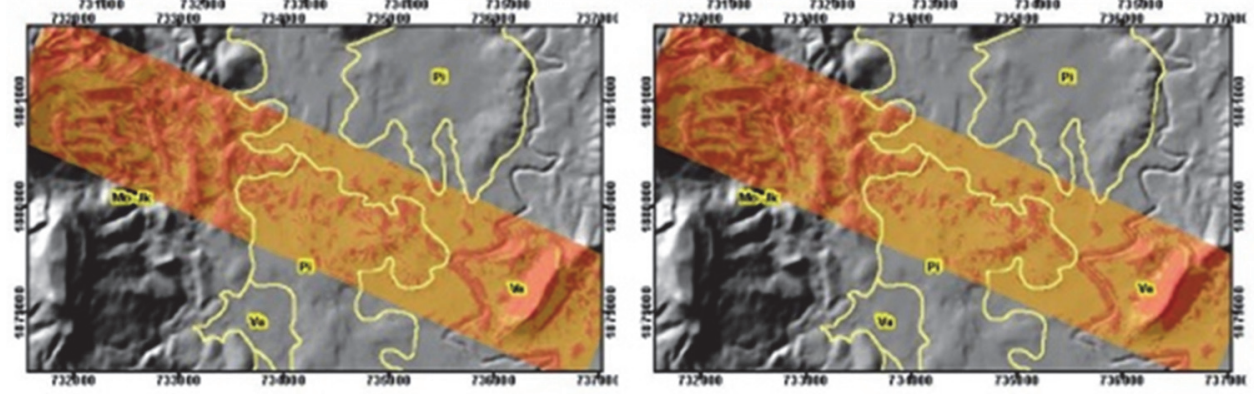

(b)
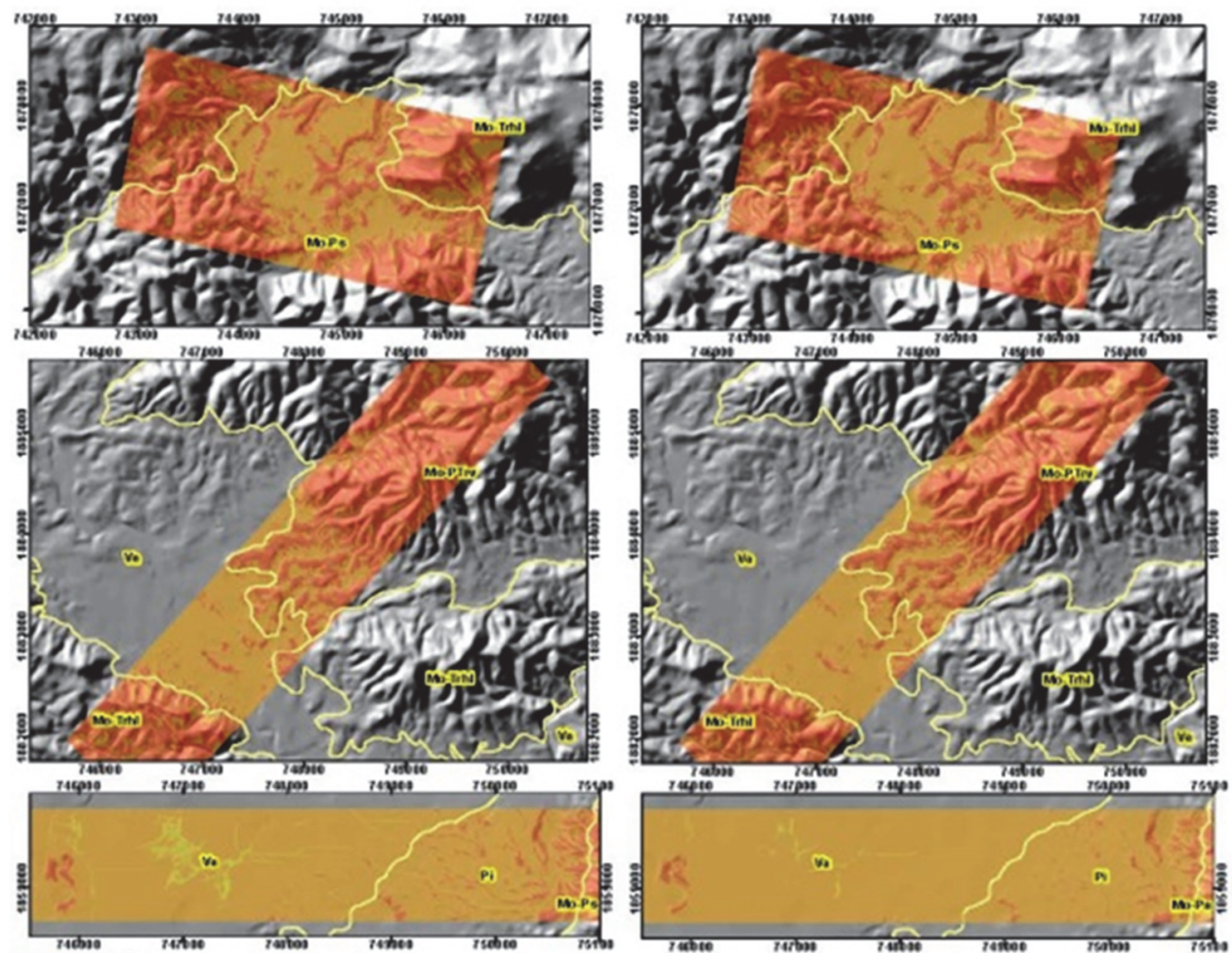

(c)

(e)

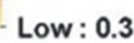

Figure 2.10 Predicted soil- landscape model in 5 sample areas ( a, b, c, d and e) implemented from soil series (Li) in five areas; A) 5-m DEM with10x10 neighborhoods size and B) 10-m DEM with 5x5 neighborhoods size. 

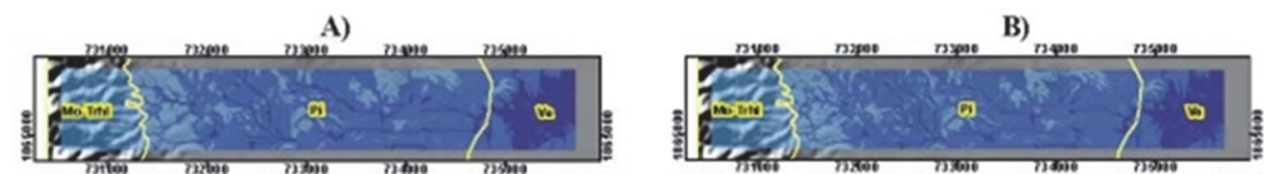

(a)
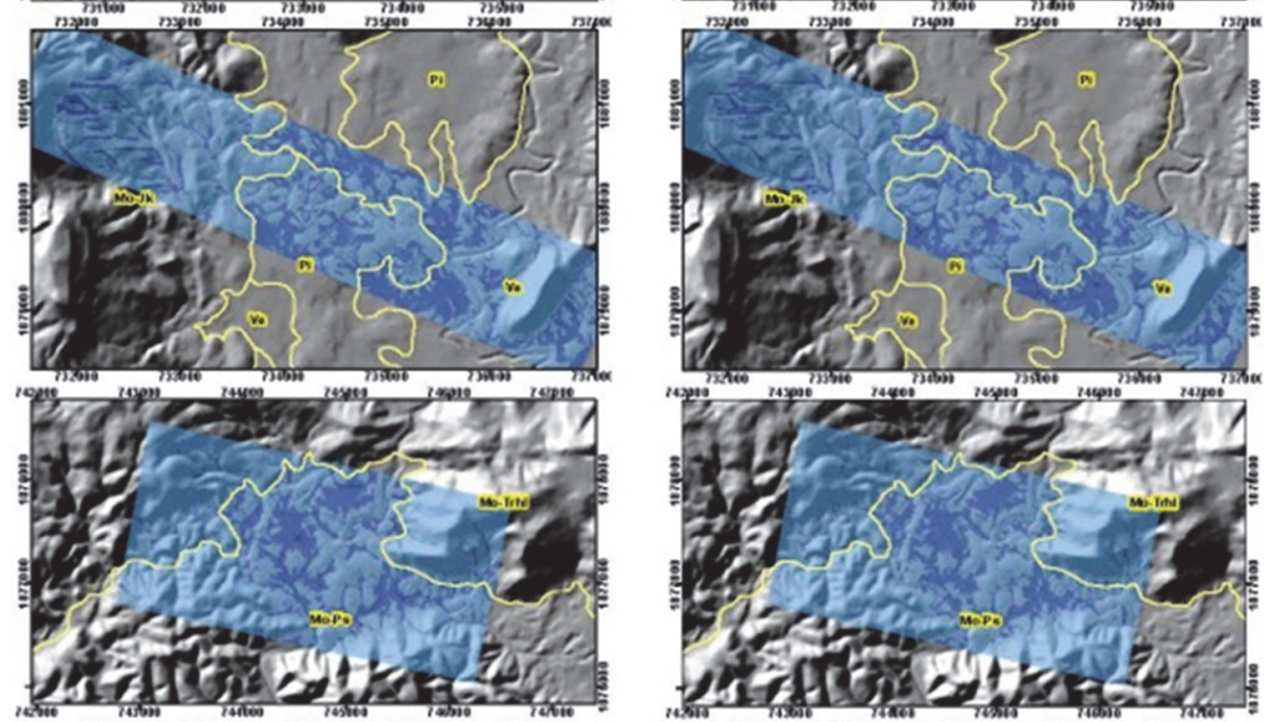

(b)
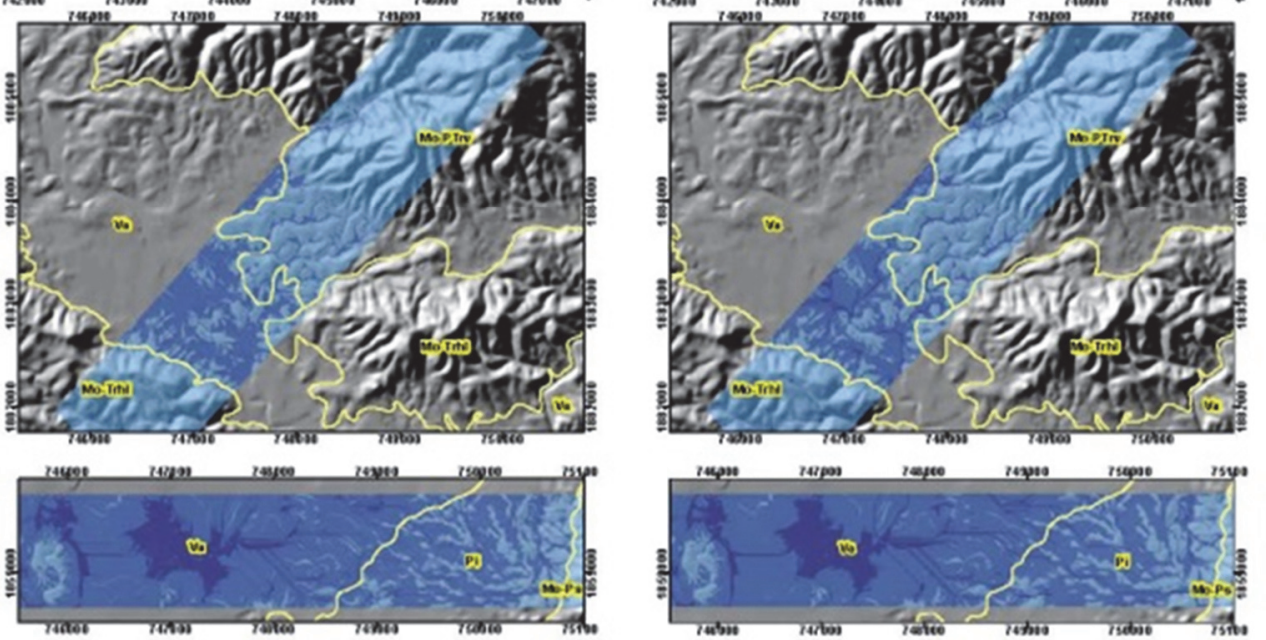

(c)

(e)

(d)

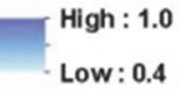

Figure 2. 11 Predicted soil- landscape model in 5 sample areas ( a, b, c, d and e) implemented from soil series (Tn) in five areas; A) 5-m DEM with10x10 neighborhoods size $\mathrm{Bb}$ ) and $10-\mathrm{m}$ DEM with $5 \times 5$ neighborhoods size. Positive value means prediction is better in $5 \mathrm{~m}$ DEM and low value means prediction is better in $10 \mathrm{~m}$ DEM. 
A)
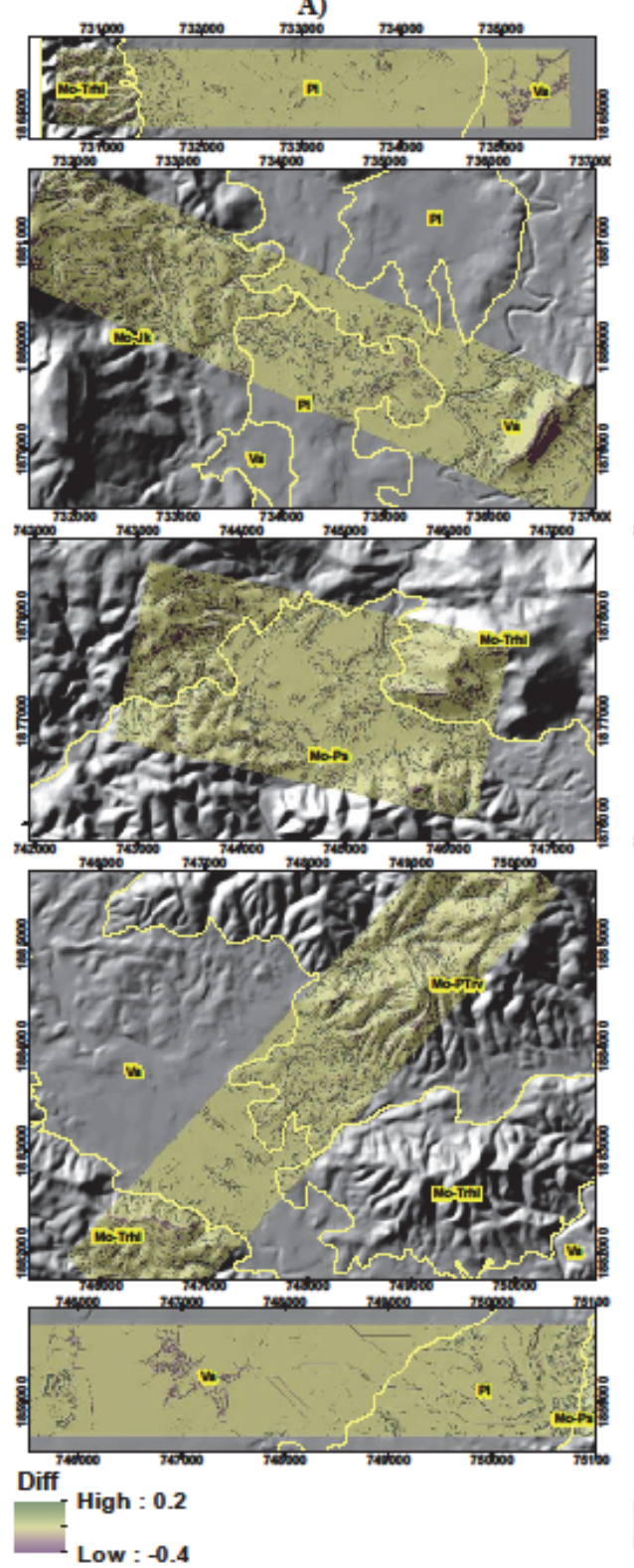
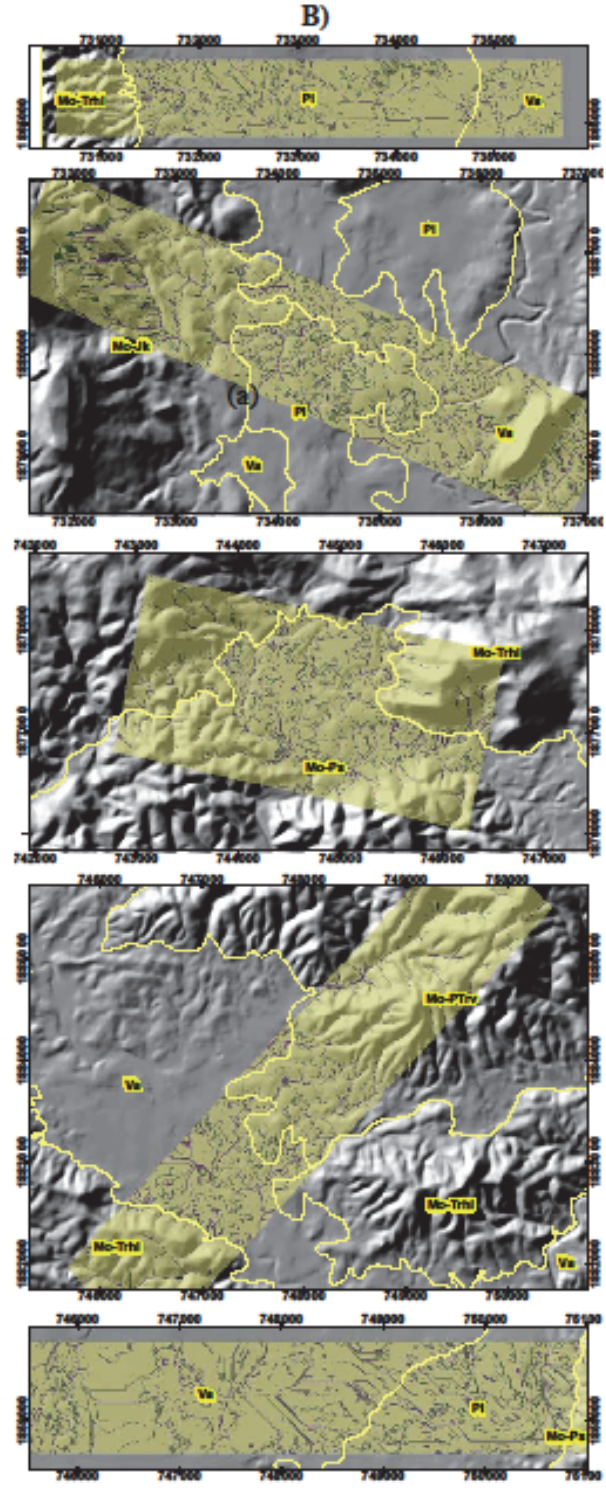

Diff

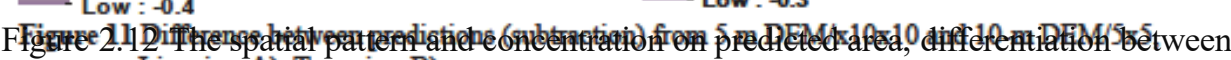

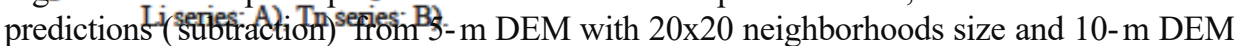
with 10x10 neighborhoods size in 5 sample areas (a, b, c, d and e); A) Li series and B) Tn series. Positive value means prediction is better in $5 \mathrm{~m}$ DEM and negative value means prediction is better in $10 \mathrm{~m}$ DEM. 


\subsection{Conclusions}

The results show that neighborhood size influences terrain details, as larger neighborhood sizes over- smooth terrain features; by contrast smaller neighborhoods can produce high frequency-noise (Thompson et al., 2001). These results had no consistent relation with models of soil properties or series. Furthermore, the spatial patterns and artifacts for soil properties were different in the various areas of interest, suggesting that these must be modeled separately in different landscapes. Models for series were much more consistent, apparently since series occur in recognizable landscape positions.

The statistical models for mapping soil properties were disappointing. This is due to two factors: (1) the application of a single model to a relatively large and complex landscape; (2) terrain alone cannot explain soil variation, when other soil-forming factors (here probably parent material and land use) are important. This finding confirms the results of Smith et al. (2006) and Zhu et al. (2008): obtaining high accurate soil map is not always obtained from smallest DEM and neighborhoods size. In contrast to soil properties, soil series maps using logistic regression give satisfactory results for the two series ( $\mathrm{Li}$ and $\mathrm{Tn}$ series) whose definition corresponded well to landscape position, and especially in different slope degree.

The 5-m DEM did not perform better than $10 \mathrm{~m}$ DEM for predicting soil properties, and indeed the large neighborhood sizes tended to improve predictions. Thus although a fine-resolution DEM can give detailed information on the terrain that might be useful for land management at the proposed 1:5,000 map scale, it is not necessary for soil-landscape modeling. Our results suggest that even a coarser horizontal resolution DEM would be adequate for that purpose. However, the 5-m DEM with 10x10 neighborhoods size was better able to predict soil series.

Topsoil properties, some subsoil properties and some soil series are poorly explained by terrain variables; even the best predictions of subsoil properties are weak and show artifacts in their predictive maps. Both soil properties and series are better explained by combined terrain attributes (primary and secondary, combined into standardized principal components) than by single terrain attributes.

The study area consists of several quite distinct landscapes, with distinct lithology, as shown in the geopedologic map, and a variety of historical and actual land uses. Thus it is not surprising that a "one size fits all" model based on terrain 
only is only partially successful. Thus fine- scale soil mapping using the SCORPAN approach must include proxies of soil forming factors (e.g. land use, lithology). (Beaudette et al., 2006). Terrain attributes very important factors to predict soil series. Other, environmental covariables e.g. land use, also need to be considered in modeling. 


\section{Chapter 3 Application of Airborne Gamma-Ray Imagery to Assist Soil Survey*}

* This chapter is based on the article: Moonjun, R., Shrestha, D. P., Jetten, V. G., and van Ruitenbeek, F.J.A., 2017. Application of airborne gamma ray imagery to assist soil survey: A case study from Thailand. Geoderma, v. 289 (2017) p. 196-212. 


\subsection{Introduction}

Soil survey is the process of representing soil types, properties or functions as a map over an area of interest (Soil Survey Staff, 1993). Since the soil can only be observed directly or sampled over a tiny fraction of its extent, soil survey is based on inferences from these limited observations, backed by understanding the processes involved in soil genesis and landscape evolution. Aerial photos have been extensively used to understand soil landscape relationship and to delineate boundaries of presumed soil differences in order to map soil (Bennema and Gelens, 1969; Goosen, 1967; McBratney et al., 2000; Zinck, 1989). Recently the advancement in digital soil mapping using an array of techniques including GIS, digital elevation model (DEM), multivariate statistical, geo-statistical, neural network, fuzzy logic, etc. claims to increase the mapping efficiency (Behrens et al., 2005a; Grimm et al., 2008; Lagacherie, 2008). Co-variables that cover the entire spatial extent at some reasonable resolution, e.g., DEM derivatives and remotely-sensed imagery, have proven to dramatically improve the quality of a soil survey using digital soil mapping (DSM) approaches (McBratney et al., 2003). One possible source of co- variables is Airborne Gamma- Ray Data (AGRD). This measures natural radioactive emanations of Uranium-238 $\left({ }^{238} \mathrm{U}\right)$, Thorium-232 $\left({ }^{232} \mathrm{Th}\right)$, and Potassium-40 $\left({ }^{40} \mathrm{~K}\right)$ decay series from the upper part of the Earth's surface (Minty, 1997; Rawlins et al., 2009; Sini et al., 2007). AGRD has been widely used in geological mapping and to study rock weathering and lithology (An et al., 1995; Carrier et al., 2006; Grasty, 1993; Jaques et al., 1997; Paradella et al., 1997; Schetselaar et al., 2000). Airborne Gamma-Ray Imagery (AGRI) is the interpolated map from AGRD acquired along flight lines, fully covering a study area at some horizontal resolution, typically $400 \mathrm{~m}$. Gamma rays radiation can penetrate about $50 \mathrm{~cm}$ of rock or soil (International Atomic Energy Agency, 2003). AGRI is often available as the result of mineral exploration studies and this source may do double duty to allow inference of soil and regolith properties as well as to help understand the soil- landscape process over the generally quite large area covered by the airborne survey.

Wilford and Minty (2007), in their review of the application of AGRI to soil survey, showed that AGRD generally relates to bedrock mineralogy and its weathering state as influenced by geomorphic stability and the climate of a region (Lacoste et al., 2011; Pickup and Marks, 2000; Pickup and Marks, 2001; Rawlins et al., 2007; Schuler et al., 2010; Tunstall, 2003 ; Wilford; Wilford, 2002; Wilford et al., 1997). These are related to soil-forming factors such as parent material, climate and time. 
Previous applications of AGRI in support of soil surveying have been used primarily to understand the geochemistry and weathering of soil parent materials. Cook et al. (1996) correlated AGRI with the distribution of soil forming materials in south-western Australia. Dickson and colleagues related radioelement concentrations to the geochemical composition of rocks and soils (Dickson et al., 1996; Dickson and Scott, 1997). Wilford and colleagues summarized the radioelement responses of rocks and soils in terms of geochemical components, pedogenic processes and geomorphic processes (Wilford, 2007; Wilford and Minty, 2007). Accordingly, high $\mathrm{K}$ is typically associated with acid igneous rocks (including granite, rhyolite and pegmatite), while low K contents are typical for mafic minerals and associated mafic to ultramafic rocks (e.g. basalts, dunites, serpentinite and peridotites). Thorium (Th) is associated with granite, pegmatite and gneiss. High uranium $(\mathrm{U})$ is associated with pegmatites, syenites, radioactive granites and some black shales. $\mathrm{U}$ and Th are found in accessory and resistant minerals such as zircon, titanite (sphene), apatite, allanite, xenotime, monazite and epidote. During pedogenesis, K concentrations often decrease with increased weathering, due to leaching of cations. In contrast, $\mathrm{U}$ and $\mathrm{Th}$ are associated with more stable weathering products in soil profiles, as $\mathrm{U}$ and $\mathrm{Th}$ released during weathering are readily absorbed into clay minerals, $\mathrm{Fe}$ and $\mathrm{Al}$-oxides and soil organic matter. In addition, $\mathrm{U}$ and $\mathrm{Th}$ are also associated with resistant minerals that persist in soils. These results show that AGRI is a valuable data source to differentiate parent materials, i. e., the lithology of the primary bedrock or transported materials in which the soil develops, as revealed by its geochemical signature (Rawlins et al., 2007). This may be an improvement over the use of geological maps, which are typically at coarse resolution and which are aimed at the stratigraphy and geological age rather than lithology, let alone details of the geochemistry. A second soil-forming factor is time, which is related to the degree of weathering. AGRI may be able to differentiate geomorphic surfaces developed from the same original lithology on the basis of relative weathering, specifically the depletion in $\mathrm{K}$ and the relative enrichment in Th.

Applications of airborne gamma-ray data are not all free from limitations. One of the problems is due to similar responses of gamma- ray signals in different regoliths as shown in some studies (Cook et al., 1996; Wilford et al., 1997). The variation of the gamma-ray signal is also influenced by soil moisture content which makes it difficult to interpret. Also the area between flight lines, are likely to be undetected, because of the relatively poor spatial resolution of the survey data. The suggestion is that, gamma-ray data should not be used in isolation, but 
should be used in combination with other data particularly terrain attributes, such as slope and relief.

In Thailand, the Land Development Department (LDD), Ministry of Agriculture \& Cooperatives, is the agency responsible for soil survey, agricultural development and rural land use planning. It produces soil series maps at 1:50,000 and 1:25,000 scales, as well as detailed farm planning maps at 1:5,000. LDD is currently transitioning to DSM methods to improve the quality of soil maps and mapping efficiency. It focuses on soil physical and chemical properties for agriculture and soil conservation advice to the farmers. Since AGRI is related to soil composition properties LDD wants to make its optimum use. Currently, AGRI is available for the entire country. The question thus arises as to how this valuable data source can be used to improve soil survey at semi-detailed and detailed scales.

This study therefore aimed to answer the following questions:

1. How much of the variation in bedrock and soil parent material can be explained using AGRI?

2. How much of the variation in soil characteristics can be explained by AGRI?

3. To what extent can AGRI explain soil pattern in terms of soil parent material, weathering, and pedogenic processes over landscape?

4. Can AGRI assist with delineating soil mapping units or refining boundaries found by other survey methods?

The study is applied in a case study in Pa Sak watershed in central Thailand. Data used are soil series map, geopedology map and map showing geology/soil parent material information. The gamma ray sensor data of the measurement of the natural radiation from decay series of potassium $(\mathrm{K})$, thorium $(\mathrm{Th})$ and uranium (U) in the upper $45 \mathrm{~cm}$ of the Earth's surface is used. The three channel data is further enhanced spatially by digital image analysis technique from which three products e.g. single channel data, band ratio and colour composites were used in the analysis. It is described in section 3.2.

\subsection{Materials and methods}

\subsubsection{Map data sources}

\subsubsection{Geopedologic map}

The soil geomorphology of the study area has been mapped at 1:50,000 scale using a geopedologic approach (Zinck, 1989) during many field seasons of the 
International Institute for Geo-Information Science and Earth Observation (ITC), Netherlands soil survey training; an integrated map was compiled by Hansakdi (1998). In this method, aerial photo-interpretation first produces an interpretation map based on systematic analysis of geomorphology which categorises geoforms in various hierarchical levels starting from landscape and going down to relief type, lithology and finally landform being at the lowest level. For interpretation of aerial photos use is made of photographic texture, grey tones and three dimensional view of the landscape with the help of a stereoscope. The geoforms are assumed to be related to soil types which are inventoried and classified during field observation at typifying locations. Field observations are carried out following stratified random method where geoforms are used for the purpose of stratification. For soil classification USDA Soil taxonomy is followed, which has six categories, in order of decreasing rank the categories are order, suborder, great group, subgroup, family and series. Soils are classified at subgroup level (Soil Survey Staff, 2006) by describing soils in mini-pit following by auguring. The resulting geopedologic map has 54 map units (Appendix 1) distributed across seven major landscapes: High mountain (HM), Low mountain (LM), Highlands (Hi), Piedmont (Pi), Lateral valley (Val), Trench valley (Vt) and Valley (Va).

\subsubsection{Soil series map}

Another source of soil type information used is a soil series map at 1:50,000 scale based on UDSA Soil taxonomy (Soil Survey and Classification Division, 2005). In Thailand soil survey is carried out in order to support cultivation of field crops, thus forest land and highland areas are excluded. Soils in the highland areas are simply mapped as slope complexes. Air photo interpretation is used to separate lowland (slope between 0-5\%), upland (slope between 5-35\%) and highland ( slope $>35 \%$ ) areas. Topographic map or digital elevation data is used to help delineate the units. Field observation points are located on ortho-photos. Soils are studied in detail by digging pits along transect lines perpendicular to major landform units while auguring is generally used to study soils outside the transects, the observation points of which are selected randomly. Soils are classified at series level which groups soils that have horizons similar in arrangement and in differentiating characteristics e.g. colour, texture, structure and similar chemical and physical properties (Soil Survey Staff, 2006). The obtained map of the study area shows 21 soil series or complexes ( several intimately associated series), two miscellaneous land types ( $\mathrm{U}=\mathrm{Urban}$ and $\mathrm{W}=$ water $)$ and an undifferentiated group ( $\mathrm{SC}=$ slope complex $)$ in mountainous areas. The series with largest extents in the study area are Lom Sak (La: fine- 
silty, mixed, super-active, non-acid, isohyperthermic Fluvaquentic Endoaquepts) from recent alluvium; Tha $\mathrm{Li}$ ( $\mathrm{Tl}$ : clayey- skeletal, mixed, semi- active isohyperthermic Ultic Haplustalfs) derived from residuum and colluvium from andesite and equivalent igneous rocks); and the Sop Prap / Tha Li complex (So/Tl: fine, smectitic, isohyperthermic Lithic Haplustolls) formed from basalt. These three series have quite contrasting geneses and characteristics e.g. the Sop Prap series are developed from basalt and have fine textured soil while the series Tha $\mathrm{Li}$ is developed from andesite and with clayey-skeletal soil.

\subsubsection{Geology and landscape map}

A geology map at 1:50,000 scale of the study area, produced by the Thai Department of Mineral Resource (2005), was also available. A landscape map showing boundary of geological formations and soil parent materials is shown in Figure 3.1. The geology map was used for taking rock samples in the area. The geologic units in the study area are Permian, Triassic, Jurassic and Cretaceous sedimentary (Ps, Trhl, Jpk, JKpw), Pleistocene and Holocene sediments (Qa and Qt), and meta-volcanic (PTrv) (Table 3.1).

\subsubsection{Field observations and laboratory analyses}

Two sets of field observations were collected over the landscape units; locations were determined by field GPS receiver (Figure 3.1). First, 32 rock samples were classified, grouped into 11 lithologic types by expert geologists from LDD and used to characterize rocks associated with soil parent materials, these data are used in section 3.3.1. Second, 11 soil profiles were described and classified according to standard procedures (Soil Survey Staff, 1993; Soil Survey Staff, 2006). Samples were analyzed using thin sections to determine mineral composition. For soil particle size distribution pipette method was used. X-ray diffraction (XRD) analysis was used to determine clay mineralogy (Jackson, 1965 ; Whittig, 1965). Flame spectrophotometer was used to determine extractable K. These data are used in section 3.3.2, 3.3.3 and 3.3.6. 


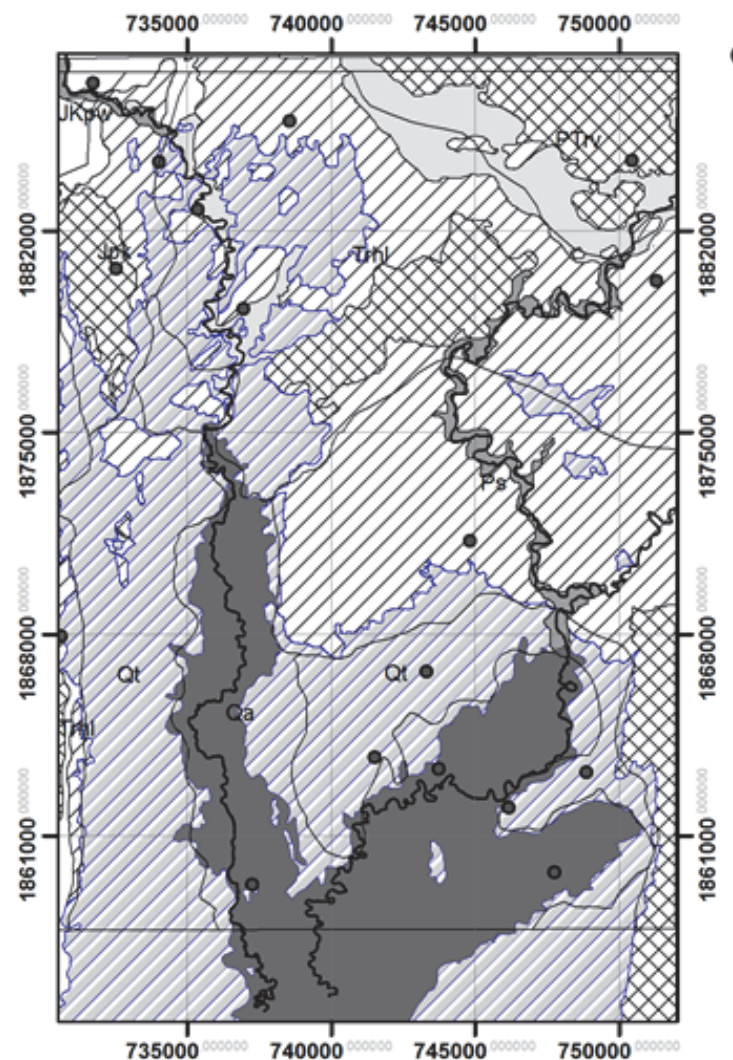

Landscape Map Showing Geology and Soil Profile Locations

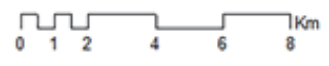

\section{Landscape}

High Mountain

D7 Hillands

Lateral Valley

$\triangle$ Low Mountain

VIS Piedmont

$\square$ Trench Valley

Valley

\section{Geology}

JKpw Cretaceous and Jurassic sediments

Jpk Jusarric metasedimets

PTrv Permiuan and Triassic meta-vulcanics

Ps Permian sediments

Qa Holocene sediments

Qt Pleistocen sediments

Trhl Triassic metasediments and igneous rock

6. Location of soil profiles

Rivers

Figure 3.1 A landscape map showing boundary of geological formations and the location of soil profiles 
Table 3.1 Description of geologic map units

\begin{tabular}{|c|c|c|}
\hline Unit & Age (Ma) & Description \\
\hline Qa & $\begin{array}{l}\text { Present- } \\
0.01\end{array}$ & $\begin{array}{l}\text { Holocene sediments; Fluvial deposits: gravel, sand, } \\
\text { silt, and clay of channel, river bank, and flood basin. }\end{array}$ \\
\hline Qt & $0.01-1.8$ & $\begin{array}{l}\text { Pleistocene sediments; Terrace deposits: gravel, sand, } \\
\text { silt, clay, and laterite. }\end{array}$ \\
\hline JKpw & $135-150$ & $\begin{array}{l}\text { Cretaceous and Jurassic meta-sediments: Quartzitic } \\
\text { sandstone, white, pink, and gray, large- scale cross- } \\
\text { bedded, thick- bedded, intercalated conglomeratic } \\
\text { sandstone; thin laminations of red siltstone; claystone. }\end{array}$ \\
\hline Jpk & $150-170$ & $\begin{array}{l}\text { Jurassic metasediments: Siltstone, maroon and purple, } \\
\text { calcareous and micaceous; sandstone, greenish gray, } \\
\text { yellowish brown; claystone and conglomerate with } \\
\text { calcrete. }\end{array}$ \\
\hline Trhl & $225-240$ & $\begin{array}{l}\text { Triassic metasediments \& igneous rock: Basal } \\
\text { limestone conglomerate, igneous rock and local } \\
\text { volcanic conglomerate; shale, mudstone, siltstone, } \\
\text { gray, brown, yellowish- brown; graywacke, } \\
\text { argillaceous limestone, and marl. }\end{array}$ \\
\hline PTrv & $240-265$ & $\begin{array}{l}\text { Permian and Triassic meta- volcanics: Rhyolite, } \\
\text { andesite, ash-flow tuff, volcanic breccia, rhyolitic tuff } \\
\text { and andesitic tuff. }\end{array}$ \\
\hline Ps & $250-290$ & $\begin{array}{l}\text { Permian sediments; shale; sand stone, lime stone, } \\
\text { chert, pillow basalt, ultramafics, and serpentinite }\end{array}$ \\
\hline
\end{tabular}

Remark: Geologic units are shown in Figure 3.1 and Fig 3.67b

\subsubsection{Airborne gamma-ray imagery}

A geo-referenced airborne gamma-ray image of the study area at nominal scale 1:250,000, produced for the Thai Department of Mineral Resources (Kenting Earth Science International limited (KESIL), 1982; Wisedsind et al., 1994) was acquired. The AGRI data was collected at the beginning of the winter season in November 1985 by aircraft with flight line spacing of $2 \mathrm{~km}$, terrain clearance of $400 \mathrm{~m}$ and a flight line direction west to east, flown at a constant height above the ground of $400 \mathrm{ft}$ (MTC). The production of radiation and ternary radiation maps of Thailand were produced using IAEA method (Angsuwathana and Chotikanatis, 1997; International Atomic Energy Agency, 2003), which resulted in an image with $400 \times 400 \mathrm{~m}$ pixels. The gamma-ray spectrometer, developed by KESIL, contained 12 crystals in a 50.34 litre Harshaw NaI ( Tl) crystal scintillator and recorded gamma-rays in 256 channels. The measured energy spectrum ranges from 0 to $3 \mathrm{MeV}$ (wavelengths between $0.03 \times 10^{-4}$ to $4.13 \times 10^{-}$ 
${ }^{4}$ nanometres). The sensor measures the natural radiation from decay series of potassium (K), thorium (Th) and uranium (U) in the upper $45 \mathrm{~cm}$ of the Earth's surface. The following energy windows were used to measure the total count (TC) and three radioelements: $\mathrm{TC}=0.40-2.82 \mathrm{Mev} ., \mathrm{K}=1.36-1.56 \mathrm{Mev} ., \mathrm{U}=$ 1.66-1.86 Mev., and $\mathrm{Th}=2.42-2.82 \mathrm{Mev}$. Potassium is measured directly from the decay of ${ }^{40} \mathrm{~K}$ and is expressed as a percentage. Thorium and Uranium are inferred from daughter elements associated with distinctive isotopic emissions from ${ }^{208} \mathrm{Tl}$ and ${ }^{214} \mathrm{Bi}$ in their respective decay chains and are expressed in equivalent parts per million and coded as $\mathrm{eU}$ and $\mathrm{eTh}$. A complication is that ${ }^{214} \mathrm{Bi}$ is also a decay product of radon gas, ${ }^{222} \mathrm{Rn}$, itself a decay product of radium, ${ }^{226} \mathrm{Ra}$. Radon concentration is highly dependent on soil moisture, being practically absent near the surface in dry soil and abundant in saturated soil (Grasty, 1997). Another complication is that the signals for ${ }^{40} \mathrm{~K}$ and ${ }^{208} \mathrm{Tl}$ (i.e., eU) are attenuated in wet soil; this has been used to map soil moisture in homogeneous soil materials using $\mathrm{K} / \mathrm{eTh}$ ratios (Carroll 1981). Atmospheric Rd is also affected by changes in air density due to temperature and pressure, thus data acquired in cool highpressure conditions may have up to $30 \%$ enhanced Rd compared to warm lowpressure, thereby distorting the eU signal (International Atomic Energy Agency, 2003). For these reasons the eU signal is considered less reliable than those for $\mathrm{K}$ and $\mathrm{eTh}$.

\subsubsection{Processing of gamma ray data for interpreting soil information}

Three types of products derived from AGRI were used in the interpretations: (1) single channel data; (2) ratios of two channels; and three- channel color composites ( so-called ternary images). Interpretation based on pseudo-color coded individual bands, ratio images and the three-channel composites were used. The three bands were further enhanced spatially by combining with artificial sunangle illuminated digital elevation model (DEM) (Wilford et al., 1997). Image fusion was performed using a hill-shaded DEM image (Figure 3.2). A DEM of the area with spatial resolution of 10 by $10 \mathrm{~m}$ was acquired. The gamma ray images were also resampled to 10 by $10 \mathrm{~m}$. In order to generate hill shading, altitude and azimuth of the illumination source is needed. Hill shading was performed using the following algorithm (Kennelly, 2008):

$$
\text { Hshade }=\cos (I) \sin (S) \cos (A-D)+\sin (I) \cos (S)
$$

Where I is the inclination (solar elevation or solar zenith angle) and D is the declination angle ( sun compass direction or solar azimuth angle), $\mathrm{S}$ is the slope gradient and $\mathrm{A}$ is the aspect of the terrain. Hill shading image was generated using 
an inclination angle of 45 degrees and a declination angle of 315 degrees (sun from the northwest direction).

For image fusion, the individual bands were assigned basic colors as follows: the gamma ray band showing high $\mathrm{K}$ was assigned red color, band showing high eTh green color, and for high eU blue color was assigned, the combination of which makes the Red-Green-Blue (RGB) color space. The RGB color space was then transformed into Intensity, Hue and Saturation (IHS) color space (Choi, 2006) as follows:

$$
\left(\begin{array}{c}
I \\
v 1 \\
v 2
\end{array}\right)=\left(\begin{array}{ccc}
1 / 3 & 1 / 3 & 1 / 3 \\
-\sqrt{2} / 6 & -\sqrt{2} / 6 & 2 \sqrt{2} / 6 \\
1 / \sqrt{2} & 1 / \sqrt{2} & 1 / \sqrt{2}
\end{array}\right)\left(\begin{array}{l}
R \\
G \\
B
\end{array}\right)
$$

The variables $\mathrm{v} 1$ and $\mathrm{v} 2$ are the $\mathrm{x}$ and the $\mathrm{y}$ axes in the color space and intensity $\mathrm{I}$ indicates the $\mathrm{z}$ axis. The hue $(\mathrm{H})$ and saturation $(\mathrm{S})$ can be expressed as: $H=$ $\operatorname{atan}\left(\begin{array}{c}v 2 \\ v 1\end{array}\right)$ and $S=\sqrt{ }\left(v 1^{2}+v 2^{2}\right)$ ( Tu et al., 2001). Alternatively, transformation from IHS to RGB can be performed as follows:

$$
\left(\begin{array}{l}
R \\
G \\
B
\end{array}\right)=\left(\begin{array}{ccc}
1 & -1 / \sqrt{2} & 1 / \sqrt{2} \\
1 & -1 / \sqrt{2} & -1 \sqrt{2} \\
1 & \sqrt{2} & 0
\end{array}\right)\left(\begin{array}{c}
I \\
v 1 \\
v 2
\end{array}\right)
$$

Since our interest is to enhance the gamma ray images by introducing artificial sun illuminated DEM image for the purpose of visual interpretation, the intensity component, I is then replaced by the hill-shaded DEM image of the area (equation 1). Image fusion was then performed from IHS to RGB space as followed:

$$
\left(\begin{array}{c}
F R \\
F G \\
F B
\end{array}\right)=\left(\begin{array}{ccc}
1 & -1 / \sqrt{2} & 1 / \sqrt{2} \\
1 & -1 / \sqrt{2} & -1 \sqrt{2} \\
1 & \sqrt{2} & 0
\end{array}\right)\left(\begin{array}{c}
\text { Hshade } \\
v 1 \\
v 2
\end{array}\right)
$$

Where FR is the fused red band, FG the fused green and FB the fused blue bands. The hill shade component (Hshade) highlights local changes in the gamma-ray signal, thus enhancing the spatial variation which is related to changes in regolith materials and lithology and sharpens boundaries associated with geomorphic features. From the resulting fused bands, a false color composite image (also called ternary image) was generated by modulating the red $(\mathrm{K})$, green $(\mathrm{eTh})$ and blue $(\mathrm{eU})$ color in proportion to the radioelement concentration values to the image and following histogram equalization method (International Atomic Energy Agency, 2003). 


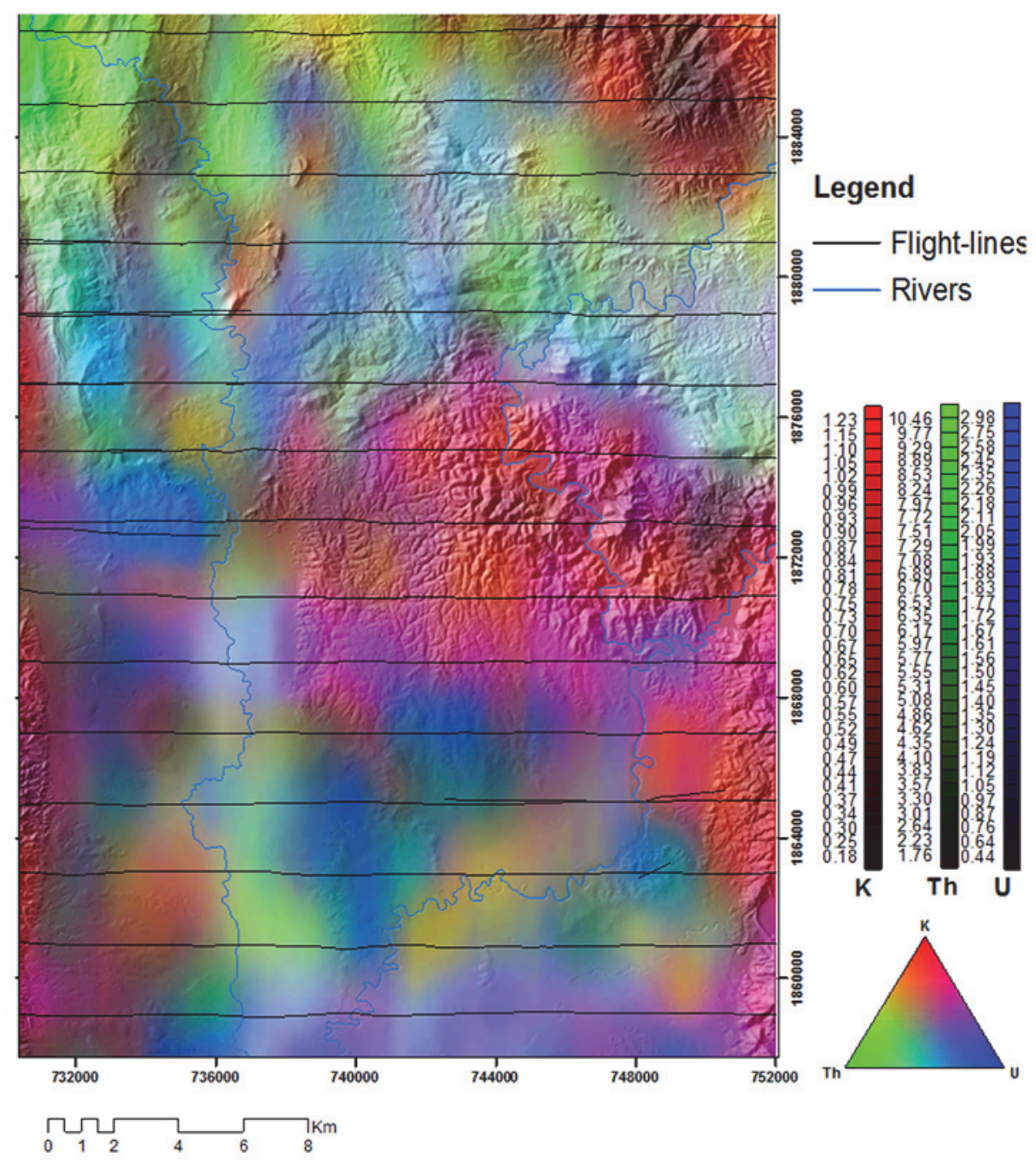

Figure 3.2 An enhanced ternary image fused with hill-shaded DEM, also indicated the locations of 15 flight lines

\subsubsection{Clustering of gamma ray data}

Soil is a continuous variable and does not have abrupt boundaries in nature. In order to map soil and soil parent material variability fuzzy classification was applied to gamma ray data. Fuzzy clustering is explained in detail in (McBratney et al., 1992). The selected method includes the use of Fuzzy k-means analysis to cluster elevation (DEM) and gamma ray 3 band data as explained in (Huang et al. , 2014). DEM is selected since soil formation especially in alluvial and colluvium material is very much expressed in elevation differences as compared 
to the use of topographic wetness index. Although many researchers have used the topographic wetness index it is considered to be not very applicable especially in the humid tropics. It consists of a multi-layer classification output file in which each layer contains likelihood value (between 0 and 1) for belonging to a class. A spectral distance file is also created in which each data file value represents the result of a spectral distance. Finally the total weighted inverse distance of all the classes in a 3 by 3 window is calculated to assign the pixel the class with the largest total inverse distance over the entire set of fuzzy classification bands (Erdas Imagine 2015 Manual). Classes with a very small distance values remain unchanged while classes with higher distance values may change to a neighboring value if there are sufficient number of neighboring pixels with class values with smaller corresponding distance values. The following equation is used:

$$
T[k]=\sum_{i=1}^{S} \sum_{j=1}^{S} \sum_{l=1}^{n} \frac{W_{i j}}{D_{i j l}[k]}
$$

where:

$\mathrm{i}=$ row index of window

$\mathrm{j}=$ column index of window

$\mathrm{s}=$ size of window $(3,5$, or 7 pixels $)$

$1=$ layer index of fuzzy set

$\mathrm{n}=$ number of fuzzy bands used

$\mathrm{w}=$ weight table for window

$\mathrm{k}=$ class value

$\mathrm{D}[\mathrm{k}]=$ distance file value for class $\mathrm{k}$

$\mathrm{T}[\mathrm{k}]=$ total weighted distance of window for class $\mathrm{k}$

The center pixel is assigned the class with the maximum $\mathrm{T}[\mathrm{k}]$.

\subsubsection{Data analysis}

AGRD from each of the three elements and ratio maps were extracted at their raster points in ArcGIS 10, from which summary statistics were calculated. Values of co- variables (geology, geopedologic units and soil series) were extracted at the same locations. The relation between gamma- ray data and geological units was examined with box-and-whisker plots. Rock and soil sample classifications were compared with the gamma- ray image and to typical radioelement responses found in the literature.

To interpret AGRI data in terms of regolith and soil genesis, we compared AGRI to two existing soil maps. First, the geopedologic map was split into four maps according to the geopedological hierarchy: landscape, lithology, relief, and 
landform; at the latter (lowest) level, soil units were also used. Secondly, soil series and geopedologic unit maps were used to examine the distribution of radioelement response to selected soil characteristics: parent material, texture, mineralogy, and thickness. Interpretations of the best correlation variables in both soil maps were described in terms of the radioelement changes during pedogenic and geomorphic process, based on a review of literature and supported by soil samples.

For clustering of gamma ray and DEM data, sufficient number of training samples were taken separately for soil as well as for soil parent material differentiation. In addition, a separate set of samples (359 test samples) were taken for performing accuracy assessment of the classification results for soil as well as for soil parent material.

\subsection{Results and discussion}

\subsubsection{Relationships between gamma-ray data and geological units}

Mean concentration of potassium in the area is $0.84 \%$ with standard deviation of $0.18 \%$. The thorium concentration varies from 1.47 to $10.46 \mathrm{ppm}$ with a mean of $5.22 \mathrm{ppm}$ (Table 3.2). As compared to thorium the concentration of uranium is lower, it varies from 0.08 to $3.14 \mathrm{ppm}$. Table 3.2 shows the descriptive statistics of the radioelements and their ratios. The radioelements vary among the geological units (boxplots in Figure 3.3 and maps in Figure 3.4), although most units show a wide range of concentrations with much overlap between the units; this is due to a combination of variations in rock composition, generalized map boundaries, surface material transport and pedogenesis. Artifacts from the interpolation are clear in all maps: (1) the 400x400 m pixel resolution, (2) the transition zone "halos" of intermediate values, especially at abrupt changes from high to low values; these represent averages of the adjacent units rather than the values within the block. Thus, we consider areas of consistent signal over several blocks and look for the central concept(s) of each unit. Not every feature can be readily explained by lithology, since the geologic map does not account for pedogenesis or locally transported materials. In addition to the single-element and ratio images (Figure 3.4), Figure 3.6shows the location of rock samples superimposed on a ternary image. The relationships with geological units are described from oldest to youngest geologic age.

1. The hilly, geomorphically-young Permian sedimentary unit (Ps, centre and center-east) have relatively high $\mathrm{K}$ and low Th and $\mathrm{U}$ contents, as shown by 
the red color in the ternary image (F1 in Figure 3.6a). These responses are related to the dominant bedrock in the geologic units, supported by the rock samples, which are shales containing high-K clay minerals such as micas (Dickson and Scott, 1997). The low Th and U contents are likely also related to the relatively unweathered rock material.

2. The Permian and Triassic meta-volcanics (PTrv) in the northeast hills are generally low in all radioelements, where diorites were found ( A2 in Figure 3.6a). However, three locations, shown as red spots in the top-right corner of a, show an enhanced $\mathrm{K}$ signal. These areas are interpreted as intrusions of meta-volcanic rocks such as andesite and rhyolite (A1 in Figure 3.6a). These interpretations are supported by the study of Dickson and Scott (1997).

3. The radioelement contents of the Triassic meta- sediments (Trhl, centrenorth) are quite variable, which is consistent with its varied lithology. The majority of the unit is relatively high in all radioelements. However, their ratio is different depending on the rock type at particular locations. The major rock types were found to be shale (F2 inFigure 3.6) and shale associated with siltstone ( $\mathrm{G}$ in Figure 3.6a). Dickson and Scott (1997) found that shales have a high response in all radioelements. We also found gamma-ray responses consistent with andesite and volcanic glass in two locations (E in Figure 3.6a), where the signal appears the same as A1 in PTrv unit. Over large areas of the unit, the radioelement signature consists of high $\mathrm{Th}$ and $\mathrm{U}$ and low $\mathrm{K}$ contents; this is shown as a green to blue green colour in Figure 3.6a and also appears as $\mathrm{eTh} / \mathrm{K}$ and eU/K ratios (Figure 3.6d-f). This is explained by the presence of sandstone ( $\mathrm{D}$ in Figure 3.6a). We conclude that this geologic unit could have been subdivided into several lithologic sub-units.

4. The Jurassic meta-sedimentary unit (Jpk) in the northwest, has relatively high Th and $\mathrm{U}$ and low $\mathrm{K}$ contents. This is interpreted as a lithology which contain abundant $\mathrm{Th}$ and $\mathrm{U}$-bearing minerals that are resistant to weathering or high silica such as sandstone, which is confirmed by rock samples B and D (Figure 3.6a), where sandstones (medium and fine grained) and calcareous sandstones were found. This interpretation is consistent with the outcome of several other studies (Cook et al., 1996; Dickson and Scott, 1997; Wilford and Minty, 2007), which reported that sandstones have high Th and $U$ and low $K$ contents.

5. The Cretaceous and Jurassic meta-sediments of JKpw, that outcrop in the mountainous area in the extreme northwest of the area, is the most consistent unit and the most easily differentiated (see boxplots in Figure 3.6), especially by its high $\mathrm{Th}$ and moderate $\mathrm{U}$ contents. The high Th content may relate to 
sandstone containing iron oxide as the cementing agent or as grains; this is supported by the rock samples where we found greenish coarse pebbly sandstone (C in Figure 3.6a). This is consistent with the studies of Wilford et al.(1997) as well as Dickson and Scott (1997).

6. The Pleistocene sediments (Qt), consisting of mixed old alluvial materials on terraces, shows three different radioelement compositions. Firstly, the centrenorthwest location of the study area shows a strongly anomalous high $U$ and moderate Th contents (I in Figure 3.6a). This could be related to transported material containing high residual quartz and the accumulation of oxides and resistant materials; but a more likely explanation is that this area is unmapped as Qt and is in fact a southward extension of the unit Jpk. Secondly, an area (K1 Figure 3.6a), which is low in all the radioelements, is interpreted as coarse-textured soil materials transported from upstream hill units. The low concentrations are likely related to source rocks deposit, where we found predominantly quartz and quartzite gravels. The low Th content is similar to that of the geologic units upstream of Qt (Ps and much of the Trhl); this is consistent with the presumed sources of the transported material. A third signal is found at the apex of big tongue in the middle-south and a small tongue in the southeast, having low $\mathrm{U}$, moderate Th and low $\mathrm{K}$. The source materials in these areas are likely the same as the main portion of the Qt unit, although in higher positions (older terraces) with a longer weathering period, leaving sesquioxides as plinthite gravels (K2 in Figure 3.6a); this is explained further in 3.3.2. Thus, the Qt unit could be split according to terrace age.

7. The Holocene sediments, indicated by Qa, in the center- south and southeast of the area cover a relatively large area and they are high in all three radioelements. These deposits consist mainly medium to fine- textured sediments, as supported by observation point $\mathrm{J}$ (Figure 3.6a). This agrees with the studies of Wilford et al. (1997) and Rawlins et al. (2007), who also found that recent alluvial deposits in younger landscapes were distinguished by elevated $\mathrm{K}$ and Th contents. Moderate to high Th contents are also found in Qa; this may be related to transported material from the upstream Trhl unit. Finer- textured overbank sediment is also likely to contain higher Th and U (Wilford et al., 1997). Elevated U may be related to soil wetness, which may lead to high Rd concentrations. 
Application of Airborne Gamma-Ray Imagery to Assist Soil Survey

Table 3.2 Summary statistics of radioelements

\begin{tabular}{lllllllll}
\hline Layer & Min. & 1st Qu. & Med & Mean & 3rd Qu. & Max. & STD. & Skew. \\
\hline K $(\%)$ & 0.09 & 0.70 & 0.86 & 0.84 & 1.00 & 1.53 & 0.18 & -0.44 \\
eTh $(\mathrm{ppm})$ & 1.47 & 3.80 & 5.15 & 5.22 & 6.59 & 10.46 & 1.50 & 0.19 \\
eU $(\mathrm{ppm})$ & 0.08 & 1.24 & 1.52 & 1.55 & 1.86 & 3.14 & 0.36 & 0.14 \\
Th/K & 2.25 & 4.29 & 6.64 & 6.78 & 8.07 & 37.63 & 2.23 & 2.99 \\
U/TH & 0.03 & 0.25 & 0.30 & 0.31 & 0.37 & 0.75 & 0.08 & 0.66 \\
U/K & 0.12 & 1.44 & 1.83 & 2.07 & 2.31 & 16.53 & 0.71 & 5.09 \\
\hline
\end{tabular}
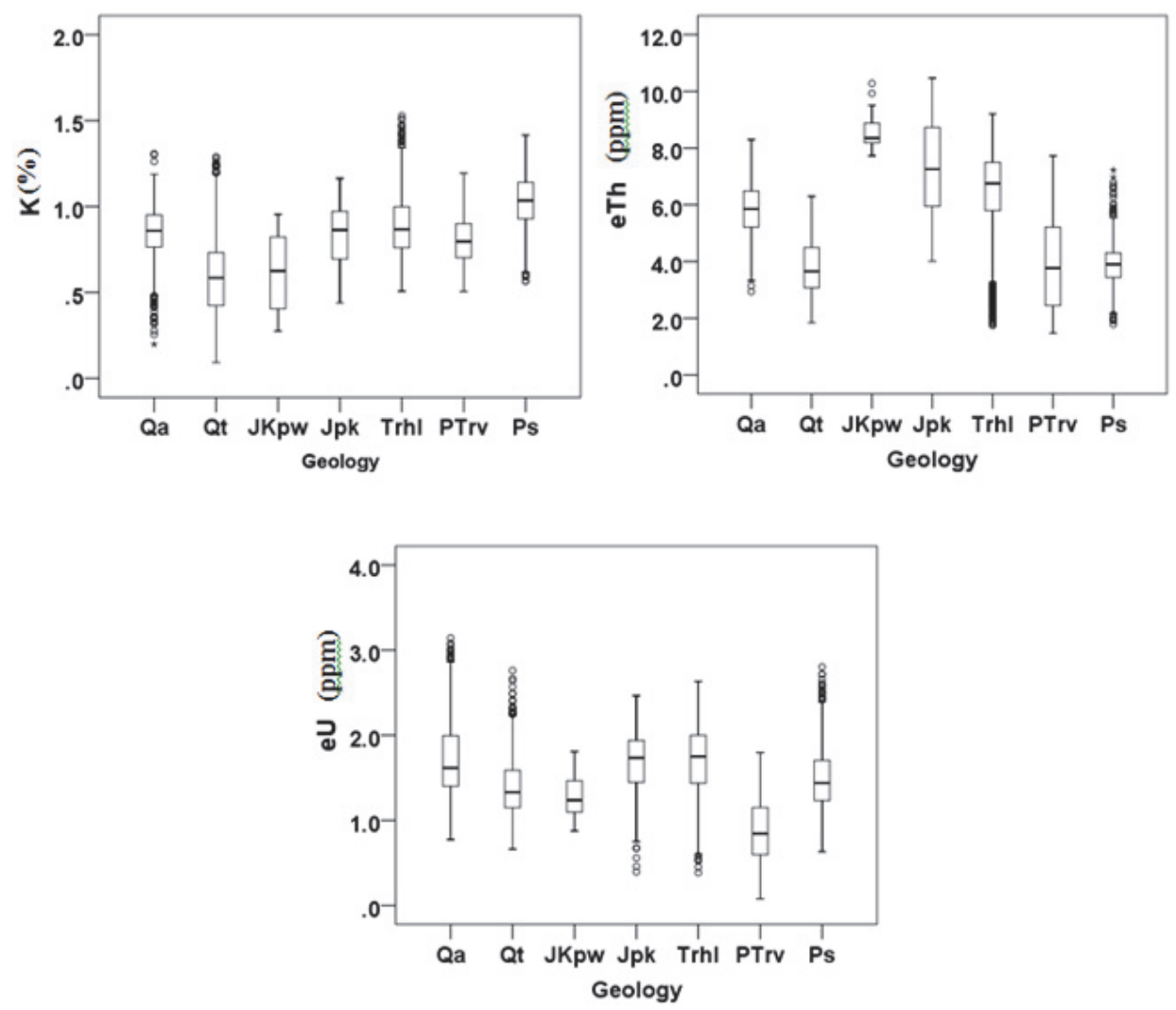

Figure 3.3 Box and whisker plots showing the radioelement contents of lithological units 
Chapter 3
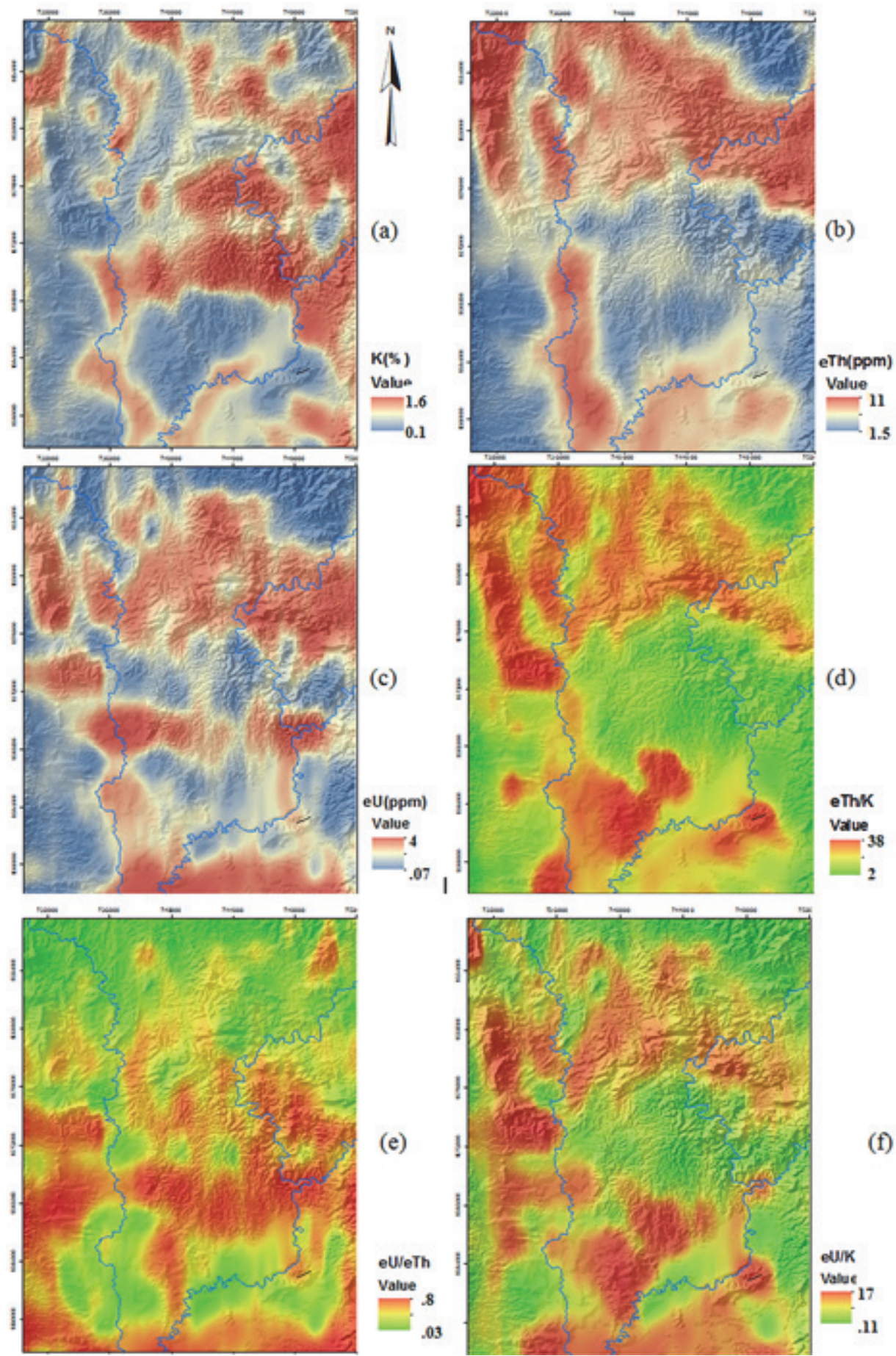

Figure 3.4 Radio element maps of Upper Pa Sak watershed map; (a)\%K, (b) eTh, (c) eU, $\mathrm{eU} / \mathrm{K},(\mathrm{e}) \mathrm{eTh} / \mathrm{K}$ and (f) eU/K 


\subsubsection{Relationships between gamma-ray data and soils developed over bedrock materials}

The previous section has anticipated that inconsistencies within lithologic units were partially attributed to pedogenesis. Here, we expand that analysis, supported by seven soil profiles and their laboratory analyses (Table 3.3, S1-S7). A stacked bar graph of the seven observations with concentrations of $\mathrm{K}$, Th and $\mathrm{U}$ is shown in Figure 3.6, where location of 11 soil profiles are shown in Figure 3.6b. The explanations are based on the understanding of the geochemical composition of soil parent rock, weathering and pedogenesis. What becomes clear in the discussion is that there is no easy explanation for a given radioelement signature. It must be interpreted in its spatial context.

Extractable $\mathrm{K}$ and percent base saturation are assumed to be related to weathering degree. In addition, soil textures (within $25 \mathrm{~cm}$ ) were used to compare the gamma-ray responses with soil particle size distributions. Time factor or soil age, is recognized by soil development process and soil forming factors (e.g. climate, plant, animal) to transform the parent material into soils over landscape. Usually described as young, mature or old, this study used soil orders assumed to be related to the soil age as young (Inceptisols), mature (Alfisols, Mollisols) and old (Ultisols and Oxisols).

The gamma-ray radioelements responses to soil and geological materials are shown in Figure 3.5, 3.6 and 3.7b. These are the same figures used in the previous section. However, here we consider pedogenesis as well as parent material. The interpretations are grouped into two main types of parent material as igneous rocks (S1-S3) and sedimentary rocks (S4-S7). The interpretations and discussions are mainly based on gamma- ray studies conducted in Australia by Dickson and Scott (1997), Wilford et al. (1997) and Wilford and Minty (2007).

1. Observation S1 (Figure 3.7b), formed from residual andesite in Permain and Triassic meta-volcanic (PTrv), has relatively moderate $\mathrm{K}$ and low Th and $\mathrm{U}$ contents $(0.71 \%, 1.78 \mathrm{ppm}$ and $0.69 \mathrm{ppm})$ (Figure 3.5). This soil is moderately deep (50-100 cm to bedrock), and has a clay-loam topsoil texture. The intermediate $\mathrm{K}$ content is likely related to the geochemistry of parent rock materials in the area: andesite on the tops and ridges of the low mountain. Partly weathered andesites are distinguished by their moderate $\mathrm{K}$ value, corresponding to K-feldspars and K-mica. Upon chemical breakdown of mineral components during the weathering process, $\mathrm{K}$ is retained in $\mathrm{A}$ and B horizon, absorbed by clay mineral (Gunn et al., 1997) and has been 
moderately leached during the intermediate weathering process, thus soil is moderately developed. In classified soil order- Alfisols, moderately high percent base saturation is likely influent to high $\mathrm{K}$ content.

2. Observation S2 (Figure 3.6b), formed from residual andesite in Triassic metasediments and meta volcanic rock (Trhl), has relatively moderate $\mathrm{K}$ and Th but low $U$ contents $(0.7,5.64$ and 1.14) (Figure 3.5). This soil is finetextured with shallow to moderately deep $(50-100 \mathrm{~cm})$ to bedrock. The high $\mathrm{K}$ content is likely to have been inherited from the parent rock, which was already explained in a previous section. Except where the Th is higher, likely associated with accumulation of topsoil humus (mollic epipedon), where organic matter can enhance Th (Wilford and Minty, 2007).

3. Observation S3 (Figure 3.7b), formed from residuum and colluvium derived from diorite in the Triassic meta-sediments (Trhl), has relatively high $\mathrm{K}$ and Th but moderate $\mathrm{U}$ contents $(0.89,6.16$ and 1.57$)$ (Figure 3.5). This soil is coarse, loamy textured and very shallow to shallow $(25-50 \mathrm{~cm}$ to bedrock) with rock fragments in the B horizon, formed over a steep slope. The Th and $\mathrm{U}$ contents are likely the signal of intermediate intrusive rocks (diorite) (Dickson and Scott, 1997). The thin soil derived from weathered diorite in this location was found to produce soil with high $\mathrm{K}$ and $\mathrm{Th}$.

4. Observation S4 (Figure 3.6b), formed from residuum and colluvium derived from shale in Permian sedimentary unit Ps, has relatively high $\mathrm{K}$, low Th and moderate $U$ contents $(1.13,3.43$ and 1.34) (Figure 3.6). This soil is loamy skeletal and shallow (25-50 cm to bedrock) on steep slopes.This implies that the thin soil (shallow) is poorly developed over parent rock fragment (skeletal) and thus reflects high $\mathrm{K}$ from weathering of source rock material in the erosion area.

5. Observation S5 (Figure 3.6b), formed from residuum and colluvium derived from shale in the Triassic meta-sedimentary units (Trhl), has relatively high contents of all radioelements (1.51, 8.51 and 1.89) (Figure 3.6). This soil is fine, loamy and moderately deep. The high radioelement contents are likely related to the intermediate weathering of shale (F2 in Figure 3.7a). The influence of relatively mature soil with "Alfisols" from fine grain sedimentary rock, seem to reflect concentration of $\mathrm{K}$, Th and $\mathrm{U}$ after soils have developed a thickness ( $100-150 \mathrm{~cm}$ to bedrock), where $\mathrm{K}$ is progressively released and low leaching process (high base and CEC, see in Table 3.3) and the high $\mathrm{Th}$ and $\mathrm{U}$ are retained in a finer texture, which differs from soil in observation S4. 
6. Observation S6 (Figure 3.6b), formed from residuum and colluvium derived from mainly siltstone with shale fragment in unit Trhl, has relatively moderate $\mathrm{K}$ but high Th and $\mathrm{U}(0.85,6.01,1.77)$ (Figure 3.6). This soil is fine loamy and moderately deep to deep (100-150 cm to bedrock), on middle and foot slopes. Here, high two radio- contents reflect parent rock geochemistry and mineralogy, as siltstones have high gamma-ray value. But the moderate $\mathrm{K}$ content is also can be a strong weathered clay fraction, as it has a moderately low or low CEC (see also Table 3.3). Another possible clue show in the profile development, the soil age is relatively mature to old (Kanhaplic Haplustalfs are intergrades between Haplustalfs and Ustox), and thus reflect increasing $\mathrm{Th}$ and $\mathrm{U}$ with reducing $\mathrm{K}$ content, which can be affected by leaching.

7. Observation $\mathrm{S} 7$ (Figure 3.6b), formed from residuum derived from sandstone in Jpk, has relatively low $\mathrm{K}$ but high $\mathrm{Th}$ and $\mathrm{U}$ contents $(0.55,6.75$ and 1.87$)$ (Figure 3.6). This soil is loamy skeletal and shallow ( $<50 \mathrm{~cm}$ to bedrock), on a steep slope. The low $\mathrm{K}$ likely relates to soil gamma-ray response and is essentially equivalent to the original bed rock. During the advanced weathering stage in soil profile ( recognised by order "Utisols"), low K content owes to less $\mathrm{K}$ content in parent material and high leaching in soil profile, where elevated $\mathrm{Th}$ and $\mathrm{U}$ is associated to retention of residual quartz sand.

\subsubsection{Relationships between gamma-ray data and soils developed over alluvial materials}

The interpretations in this section are based on four soil profiles and their laboratory analyses (soils number A1.1-A2.2 in Table 3.3). A stacked bar graph of the four observations with concentrations of $\mathrm{K}$, Th and $\mathrm{U}$ is shown in Figure 3.6. As in the previous section, we discuss the radioelements contents of the soil samples. The discussion is grouped by the age of alluvial materials.

\subsubsection{Recent alluvial}

Two major alluvial soils (Figure 3.6b) have been developing over recent alluvium in flood plains and valleys (see in Figure 3.6c), developed from young or recent alluvial material. The gamma- ray radioelements vary over alluvial plains as follows:

1. Observation A1.1, where fine-silty textured soil developed in the flood plain and formed from alluvial sediment, is relatively high in $\mathrm{K}$ content but moderate in Th and $\mathrm{U}$ contents $(0.98 \%, 4.23 \mathrm{ppm}$ and 2.24 ppm, in Figure 
3.4) (A1.1 in Figure 3.6b and Table 3.3). This implies that recent alluvial deposits have high $\mathrm{K}$ contents and contain deposits of high-activity clays (e.g. montmorillonite, illite) that have both structural and exchangeable K. The high-activity clays also lead to the decrease of Th content which is confirmed by cracked soil or cracking clays (montmorillonite group clay) as classify to Vertic subgroup (Pendleton and S. Montrakun, 1957). The soil classified into Aeric subgroup with Episaturation ( saturated with water in one or more layers and also has one or more unsaturated layers within $200 \mathrm{~cm}$ of the mineral soil surface), have moderate $U$ contents.

2. Observation A1.2, where fine textured soil developed in recent alluvium deposit of the Pa Sak and Numpueng rivers (A1.2 in Figure 3.6b), is relatively high in all radioelements (Figure 3.6). The high $\mathrm{K}$ and Th contents in this location are likely associated with the amount of silt and clay particles in the alluvial sediments. Both $\mathrm{K}$ and $\mathrm{Th}$ contents are known to absorb onto clay particles and some $\mathrm{K}$ may be present in silt and clay. This means that radiometric signatures might be helpful to identify fine grain size in alluvial soil. This agrees with the studies of Wilford et al. (1997) and Rawlins et al. (2007), who also found that recent alluvial deposits in younger landscapes were distinguished by elevated $\mathrm{K}$ and Th contents. This is also supported by the study of Dickson and Scott (1997). As for the high U in this location, it likely relates to transported material from upstream (from the Trhl geological unit) to the deposition area in the flood plains downstream. However, another possible reason is that this area is a lower part of the Pa Sak watershed and covered by paddy fields. Soil moisture in Endo-saturation with an "Aquic" condition (Endoaqalfs), lead to the possibility for high $U$ over the valley floor. This might relate to high radium isotopes deposited from ground water, similar to the study of Wilford et al. (1997).

\subsubsection{Old alluvium}

Soils developed from old alluvium on higher terraces correspond to transported gravel and accumulation. Two major soils were found in different positions as follows:

1. Observation A2.1 where coarse loamy textured soil developed on the higher terraces (A2.1 in Figure 3.6b and Table 3.3), has a relatively low K content but is high in Th and moderate in $\mathrm{U}$ contents $(0.2 \%, 6.53 \mathrm{ppm}$ and $1.45 \mathrm{ppm}$, in Figure 3.6). High Th and moderate $U$ contents are likely associated with 
an accumulation of resistant materials in the soil profile, where we found the percentage of gravel to be more than 35 percent. The accumulation of inactive clay (kaolinite) also reflects high Th. Moreover, this soil has been developed over a stable terrace where $\mathrm{K}$ has been removed by weathering, leaching and clay eluviations.

2. Observation A2.2 where fine loamy textured lateritic soil developed on the lower terraces in the Pleistocene sediments (A2.2 in Figure 3.6b and Table 3.3), has relatively low $\mathrm{K}$, high Th and moderate $\mathrm{U}$ contents (Figure 3.6). In observation Qt, the position of the area and sources of materials reflect the higher leaching of $\mathrm{K}$ but retention of $\mathrm{Th}$ and $\mathrm{U}$ in resistant materials such as gravel accumulation. In unit A2.2 high Th was found due to the laterization process resulting in high enrichment of $\mathrm{Fe}$ and $\mathrm{Al}$ in the soil (confirmed by field survey - Petroferic subgroup). This is also supported by study of Pickup and Marks (2000). Indeed, large areas of Qt are capped by ironstone, a final product of pedogenesis, enriched in $\mathrm{Fe}$ and depleted in $\mathrm{K}$ from primary minerals. The $\mathrm{Fe}$ enrichment is associated with oxidization as stated by Wilford and Minty (2007). It is also similar with the study of Dickson and Scott (1997), which states that an area where K depletion and Th-rich material is associated with material such as laterite. 


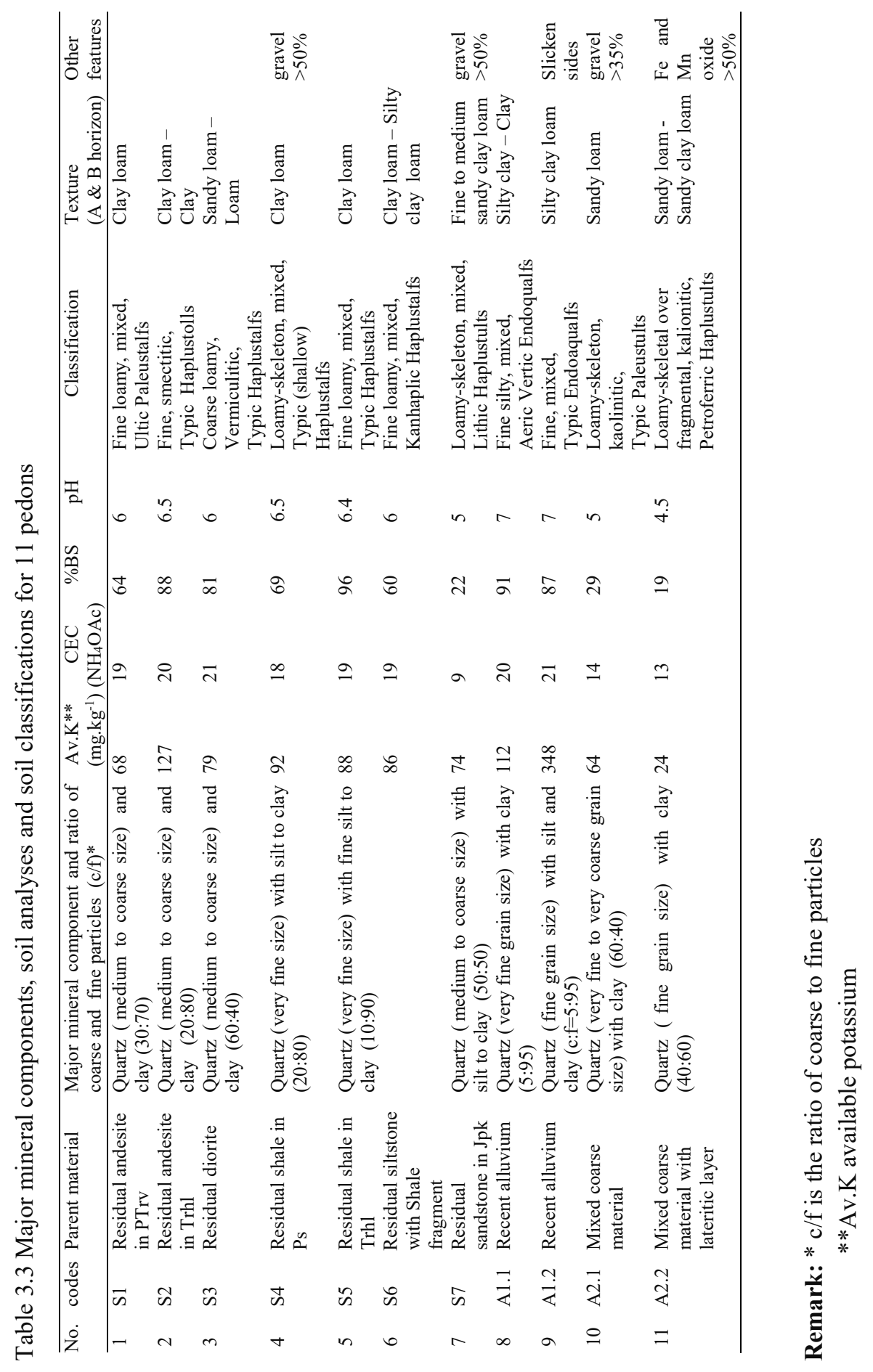


Application of Airborne Gamma-Ray Imagery to Assist Soil Survey

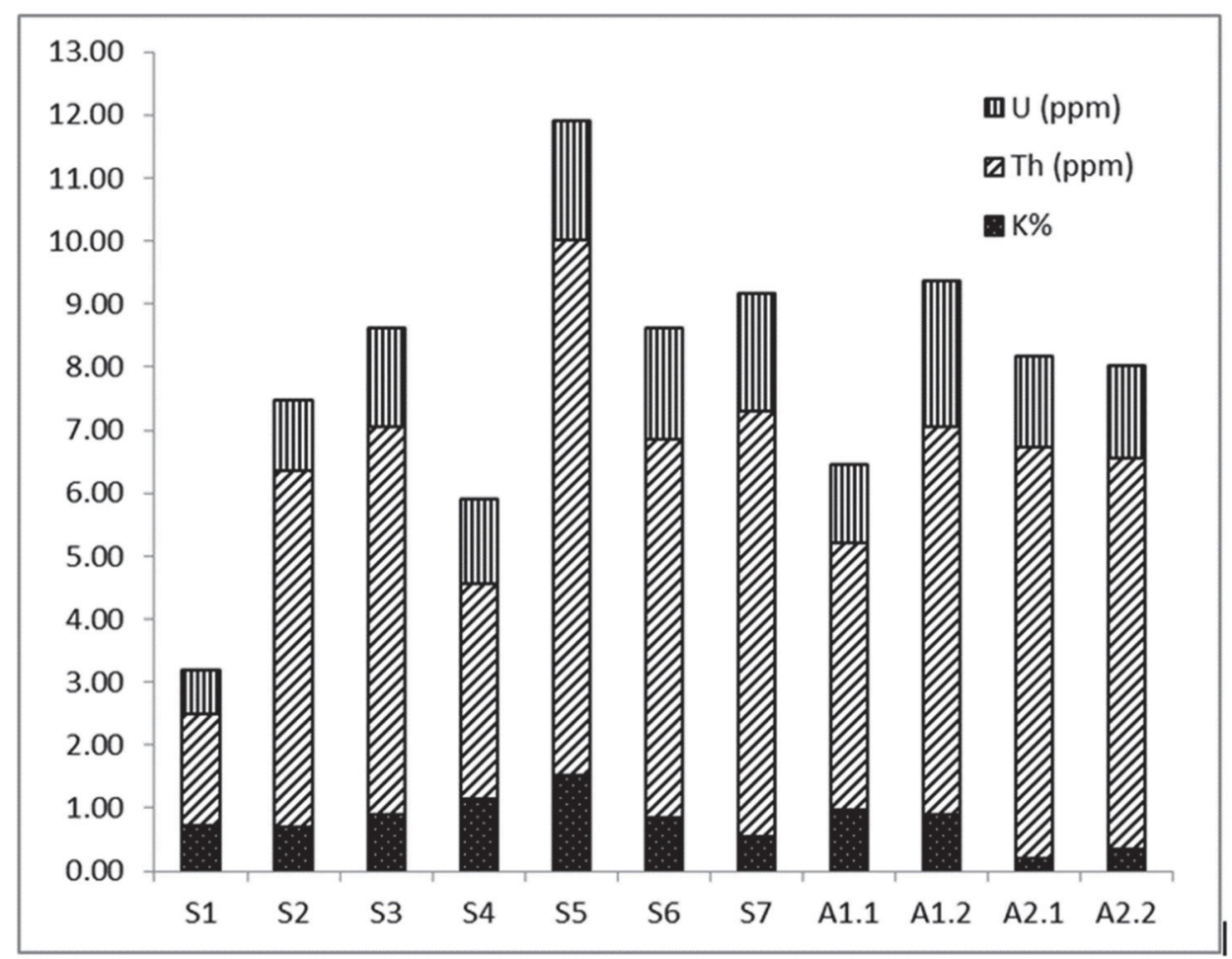

Figure 3.5 Concentration of $\mathrm{K}$, eTh and eU of 11 soil profile observations 


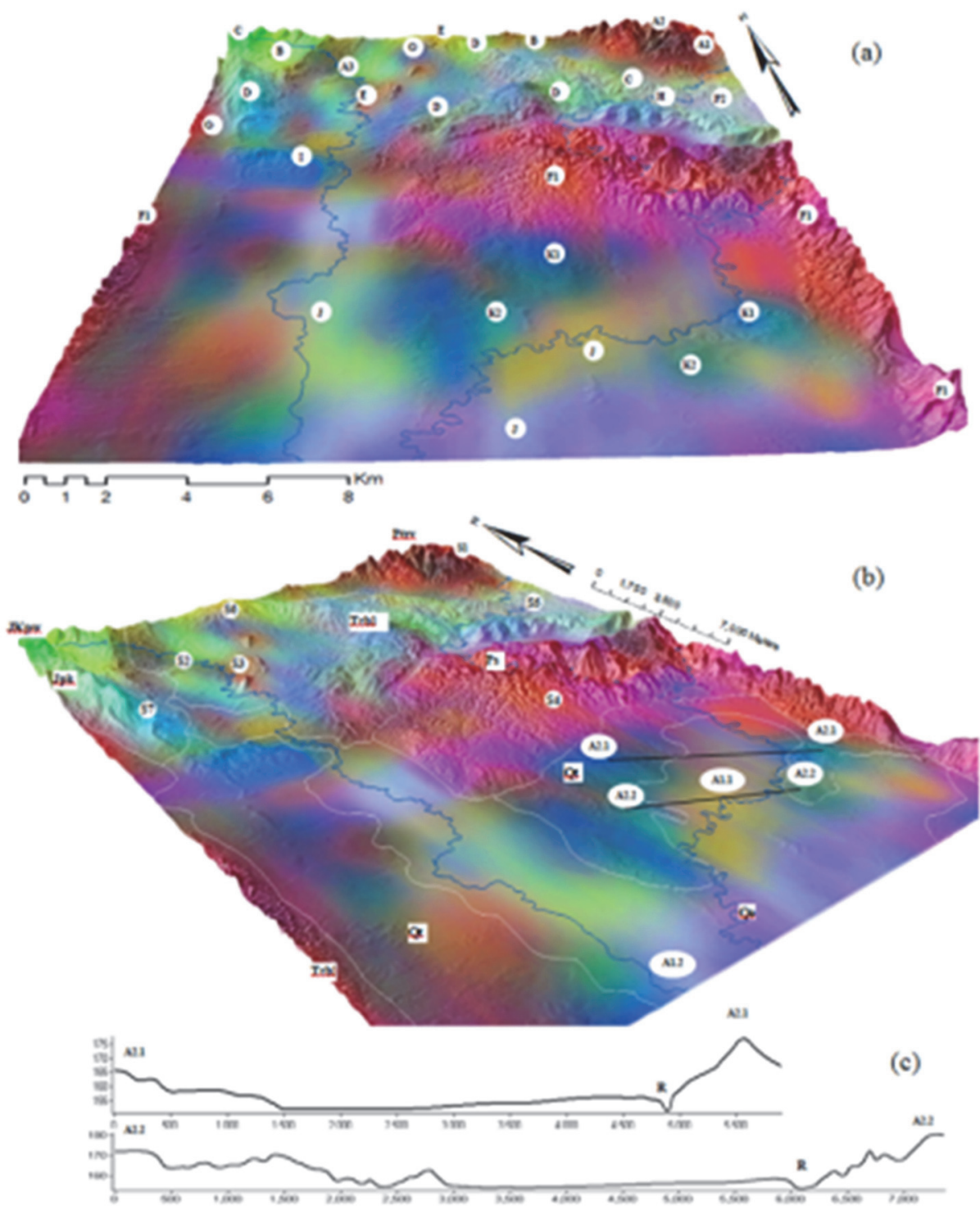

Figure 3.6 3D landscape perspective of ternary image and geology (Description of the geological map units are shown in Table 1) with (a) rock samples: A1, andesite\& rhyorite\&tuff; A2, diorite; A3, andesite; B, calcareous sandstone\&sandstone; C, greenish coarse pebblish sandstone; D, sand stone; E, diorite\&andesite\&volcanic grass; F1, shale in Ps: F2, shale in Trhl; G, shale\&silt stone; H, silt stone; I, residual quartz and accumulation of oxides and resistant materials; J, mixed-fine material; K1, mixed-coarse material, quartz and quartzite gravels and K2, laterite. (b) Soil characteristic formed over gresidual material in upland and alluvial material in flood plain. (c) Two topographic profiles along Pasak river (R), mixed recent alluvial soil (A1), two cross lines from left to right; A2. $1=$ old alluvium material formed extremely gravelly soil and A2.2 = old alluvium formed lateritic soil. 


\subsubsection{Comparison of gamma-ray imagery and the geopedologic map}

The overlay of geopedologic maps (at four categorical levels, landscape, lithology, relief and landform) on the ternary image shows that there is reasonable correspondence which is better than that for the geology map (Figure 3.7a). Some landscape units cannot be seen on the fused images because of the low resolution of the AGRI, notably along the valley of the Pa Sak river (Vt). Some large units have diverse signatures, e.g. low mountains (LM). However, some large features are also missed, e.g., the "tongue" of high-K (red in the ternary image) in the middle of Pi unit. Several contrasting units of low mountains can be distinguished (e.g., the northeast from the central northwest and the central north) but within several of these there are still important contrasts. Over most of the piedmont (Pi), a lower part of glacis terraces, the AGRI signal is distinguished by low $\mathrm{K}$ and high Th and $\mathrm{U}$ content and corresponds to highly weathered Quaternary terraces. However, the upper sections share a signature with the adjacent hill-land (Hi), indicating recent colluvium overlaying the older sediments.

At the lithology level (Figure 3.7b), many fine divisions of the landscape do not correspond to AGRI. This is because most of the GP lithology units are defined as an association of different rock types. A few units have good correspondence with AGRI. Examples of this are in areas relating to Pi landscape just given, where lithology is alluvio- colluvium (coded by 1) and distinguished by low contents in all radioelements, shown as a blue colour. In the northwest, mainly sandstone was found as a lithologic type ( 13 in Figure $3.7 \mathrm{~b}$ ), which is distinguished by high $\mathrm{U}$ content, given as a green colour. Also in the alluvial plain ( 2 in Figure 3.7b), high concentrations of three radioelements are found, distinguished by a mix of bright colours. In other complex lithologic units, it appears to be reliable when desegregating the units by lithogic types such as in a group of shale, sandstone and andesite (17 in Figure 3.7b). For example, shale should be distinguished by high K content material (red), sandstone (relies in the western) should be distinguished by high $\mathrm{U}$ content (green or blue) and low $\mathrm{K}$ content (andesite and diorite) distinguished by low elements should be black or other dark color (small spot in middle-north).

For the other two lower levels, relief (Figure 3.7c) and landform units (Figure 3.7d), there is poor correspondence with AGRI. However, there appears to be the possibility of adjusting obvious map boundaries using AGRI. For example, at the relief level (Figure 3.7c), different levels can be distinguished by the ratio of the 
element, e.g., low K, Th and U contents in higher terraces (Pi2 in Figure 3.7c) and gaining higher $\mathrm{U}$ in lower terraces ( $\mathrm{Pi} 3$ in Figure 3.7c).

Similarly, no relation of soil classification (soil subgroup level, e.g. Typic Haplustalfs in Pi111, Pi311 and Pi411, see Table 1 in supplementary information) corresponds to radioelement signals (Figure 3.7d). As this level includes soil properties within the control section, which normally is lower than $50 \mathrm{~cm}$ depth, no gamma-ray signal can be detected. However, from researches of (Bierwirth et al., 1996) and Petersen et al. (2012) show that it seems to be possible to define the clay mineral properties, which are included in higher levels, e.g. smectitic, Typic Endoaqualfs or montmorillonite, Typic Endoaquolls, but answer for this area is unclear, unless it will be further research to confirm this assumption.
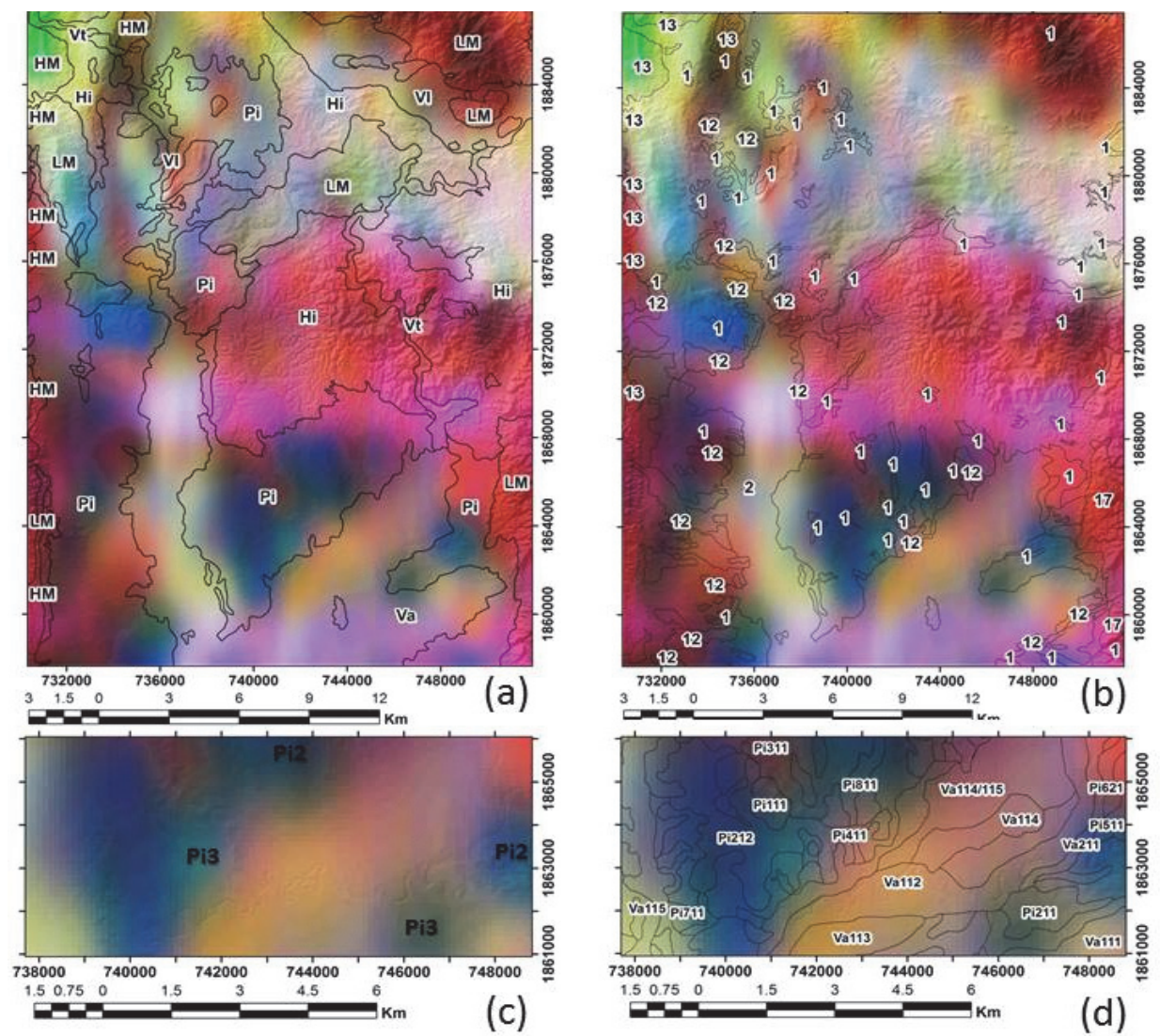

Figure 3.7 Geopedologic map over lay on a ternary image draped over digital elevation, showing the four geopedologic levels to gamma-ray response. (a) Landscape level. (b) Lithologic level, 1; Alluvio-colluvium, 2; Alluvium, 12; Residual/Alluvio-colluvium, 13; sandstone \& siltstone \& shale and17; shale sandstone\& mudstone \& andesite. (c) Relief types, in red circles show distribution of radioelement on higher terraces-Pi2 and lower terraces -Pi3 and (d) Landform map units (coded to soil classification at great soil group). 


\subsubsection{Comparison of gamma-ray imagery and the soil series map}

The overlay of the soil series map on the gamma ray image shows correspondence between some series and AGRI, but also important differences (Figure 3.8). The obvious deficiency of this map is the undifferentiated slope complex (code SC), where no soil survey was carried out. The best correspondences are found in five six series namely Bo, Ty, Cd, So and Sk. Main soil characteristics and relative contents of $\mathrm{Th}, \mathrm{K}$ and $\mathrm{U}$ contents are given in Table 3.4. For other soils there seems to be poor agreement with gamma ray data. For an example the La series occupies most of the alluvial plain but the AGRI signal varies considerably within the unit, suggesting that the series is too broadly defined. In case of Mr. Series there is an unclear relationship in radioelement response (Typic, Kandic, Paleustults). In the quaternary terraces in the lower middle part of the area several soil series have similar AGRI signatures. This is likely because important series differentiating soil properties such as depth and stoniness do not influence AGRI and so cannot be distinguished. Next to this, there is a complex unit of So/Tl (Lithic Haplustolls/Ultic Haplustalfs) in which the AGRI signal is quite variable, whereas the soil unit was mapped over a large area.

Table 3.4 Main soil characteristics and relative contents of Th, K and U

\begin{tabular}{|c|c|c|c|c|c|}
\hline Soil series & Formation & $\begin{array}{c}\text { Th } \\
\text { conten }\end{array}$ & $\begin{array}{c}\mathrm{K} \\
\text { ontent }\end{array}$ & $\begin{array}{c}\mathrm{U} \\
\text { content }\end{array}$ & Remarks \\
\hline $\begin{array}{l}\text { Bo series (Coarse } \\
\text { loamy, kaolinitic, } \\
\text { Typic Eutrustox) }\end{array}$ & $\begin{array}{l}\text { Residuum/colluvium } \\
\text { from sandstone or } \\
\text { calcareous sandstone }\end{array}$ & high & low & low & $\begin{array}{l}\text { High Th content } \\
\text { is reflected in } \\
\text { clay type } \\
\text { kaolinite }\end{array}$ \\
\hline $\begin{array}{l}\text { Ty series (Loamy- } \\
\text { skeletal, siliceaous, } \\
\text { Kanhaplic Haplustults) }\end{array}$ & $\begin{array}{l}\text { Residuum/colluvium } \\
\text { from sandstone and } \\
\text { quartzite imbedded } \\
\text { with phyllite and } \\
\text { shale }\end{array}$ & high & low & low & $\begin{array}{l}\text { Soils developed } \\
\text { on erosional } \\
\text { surfaces } \\
\text { (Ultisols) }\end{array}$ \\
\hline $\begin{array}{l}\text { Cd series (Fine, } \\
\text { smectitic, Leptic } \\
\text { Haplusterts) }\end{array}$ & $\begin{array}{l}\text { Residuum and } \\
\text { colluvium from } \\
\text { andesite and rhyolite }\end{array}$ & noderate & noderate & Low & \\
\hline $\begin{array}{l}\text { So series (Fine, } \\
\text { smectitic, Lithic } \\
\text { Haplustolls) }\end{array}$ & Weathering andesite & modera & high & moderate & $\begin{array}{l}\text { Moderate level } \\
\text { of Th and U may } \\
\text { be due to high } \\
\text { organic matter } \\
\text { content (Mollic) }\end{array}$ \\
\hline $\begin{array}{l}\text { Sk series (Loamy } \\
\text { skeletal over } \\
\text { fragmental,mixed } \\
\text { Petroferric Haplustults) }\end{array}$ & $\begin{array}{l}\text { Gentle to undulating } \\
\text { relief }\end{array}$ & high & low & high & $\begin{array}{l}\text { Presence of } \\
\text { laterite layer } \\
\text { within } 50 \mathrm{~cm} \\
\text { can be related to } \\
\text { high Th and U } \\
\text { contents }\end{array}$ \\
\hline
\end{tabular}


Chapter 3

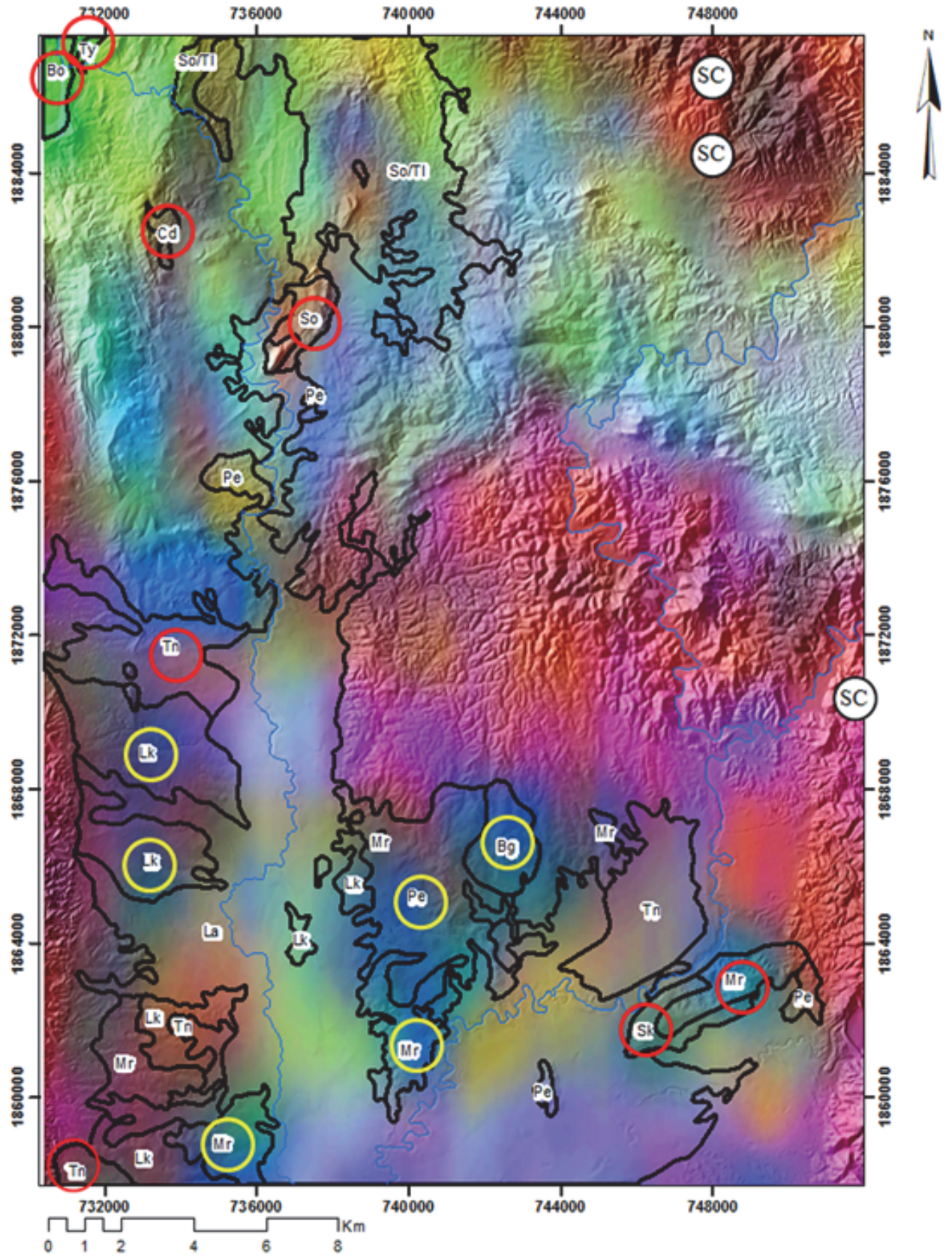

Figure 3.8 Overlay of soil series map on gamma-ray ternary image. Red circles show good matching of soil series to radioelement and yellow circles show miss-matching. Black circles with unit SC mean slope complex. 


\subsubsection{Clustering of gamma ray data}

Final classification result obtained after clustering of gamma ray 3 band data and DEM, and fuzzy convolution by calculating the total weighted inverse distance of all the classes in a 3 by 3 window is shown in Figure 3.9 and Table 3.5. The clustering for soil differentiation shows an overall accuracy of 67 percent with overall kappa statistics of 63 percent ( Table 3.6). User's accuracy ranged from $44-82 \%$ while producer's accuracy ranged from $43-100 \%$. The user's accuracy, also called the reliability of the classification, takes into account the number of correctly classified pixel with regard to all the pixels. Regarding the highest user's accuracy and producer's accuracy, S1 has consistently highest value of user's accuracy, which means approximately $82 \%$ of the S1 pixels in the classified map actually represent S1 on the ground. But S3 has the highest value of producer accuracy $(100 \%)$.

Separation of the units A1.1 and A1.2 did not give good results. Although producer's accuracy is 80 percent for A1.1, reliability of the classification is only $59 \%$. In case of A1.2 the reliability of the classification is higher (79\%) but producer's accuracy is only $46 \%$ (Table 3.6 ). Both the soil units A1.1 and A1.2 have been formed in the alluvium along the river, only the difference is in top soil texture which is difficult to differentiate using coarse resolution imagery. Similar result is shown in unit A2.1. Only in unit A2.2 both the producer's as well as the user's accuracy is higher (75\%). Another classification error is found in S5, as 7 test pixels of S4 were classified as S5.

Table 3.5 Clustering of gamma ray and DEM for soil differentiation

\begin{tabular}{|c|c|c|c|}
\hline Symbols & Soil types & Area $\left(\mathrm{Km}^{2}\right)$ & Percent $(\%)$ \\
\hline S1 & Fine loamy, mixed, Ultic Paleustalfs & 24.99 & 3.78 \\
\hline S2 & Fine, smectitic, Typic Haplustolls & 49.2 & 7.44 \\
\hline S3 & Coarse loamy, Vermiculitic, Typic Haplustalfs & 37.47 & 5.67 \\
\hline S4 & $\begin{array}{l}\text { Loamy-skeleton, mixed, Typic (shallow) } \\
\text { Haplustalfs }\end{array}$ & 11.09 & 16.78 \\
\hline S5 & Fine loamy, mixed, Typic Haplustalfs & 45.65 & 6.9 \\
\hline S6 & Fine loamy, mixed, Kanhaplic Haplustalfs & 145.96 & 22.08 \\
\hline S7 & Loamy-skeleton, mixed, Lithic Haplustults & 72.14 & 10.91 \\
\hline A1.1 & Fine silty, mixed, Aeric Vertic Endoqualfs & 52.09 & 7.88 \\
\hline A1.2 & Fine, mixed, Typic Endoaqualfs & 35.1 & 5.31 \\
\hline $\mathrm{A} 2.1$ & Loamy-skeleton, kaolinitic, Typic Paleustults & 51.47 & 7.79 \\
\hline \multirow[t]{2}{*}{ A2.2 } & $\begin{array}{l}\text { Loamy-skeletal over fragmental, kalionitic, } \\
\text { Petroferric Haplustults }\end{array}$ & 36.15 & 5.47 \\
\hline & Total & 561.31 & 100 \\
\hline
\end{tabular}


Table 3.6 Classification accuracy assessment for soil differentiation

\begin{tabular}{cccccc}
\hline Class name & $\begin{array}{c}\text { Reference } \\
\text { totals }\end{array}$ & $\begin{array}{c}\text { Classified } \\
\text { totals }\end{array}$ & $\begin{array}{c}\text { Number } \\
\text { correct }\end{array}$ & $\begin{array}{c}\text { Producers } \\
\text { accuracy } \\
\%\end{array}$ & $\begin{array}{c}\text { Users } \\
\text { accuracy } \\
\%\end{array}$ \\
\hline A1.1 & 20 & 27 & 16 & 80 & 59 \\
A1.2 & 41 & 24 & 19 & 46 & 79 \\
A2.1 & 31 & 19 & 15 & 48 & 79 \\
A2.2 & 24 & 24 & 18 & 75 & 75 \\
S1 & 20 & 17 & 14 & 70 & 82 \\
S2 & 22 & 39 & 17 & 77 & 44 \\
S3 & 12 & 17 & 12 & 100 & 71 \\
S4 & 64 & 73 & 56 & 87 & 77 \\
S5 & 44 & 29 & 19 & 43 & 66 \\
S6 & 55 & 61 & 39 & 71 & 64 \\
S7 & 26 & 22 & 15 & 58 & 68 \\
Totals & 359 & 359 & 240 & & \\
\hline Overall classification accuracy $=66.85 \%$, \\
Overall kappa statistics $=63 \%$
\end{tabular}

The clustering of gamma ray and DEM data for soil parent material differentiation using fuzzy convolution shows an overall accuracy of 72.16 percent ( with kappa statistics of 0.69) (Table 3.7), which is relatively better as compared to the clustering for soil differentiation. User's accuracy ranged from $58-100 \%$ while producer's accuracy ranged from $47-100 \%$. Class 1 and class 2 are the ones with relatively higher producer' $s$ and user' $s$ accuracy, which is followed by class 12 . The highest user' $s$ and producer' $s$ accuracy is obtained in class 6 (sandstone) but the number of test samples used for this class are very low. Classification of diorite, andesite and volcanic glass (class 9) has the highest producer's accuracy $(100 \%)$ since all the test pixels were correctly classified. Class 3 has only $47 \%$ accuracy, meaning that this class is probably underestimated. The unit with the lowest reliability is class 4 with $58 \%$ user's accuracy. 
Application of Airborne Gamma-Ray Imagery to Assist Soil Survey

Table 3.7 Classification accuracy assessment for soil parent material differentiation

\begin{tabular}{cccccc}
\hline $\begin{array}{c}\text { Class } \\
\text { name }\end{array}$ & $\begin{array}{c}\text { Reference } \\
\text { totals }\end{array}$ & $\begin{array}{c}\text { Classified } \\
\text { totals }\end{array}$ & $\begin{array}{c}\text { Number } \\
\text { correct }\end{array}$ & $\begin{array}{c}\text { Producers } \\
\text { accuracy } \\
\%\end{array}$ & $\begin{array}{c}\text { Users } \\
\text { accuracy } \\
\%\end{array}$ \\
\hline Class 1 & 58 & 47 & 43 & 74 & 91 \\
Class 2 & 28 & 30 & 26 & 93 & 87 \\
Class 3 & 30 & 18 & 14 & 47 & 78 \\
Class 4 & 41 & 53 & 31 & 76 & 58 \\
Class 5 & 25 & 33 & 22 & 88 & 67 \\
Class 6 & 3 & 3 & 3 & 100 & 100 \\
Class 7 & 10 & 11 & 7 & 70 & 64 \\
Class 8 & 25 & 35 & 24 & 96 & 69 \\
Class 9 & 10 & 16 & 10 & 100 & 63 \\
Class 10 & 26 & 24 & 16 & 62 & 67 \\
Class 11 & 63 & 50 & 35 & 56 & 70 \\
Class 12 & 33 & 32 & 23 & 70 & 72 \\
\hline Totals & 352 & 352 & 240 & & \\
\hline Overall classification accuracy $=72.16 \%$ \\
Overall kappa statistics $=69 \%$
\end{tabular}

Class 1=Fine recent alluvium, Class 2=Old alluvium+laterite, Class $3=$ Old alluvium + mixed texture,Class $4=$ Siltstone, Class 5=Sandstone, Class $6=$ Peblish Sandstone, Class $7=$ Shale\&siltstone, Class 8= Diorite in Ps, Class 9=Diorite\&andesite \& volcanic glass, Class $10=$ Andesite in trhl, Class $11=$ Shale in Trhl and Class $12=$ Shale in Ps. 


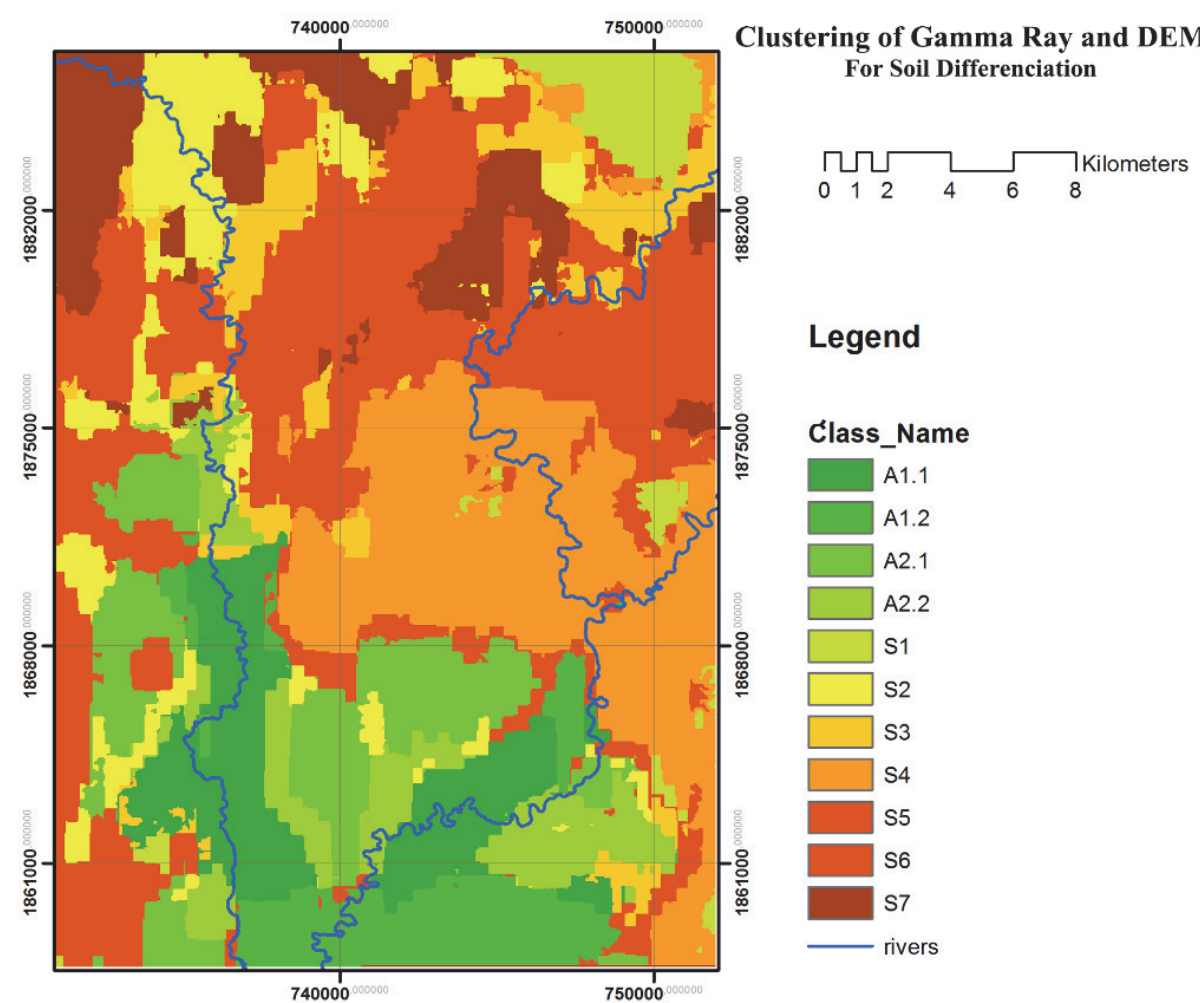

Figure 3.9 Clustering of gamma ray and elevation (DEM) for differentiating soil types

\subsection{Conclusions}

The AGRI data varied greatly over the survey area and provided clear relationships with several soil-forming factors as well as existing soil maps. However, it is clear that AGRI data must be interpreted in the context of known principles of soil geography and pedogenesis and with good knowledge of the specific study area. The most useful ternary image for interpreting soil environments proved to be red (high K), green (high eTh), blue (high eU); mixtures of these colours result in cyan (high eTh \& eU), magenta ( high $\mathrm{K} \&$ eTh), yellow (high $\mathrm{K} \& \mathrm{eU}$ ) and white (all elements high). As a data source for soil mapping, AGRI may play several roles:

Exploratory: Radioelement signals can suggest soil-forming processes in a study area. This should be based on prior knowledge of the geology (parent material), geomorphology (erosion- deposition, surfaces of different ages) and climate (chemical weathering environment). Areas with strong differences in signals are obvious ones to test theories of pedogenesis and soil-landscape relations by 
purposive placement of characterization profiles. However, similar signals may result from different combinations of soil-forming factors; for example, in the study area low $\mathrm{K}$ signals were associated both with low-K parent materials and with intensive $\mathrm{K}$ leaching; these areas can be separated by other evidence such as geomorphology.

Stratification for field sampling: AGRI layers are suitable as co-variables for sampling schemes based on feature-space relations to soil patterns, e.g. Latin hypercube sampling (Minasny and McBratney, 2006). Figure 3.6 and Fi Figure 3.7 show clear areas of interest that should be sampled, either for differences in parent material or weathering stage.

Pre- mapping: The gamma- ray imagery can be used in the initial stage of image/photo interpretation for soil survey, for example in preparing the lithology component of the geoform map in case of following the geopedologic approach. The DEM enhanced ternary image is very useful in improving the coarse resolution of the gamma ray image helping in image/photo interpretation. The single- element and ratio maps suggest soil geochemistry, which can be interpreted as parent material, transport and weathering, based on geomorphic interpretation.

Boundary refinement of existing maps: AGRI can be used to define proper location of boundaries. An example is the boundary between the PTrv and Trhl lithologic units in the northeast of the study area. The eTh, eU, eTh/K, and eU/K maps (Figure 3.4) show a clear and more refined boundary line than the geology map made by landscape interpretation. In addition, new internal boundaries may be suggested. For example, the large map units with widely defined soil series in the flood plain (Figure 3.7) may be separable into smaller maps units and more narrowly defined series based on boundaries suggested by AGRI. Such refinement should be reinforced by field investigation to locate boundaries with acceptable precision considering the map scale. AGRI resolution is fairly coarse: its $400 \mathrm{x} 400 \mathrm{~m}$ pixels roughly correspond to map scale 1:320,000 (assuming 5x5 $\mathrm{mm}$ map delineation, $4 \times 4$ pixels per minimum map unit, so $5 \mathrm{~mm}$ map $=1600 \mathrm{~m}$ ground). Further, there are transition pixels due to interpolation. Thus, although the AGRI data should probably not be used directly using a contouring or segmentation algorithm, they can show strongly contrasting areas within what were, by other means, presumed homogeneous map units. In some parts of the world, higher resolutions AGRD are available with $50 \times 50 \mathrm{~m}$ pixel size. These would directly support boundary delineation at 1:40,000 scale (Taylor et al., 2002; Wilford, 2009). 
An example from the present study is the very low $\mathrm{K}$, high $\mathrm{eTh} / \mathrm{eK}$ and $\mathrm{eU} / \mathrm{eK}$ areas within the quaternary terraces that were mapped, based on physiography, as one unit. Another example is the clear differentiation of high $\mathrm{U}$ and $\mathrm{eU} / \mathrm{eTh}$ areas within the recent alluvium, which could be due to Rd gas emissions in wetter positions (Grasty, 1997; International Atomic Energy Agency, 2003; Minty et al., 1997). These features were missed completely in the soil series and geopedologic maps, despite their finer delineations based on physiography. The surveyor would then visit these areas and determine the differences in soil properties (e.g., weathering stage, source of parent materials, wetness), causing the observed AGRI differences.

Some soil series show clear AGRI signals, which can be used to improve the boundaries of their map units. For example, in the Quaternary alluvium (Qa), gamma-ray elements seem to relate to young soil formed from recent alluvium (Inceptisols), e.g. Tn and La. In gently undulating to undulating areas, where landscapes are defined as terraces or piedmonts, gamma-ray elements seem to relate to developed soil formed from old alluvium (Ultisols), e. g Pe, Mr, Lk, Ly, Ty. In hilly areas, where soils generally relate to in-situ and locally transported materials, soils are influenced by rock materials and chemical weathering. Thus, soils appear varied. This very clear boundary was not used in the GP map at the proper (lithology) level. Many fine divisions of the landscape do not correspond to AGRI, again perhaps due to limited AGRI resolution. Perhaps, it is due to the quality of GP map by itself, which was made for a large scale purpose (original 1: 100,000 scale). On the other hand, the relief types and landform units are at a much finer scale than can be supported by AGRI.

Parent material differentiation: Shale of different clay mineral compositions in hilly landscapes (hence, shallow, relatively unweathered soils) can be differentiated by AGRI. In this study area, the Permian-age shale (SPSS) associated high K and low Th, hence low eTh/K (Figure 3.4d), whereas the Triassic-age shale ( Trhl) associated high $\mathrm{K}$ and $\mathrm{Th}$. These differences can be extended to soil series developed from different shale.

The study also shows potential for clustering of gamma ray and DEM data for generating a map showing soil variation. The result shows that clustering performs relatively better for differentiating soil parent material than for soil units. The later could be useful in getting lithology information for soil mapping using geopedologic approach. This is also shown in the results of the interpretation of the digitally combined gamma ray image with relief shaded image. The clustering of gamma ray with ancillary data could be area specific. Use of elevation data in 
clustering can be very logical in river basin where there is priori knowledge of fluvial soil occurrences related to elevation differences (soils developed in alluvium in lower areas versus residual soils on higher grounds). However in hilly and mountainous areas DEM derivatives e.g. topographic wetness index might be more useful.

\subsection{Recommendations for using gamma ray data in soil survey in Thailand}

Soil is a continuous variable and mapping soil units with abrupt boundaries between the soil bodies depends on mapping scale, the level of generalization (Ibán `ez et al., 1995; Lorenzetti et al., 2015) as well as on the spatial resolution of available data e.g. gamma ray data. We recommend that gamma ray data at 400 by $400 \mathrm{~m}$ resolution can be adequately used for mapping soil bodies at 1:25,000 scale. The Thai soil survey is introducing DSM techniques to improve existing soil maps, map non-agricultural areas in more detail (e.g., replacing slope complex mapping units with soil series), and map at more detailed scales. It is recommended to apply AGRI imagery in combination with optical remote sensing and DEM in the premapping stage. Since gamma-ray obtains data of earth surface up to $45-50 \mathrm{~cm}$ depth, it is possible to apply it to map topsoil properties or to differentiate phases of soil series due to its relation between radio element content and geochemistry (weathering and component), geomorphic and pedogenic processes (Wilford and Minty, 2007) and thereby to improve the quality of traditional soil mapping. For example, $\mathrm{eTh} / \mathrm{K}$ is recommended to be a co-variable for mapping topsoil texture and closely related properties, as $\mathrm{K}$ content is readily absorbed in areas with high clay content and high Th relates to resistant materials such as sand particle.

AGRI imagery can also be applied to predict large-scale erosion prone area, since there is remarkable relationship between geomorphic and weathering processes with surface materials. Of course one needs additional environmental variables and suitable model in order to estimate soil erosion. AGRI can be considered as a complementary data layer to make initial assessment of erosion prone areas. 


\section{Chapter 4 Fuzzy logic for fine-scale digital soil mapping ${ }^{1}$}

${ }^{1}$ Accepted with major revision in CATENA 


\subsection{Introduction}

Soil is a non-renewable resource, the basis for food security and the foundation for our sustainable future. For mapping this valuable resource, the conventional techniques generally include: air photo interpretation to separate landform units, followed by detail study of soils by digging pits along predefined transects lines, which also includes taking samples for laboratory analysis, and finally classification of soil following an established system. Outside the transect lines the soils are studied using auger holes in order to map their spatial variation. Finally, soil spatial variation is mapped, the mapping units can be consociations (dominant one soil class) or complexes (intimately associated soil classes). One should also take into account that there should be at least 6 observation points per hectare in a mapping scale of 1:50,000, more the observation points the better will be the accuracy of the map. The whole procedure is time demanding, labor intensive and expensive. Cost will further go up if grid survey is carried out (Beckett and Burrough, 1971). Since the recent past, the availability of remote sensing data and the advancement of data analysis techniques open many opportunities for digital soil mapping (DSM). Yet, most studies on DSM using remote sensing techniques so far have been performed on a local scale (Mulder et al., 2011a). Soil is a continuous variable and does not have abrupt boundaries in nature. One soil type can change gradually to become another class. This creates problem in delineating soil boundaries due to overlapping of classes, which results in lower mapping accuracy. Unlike conventional soil mapping, DSM techniques help in continuous soil property mapping, which increases the usefulness of the data e.g. applications in hydrological model, etc. DSM techniques include a large number of methods such as the use of random forest (Pahlavan-Rad et al., 2016; Sreenivas et al., 2016; Wiesmeier et al., 2011b), quartile regression forest (Vaysse and Lagacherie, 2017), artificial neural network (Chagas et al., 2011b), machine learning (Keskin et al., 2019; Zeraatpisheh et al., 2019) and also using legacy soil survey maps as covariate for updating soil surveys (Pahlavan-Rad et al., 2016). Since soil is a continuous variable and one soil type can change gradually to become another class, fuzzy classification becomes very suitable (Foody, 1996). In classification using fuzzy logic a pixel may have multiple class membership and the one with the highest membership gets the class label. The advantage of this method is the ability to use knowledge of soil-environment relations to make inferences (Scull et al., 2003). Many soil concepts or systems can be modeled, simulated and even replicated with the help of fuzzy systems, which may even be applied to human 
reasoning (McBratney and Odeh, 1997). In order to help map soil parent material differentiation, fuzzy clustering was applied to gamma ray and elevation data in Thailand, which improved classification accuracy (Moonjun et al., 2017). Zhu (1997d) developed a fuzzy logic based model, the co-called a similarity model, to represent soil spatial information in which soil landscapes are perceived as continuums in both their parametric and geographical spaces. A similarity model consists of two components: a similarity representation component and a raster representation scheme. The similarity representation component uses a set of prescribed soil taxonomic categories as a central concept of the fuzzy soil classes, and can represent soils at any given location as a set of similarity values to the central concept. A collection of these similarity values forms an 'n-element vector' known as a soil similarity vector. Zhu et al. (1997) developed a SoLIM (Soil Land Inference Model) to estimate and represent spatial distributions of soil types in the landscapes.

In conventional soil mapping following USDA soil taxonomy, soil series is the lowest categorical level, which represents a three-dimensional soil body having a unique combination of properties that distinguish it from neighbouring series. More specifically, each series consists of pedons having soils that are similar in properties e.g. soil texture, chemical compositions and their arrangement in the soil profile. Topsoil texture is an important soil property used in differentiating phases of soil mapping unit. Soil texture is also useful in getting information on soil fertility and land management. Moreover, soil texture is often used to get other soil physical properties such as water holding capacity, porosity etc. through pedo-transfer functions.

Since conventional soil mapping is labour intensive and costly to operate, it is interesting to see if DSM methods can help in increasing the efficiency of soil mapping. The available DSM methods are mostly dominated by statistical/machine learning approaches. In the current study, fuzzy logic is incorporated in soil mapping. Fuzzy logic is easy to understand and implement, and is thus selected in the current study. The main objective of the study is to see if fuzzy logic helps in increasing mapping efficiency. The study therefore aimed to answer the following 2 main questions:

- Can fuzzy logic help in mapping soil under a highly heterogeneous topography?

- What is the uncertainty of mapping soil series and surface texture using fuzzy logic? 
This approach consists of three steps: i) developing a similarity model for representing soils as a continuum (fuzzification), ii) inference techniques for mapping the soils, and iii) a set of procedures for getting soil information from the similarity model, the so-called de-fuzzification. The study was applied in a case study in Pa Sak watershed in central Thailand. Data used are soil series map, lithology map and DEM. The software package called ArcSIE was used to perform fuzzy soil inference.

\subsection{Materials and methods}

\subsubsection{Map data sources as predictor variables}

\subsubsection{Lithology parameter}

Lithology, which represents soil parent material, is very important predictor for soil differences. The lithology map scale, at 1:50,000, prepared by first generating a geopedologic approach (Zinck, 1988/1989) was available (see also in Appendix 1). The integrated map was compiled by Hansakdi (1998). In this method, aerial photo-interpretation produced a geoform map based on relief, drainage, photographic texture, land use and photographic tonality. The geoforms (pedons - the smallest soil body to be classified) are characterised relating to soil parent materials, during field observations at typifying locations. The lithology map has six identified classes: 1) recent alluvium, 2) old alluvium, 3) andesite, 4) sandstone, 5) shale and 6) association of shale and siltstone (Figure 4.1). 


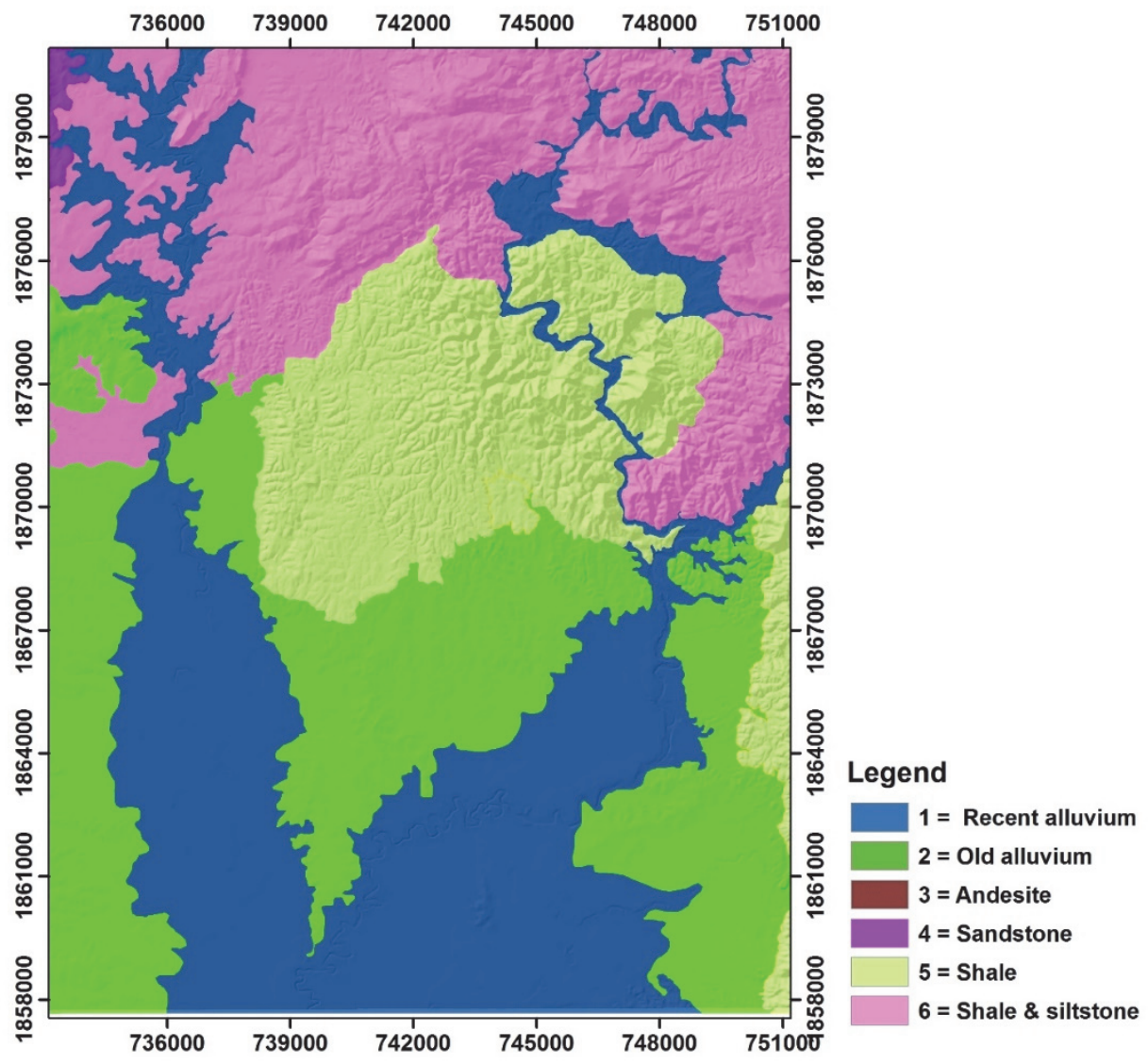

Figure 4. 1: Clustering of gamma ray and elevation (DEM) for differentiating soil Lithology map of the study area

\subsubsection{Terrain parameters}

Other predictor variables are terrain parameters such as slope gradient and compound topographic index (CTI), which were derived from a digital elevation model (DEM). A DEM of the study area at 10 meter spatial resolution was available. It was prepared from the base DEM with spatial resolution of $5 \times 5 \mathrm{~m}$ and with $90 \%$ horizontal accuracy of $<2 \mathrm{~m}$ in flat and $<4 \mathrm{~m}$ in sloping areas and relative vertical accuracy of $\pm 0.3 \mathrm{~m}$. It was produced by digital photogrammetry technique using aerial photographs at scale 1:4,000 to $1: 25,000$, and stored in SDTS format according to the USGS DEM standard (ESRI-Thailand, 2006). Elevation in the area varies from 140 to 590 meters above sea level. From the DEM, the primary and secondary terrain attributes (terrain slope and compound topographic index : CTI) were derived, which were used as the predictor 
variables. Slope gradient indicates soil denudation and transportation processes which can be related to shallow soil in the sloping areas while the compound topographic index or better known as topographic wetness index can be related to sediment deposition and soil formation resulting in deeper soil. Other DEM derivatives e.g. slope aspect and curvature, do not seem to have much effect on soil variation and they were not used. In areas located in high latitude slope aspect could play a role in micro-climatic variation due to sun exposition having effect on soil differences, but in Thailand aspect does not play much role. Also slope curvatures were assumed not to play much role because of not having pronounced variations on slope forms in the area. The slope classes were made adopting the USDA system for agricultural use as follows: $0-2 \%=$ level to nearly level, $2-5 \%=$ slightly undulating, $5-12 \%=$ undulating, $12-20 \%=$ rolling, $20-35 \%$ $=$ hilly, $35-50 \%=$ steep, and $>50 \%=$ very steep (Figure 4.3 ).

The slope map (in percentage) was generated using the following equation:

$$
\text { Slope percent }=\left(\sqrt{ }\left([\mathrm{dz} / \mathrm{dx}]^{2}+[\mathrm{dz} / \mathrm{dy}]^{2}\right) / \text { grid size }\right)^{*} 100
$$

Where, $\mathrm{dz} / \mathrm{dx}$ is height change in $\mathrm{x}$ direction and dz/dy is the height change in $\mathrm{y}$ direction in a window of $3 \times 3$. The topographic wetness index was generated using the soil inference engine (SIE) extension tool in ArcGIS 10. The formula to derive CTI (Figure 4.2) is as followed:

$$
\mathrm{CTI}=\ln (A s / \tan \theta)
$$

Where As is specific catchment area (in sq.m2) and $\theta$ is local slope gradient (in degrees). With reference to the relation of slope and CTI with soils, Bishop and Minasny (2006) concluded the potential of terrain attributes to predict soil classes (type, series) or soil properties for mapping purposes. Where CTI is highly correlated to soil properties, such as texture, bulk density, CEC, organic matter content and pH (Moore et al., 1991). 


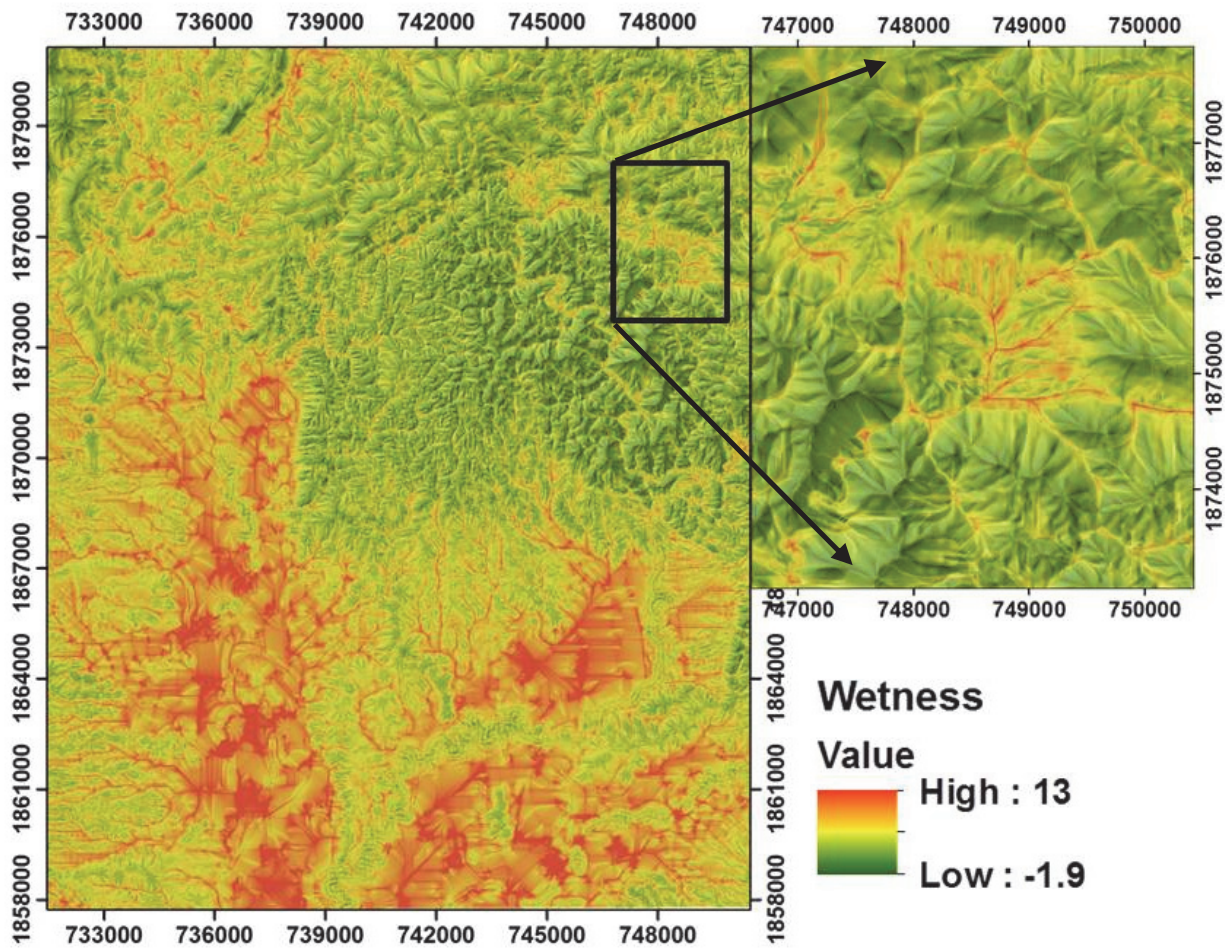

Figure 4.2: Compound topographic index calculated from 10x10 m DEM indicating level of topographic wetness.

\subsubsection{Conventional soil map}

Conventional soil series map at a scale of 1:50,000 (Figure 4.3) was prepared during the semi-detail soil survey and mapping project of LDD in 2002. The map consists of 27 mapping units with 20 consolidations, 4 associations and 3 miscellaneous units (SC, $\mathrm{W}$ and $\mathrm{U}$ ). The soil series map was compared with soil map derived from fuzzy method. 


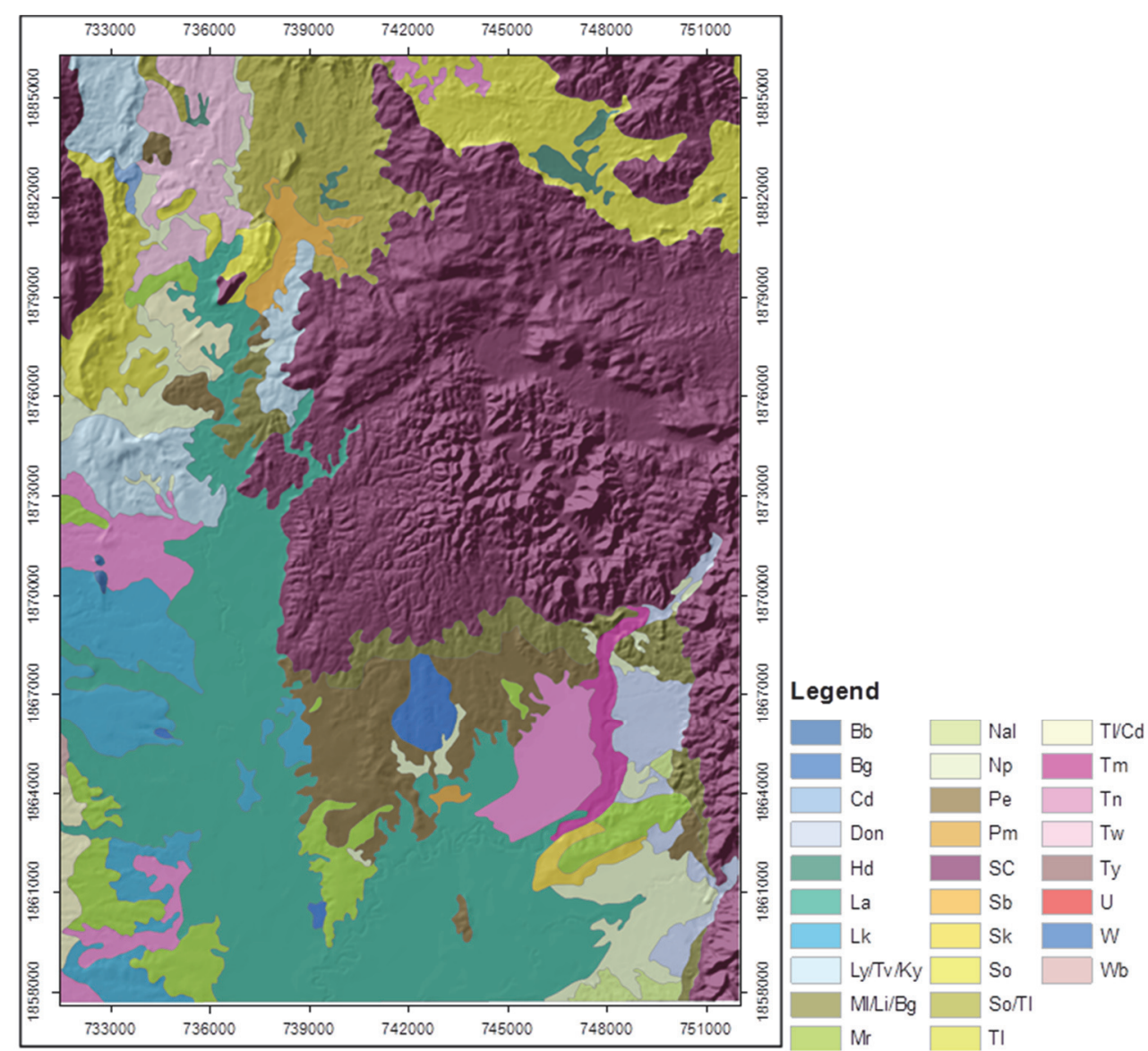

Figure 4.3: Conventional soil map at scale 1:50,000 (see also Appendix 2)

\subsubsection{Soil observations based on geopedological map units}

A geology map at 1:50,000 scale of the study area, produced by the Thai Department of Mineral Resource Department of Mineral Resource (2005), was also available.The geologic units in the study area are Permian, Triassic, Jurassic and Cretaceous sedimentary (Ps, Trhl, Jpk, JKpw), Pleistocene and Holocene sediments (Qa and Qt), and meta-volcanic (PTrv). Seven major landscapes units were extracted from geopedologic map (Figure 4.4): High mountain (HM), Low mountain (LM), Highlands (Hi), Piedmont (Pi), Lateral valley (Val), Trench valley (Vt) and Valley (Va). A landscape map showing boundary of geological formations and soil observation points are shown in Figure 4.4. The landscape and geology map were used for taking soil samples in the area. In total 235 observation points were used as the basis for stratified sampling in the seven geologic units and the seven major landscape units. These were used as the basis 
for stratified sampling, about a quarter of the whole study area, were selected to crossing maximum landscape variability

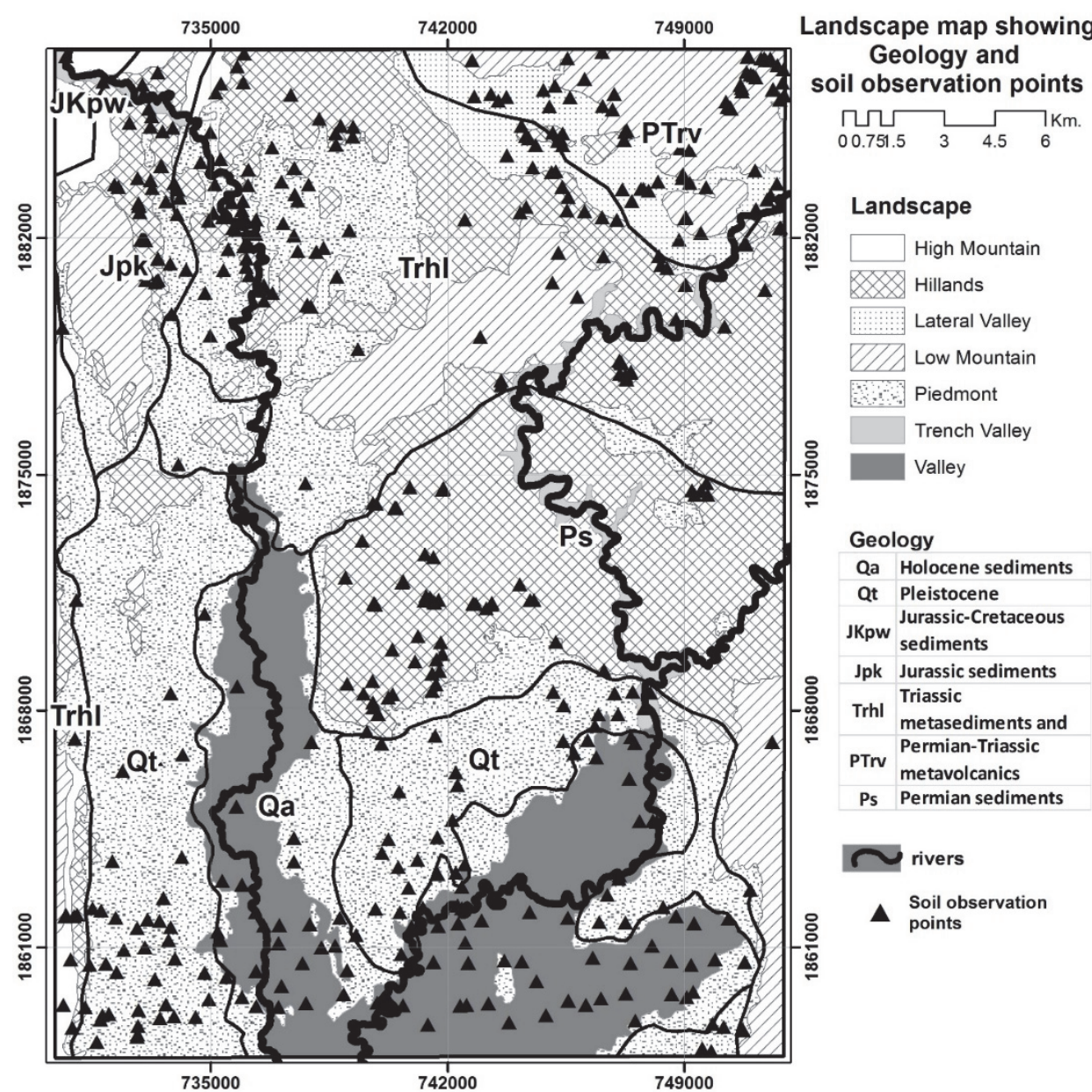

Figure 4.4: Geopedological units with soil observation points (see appendices 1 and 2 for the description of the legend)

Soil samples were collected to analyze the required properties for differentiating the soil series. In Table 1 soils series with their corresponding properties are shown. Soil observations were made using mini- pits description which was followed by augering. Soils were classified following USDA Soil taxonomy system, which has six categories, in order of decreasing rank as order, suborder, great group, subgroup, family and series. Soils were described by standard LDD methods using mini-pits and augering, which are an adaptation of the Soil Survey Manual (Soil Survey Staff, 1993). Soil samples were analyzed at LDD laboratory following USDA methods (USDA., 1996). Soils were classified at subgroup level 
(Soil Survey Staff, 2006) with mapping units as consociations or associations of soil series as described in the established soil series manual of Thailand (Potichan et al., 2004). In this study, we used soil series and topsoil texture (as topsoil phase) for mapping soil using fuzzy logic (Table 4.1).

Table 4.1 Observation data, soil series and lithology

\begin{tabular}{|c|c|c|c|c|c|c|c|c|}
\hline \multirow{2}{*}{\multicolumn{2}{|c|}{ No. iymbols }} & \multirow{2}{*}{ Series } & \multicolumn{2}{|c|}{ Classification } & \multirow{2}{*}{ Lithology } & \multirow{2}{*}{ drainage } & \multirow{2}{*}{$\begin{array}{l}\text { Topsoil } \\
\text { Texture }\end{array}$} & \multirow{2}{*}{ No.Obs. } \\
\hline & & & USDA & WRB & & & & \\
\hline 1 & $\mathrm{Cm}$ & $\begin{array}{l}\text { Chian } \\
\text { Mai }\end{array}$ & $\begin{array}{l}\text { Coarse-loamy, } \\
\text { mixed, } \\
\text { superactive, } \\
\text { nonacid, } \\
\text { isohyperthermic, } \\
\text { Oxyaquic } \\
\text { ustifluvent }\end{array}$ & $\begin{array}{l}\text { Eutric } \\
\text { Fluvisols }\end{array}$ & $\begin{array}{l}\text { Recent } \\
\text { alluvium }\end{array}$ & $\begin{array}{l}\text { moderately } \\
\text { well }\end{array}$ & $\begin{array}{c}\mathrm{cl} \\
\mathrm{I} \\
\mathrm{scl} \\
\mathrm{sicl} \\
\mathrm{sl}\end{array}$ & $\begin{array}{l}2 \\
1 \\
2 \\
3 \\
3\end{array}$ \\
\hline 2 & Tn & $\begin{array}{l}\text { Tha } \\
\text { Phon }\end{array}$ & $\begin{array}{l}\text { Fine, mixed, } \\
\text { superactive, } \\
\text { nonacid, } \\
\text { isohyperthermic, } \\
\text { Aeric } \\
\text { Endoaquepts }\end{array}$ & $\begin{array}{l}\text { Gleyic } \\
\text { Fluvisols }\end{array}$ & $\begin{array}{l}\text { Recent } \\
\text { alluvium }\end{array}$ & $\begin{array}{l}\text { poorly } \\
\text { drained }\end{array}$ & $\begin{array}{l}\mathrm{cl} \\
\mathrm{scl} \\
\mathrm{sic} \\
\mathrm{sicl} \\
\mathrm{sil}\end{array}$ & $\begin{array}{c}6 \\
2 \\
11 \\
23 \\
3\end{array}$ \\
\hline 3 & La & Lamsak & $\begin{array}{l}\text { Fine-silty, mixed, } \\
\text { superactive, } \\
\text { nonacid, } \\
\text { isohyperthermic } \\
\text { Fluvaquentic } \\
\text { Endoaquepts }\end{array}$ & $\begin{array}{l}\text { Gleyic } \\
\text { Fluvisols }\end{array}$ & $\begin{array}{l}\text { Recent } \\
\text { alluvium }\end{array}$ & $\begin{array}{l}\text { somewhat } \\
\text { poorly } \\
\text { drained }\end{array}$ & sic & 2 \\
\hline 4 & $\mathrm{Ncu}$ & $\begin{array}{l}\text { Nam } \\
\text { Chun }\end{array}$ & $\begin{array}{l}\text { clayey skeleton, } \\
\text { mixed,active, } \\
\text { isohyperthermic } \\
\text { Aquic Haplustalfs }\end{array}$ & $\begin{array}{l}\text { Skeletic } \\
\text { Luvisols }\end{array}$ & $\begin{array}{l}\text { Old } \\
\text { alluvium }\end{array}$ & $\begin{array}{l}\text { moderately } \\
\text { well drained }\end{array}$ & $\begin{array}{l}\mathrm{cl} \\
\mathrm{scl} \\
\mathrm{sl}\end{array}$ & $\begin{array}{l}3 \\
4 \\
4\end{array}$ \\
\hline 5 & $\mathrm{~Wb}$ & $\begin{array}{l}\text { Wichain } \\
\text { Buri }\end{array}$ & $\begin{array}{l}\text { Loamny, mixed, } \\
\text { active, } \\
\text { isohyperthermic, } \\
\text { Aquic (Arenic) } \\
\text { Haplustalfs }\end{array}$ & $\begin{array}{l}\text { Chromic } \\
\text { Luvisols }\end{array}$ & $\begin{array}{l}\text { Old } \\
\text { alluvium }\end{array}$ & $\begin{array}{l}\text { moderately } \\
\text { well drained }\end{array}$ & sicl & 5 \\
\hline 6 & $\mathrm{Ct}$ & Chaturat & $\begin{array}{l}\text { Fine, mixed, } \\
\text { isohyperthermic, } \\
\text { Typic Haplustalfs }\end{array}$ & $\begin{array}{l}\text { Chromic } \\
\text { Luvisols }\end{array}$ & $\begin{array}{l}\text { Shale\& } \\
\text { siltstone }\end{array}$ & well drained & $\mathrm{cl}$ & $\begin{array}{l}3 \\
3\end{array}$ \\
\hline \multirow[t]{2}{*}{7} & \multirow[t]{2}{*}{ Li } & \multirow[t]{2}{*}{$\mathrm{Li}$} & \multirow[t]{2}{*}{$\begin{array}{l}\text { Clayey skeleton, } \\
\text { mixed,semiact,iso } \\
\text { shallow, Ultic } \\
\text { Haplustalfs }\end{array}$} & \multirow[t]{2}{*}{$\begin{array}{l}\text { Skeletic } \\
\text { Luvisols }\end{array}$} & \multirow[t]{2}{*}{ Shale } & well drained & $\begin{array}{c}\mathrm{cl} \\
\mathrm{gcl} \\
\mathrm{I} \\
\mathrm{sgc}\end{array}$ & $\begin{array}{l}10 \\
5 \\
3 \\
7\end{array}$ \\
\hline & & & & & & & sgcl & 5 \\
\hline
\end{tabular}




\begin{tabular}{|c|c|c|c|c|c|c|c|c|}
\hline 8 & $\mathrm{Tl}$ & Tha Li & $\begin{array}{l}\text { Clayey skeleton, mixed, } \\
\text { semiactive, } \\
\text { isohyperthermic, Ultic } \\
\text { Haplustalfs }\end{array}$ & $\begin{array}{l}\text { Skeletic } \\
\text { Luvisols }\end{array}$ & Andesite & well drained & $\begin{array}{c}\mathrm{cl} \\
\mathrm{I} \\
\mathrm{sgc} \\
\mathrm{sgcl}\end{array}$ & $\begin{array}{l}3 \\
1 \\
1 \\
4\end{array}$ \\
\hline 9 & Ws & $\begin{array}{l}\text { Wangsa } \\
\text { Pung }\end{array}$ & $\begin{array}{l}\text { Fine, mixed, act, } \\
\text { isohyperthermic, Typic } \\
\text { Haplustalfs }\end{array}$ & $\begin{array}{l}\text { Chromic } \\
\text { Luvisols }\end{array}$ & Shale & well drained & $\begin{array}{cl}\mathrm{cl} \\
\mathrm{sgcl}\end{array}$ & $\begin{array}{l}14 \\
8\end{array}$ \\
\hline 10 & Png & Phon Ngam & $\begin{array}{l}\text { Fine-loamy, mixed, } \\
\text { semiactive, } \\
\text { isohyperthermic, Typic } \\
\text { Haplustalfs }\end{array}$ & $\begin{array}{l}\text { Chromic } \\
\text { Luvisols }\end{array}$ & iandstone & well drained & $\begin{array}{l}\mathrm{cl} \\
\mathrm{scl} \\
\mathrm{sl}\end{array}$ & $\begin{array}{l}2 \\
1 \\
7\end{array}$ \\
\hline 11 & Ds & Dan Sai & $\begin{array}{l}\text { Fine-loamy, kaolinitic, } \\
\text { isohyperthermic, Typic } \\
\text { Kandiustults }\end{array}$ & $\begin{array}{l}\text { Haplic } \\
\text { Acrisols }\end{array}$ & iandstone & well drained & $\mathrm{scl}$ & 2 \\
\hline 12 & Lk & Lom Kao & $\begin{array}{l}\text { Fine- } \\
\text { loamy,mixed,semiact, iso } \\
\text { Typic (Aquic) } \\
\text { Paleustults }\end{array}$ & $\begin{array}{l}\text { Haplic } \\
\text { Acrisols }\end{array}$ & $\begin{array}{l}\text { Jld } \\
\text { alluvium }\end{array}$ & $\begin{array}{l}\text { somewhat } \\
\text { poorly } \\
\text { drained }\end{array}$ & $\begin{array}{l}\mathrm{cl} \\
\mathrm{scl} \\
\mathrm{sl}\end{array}$ & $\begin{array}{l}2 \\
1 \\
4\end{array}$ \\
\hline 13 & $\mathrm{Pe}$ & Petchaboon & $\begin{array}{l}\text { Fine-loamy,mixed, } \\
\text { isohyperthermic, Ultic } \\
\text { Paleustalfs }\end{array}$ & $\begin{array}{l}\text { Chromic } \\
\text { Luvisols }\end{array}$ & $\begin{array}{l}\text { Jld } \\
\text { alluvium }\end{array}$ & well drained & $\mathrm{cl}$ & 5 \\
\hline 14 & Wi & Wang $\mathrm{Hi}$ & $\begin{array}{l}\text { Fine, mixed, active, } \\
\text { isohyperthermic, } \\
\text { Oxyaquic (Ultic) } \\
\text { Paleustalfs }\end{array}$ & $\begin{array}{l}\text { Haplic } \\
\text { Luvisols }\end{array}$ & Shale & $\begin{array}{l}\text { moderately } \\
\text { well drained }\end{array}$ & $\mathrm{cl}$ & $\begin{array}{l}20 \\
6\end{array}$ \\
\hline 15 & Bpo & Ban Phot & $\begin{array}{l}\text { Very fine, smectitic, } \\
\text { isohyperthermic, } \\
\text { (Chromic) Ustic } \\
\text { Epiaquerts }\end{array}$ & $\begin{array}{l}\text { Pellic } \\
\text { Vertisols }\end{array}$ & $\begin{array}{l}\text { Recent } \\
\text { alluvium }\end{array}$ & $\begin{array}{l}\text { very poorly } \\
\text { drained }\end{array}$ & $\mathrm{cl}$ & $\begin{array}{l}2 \\
3\end{array}$ \\
\hline 16 & So & Sop Prap & $\begin{array}{l}\text { Fine, smectitic, } \\
\text { isohyperthermic, Lithic } \\
\text { Haplustolls }\end{array}$ & $\begin{array}{l}\text { Haplic } \\
\text { Kastanozems }\end{array}$ & Andesite & well drained & $\mathrm{cl}$ & 1 \\
\hline 17 & $\mathrm{Cg}$ & Ching Kong & $\begin{array}{l}\text { Very fine, kaolinitic, } \\
\text { isohyperthermic, Typic } \\
\text { Kandiustox }\end{array}$ & $\begin{array}{l}\text { Haplic } \\
\text { Ferralsols }\end{array}$ & Andesite & well drained & $\mathrm{cl}$ & 10 \\
\hline 18 & $\mathrm{RL}$ & Rock land & Rock land/Rock outcrop & - & $\begin{array}{l}\text { Shale, } \\
\text { siltstone, } \\
\text { Sanstone }\end{array}$ & - & - & 4 \\
\hline
\end{tabular}

Remark: $\mathrm{cl}=$ clay loam, $\mathrm{gcl}=$ gravelly clay loam, $\mathrm{l}=$ loam, $\mathrm{RL}=$ Rock land + Rock out crop, $\mathrm{scl}=$ sandy clay loam, $\mathrm{sgcl}=$ slightly gravelly clay loam, $\mathrm{sic}=$ silty clay, sicl=silty clay loam, sil=silt loam and $\mathrm{sl}=$ sandy loam and $\mathrm{RL}=$ Rock land. 


\subsubsection{Inference model}

The selected method is the Soil Inference Engine (SIE) using fuzzy logic, based on the soil-environmental model as $\mathrm{S}=f(\mathrm{E})$ (Shi, 2013). This model states that information about a soil (S) can be derived from information about the soil formative environment (E), including its topography and lithology. Thus, only topography and lithology parameters were used for mapping soil series and topsoil texture. Although climate plays a role in soil formation, it is not easy to incorporate it in the model. Land use change (thus vegetation change) can have influence on changes in soil properties such as bulk density, porosity, etc. but these properties are generally not mapped during conventional soil survey. A rule-based reasoning (RBR) inference method was implemented for calculating fuzzy membership values using variables such as slope gradient, topographic wetness index and lithology for each soil series

\subsubsection{Rule based reasoning (RBR)}

In this study, the RBR was selected for mapping 17 soil units ( 16 series and 1 rock land: RL). To prepare data layers and create rules, the three environmental covariables (e.g. lithology, slope gradient and compound topographic index), were added to inference engine. The 17 soil units were also added in the rulebase. The RBR was created based on soil-landscape relationships and associated environmental conditions e.g. a specific soil type is more likely to occur in specific conditions (Table 4.2). The values of the environmental covariates and ranges associated with each soil map class (rules) are used to define membership functions, which in turn are referred to as optimality functions as they define the relationships between the values of an environmental feature and a soil type. Fuzzy membership value is assigned by calculating the similarity of a test location to the reference soil types, which means a test location is assigned a set of similarity values. The fuzzy membership formulated by Shi ( 2013), is calculated as followed:

$$
\mathrm{S}_{\mathrm{ij}}^{\mathrm{k}}=\underset{\mathrm{g}=1}{\mathrm{n}}\left\{\underset{\mathrm{T}=\mathrm{l}}{\mathrm{n}}\left\{\mathrm{P}_{\mathrm{g}, \mathrm{a}}^{\mathrm{m}}\left(\mathrm{Z}_{\mathrm{ij}}, \mathrm{Z}_{\mathrm{g}, \mathrm{a}}\right)\right]\right\}
$$

Where, $S i j, k$ is the fuzzy membership value at location $(\mathrm{i}, \mathrm{j})$ for soil $k . m$ is the number of environmental features used in the inference. $n$ is the number of instances for soil series $k$. Zij, $a$ is the value of the $\mathrm{a}^{\text {th }}$ environmental feature at location $(i, j) . Z g, a$ is the most optimal range given by instance $g$, defining the most favouring condition of feature $a$ for soil $k . E$ is the function for evaluating 
the optimality value at the environmental feature level. $P$ is the function for evaluating the fuzzy membership at the instance level, $T$ is the function for deriving the final fuzzy membership value for soil $\mathrm{k}$ at site $(i, j)$ based on all the instances for soil $k$.

The values of the environmental covariates and ranges associated with each soil map class (rules) are used to define membership functions, which in turn are referred to as optimality functions as they define the relationships between the values of an environmental feature and a soil type. The verification and rule adjustment process were repeated multiple times. This results in a number of individual soil class maps based on the fuzzy membership.

Table 4.2 Fuzzy membership function construction

\begin{tabular}{cccc}
\hline & \multicolumn{3}{c}{ Membership } \\
\cline { 2 - 4 } Series names & & & \\
& Lithology & Slope \% & CTI \\
\hline Bpo (Ban Phot) & 1 & $<2$ & $7-8$ \\
Cg (Ching Kong) & 3 & $3-35$ & $<3$ \\
Cm (Chiang Mai) & 1 & $<3$ & $3.5-7$ \\
Ct (Chaturat) & 6 & $1-5$ & $1.5-3.2$ \\
Ds (Dan Sai) & 4 & $6-30$ & $0.5-3$ \\
La (Lamsak) & 1 & $<1$ & $4.5-9$ \\
Li (Li) & 5 & $4-30$ & $0.5-2.5$ \\
Lk (Lomkao) & 2 & $<2.5$ & $4.5-5.5$ \\
Ncu (Nam Chun) & 2 & $1-5$ & $5.5-8$ \\
Pe (Petchaboon) & 2 & $5-12$ & $2.5-4.5$ \\
Png (Phon Ngam) & 4 & $2-10$ & $1.8-3$ \\
So (Sop Prap) & 3 & $3-12$ & $2-4$ \\
Tl (Tha Li) & 3 & $5-25$ & $1.5-3.5$ \\
Tn (Tha Phon) & 1 & $<2$ & $6-12$ \\
Wi (Wang Hai) & 5 & $2-12$ & $2-4$ \\
Ws (Wangsa pung) & 5 & $4-20$ & $2-4$ \\
RL (Rock land) & 6 & $>19$ & $2-3$ \\
\hline
\end{tabular}




\subsubsection{Hardening}

After the creation of individual soil class maps the next step is the creation of the final soil map. Final map was created by combining the individual maps where each soil series or soil texture class map was aggregated to create a hardened or "defuzzified" map by assigning each pixel of the soil series or texture class map with the highest fuzzy membership value at a given location. After the hardening process isolated pixels or pixel in small clusters were merged into their surrounding patches, effectively creating larger patches of pixels with contiguous identical values (Shi, 2013).

\subsubsection{Uncertainty}

From the hardening process, two uncertainty layers e. g. "ignorance" and "exaggeration" uncertainty are calculated. The explanations of the uncertainty layers are explained by Zhu (1997b). The ignorance uncertainty in a given location $\left(\mathrm{H}_{\mathrm{ij}}\right)$ is calculated as the relative sum of memberships to the classes 1 $\mathrm{n}$ as:

$$
H_{i j}=-\left[\frac{1}{\log _{e} n} \sum_{k=1}^{n}\left[\left(S_{i j}^{n k}\right) \log _{e}\left(S_{i j}^{n k}\right)\right]\right.
$$

where, $S_{i j}{ }^{k}$ is the fuzzy membership value of soil type $k$ at a given location $(\mathrm{i}, \mathrm{j})$, and $n$ is the total number of soil types. The higher the entropy value at a location, the higher the uncertainty caused by the hardening process. With an equal membership to all classes (no preference) the value of ignorance is 1.0.

The exaggeration uncertainty $\left(E_{\mathrm{ij}}\right)$ is calculated as the residual value after the hardening has been done (to class ' $\mathrm{g}$ '):

$$
\mathrm{E}_{\mathrm{ij}}=\left(1-\mathrm{S}_{\mathrm{ij}}{ }^{\mathrm{g}}\right)
$$

The higher the exaggeration value, the higher the uncertainty caused by the hardening process. With 17 classes, the maximum uncertainty is obtained if there is an equal membership to all classes $(1 / 17=0.0588)$ in which case the exaggeration is $0.941(1-0.059)$.

\subsubsection{Evaluation of the prediction performance}

The soil series and soil texture maps derived from fuzzy method was assessed and compared with the conventional soil map prepared using field survey .An error matrix was used to evaluate the accuracy of the result. For this purpose, a separate data set consisting of 167 soil observation points was collected in 35 soil mapping units: SMU). The soil mapping units fall within the six landscape units and seven geological units) described in section 4.2.2 and 4.2.3. 


\subsection{Results and discussion}

\subsubsection{Soil predictor variables}

\subsubsection{Lithology}

To see the distribution of soils in relation to lithology types (1. recent alluvium, 2. old alluvium, 3 . andesite, 4 , sandstone, 5 . shale and 6 . association of shale and siltstone) the soil series map was overlaid onto the lithology map. The result shows the highest occurrences of Tn series in the lithology type, recent alluvium (9.1\%) and the lowest for Ds series in sandstone (1.7\%) (Figure 4.5).

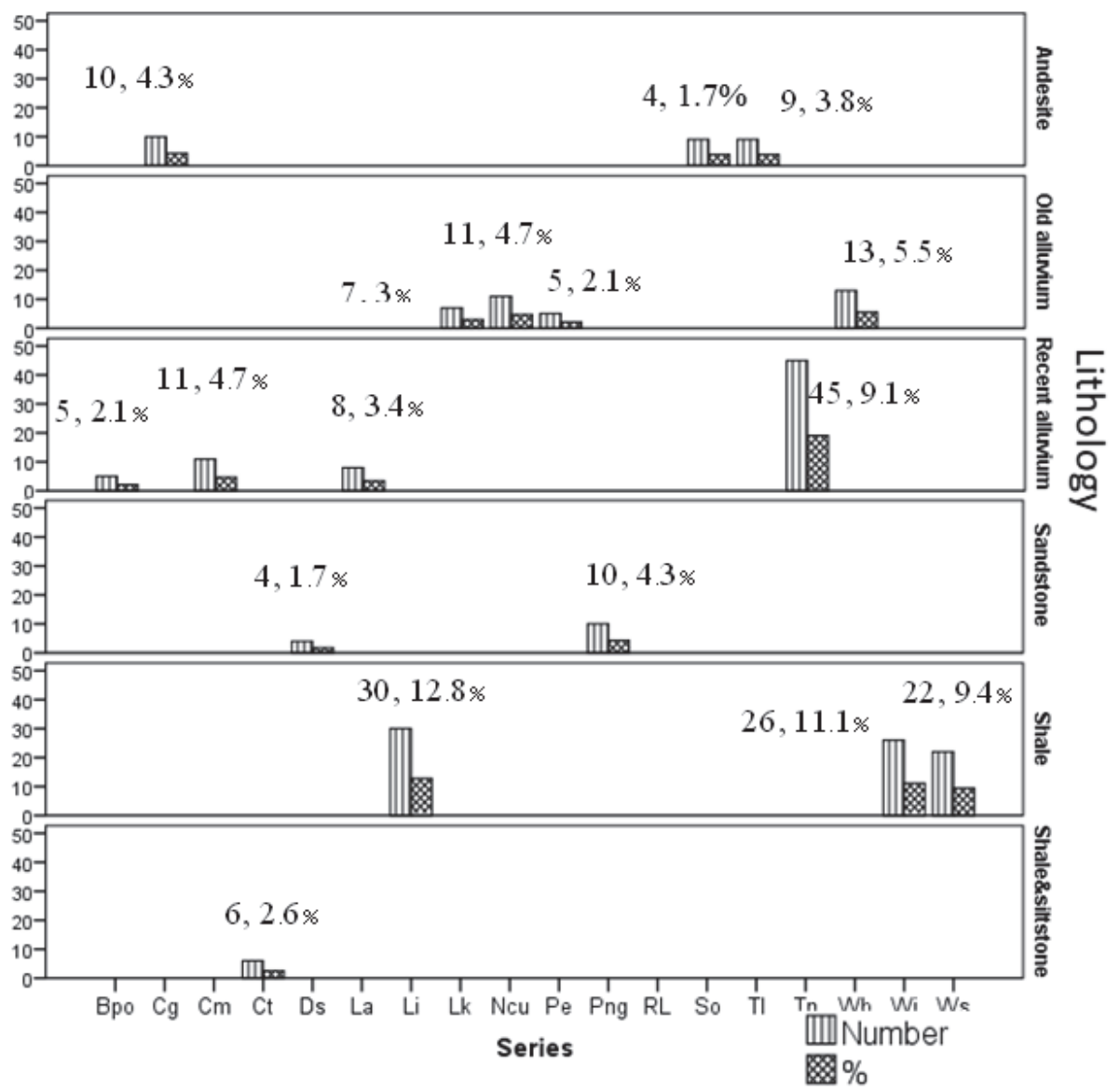

Figure 4.5: Distribution of soil series observations in 7 lithological units, the first bar represents the number of observations and the second bar the percentage of occurrences 


\subsubsection{Terrain parameters}

In Figure 4.6 boxplots of 18 mapping units ( 17 soil series, one Rock land) and two terrain derivatives (CTI and slope) of the Upper Pasak watershed are shown. The boxplots present the differences or similarities in quartile and median of various soil series in each terrain parameters e.g. slope and wetness indices. The least possible overlapping of values is pursued, to better understand the mapping method and to present the distribution of soil series on terrains.

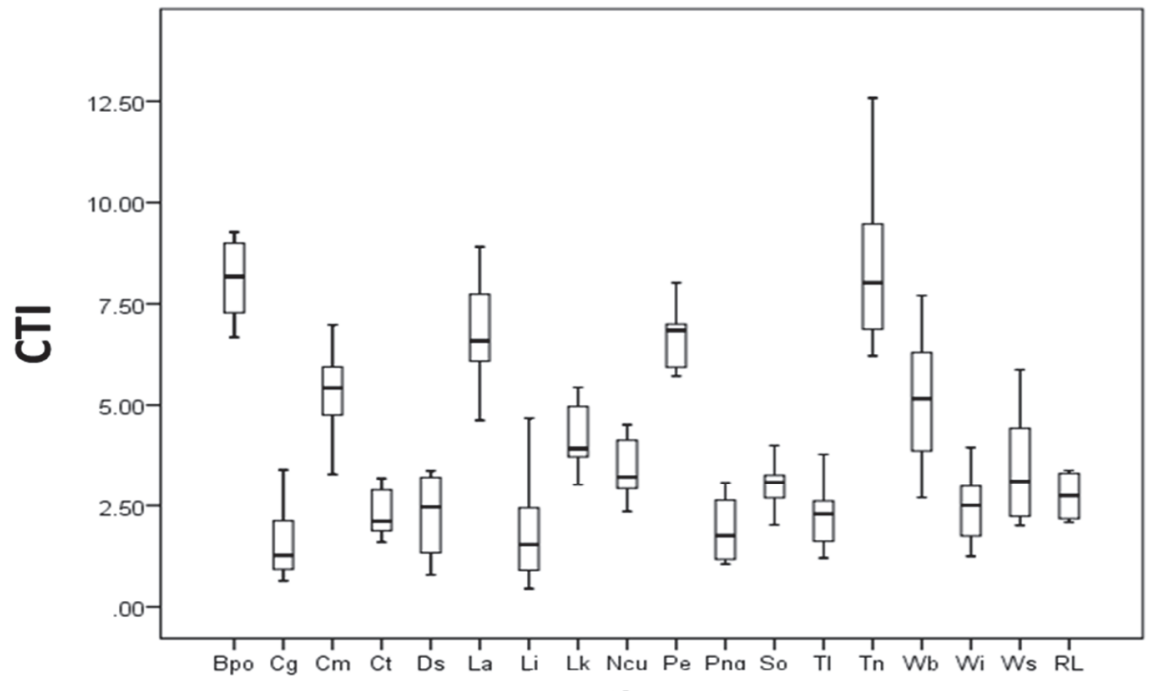

Soil series

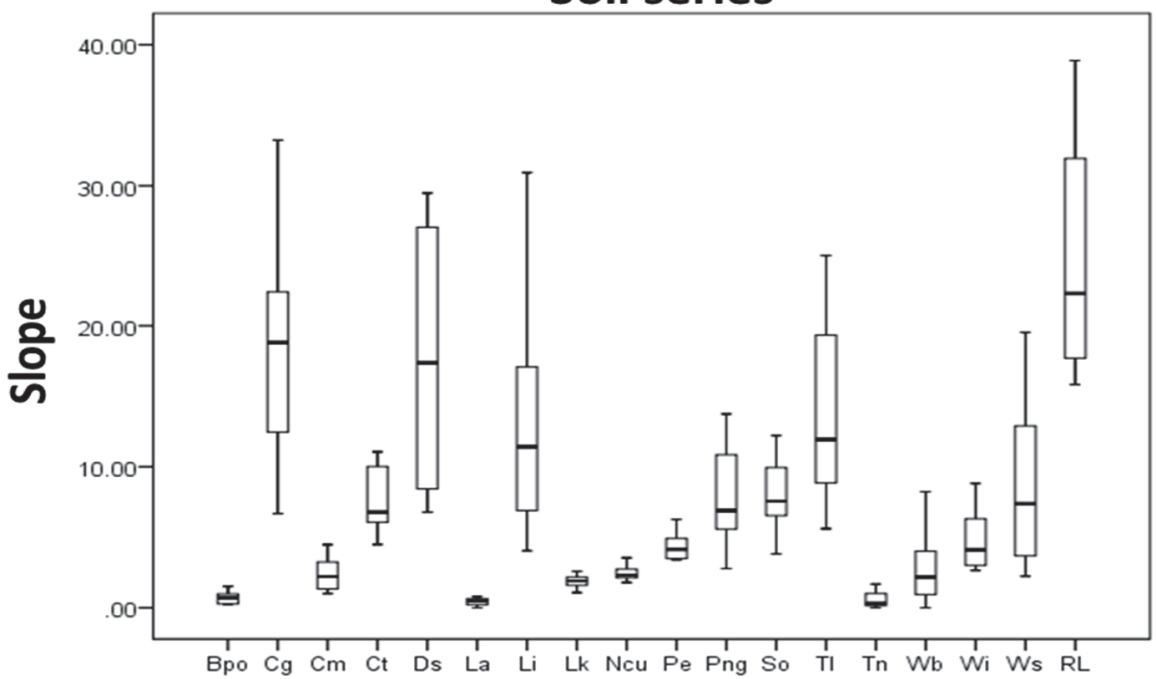

Soil series

Figure 4.6: Boxplot showing the relation of 17 soil series and Rock land (RL), a) Compound topographic index (CTI) and b) slope with a 10x10 m grid cell 
Analyzing the boxplots, some overlapping of ranges in value can be seen in CTI data, although the mean and slope data are well separated for La vs. Ncu as well as La vs. Pe. This is due to the fact that slope setting of each soil series are overlapping but they have different soil drainage, La has slope range of $0-2 \%$ (drainage is somewhat poorly drained and permeability is low), Ncu 1-5\% (drainage is moderately well drained and low permeability) and Pe is $2-8 \%$ with moderately well drained and permeability is estimated to be moderate) (Table 4.3). There is also an overlapping of range in value for CTI and slope data in Wi and Ws series, although the medians are well separated. This is due to the setting of two series which are associated with each other, main setting are very similar such as slope is $2-12 \%$, parent material is residual from fine grain classic rock form over the mountain and hilland, but the difference is the soil drainage class of Wi (moderately well drained) which is higher than Ws (well drained), as Wi is classified to into oxyaquic condition (soil is being saturated with water within $100 \mathrm{~cm}$ of the mineral soil surface for 20 or more days consecutively, or 30 or more days cumulative, in normal years.) in the sub-group level, see also in the table 4.1).

The CTI boxplots for Cg vs. Li vs. Png, Cm vs. Wb, Ct vs. DS, Png vs. RL and RL vs. So series show that some series are overlapping but they are separated in terrain slope. As in the established soil series concept, three soil series $(\mathrm{Cg}, \mathrm{Li}$ and Png), all these soils characteristic have the similar setting in term of the moisture condition of 3 series (drainage is well drained and permeability is moderate), but they are derived from different parent material: $\mathrm{Cg}$ is derived from granite, $\mathrm{Li}$ from shale and Png from sandstone. In the alluvial plain, $\mathrm{Cm}$ and $\mathrm{Wb}$ is overlapping in CTI since they were formed in the same setting, but they are different by parent material (lithology of $\mathrm{Cm}$ is recent alluvium and that of $\mathrm{Wb}$ is old alluvium). The differences between soil series in relation to CTI (topographic wetness) are shown in Table 4.4 where significant differences are indicated in bold when p-value is less than 0.005 . 
Fuzzy logic for fine-scale digital soil mapping

Table 4.3 Statistics of terrain parameters of soil series

\begin{tabular}{llllll}
\hline & & CTI & \multicolumn{3}{c}{ Slope } \\
& Mean & Std & Mean & Std & N \\
\hline Bpo & 8.08 & 1.1 & 0.75 & 0.53 & 5 \\
$\mathrm{Cg}$ & 1.6 & 0.93 & 17.99 & 8.05 & 10 \\
$\mathrm{Cm}$ & 5.37 & 1.12 & 2.42 & 1.32 & 11 \\
$\mathrm{Ct}$ & 2.3 & 0.61 & 7.19 & 2.03 & 6 \\
$\mathrm{Ds}$ & 2.27 & 1.18 & 17.75 & 11.01 & 4 \\
$\mathrm{La}$ & 6.79 & 1.42 & 0.44 & 0.28 & 8 \\
$\mathrm{Li}$ & 1.82 & 1.1 & 14.89 & 7.85 & 30 \\
$\mathrm{Lk}$ & 4.25 & 0.88 & 1.88 & 0.52 & 7 \\
$\mathrm{Ncu}$ & 3.46 & 0.75 & 2.46 & 0.57 & 11 \\
$\mathrm{Pe}$ & 6.7 & 0.92 & 4.44 & 1.19 & 5 \\
$\mathrm{Png}$ & 1.92 & 0.82 & 7.97 & 3.4 & 10 \\
$\mathrm{So}$ & 3 & 0.55 & 7.96 & 2.57 & 9 \\
$\mathrm{Ti}$ & 2.22 & 0.87 & 14.11 & 6.6 & 9 \\
$\mathrm{Tn}$ & 8.41 & 1.79 & 0.52 & 0.52 & 45 \\
$\mathrm{~Wb}$ & 5.15 & 1.55 & 2.83 & 2.41 & 13 \\
$\mathrm{Wi}$ & 2.51 & 0.85 & 4.89 & 2.07 & 26 \\
$\mathrm{Ws}$ & 3.39 & 1.26 & 8.41 & 4.74 & 22 \\
$\mathrm{RL}$ & 2.74 & 0.66 & 24.82 & 10.1 & 4 \\
\hline
\end{tabular}


Table 4.4 Similarity/dissimilarity between soil series in topographic parameter

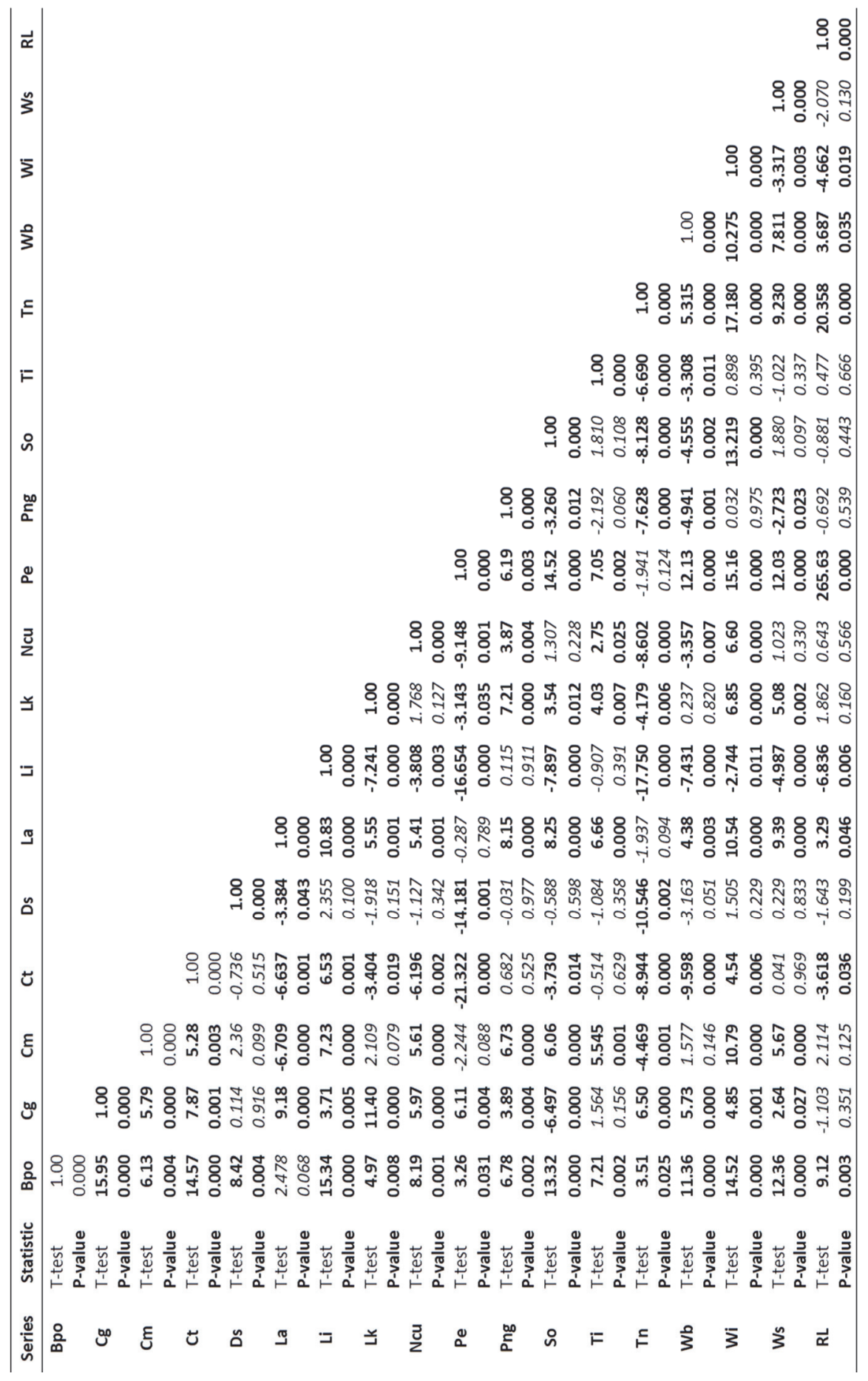


The boxplots of 10 topsoil texture classes with only one miscellaneous type (RL) and terrain derivatives are shown in Fig. 4.7. In the mapping method for topsoil texture with RL unit, the lithology was not used. Only two terrain parameters (wetness index and slope) were used. Analysing the boxplot, some overlapping of range in value can be seen in the CTI data for sic vs. sicl, although the mean is well separated. This is attributed to the fact that silt and clay particles can be easily transported by water from higher position and deposited in the lower position in the landscape. The entire overlapping of CTI data is present, but the mean is well separated in $\mathrm{cl}$ vs. scl and gcl vs. sgc. Also present is the entire overlapping of the CTI but mean and slope are well separated in $\mathrm{gcl}$ and sl. For 1 vs. RL is well separated by slope (Fig. 4.7). 

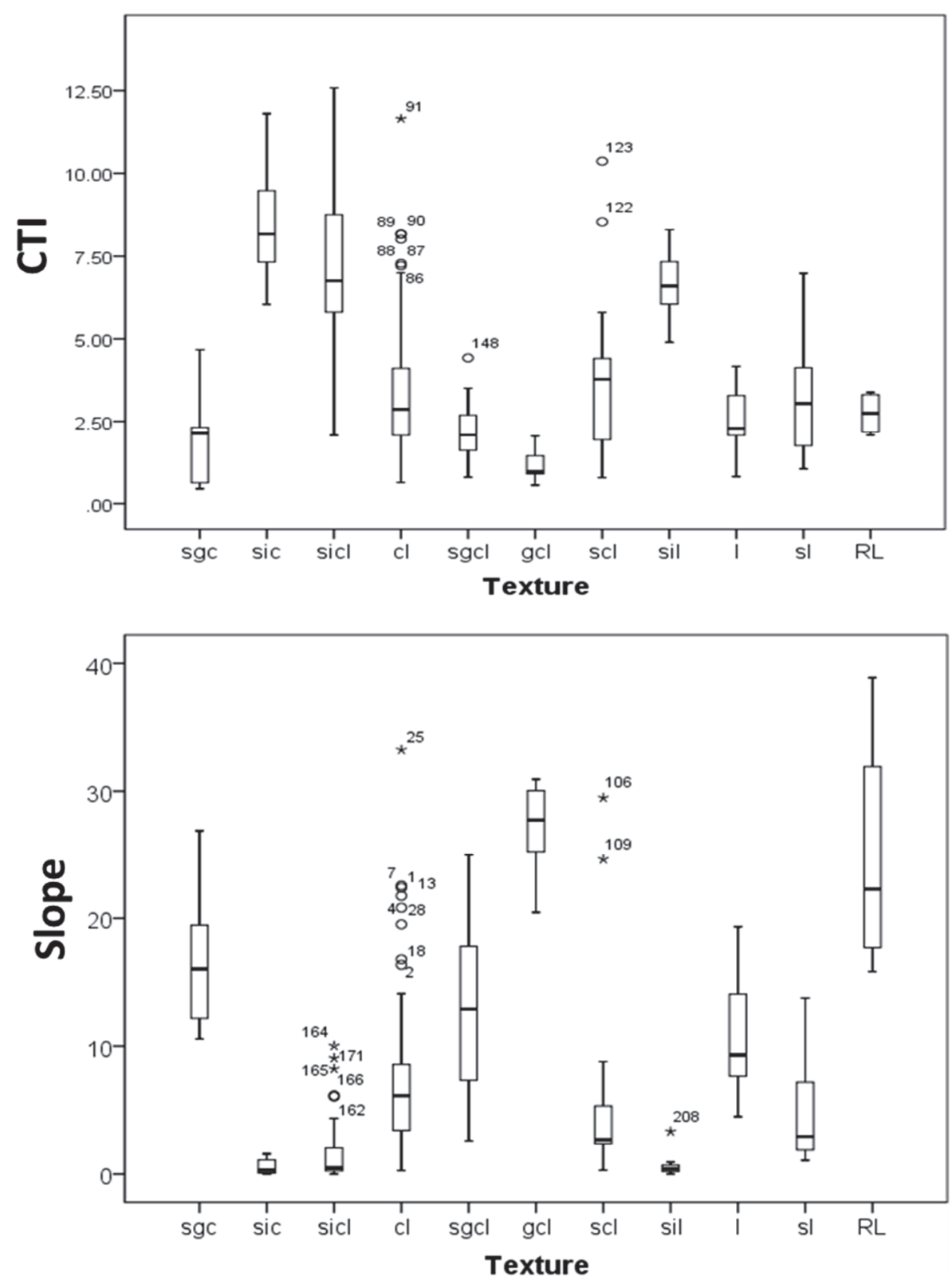

Figure 4.7: Boxplot showing the relation of topsoil texture with: a) slope percent and b) compound topographic index. Where $\mathrm{cl}=$ clay loam, $\mathrm{gcl}=$ gravelly clay loam, $\mathrm{l}=$ loam, $\mathrm{RL}=$ Rock land + Rock out crop, $\mathrm{scl}=$ sandy clay loam, $\mathrm{sgcl}=$ slightly gravelly clay loam, $\mathrm{sic}=$ silty clay, $\mathrm{sicl}=$ silty clay loam, $\mathrm{sil}=$ silt loam and $\mathrm{sl}=$ sandy loam and $\mathrm{rl}=$ Rock land. 


\subsubsection{Predicted soil maps}

\subsubsection{Soil series map}

Figure 4.8 shows an example of the single or individual soil series maps of $\mathrm{Cm}$, Tn, Ws and Wi series. The "hardening" process selects the soil series with the highest fuzzy membership value at a location as the representative soil series at that location. In a result map from hardening, a pixel is only labeled with its representative soil type.

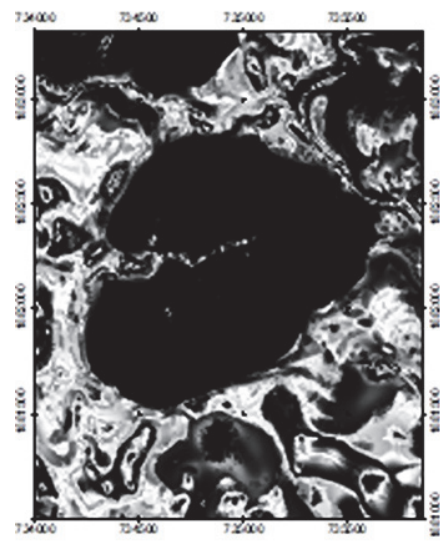

(a)

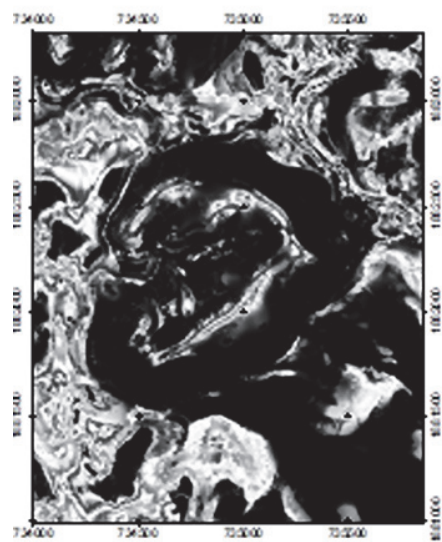

(c)

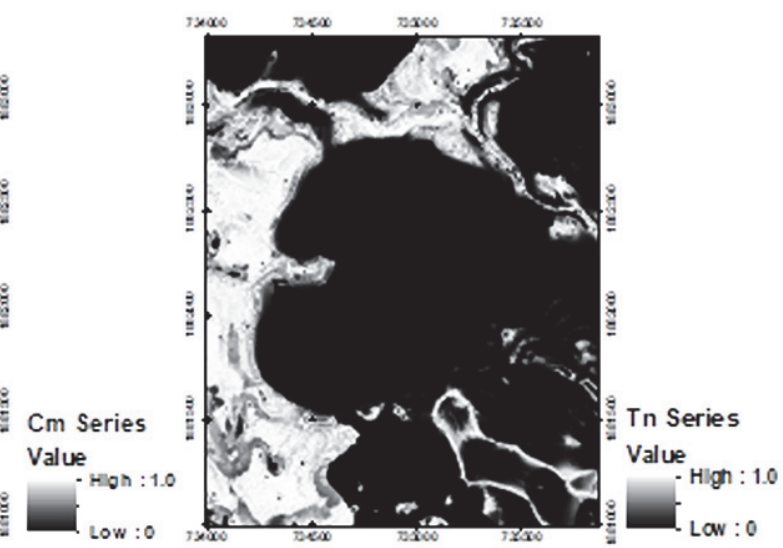

(b)
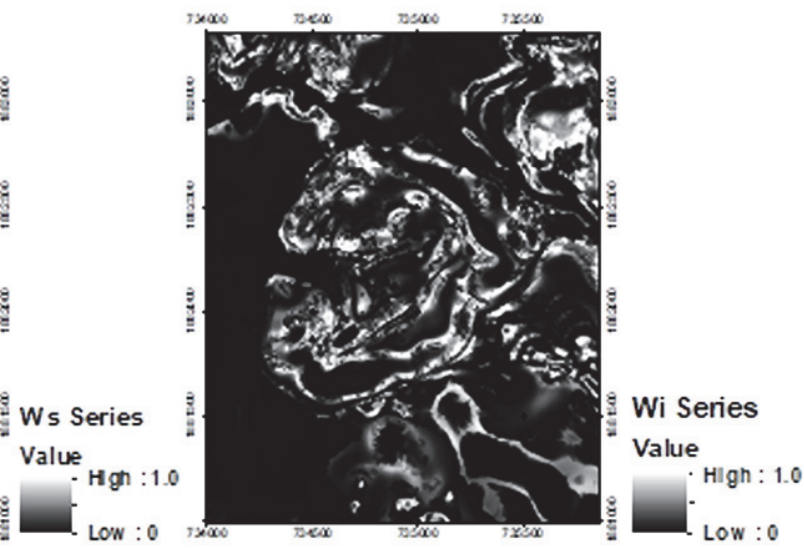

(d)

Figure 4. 8: Examples of normalized membership to individual soil series derived from fuzzy logic: the values show the degree of membership to a given soil series.

The resulting soil series map is based on rule based reasoning (RBR) and hardening classes with the highest fuzzy membership valued to a $10 \times 10 \mathrm{~m}$ grid cell. The result produced significantly detailed spatial resolution of the 
distribution and complexity of soil series, as they occupy the topographical niches in the complex landscape (Figure 4.9). In low lands, such as flood plains, where the lithology is recent alluvium, Bpo, Tn and La series are predominant, but $\mathrm{Cm}$ series was also found along rivers and streams. On terraces, where the lithology is old alluvium, $\mathrm{Pe}, \mathrm{Ncu}, \mathrm{Lk}$ and $\mathrm{Wb}$ were found. In high land areas the lithology plays an important role in soil genesis ( soil series setting): Ds and Png were mainly found in sandstone, $\mathrm{Cg}, \mathrm{Tl}$ and So in andesite, Wi and Ws in shale and $\mathrm{Ct}$ in the siltstone and sandstone association. RL was found covering the ridge and on very steep slopes in the highland area.

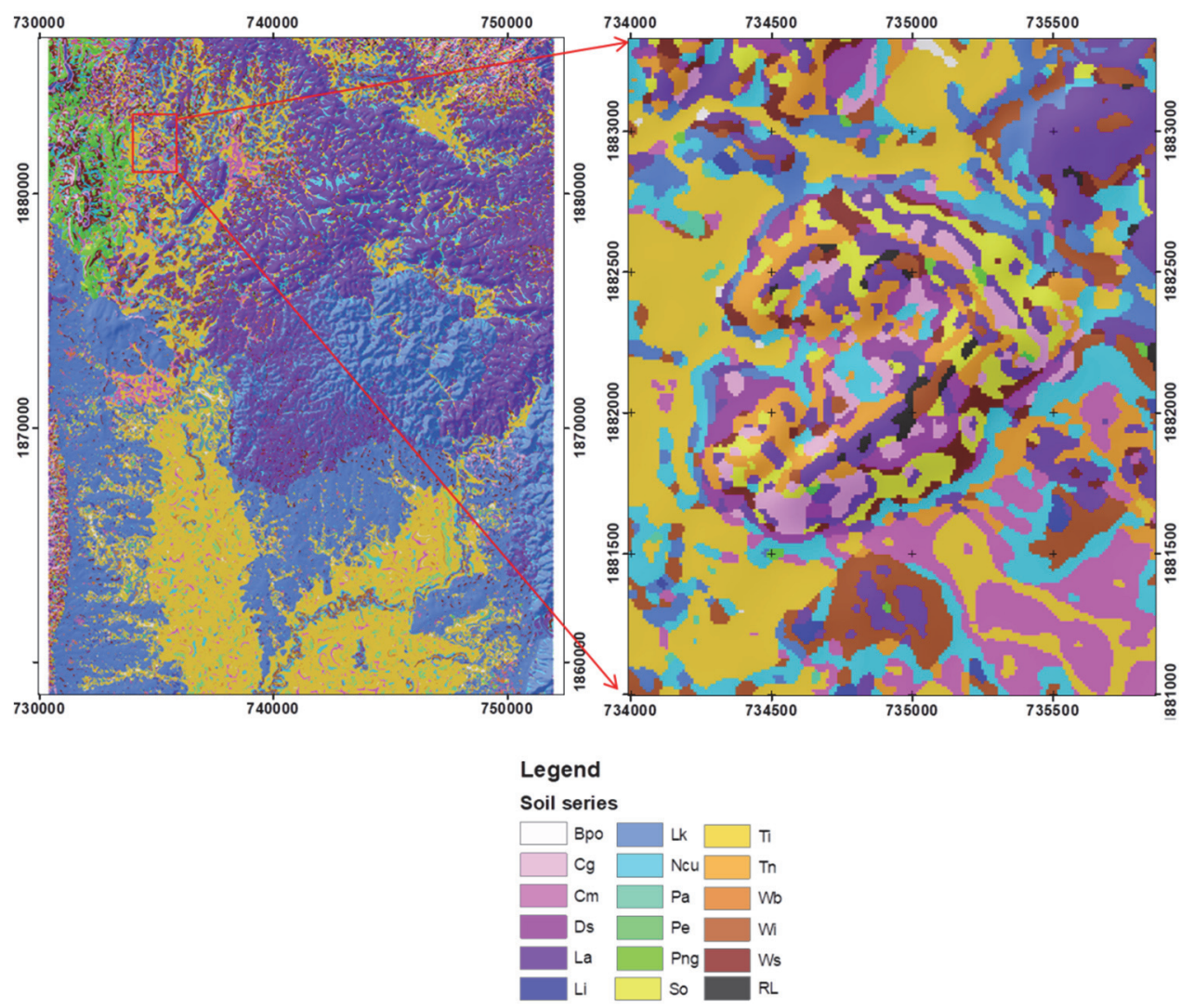

Figure 4.9: Soil series map derived from hardening (defuzzification) with a) hardened map at 1:120,000 map scale and b) enlarged view of area in red box with 1:10,000 map scale

\subsubsection{Topsoil texture map}

Figure 4.10 shows an example of the single or individual topsoil texture maps of sl, sgcl, scl and c. Eleven topsoil texture classes with one miscellaneous unit ( $R L=$ rock land + rock outcrop) are mapped (Figure 4.11). In the low land, such 
as the flood plain, $\mathrm{cl}$, sicl and sicl are predominant. In the terraces, $s g c l$ is common and sgc and $R L$ occur in the highland.

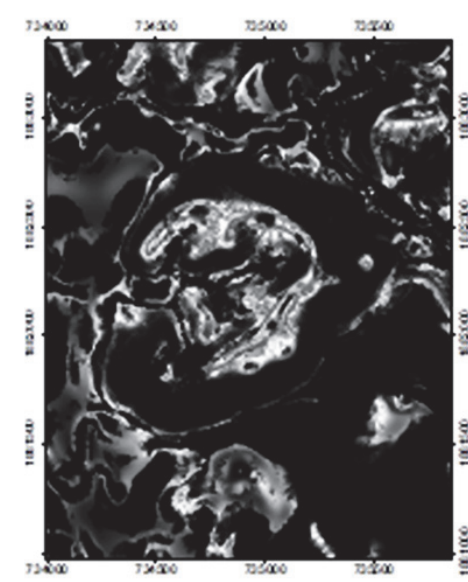

(a)

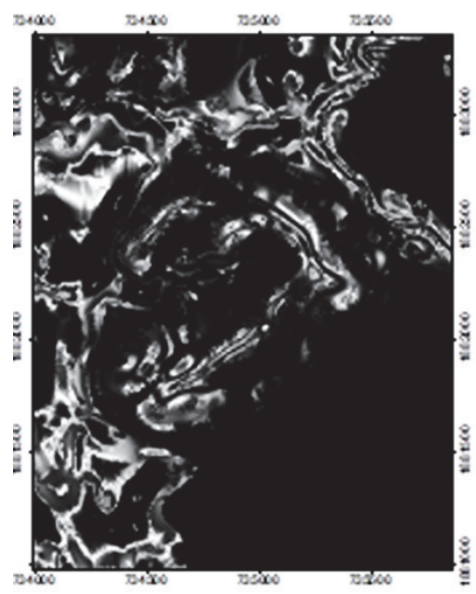

(c)

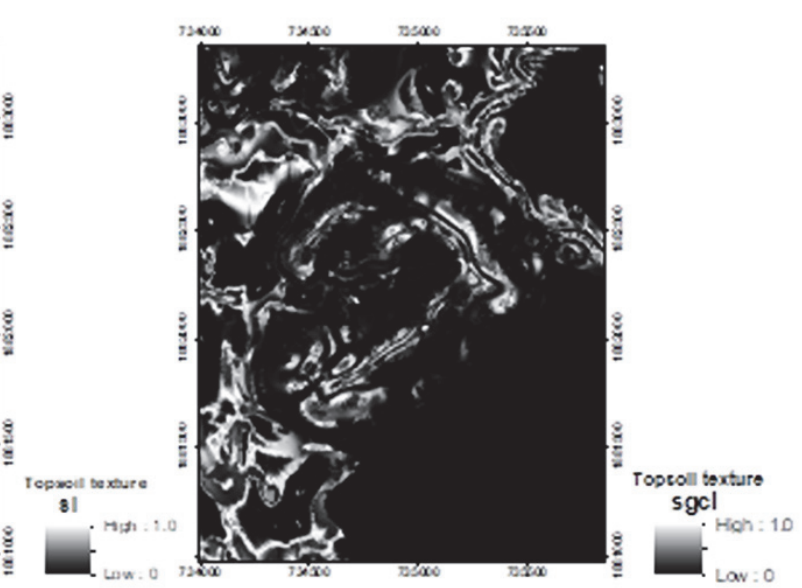

(b)

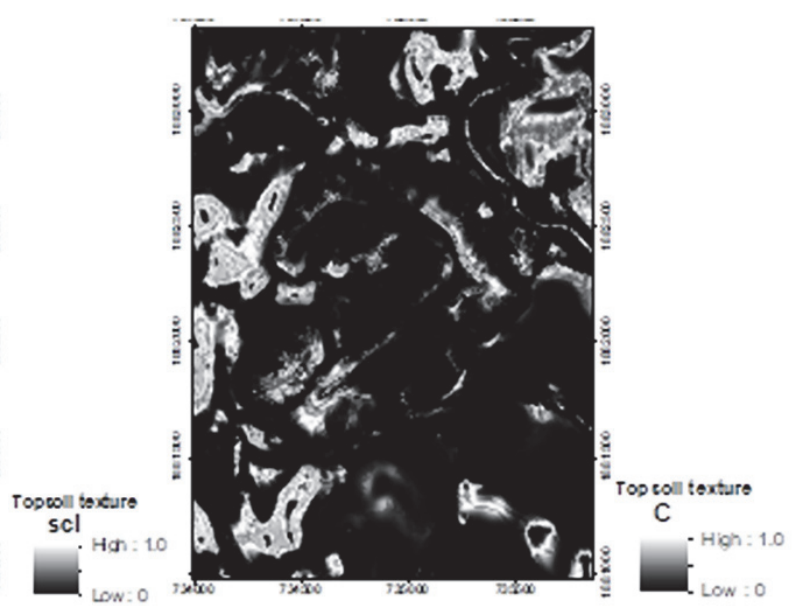

(d)

Figure 4.10: The representative of individual topsoil texture units derived from fuzzy logic: the value is the fuzzy membership to the topsoil texture class $(0-1)$ 


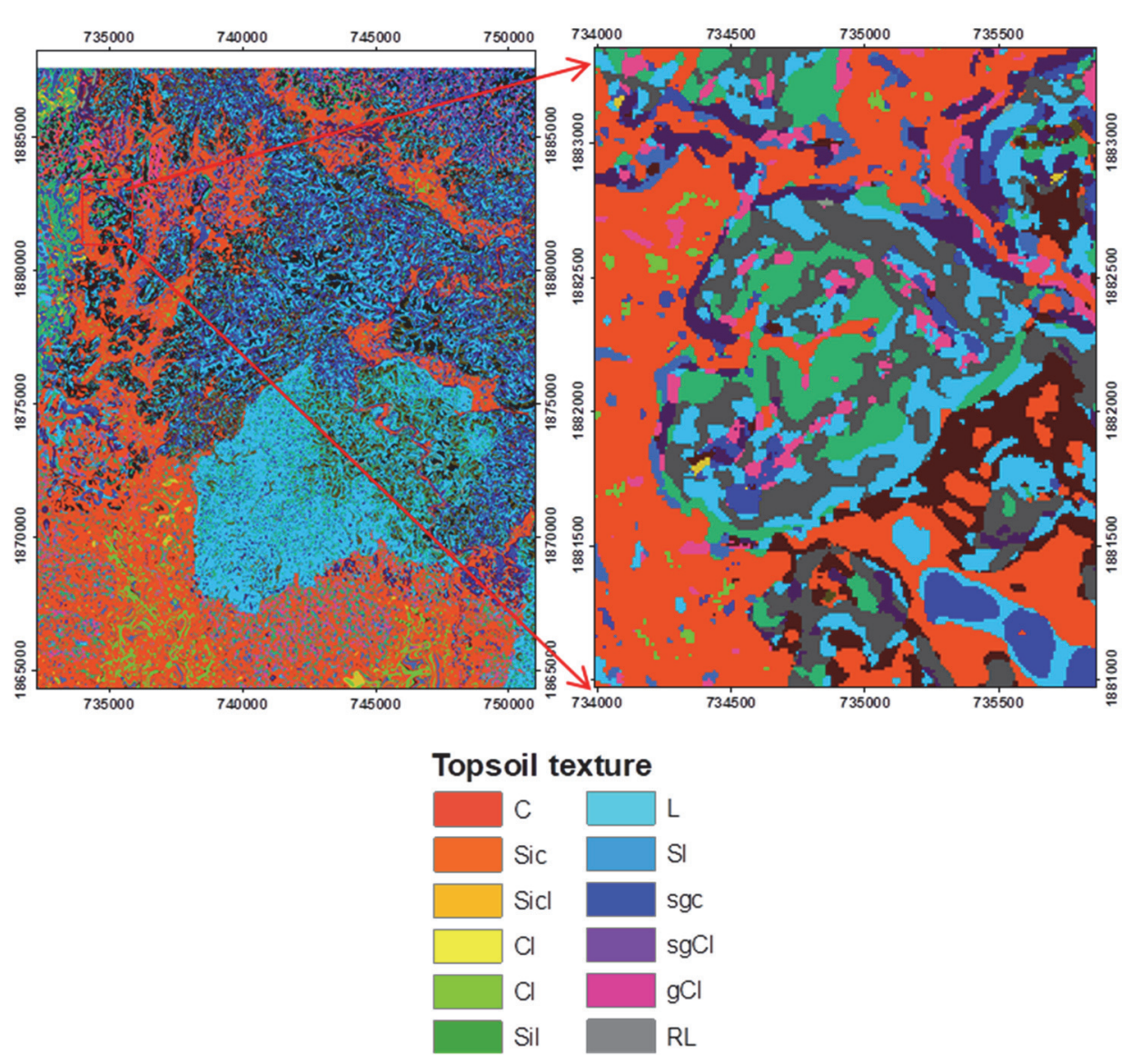

Figure 4.11: Topsoil texture map derived from fuzzy method with a) hardened map enlarged view at 1: 1,000,000 map scale and b) enlarged view of area in red box with $1: 15,000$ map scale

\subsubsection{Accuracy and uncertainty assessments}

\subsubsection{Accuracy assessment of soil series map}

To validate the soil series map inferred by Fuzzy logic, 167 separate soil observations were used. The evaluation data was collected along the main landscape units (see section 4.2.3). The results from the error matrix are shown in Table 4.5. The overall accuracy is $68 \%$. The two mapping units giving the highest accuracy are RL and Ct series, with 100 and $88 \%$ respectively. The accuracy for Ds and Li series varies from 70-80\% (average of 75\%). Bpo, Cg, $\mathrm{Cm}$, La, Lk, Ncu, Pe, Png, Tl, Tn,Wb, Wi and Ws series show accuracy between $60-70 \%$. The lowest accuracy is for the So series, (57\%). 
Both the Bpo and the La series have been found in the same position in the alluvial plain. They both have a fine texture, and differ for their classification at soil order level (Bpo=Vertisols and $\mathrm{La}=\mathrm{Alfisols}$ ) since their morphologic features are different. The order Vertisols of the Bpo series contain a higher clay content (mostly montmorillonite), which causes shrinking and swelling and the formation of cracks. Alfisols contain both kaolinite and montmorillonite and do not show the swelling and shrinking behavior. This difference is not related to the terrain properties and lithology that is used for the procedure in this analysis. The Cg series can be found in the same location as the $\mathrm{Tl}$ and So series, as they are formed from residual granite and andesite, which can be in the same landscape, but the soil depths are different, (Cg is very deep, $\mathrm{Tl}$ is moderately deep and So is shallow). Although there might be a relation between slope steepness and soil depth, this is not found in this analysis. The $\mathrm{Cm}$ and Tn series are both found in the recent alluvium but they differ in particle size classes.

Table 4.5 The error matrix for 17 soil series and one rock land unit derived from fuzzy logic

\begin{tabular}{|c|c|c|c|c|c|c|c|c|c|c|c|c|c|c|c|c|c|c|}
\hline$\frac{\text { Obs. }}{\text { Inf. }}$ & Bpo & $\mathrm{Cg}$ & $\mathrm{Cm}$ & $\mathrm{Ct}$. & Os & $\mathrm{La}$ & $\mathrm{Li}$ & ${ }_{\mathrm{k}}^{\mathrm{L}} \mathrm{Ncu}$ & $\mathrm{Pe}$ & Png & & $\mathrm{Tl}$ & $\operatorname{Tn}$ & $\mathrm{Wb}$ & Wi & Ws & RL & $\begin{array}{l}\text { User's } \\
\text { Accurac } \\
\text { y }\end{array}$ \\
\hline Bpo & 6 & - & - & - & - & 2 & - & - & - & - & - & - & - & - & - & - & - & 75 \\
\hline $\mathrm{Cg}$ & - & 3 & - & - & - & - & - & - & - & - & 2 & 2 & & - & - & - & - & 43 \\
\hline $\mathrm{Cm}$ & - & - & 6 & - & - & - & - & - & - & - & - & - & 1 & - & - & - & - & 86 \\
\hline $\mathrm{Ct}$ & - & - & - & 7 & - & - & - & - & - & 2 & - & - & - & - & - & - & - & 78 \\
\hline Ds & - & - & - & & 6 & - & - & - & - & 2 & - & - & - & - & - & - & - & 75 \\
\hline $\mathrm{La}$ & 2 & - & - & - & & 8 & - & $-\quad-$ & - & - & - & - & 2 & - & - & - & - & 67 \\
\hline $\mathrm{Li}$ & - & - & - & - & - & - & 9 & - & - & - & - & - & - & - & - & 4 & - & 69 \\
\hline $\mathrm{Lk}$ & - & - & - & - & - & - & - & 63 & - & - & - & - & - & 1 & - & - & - & 60 \\
\hline $\mathrm{Ncu}$ & - & - & - & - & - & - & - & 28 & 1 & - & - & - & - & 2 & - & - & - & 62 \\
\hline $\mathrm{Pe}$ & - & - & 1 & - & - & - & - & - & 6 & - & - & - & - & - & - & - & - & 86 \\
\hline Png & - & - & - & 1 & 2 & - & - & - & - & 7 & - & - & - & - & - & - & - & 70 \\
\hline So & - & - & - & - & - & - & - & - & - & - & 4 & 1 & - & - & - & - & - & 80 \\
\hline $\mathrm{Tl}$ & - & 2 & - & - & - & - & - & $-\quad-$ & - & - & 1 & 5 & - & - & - & - & - & 63 \\
\hline $\mathrm{Tn}$ & 2 & - & - & - & - & 2 & - & $-\quad-$ & - & - & - & - & 5 & - & - & - & - & 56 \\
\hline $\mathrm{Wb}$ & - & - & 3 & - & - & - & - & 11 & 3 & - & - & - & - & 6 & 1 & - & - & 40 \\
\hline $\mathrm{Wi}$ & - & - & - & - & - & - & - & $-\quad-$ & - & - & - & - & - & - & 6 & 1 & - & 100 \\
\hline Ws & - & - & - & - & - & - & 3 & - & - & - & - & - & - & - & 2 & 7 & - & 58 \\
\hline $\mathrm{RL}$ & - & - & - & - & - & - & - & $-\quad-$ & - & - & - & - & - & - & - & - & 8 & 100 \\
\hline $\begin{array}{l}\text { roducer's } \\
\text { Accuracy }\end{array}$ & 60 & & 60 & 88 & 75 & $67^{\circ}$ & 75 & 6767 & 60 & 64 & 57 & 63 & 63 & 67 & 67 & 55 & 100 & 68 \\
\hline
\end{tabular}

Remarks: Obs. $=$ Observed soil series and Inf. $=$ Inference soil series 
The accuracy of the soil series map produced by conventional soil survey method was assessed again using the same evaluation data set. The results are shown in Table 4.6. Only 8 map units with total of 31 observations points were defined and matched with the evaluation dataset, the rest are other soil units which are mainly SC (slope complex). In this evaluation, only the consolidation map units were considered. The association map unit as well as the SC units were not assessed. The overall accuracy of $68 \%$ is obtained, with the soil series $\mathrm{Li}, \mathrm{Pe}, \mathrm{Tn}$ and $\mathrm{Wb}$ series having the highest accuracy (100\%). The lowest accuracy of 33\% was obtained for La series, which is mixed with Tn series since booth the soils were formed on recent alluvium. Lk and $\mathrm{Wb}$ series have been set up in old alluvium plain, thus they cannot be separated in coarse scale but can be separated in finer scale.

Table 4.6 The error matrix for conventional soil map with 8 soil series

\begin{tabular}{|c|c|c|c|c|c|c|c|c|c|c|}
\hline Con. & La & $\mathrm{Li}$ & Lk & $\mathrm{Pe}$ & So & TI & $\mathrm{Tn}$ & Wb & other & $\begin{array}{c}\text { User's } \\
\text { Accuracy } \\
(\%)\end{array}$ \\
\hline La & 1 & - & - & - & - & - & 2 & - & - & 33 \\
\hline $\mathrm{Li}$ & - & 5 & - & - & - & - & - & - & & 100 \\
\hline Lk & - & - & 4 & - & - & - & - & 2 & - & 67 \\
\hline $\mathrm{Pe}$ & - & - & - & 2 & - & - & - & - & - & 100 \\
\hline So & - & - & 2 & - & 2 & - & - & 1 & - & 40 \\
\hline TI & - & - & 2 & - & 1 & 2 & - & - & - & 40 \\
\hline Tn & - & - & - & - & - & - & 3 & - & - & 100 \\
\hline $\mathrm{Wb}$ & - & - & - & - & - & - & - & 3 & - & 100 \\
\hline Other & & & - & - & - & - & - & - & 135 & - \\
\hline $\begin{array}{c}\text { Producer's } \\
\text { Accuracy (\%) }\end{array}$ & 100 & 100 & 50 & 100 & 67 & 100 & 60 & 50 & - & 68 \\
\hline
\end{tabular}

The soil map resulting from fuzzy logic shows much more detail information on the occurrence of soil series as compared to conventional soil map (Figure 4.12). For example, most of the mountainous and hilly areas are mapped as slope complex in the conventional soil map, which is not useful information for the users, whereas soil differences are shown in much detail in the resulting map from fuzzy logic. Moreover, the soil mapping units in the conventional soil maps are often soil associations whereas in the soil map derived from fuzzy logic they are mostly consociations (single or individual soil series). 


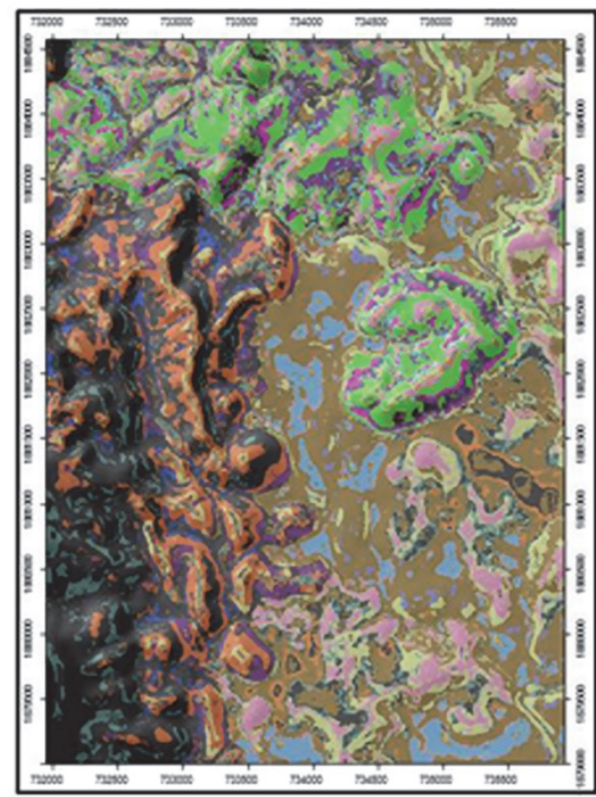

a)

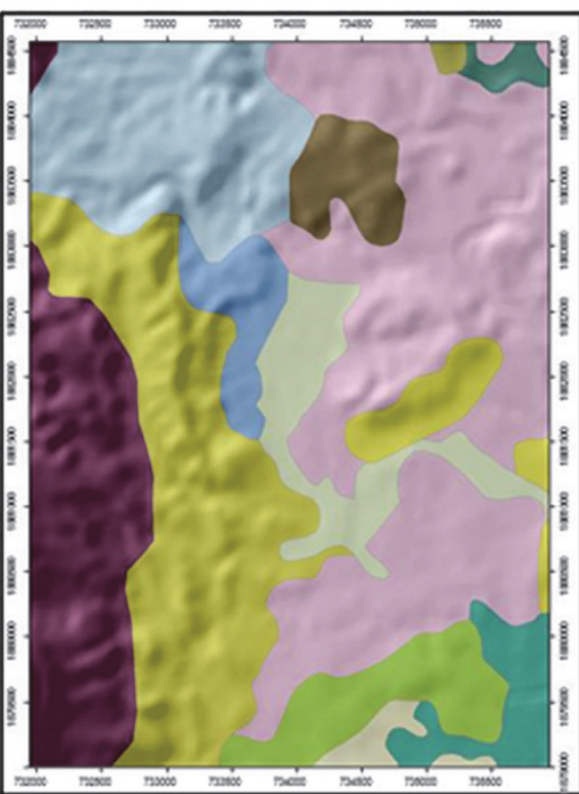

b)

Figure 4.12: Soil series maps based on: a) fuzzy logic, and b) conventional soil mapping

\subsubsection{Accuracy assessment of topsoil texture map derived from fuzzy logic}

To assess the accuracy of topsoil texture map inferred by fuzzy logic, 167 separate set of soil observations was used. The results show overall accuracy of $65 \%$ (Table 4.7). The three mapping units giving the highest accuracy (greater than $80 \%)$ are sic, sgcl and RL. The lowest accuracy is for $\mathrm{cl}(53 \%)$. 
Table 4.7 The error matrix for topsoil texture classes and one miscellaneous unit (RL) derived from fuzzy logic. The first column contains topsoil texture classes from inference results and the first row contains topsoil texture specified by field observation data.

\begin{tabular}{|c|c|c|c|c|c|c|c|c|c|c|c|c|}
\hline $\begin{array}{l}\text { Obs. } \\
\text { Inf. }\end{array}$ & $\mathrm{sgc}$ & sic & sicl & $\mathrm{cl}$ & $\mathrm{sgcl}$ & $\mathrm{Gcl}$ & $\mathrm{scl}$ & sil & I & sl & $\mathrm{RL}$ & $\begin{array}{c}\text { \%Producer's } \\
\text { Accuracy }\end{array}$ \\
\hline$s g c$ & 11 & - & - & - & - & 5 & - & - & - & 1 & - & 65 \\
\hline sic & - & 11 & 4 & - & - & - & - & - & - & - & - & 73 \\
\hline sicl & - & 2 & 11 & - & - & - & - & 3 & - & - & - & 69 \\
\hline$c l$ & - & - & - & 9 & 2 & & 2 & - & 3 & - & - & 56 \\
\hline$s g c l$ & 3 & - & - & 2 & 14 & & 2 & - & - & - & - & 67 \\
\hline$g c l$ & - & - & - & - & - & 8 & - & - & 1 & - & - & 89 \\
\hline$s c l$ & 5 & - & - & 4 & - & - & 11 & - & 2 & 4 & - & 42 \\
\hline sil & - & - & 5 & - & - & - & - & 8 & - & 1 & - & 57 \\
\hline I & 1 & - & - & 2 & - & - & 3 & - & 10 & - & - & - \\
\hline$s l$ & - & - & - & - & - & - & - & - & 2 & 7 & - & - \\
\hline$R L$ & - & - & - & - & - & - & - & - & - & - & 8 & 100 \\
\hline $\begin{array}{l}\text { Producer's } \\
\text { Accuracy }\end{array}$ & 53 & 67 & 56 & 55 & 69 & 88 & 85 & 55 & 73 & 54 & 100 & 64.7 \\
\hline
\end{tabular}

\subsubsection{Uncertainty assessment of the soil series map by fuzzy logic}

The hardened soil series map (Figure 4.9) has an associated uncertainty expressed in the exaggeration and ignorance values. Figure 4.13a and $4.13 \mathrm{~b}$ show the spatial variation of these uncertainties in the study area. An example of spatial variation of ignorance and exaggeration uncertainties during hardening process are shown in Figure 4.14b and Figure 4.14c for the three units shown in Figure 4.14a. The highest similarity of point A Ds series (0.87), with an ignorance uncertainty of 0.56 and the exaggeration uncertainty 0.13 (Table 4.8). The three soil series that give the lowest similarity are Bpo, $\mathrm{Cm}$ and $\mathrm{La}$. The highest similarity for the location B is Ws series (0.96) with an ignorance uncertainty of 0.42 and exaggeration uncertainty 0.04 . Similarly, the highest similarity for location $\mathrm{C}$ is the Ws series $(0.61)$ with ignorance uncertainty of 0.62 and exaggeration uncertainty 0.39 . 

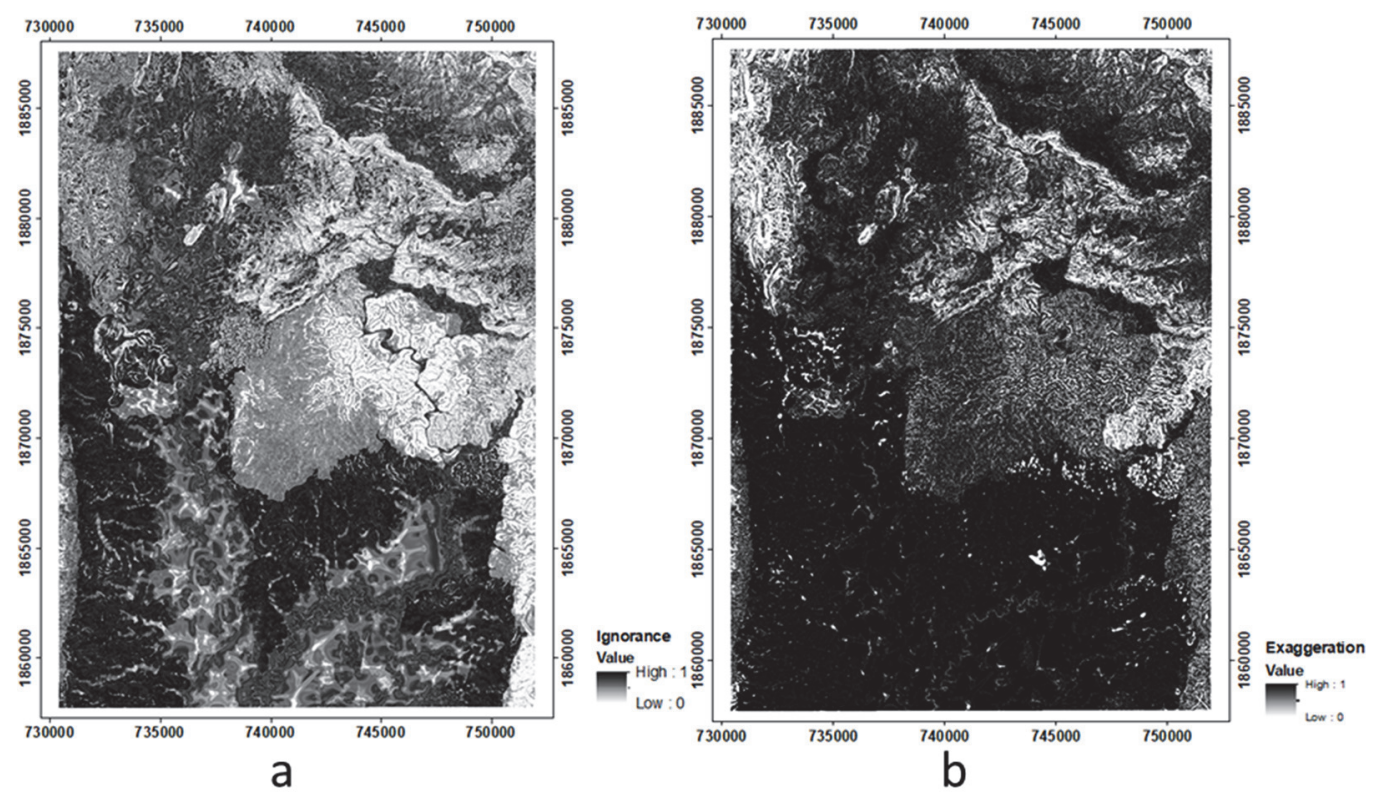

Figure 4.13: Ignorance uncertainty map (a) where low values indicate a low uncertainty, and a high membership to one of the given soil series, and the exaggeration uncertainty map (b)
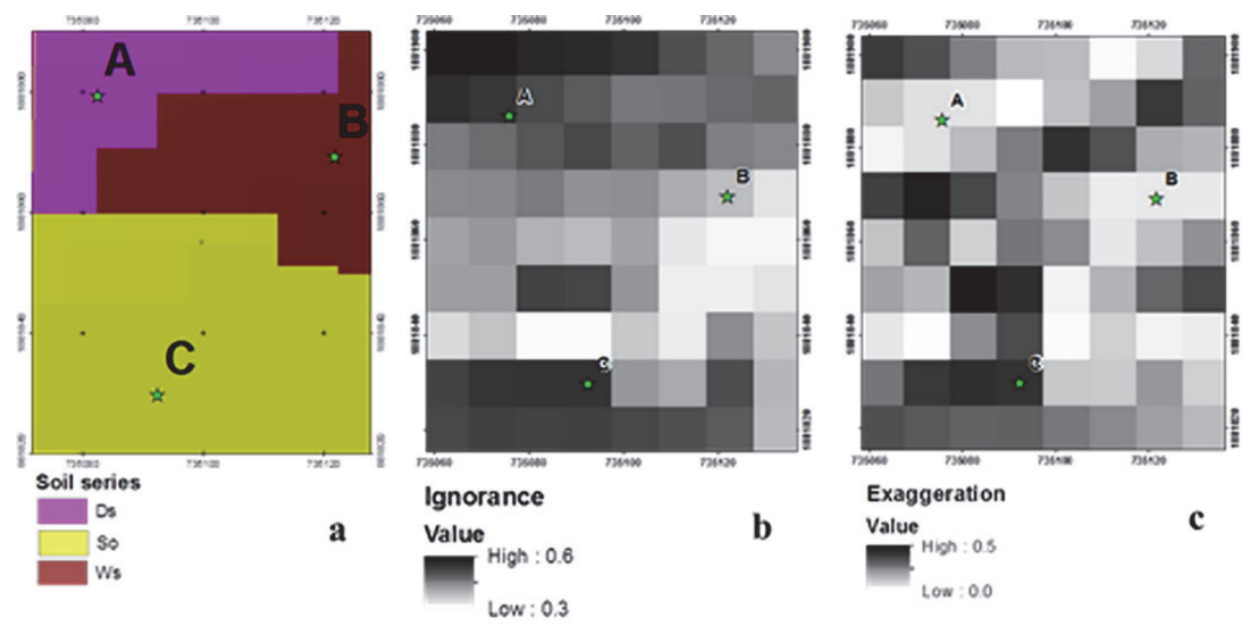

Figure 4. 14: Example of image fragments of result of hardening of three soil serie; Ds, So and Ws (a) uncertainties ignorance uncertainty (b) and exxageration uncertainty (c). 
Table 4. 8 Example of three locations showing membership value of 17 soil series with their final classification and their uncertainty values

\begin{tabular}{crrr}
\hline & \multicolumn{3}{c}{ Membership value } \\
\cline { 2 - 4 } Series & 0 & 0 & 0 \\
& Point A & Point B & Point C \\
Bpo & 0.0449 & 0.0005 & 0.2987 \\
Cm & 0 & 0 & 0 \\
Ct & 0.1844 & 0.1024 & 0 \\
Ds & 0.8745 & 0.0844 & 0.0023 \\
La & 0 & 0 & 0 \\
Li & 0.464 & 0.0857 & 0.2733 \\
Lk & 0.0002 & 0 & 0 \\
Ncu & 0.0104 & 0.0104 & 0.0104 \\
Pe & 0.0003 & 0 & 0 \\
Png & 0.0104 & 0.0104 & 0.1272 \\
So & 0.0439 & 0.2156 & 0.6101 \\
Tn & 0.0005 & 0 & 0 \\
Tl & 0.0064 & 0.0006 & 0.1422 \\
Wi & 0.0002 & 0.0104 & 0.0005 \\
Ws & 0.2448 & 0.9581 & 0.0493 \\
RL & 0.0104 & 0 & 0 \\
\hline Hardening. & Ds $(0.87)$ & Ws $(0.96)$ & So $(0.61)$ \\
Ignorance & 0.56 & 0.42 & 0.62 \\
Exaggeration & 0.13 & 0.04 & 0.39 \\
\hline Uncer & & &
\end{tabular}

\subsubsection{Uncertainties of topsoil texture soil map}

The hardened map of topsoil texture is shown in Figure 4.11. The spatial variation uncertainties in overall area is shown is Figure 4.15a and Figure 4.15b. Figure 16 show the spatial variation of ignorance and exaggeration uncertainty. Table 4.9 shows the fuzzy membership values. The highest similarity of point A is 0.27 for sandy loam $(S l)$ topsoil texture class. At this point, no similarity (value 0 ) to any of the texture classes e.g. $\mathrm{SiC}, \mathrm{L}, \mathrm{sgC}$ and $\mathrm{gCl}$ were noticed. The uncertainties in this location are: ignorance uncertainty of 0.31 and exaggeration uncertainty of 0.73 . At point $\mathrm{B}$, the highest similarity of 0.96 to topsoil texture class slightly gravelly clay loam can be seen. The point has no similarity with a number of texture classes e.g. Sic, $\mathrm{Scl}, \mathrm{Cl}$, Sil, $\mathrm{L}, \mathrm{sgC}$ and $\mathrm{gCl}$. Here the ignorance uncertainty is 0.09 and exaggeration uncertainty is 0.04 . At point $C$, the highest similarity (0.94) to the miscellaneous rock land unit is shown with corresponding ignorance uncertainty of 0.28 and exaggeration uncertainty 0.06 . 
Table 4.9 The variation of soil occurrence probability of 12 topsoil texture in three locations and with their uncertainty values.

\begin{tabular}{crrr}
\hline & \multicolumn{3}{c}{ Membership value } \\
\cline { 2 - 4 } Texture & Point A & Point B & Point C \\
Sic & 0.0104 & 0.0104 & 0.0099 \\
$S i c l$ & 0.0000 & 0.0000 & 0.0000 \\
$S c l$ & 0.0104 & 0.0002 & 0.0000 \\
$C l$ & 0.0029 & 0.0000 & 0.0000 \\
$S i l$ & 0.0103 & 0.0000 & 0.0025 \\
$L$ & 0.0012 & 0.0000 & 0.0000 \\
$S l$ & 0.0000 & 0.0000 & 0.0003 \\
$s g C$ & 0.2657 & 0.0104 & 0.0104 \\
$s g C l$ & 0.0000 & 0.0000 & 0.0514 \\
$g C l$ & 0.0395 & 0.9581 & 0.3422 \\
$R L$ & 0.0000 & 0.0000 & 0.0000 \\
Hardening & 0.0359 & 0.0268 & 0.9369 \\
\hline Ignorance & $S l(0.27)$ & $s g C l(0.96)$ & $R L(0.94)$ \\
\hline Exaggeration & 0.31 & 0.09 & 0.28 \\
& 0.73 & 0.04 & 0.06 \\
\hline
\end{tabular}
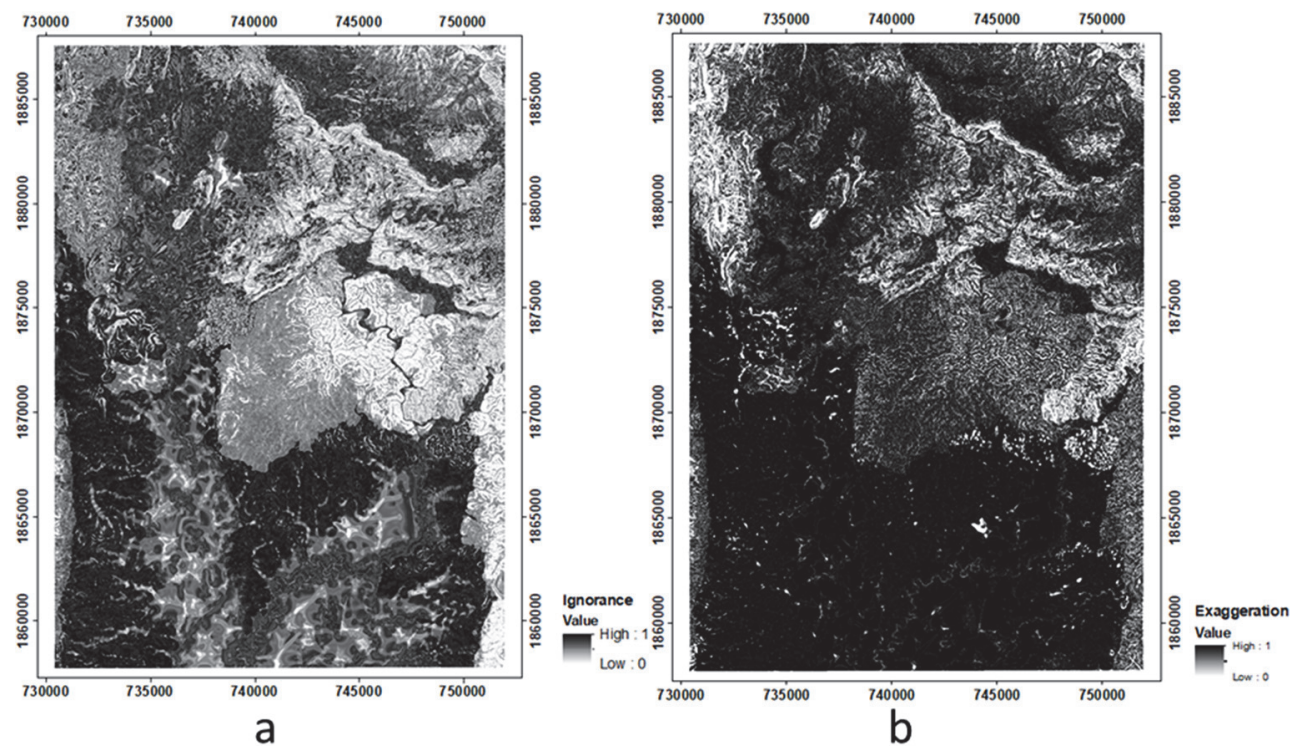

Figure 4. 15: Ignorance uncertainty map of topsoil texture map (a) with light tones indicating low ignorance uncertainty value and exaggeration uncertainty map (b) with light tone is low exaggeration uncertainty 

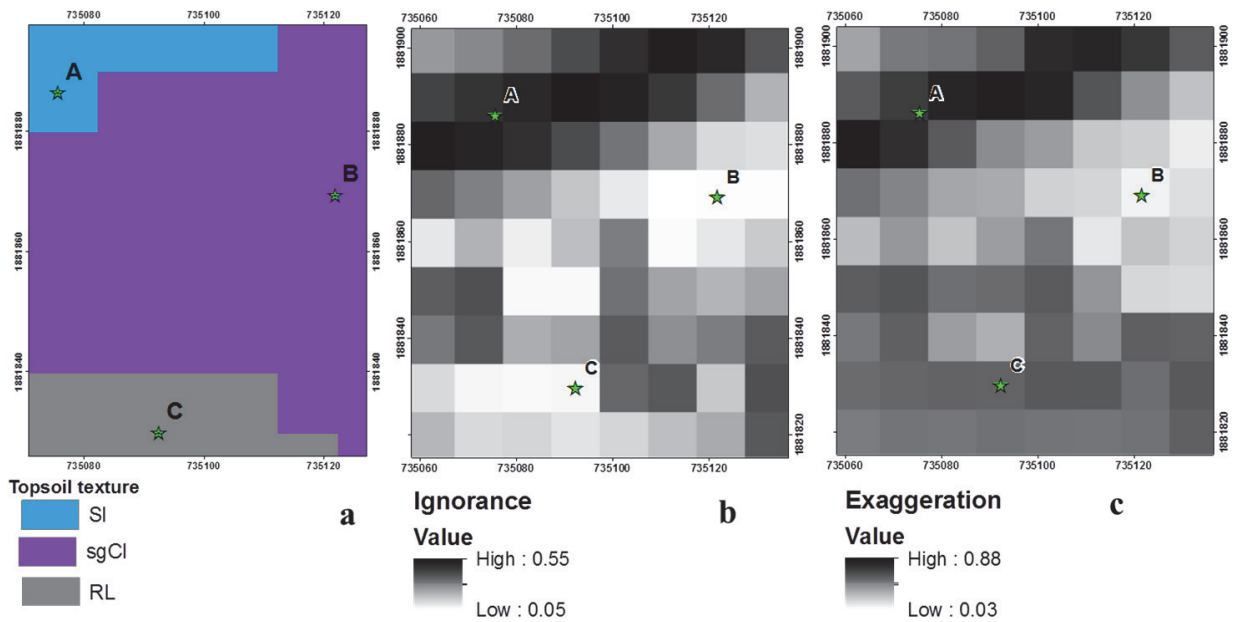

Figure 4. 16: a) Three variation of topsoil texture map units which also includes a miscellaneous rockland unit (RL), b) spacial variation of ignorance uncertainty and c) spatial variation of exageration uncertainty.

\subsubsection{Discussion}

A variety of DSM methods are available, many of the methods uses co-variables which are derived from DEM or remote sensing techniques, and dominated by statistical/data mining/machine learning methods (Hengl et al. 2017) (Sreenivas et al. 2016) (Zeraatpisheh et al. 2019) (Keskin et al. 2019). Since the aim of the study was to help conventional soil resources mapping fuzzy logic was selected as a DSM technique. We aimed at increasing the efficiency of mapping by combining conventional methods with fuzzy logic. Careful selection was done in selecting the co-variables. For application of fuzzy logic in the case study area only the variables, which were considered to have direct influence on soil, were selected. Accordingly, the selected variables were lithology, slope gradient and the compound topographic index or the topographic wetness index. Soil is derived from parent material as a result of soil forming processes, thus lithology certainly plays a central role. Similarly, surface processes e.g. soil denudation and transportation processes are governed by slope, which can be related to shallow soil in the steeply sloping areas and to deeper soil in less steep or flatter areas. The compound topographic index or better known as topographic wetness index can be related to sediment deposition and soil formation resulting in deeper soil. In the study area, the influence of other DEM derivatives such as slope aspect or curvatures on soil variations was considered not to play very important role. Thailand is located in the tropics (below $23^{\circ}$ latitude) and the effect of slope aspect in causing micro-climatic variation due to exposure to sun having effect 
on soil variation is considered not to play major role. Similarly, the study area is characterized by having dominantly gently sloping to flatter areas and with some areas having gently undulating to hilly terrain with steep slopes. Here again, slope curvatures were not used since they were assumed to have not so much effect on soil variations. Since the main objective of the study was on making soil survey more efficient, field survey data were incorporated in the model, which included description of soil, sample collection for laboratory analysis and classification at series level. (Pahlavan-Rad et al., 2016) also reported an increase of DSM model accuracy using legacy soil survey maps as a covariate.

In fuzzy logic, a given location may have multiple fuzzy class membership, their membership is defined by similarity values to the prescribed units, and the elements in a similarity vector do not have to sum to unity since they are not assumed to be mutually exclusive (Zhu, 1997c) (Zhu, 1997a). During the hardening process, the class having the highest fuzzy similarity membership takes the final class label. Final assignment of class label will be perfect when the similarity membership value is clearly very high (close to 1.0 ). In Table 8 , the highest similarity of 0.87 to the soil series Ds is shown for the location point A, with an exaggeration error of 0.13 and ignorance error of 0.52 . The reason for getting high ignorance error is because point $\mathrm{A}$ has also moderately high similarity to soil series $\mathrm{Li}(0.46)$ and to series Ws $(0.24)$. Since the similarity of the location is very high (87\%) to the prescribed soil series (Ds), the unit can be considered being pure. At point B, the similarity to the soil series Ws is even higher $(96 \%)$. In case of point $C$, the highest similarity with a value of 0.61 to the soil series So is shown with an exaggeration error of 0.39 and ignorance error of 0.56 . The location also shows distinct similarity to $\mathrm{Cg}$ series $(0.29)$ and to $\mathrm{Li}$ series (0.27). In this case it may not be appropriate to call it a pure unit but rather an association of $\mathrm{So}, \mathrm{Cg}$ and Li series. When the highest similarity value becomes very low, the validity of the final class labelling will be questionable. In this case, an adaptation in the system will be required, which allows assigning a miscellaneous or a very complex mapping unit by setting up a limit.

Similarly for classifying topsoil texture, the result shows the lowest level of ignorance (0.09) and exaggeration (0.04) uncertainties for labelling the topsoil texture at point B (high similarity value of 0.96 to $\mathrm{sgCL}$ ) (Table 9). In case of point $C$, although the similarity value is very high $(0.94)$ to the rock land class, the ignorance error is 0.28 which is slightly higher than that in point $\mathrm{B}$. This is because the location has also some level of similarity $(0.34)$ to the texture class $\mathrm{sgCL}$. The result shows that ignorance error can be higher even if a given location 
may have very high similarity to the prescribed unit. In case of point A, exaggeration error is quite high (0.73) since the highest similarity value is only 0.27

\subsection{Conclusions and recommendations}

The study shows that fuzzy logic can help in predicting soil series and topsoil texture in more detail. The advantage of using expert knowledge in fuzzy logic is in reducing inconsistency and the number of soil observations, thus effectively making soil mapping more efficient. Using lithology and two terrain parameters (wetness index and slope) as soil predictor variables, the SoLIM fuzzy logic model shows advantages in associating them to the expert field knowledge, in order to produce high quality maps. The results provide detailed information about spatial variations, and represent realistic spatial patterns of the soil series in the study area. In addition, use of fuzzy logic is worthwhile in view of the added level of detail, which can be obtained as compared to the very large and poorly defined units of upland soils (such as "slope complex") in conventional soil mapping. The technique can also be used for mapping soil properties (e.g. topsoil texture) but one has to be careful in selecting the predictor variables: these have to have a conceptual link to the soil forming processes or soil properties under investigation. 


\section{Chapter 5 Modernizing the Thai soil survey}




\subsection{Introduction}

Soil survey is the process of understanding and mapping the distribution of soil types, properties, functions and services on the landscape and presenting this information to clients in maps and reports that they can understand and directly use. In Thailand systematic soil survey is the responsibility of the Land Development Department (LDD), Ministry of Agriculture \& Cooperatives. Soils are an important basis of Thailand's economy, so soil survey, primarily for agriculture, has a long history in the country. With increasing pressure on land and new demands for soil information, soil survey is facing new challenges. In this paper, we present a brief history of soil survey in Thailand, a description of current clients and their needs, organization and survey methods, and current challenges which require a modernization effort, including the introduction of digital soil mapping (DSM) concepts and methods (McBratney et al., 2003).

Soil survey activities were initiated in 1941 before the establishment of the LDD by applying the prevailing American methods (USDA 1938) in promoting the study of soils as a science. A soil course was taught in Kasetsart University as early as 1943, and since 1956students have been able to major in soil science. In 1953, a provisional map of soils and rocks " $1: 2,500,000$ scale reconnaissance soil map" (revised in 1964) was produced at scale by Dr. R. L. Pendelton, a soil scientist from USA and Dr. Saroj Montrakul and Mr. Rerm Buranarerk (as advisors to the Department of Agriculture and Fisheries)the Department of Agriculture and Fisheries (Figure 1-a). This map legend was composed of a small number of soil units, called "series" but described as associations of Great Soil Groups (USDA 1938). The major uses and purpose of this soil map is for broad generations of kinds of soils for broad land class (not more than 3 classes).

The LDD was established in 1963 under the purview of Ministry of National Development with the mandate to systematize and centralize soil survey activities, provide soil information and serve other agencies. In 1964, LDD started a soil survey project jointly with the FAO (Dr. F. R. Moorman) and Kasetsart University (Dr. Santad Rojanasoonthorn). They revised the 1:2,500,000 map and produced a 1:1,000,000 scale general soil map, also of association of Great Soil (1938, amended 1949) (Figure 5.1-b). These maps were aimed at broad-scale land-use planning and education in general soil geography. The soil map and accompanying report are extensively used for education in soil science, broad-scale land use planning, and formulation of land development projects in the country 
In 1979, in response to the first national development plan, a soil map was needed for project planning by government agencies for irrigation, soil conservation, and rural development. The LDD again revised the 1:1,000,000 general soil map (Figure 5.1-c), but with the map units as association of Great Groups which defined in the recentlypublished Soil Taxonomy (Soil Survey Staff, 1975). The map units were modified with dominant particle size class (as defined for soil families), due to the importance of particle size class for many soil properties such as water retention, cation exchange capacity and engineering properties.

In 1983, the LDD was transferred to the Ministry of Agriculture and Cooperatives and became the main organization is responsible for soil survey. Consequently, soil survey became closely associated with agricultural land use planning. The LDD adopted thencurrent American methods (Soil Taxonomy, Soil Survey Manual, Land Capability Classification) under the influence of USDA's Natural Resources Conservation Service international office, led by Dr Hari Eswaran. The main purpose of soil surveys is to benefit agriculture, so interpretations have been made to aid agricultural users. General land capability classes and individual soil suitability ratings for specific crops have been made based on soils, climate and other environmental features as they affect agricultural uses. In other cases, the potential of soils for production in proposed irrigation projects has been evaluated. Information provided by a soil survey is also useful to non-agricultural users such as engineers and architects, but it must be understood that a soil map cannot eliminate the need for sampling and testing soils at the site of specific engineering works. 

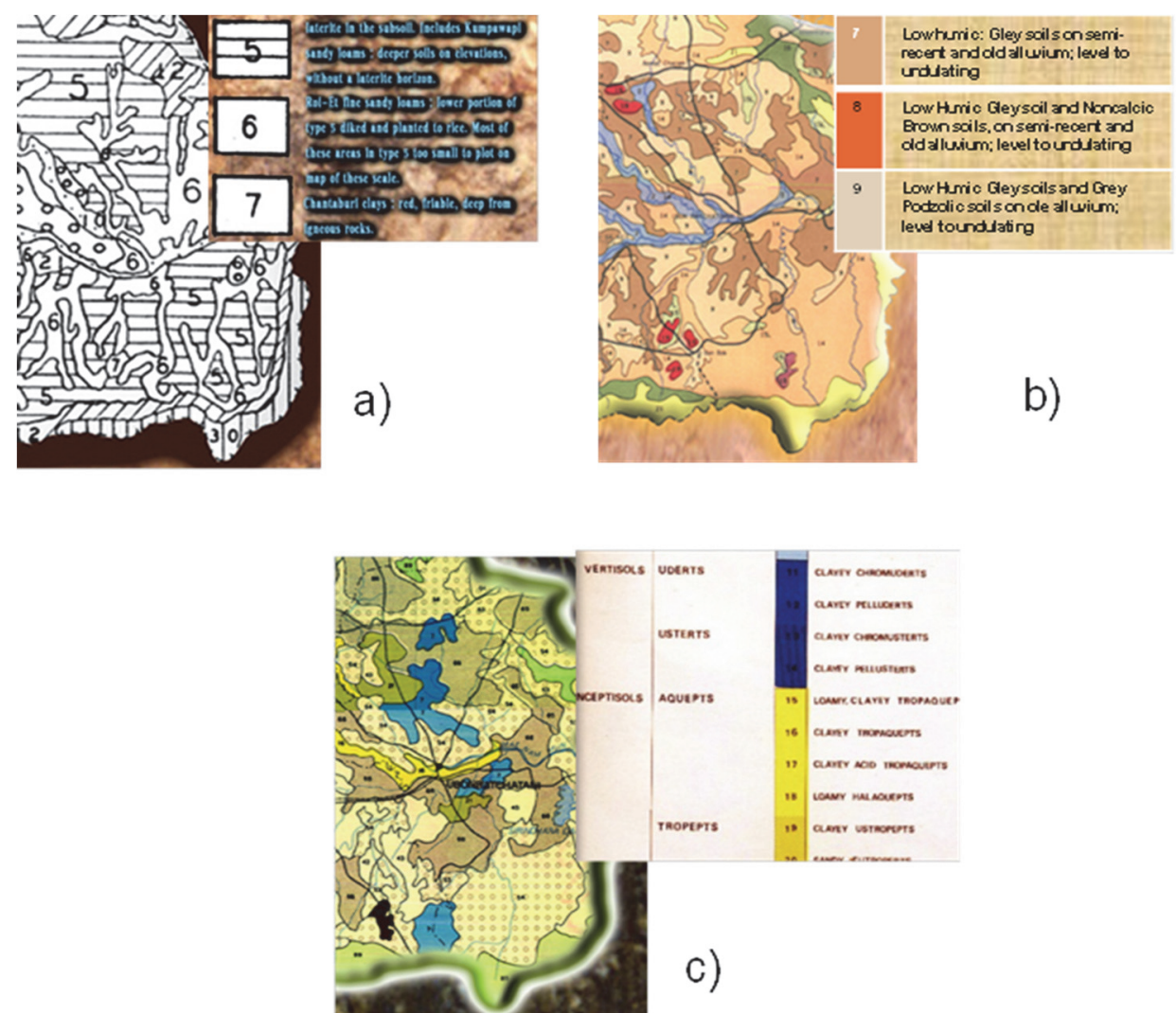

Figure 5. 1 Historical soil maps of Thailand: a) general soil map 1953 at 1:2,500,000 scales, b) general soil map 1964 at 1:1,000,000 scales and c) revised soil map 1979 at $1: 1,000,000$ scales

\subsection{Product generation from soil maps}

The LDD also produces secondary products of soil information extracted from soil maps in tern of a series of GIS-based applications (CD and internet web-service), aimed to transfer and promote a use of soil map to several client's need groups as follows.

In 1995-1996, LDD tried to create a spatial database of the soil resource (soil series map) and search engine program to achieve soil information and displaying soil maps of LDD, therefore the SoilView program was developed and finished covering whole country in 1999. The SoilView: soil map unit definitions, soil properties, and interpretations of the 1: 50,000 maps series for economic crops following the FAO framework for land evaluation (FAO., 1976). 
- In 2001, LDD has developed the ThaiPedon program : typifying pedons of major soil series linked to the 1:50,000 soil maps.

- In 2000, LDD has developed the LandSuit 1.0: physical land evaluation for economic crops (Jasmine rice and maize) based on the 1:100,000 and 1:50,000 soil maps. The resulting display showing the type of land quality and limitation in land use. This can be used to support management decisions to limit crop production according to market demand.

- In 2001, LDD has developed the ErosView: identifies erosion-prone lands from soil properties, land cover, precipitation intensity, and slope. Map units are based on the 1:50,000 soil map.

- In 1999, LDD has developed ConsPlan program : soil and water conservation planning in Land Development villages. Base data is from 1:100,000 and 1:50,000 soil maps.

- FarmPond: Physical Land Evaluation for farm ponds based on the 1:50,000 soil map.

- In 2001, LDD has developed the AgZone program : zoning for 15 economic crops (considered as Land Utilization Types) following the FAO framework for land evaluation (FAO., 1976). Base data is the 1:100,000 and 1:50,000 soil maps, land use / land cover, land units, forest areas, irrigation areas, moisture availability, and distance from processing centres.

In recent years, based on information service of $\mathrm{LDD}$, The application of information technology (IT) and communication network to increase the efficiency of the performance of the Land Development Department (LDD) supports the main processes of the Department to attain good value, to become modern, continuous and up-to-date and the IT can be used for its maximum benefit. This will enable the organization to make decision on the data to solve the occurring problems accurately, quickly and timely, up to varying situations. Several modern search engines of web services and mobile applications have been developed to support in multi-users as follows.

- In 2016, LDD and Ministry Agriculture and Cooperatives have developed the Agri-Map program. Is an agricultural map for online proactive management by integrating basic agricultural information from all agencies under the Ministry of Agriculture and Cooperatives using as a tool to manage Thai agriculture efficiently covers all areas. And to update information and provide the easy access of LDD information with the ability to track changes that has occurred correctly 
around the whole area, covering the use of all important aspects as applying technology to apply to agricultural information which can answer the help and solving problems for Thai farmers in the area as well. Ministry of Agriculture and Cooperatives with the Ministry of Science and Technology by the National Electronics and Computer Technology Center (NECTEC) under the National Science and Technology Development Agency (NSTDA) to develop an agricultural map system for online Agri-Map management for all people can access via the internet network and mobile application.

- In 2017, LDD has developed the LDD Zoning, this aims to define the suitable areas for economic crop according to physical, economic and social aspects, to establish the database for economic crop plan and policy setup and to support the action plan for communities of provincial level. Presently, Ministry of Agriculture and Cooperatives (MOAC) has declared suitable areas for eight economic crops: rice, oil palm, para rubber, maize, cassava, sugarcane, pineapple and longan. Furthermore, there are five crops still in the process: durian, mangosteen, rambutan, coffee and coconuts. This has become a guideline for relevant organizations to deal with the demand and supply balance of agricultural products in provinces systematically.

These products are mainly used by LDD and other departments of the Ministry of Agriculture \& Cooperatives, such as the Agricultural Development and Irrigation departments. They also support agriculture and soils research in academic institutes. The maps and products are sold to the public; the main customers are agricultural officers and researchers.

\subsection{New challenges to the Thai soil survey}

Recent trends in society, technology and soil survey concepts present challenges to the Thai soil survey. Its traditional role of purely supporting agriculture is now not sufficient justification for its continued existence. Further, as with all mapping agencies in the digital age, it must become an information agency. As a result, the LDD is confronting challenges as described below. Responses to challenge are result reported in the subsequent section.

\subsubsection{New clients, new uses}

Fortunately, soil information is increasingly requested for both agricultural and other applications. Some new clients are presented below, along with their uses of soil information. 
1. Soil information is being used by researchers and officers from other departments in the Ministry of Agriculture \& Cooperatives, e. g., the Royal Irrigation Department (RID), Development of Agriculture Department (DOA), Department of Agricultural Extension (DOAE) and the Royal Project Foundation. Researchers in academic institutes concerned with agriculture e.g., Kasetsart University, use soil information as basic information to formulate land development programs aimed at increasing farm income and standard of living in model project areas.

2. Soil information is being used for non-agricultural applications by several government departments, including the Department of Disaster Prevention and Mitigation (DDPM) and Ministry of Interior, which need to interpret soil information to assess land degradation and land management to prevent or mitigate floods, erosion, and landslides. The Pollution Control Department (PCD) of the Ministry of Natural Resources and Environment uses soil information for environmental impact assessment and to monitor soil and water quality standards. The Royal Forest Department (RFD) of the same ministry uses soil suitability for re-forestation projects. The Department of Highways ( $\mathrm{DOH}$ ) of the Ministry of Transport applies soil information for engineering and transportation construction.

3. Some users require soil properties, rather than soil units, as inputs to land surface models. At present, these are derived per map unit from representative pedons and extended uniformly to the map unit (s) represented by the pedon; however, for some applications such as watershed hydrology a continuous field ("raster" or "pixel") map is requested. These must be created from point samples by interpolation techniques such as regression kriging (Hengl et al., 2007). The LDD has only sparse georeferenced point observations for most of the country and only for certain properties (e.g., organic matter, particle-size distribution, and cation exchange capacity) and has little experience in interpolation techniques.

\subsubsection{New survey activities by the LDD}

LDD has recently initiated two activities in response to the renewed mandate of the Ministry of Agriculture \& Cooperatives to boost agricultural production.

First, sloping areas, which were forested at the time of earlier soil surveys were being considered out-of-hand as not being suitable for agriculture and were not mapped or were mapped as undifferentiated slope complexes with no accompanying soil series, representative pedons, or soil properties. In the last decade, many of the sloping areas have been converted to agricultural land due 
to increasing population, wealth, and demand for animal products and requied high-protein animal feed. Further, these areas are important for infrastructure planning and hazard zonation (Land Development Department, 2009a). Therefore, the demand of soil information in this area is increasing importantly. There are currently projected to map these areas at large scale $(>1: 50,000)$ as soil series or soil variants with slope phases in northern Thailand. Since these areas were not previously studied in detail, thus new soil series must be established, characterized, and interpreted.

Secondly, since 2017, the Ministry of Agriculture and Cooperatives, Thailand has stated the 4 years action plan (2017-2021) and a sub-district planning and management projects have become priorities of the LDD, corresponding to "Strategies for Land Development under the $12^{\text {th }}$ plans (2017-2021)" (Land Development Department, 2017). By means of sub-district planning projects in so-called "Tum Bon planning project", farmers should be supported by the LDD by transferring knowledge and technologies to promote landuse optimization, soil improvement, and infrastructure development in order to increase productivity and farm income. The country has been divided into 7,255 sub-districts (Tumbon) provinces, of which the 7,255 Tumbons (covering 5,280 $\mathrm{km}^{2}$ ) have been identified as target areas. Because of the typical small farmer's field size, the LDD proposed to produce a large soil map scale with more detailed soil information, and thus the 1:4,000-10,000 scale was chosen. This scale implies a very small minimum mapping area, $0.064 \mathrm{ha}\left(640 \mathrm{~m}^{2}\right)$, which would require a minimum observation density of 156 points per $\mathrm{km}^{2}$ according to conventional guidelines of 1 observation per 4- $\mathrm{cm}^{2}$ map (Forbes et al., 1987). Clearly, this observation density is not feasible over large areas. Consequently, efficient methods must be developed to link landscape and soil, with fewer direct observations. The obvious choice is digital soil mapping (DSM). However, on DSM has this has rarely been applied at such large scales without a prior detailed understanding of narrowly-defined soil series on landscape facets (e.g., the work of Zhu and colleagues in Wisconsin, USA (Burt et al., 2006)). Map units at this scale must be narrowly-defined soil series, with topsoil texture, stoniness, slope and slope phases and an appropriate legend must be developed.

\subsubsection{Challenges in applying modern soil survey concepts}

A worldwide soil survey is undergoing a radical transformation as the result of new possibilities in information technology, sensors, geostatistics and modelling. This transformation has been termed "Digital Soil Mapping" (DSM) (Boettinger, 
2010; McBratney et al., 2003) and includes a wide variety of methods. Areas of the LDD's operations which can benefit from DSM techniques include (1) establishing a harmonized soil pedon database similar to the USA's PEDON; (2) establishing a monitoring database for repeat measurements to evaluate longterm changes in soils due to management; (3) use of remote sensing and terrain analysis to more objectively identify soil units and their boundaries; (4) refining ( downscaling) medium- scale map units to detailed map units; and (5) establishing a quality assurance and evaluation system to provide clients with information on the reliability of the survey products. DSM methods are now widely used to accelerate soil survey and to make more precise and detailed maps, e.g. in Australia (Bui, 1999). Considering the large area to be mapped and the availability of excellent- quality digital elevation models and remote sensing products, DSM is an obvious direction method for the Thai soil survey. However, at present, the LDD has not developed either conceptual or operational frameworks for DSM.

\subsubsection{Human resource and budget constraints}

In common with many soil survey organizations, the LDD faces constraints such as inadequate facilities, vehicles and equipment, no provision for in- house training in either traditional or digital soil survey. In addition, structural problems in the civil service limit staff promotion and recruitment, since 2003, the number of soil surveyors has been reduced from 300 to fewer than 100 . Thus doing more works with less budgets becomes necessary unless other funding sources can be exploited.

\subsection{Methodology}

Since 1996 LDD has incorporated information technology in its operations. These include the GIS-based applications listed above, GPS for field location of sampling sites (Figure 5.2-a), and on-screen digitizing of soil map unit lines on ortho-photographs (Figure 5.2-b). Beginning in 2005 and completed by 2008, ortho-photographs at 1:25,000 and 1:4,000 scales, as well as a high-accuracy 2$\mathrm{m}$ vertical resolution DEM (Figure 5.2-c and d) have been produced to support soil survey. These products have been used by LDD for manual revision of boundaries between soil polygons, and to split 1:50,000 and 1:25,000 map units for the 1:4,000 soil series map based on slope classification calculated from digital elevation data (DEM) (Figure 5.2-e and f). The ortho-photographic maps are technically being used also for landuse mapping. 


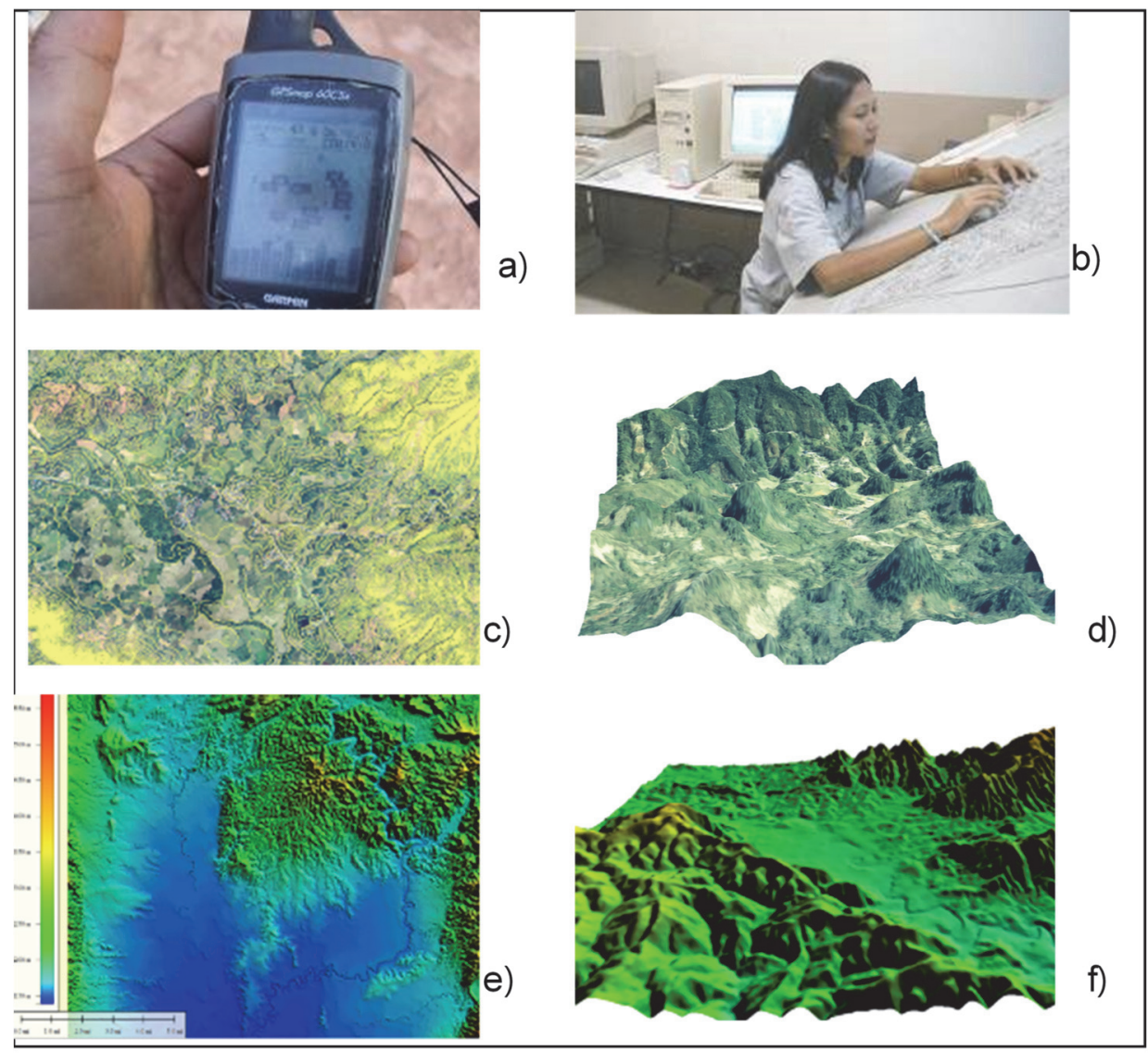

Figure 5.2: Modernizing soil survey with GIS and RS environment: a) GPS device, b) GIS application for digitizing and storing soil map, c) ortho-photography with 2-m contour interval, d) 3D perspective of ortho-photography, e) 3D of high resolution DEM (5-m) and f) 3D perspective generated from 5-m DEM.

\subsubsection{Introducing DSM at medium scales}

Digital Soil Mapping (DSM) refers to the computer-assisted production of digital maps of soil type and soil properties (McBratney et al., 2003). These authors provide a general framework known as SCORPAN. Scull et al. (2003) classify methods under the related term "predictive soil mapping". Although all mapping is in same sense as predictive, these authors refer to computational methods to predict (often prior to field work) what soil class or property will be encountered at a location. In this section, we outline a framework for DSM in the Thai context, to improve soil series map at scale 1:50,000 and 1:25,000, which we plan to implement in the near future. 
A framework to undertake the Thai digital soil mapping, which take into consideration the large geographic area of Thailand and organize soil data and information and the environmental variables required by the digital soil mapping, could replace the five steps of conventional soil survey as follows. (1) Prepare required information for field observation; (2) observe and sample the soil in the field; (3) map by DSM methods; (4) quality control; and (5) interpretation. The "mapping" stage can be separated into two phases: prepare soil predictor covariables and map using these.

The step that controls methods selected for the other step is in (3), mapping by DSM methods. This is also termed soil spatial prediction and modelling. Following Jenny (1941) and many successors, the LDD has considered soil to be the more-or-less natural soil bodies resulting from the effect of climate and living organisms acting on parent material with topography or local relief over time required for soil-forming process (Soil Survey Staff, 1993). LDD has used this conceptual framework for its conventional methods. It is therefore natural to use DSM techniques that also use this framework.

Jenny's conceptual model was operationalized for DSM by McBratney et al. (2003) as the so-called "SCORPAN" model, which describes the relationships between soil and other spatially referenced factors:

$$
\mathrm{S}=f(\mathrm{~S}, \mathrm{C}, \mathrm{O}, \mathrm{R}, \mathrm{P}, \mathrm{A}, \mathrm{N})
$$

Where, ' $\mathrm{S}$ ' is soil or other properties of the soil at the points; ' $\mathrm{C}$ ' is climate, climatic properties of the environment at a point; ' $\mathrm{O}$ ' is organism, vegetation or fauna or human activity; ' $\mathrm{R}$ ' is topography, landscape attributes; ' $\mathrm{P}$ ' is parent material, lithology; ' $A$ ' is age, the time factor and ' $N$ ' is space, i.e., georeferenced spatial position. ' $\mathrm{S}$ ' appears on both sides of the equation; on the right side it refers to soil observations, on the left to soil predictions. The ' $\mathrm{N}$ ' factor allows for geostatistical techniques using both soil observations and environmental co- variables, since the position of observations in space is explicitly included. In many areas of Thailand, the " $\mathrm{O}$ " factor is dominated by human influence, notably in paddy soils, but also recently with intensive fertilization. The ' $R$ ' factor in landscapes with significant relief is typically represented by terrain analysis, an application of geomorphometry (Hengl and Reuter, 2009). The derivation, application and limitation of this approach have been discussed by many researches (Florinsky, 2012; Hengl and Reuter, 2009; Wilson and Gallant, 2000). 
The SCORPAN framework must be operationalized in each setting according to the dominant soil-forming factors, data sources, and institutional setting. Figure 5.3 shows the proposed framework for Thailand; the above-mentioned five steps are labelled.

The first step (soil survey data preparation) includes assembling existing soil data, data interpretation/analysis and complementary post-survey sampling. These include image interpretation using ortho-photographs and landscape delineation using high resolution DEM. Pedotransfer functions can be used to estimate soil properties (e.g., soil bulk density and soil hydraulic properties). Target scale must also be selected in this step. The result of this initial step is a preliminary soil-environment model which will be used in next steps.

The second step is fieldwork. Sampling is stratified by landscape and environmental covariables. Mobile GIS is used for data entry and editing. Soil and environment data will be recorded using Thai soil profile database.

In the third step, soil samples will be analysed in the laboratory to support classification mapping.

The fourth step is mapping, operationalizing the soil-landscape model (SCORPAN) from the first step will be used. Covariables include airborne gamma-ray data and other imagery (e.g. from SMMS_-Small Multi-Mission Satellite, is a low earth orbit satellite for natural and agricultural application in Thailand, Theos - Thailand Earth Observation Satellite is the first operational Earth Observation Satellite of Thailand) will be contributed. To satisfy users in almost all applications, as well as DEM derivatives, suitable predictive methods are required for the mapping process, and (updated) Thai soil series and soil properties maps are the products. The products should be assessed the quality and can be progressively updated as more field observations are made.

The fifth step should be mapping additional soil properties using pedotransfer functions (PTF), which are predictive functions associating basic soil properties from available data (e.g. soil texture, $\mathrm{pH}, \mathrm{OM}$ ) with difficult-to-measure properties (e.g., water retention curve, hydraulic conductivity).

The sixth step should be soil data interpretation for national and specific uses, to be stored in LDD server, thus the data can be vailable and accessible to users though GIS web service. 


\subsubsection{Introducing DSM at detailed scaled}

For the 1:4,000 map series, map units are phases of soil series. The DSM framework of Figure 4 can also be used at this scale, with the following adaptations: (1) finescale covariates commensurate with the MLD $\left(640 \mathrm{~m}^{2}\right.$, i.e., approximately $25 \times 25$ $\mathrm{m})$; (2) soil series or phases identified for each detailed landscape facet; (3) inference from covariates to map units. The SoLIM approach of fuzzy inference from environmental covariates and typical locations of series or phases seems welladapted to this last phase.

\subsubsection{Quality control / adequacy assessment}

The quality of LDD soil survey products and databases has never been assessed. In common with many countries, field effort has been spent on mapping and not on independent surveys to assess the maps. It is proposed to incorporate quality assurance (thus, automatically generating a quality assessment) in DSM-based surveys. Most DSM methods, including SCORPAN models built by regression kriging and SoLIM models, automatically report the mapping uncertainty of each mapped location. Quality aspects include 1) standards for soil survey and classification, 2) map scale, 3) soil boundaries, 4) profile observations, 5) soil mapping units, 6) adequacy assessment and 7) database and validation.

The proposed methods will be applied in near future is evaluating existing maps, quality could be assessed by the Cornell methods (Forbes et al., 1987), supplemented by complementary work such as the accuracy of soil boundaries applied in Croatia (Hengl and Husnjak, 2006). However, if new maps are produced, the quality of the existing maps becomes moot, so we prefer to assure quality of new products rather than assess the quality of existing products. 


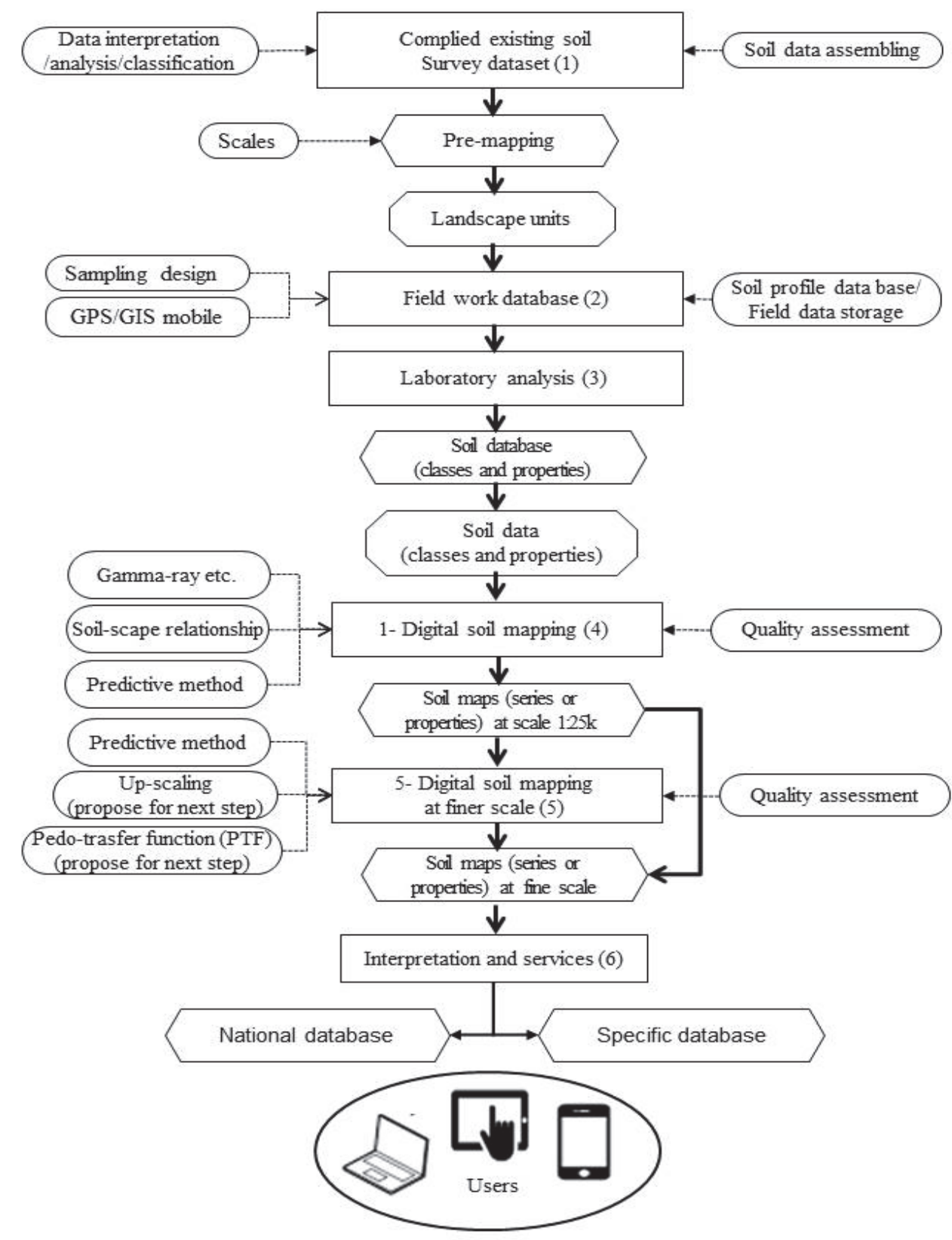

Figure 5.3:Simplification of digital soil mapping framework for Thai soil survey 


\subsection{Applications of the new methods and results}

Two decades ago, only 3 project studies (Desta, 2009; Moonjun et al., 2008; Udomsri, 2006 ) had been applied digital soil mapping method. The digital soil mapping based on clorpt soil and SCORPAN were applied with the collected data in sampled area to map soils in unsampled areas.

The first study, Udomsri (2006) used a set of sampled soil data with decision tree model to predict soil (based on SCORPAN) in erosion prone are in the area of Ang Khang Royal project foundataion, Chiang Mai. The second study, Moonjun et al. (2008) used soil data set based on SCORPAN model applying artificial neural networks (Artificial Neural Network - ANN) and Decision tree to map soil in a mountainous area in Huai Numarin Royal project, Chiang Rai province. The third study, Desta (2009) used a soil data set applying clopt model to assess and mapping saline soils in Nakhon Ratchasima.

\subsection{Responding to the challenges}

To meet the above challenges and remain relevant for the continued economic development and environmental protection of Thailand, the LDD must take specific actions, which are here outlined.

\subsubsection{Communication with and identification of new clients}

Although the LDD has published soil maps and reports for all of Thailand, this information is undervalued and underused for two reasons: (1) potential clients are not aware of it; (2) it does not directly meet client needs, often because of a lack of cross- discipline scientific language. To promote the use of soil information, the LDD must forge a closer link between itself as producer and a wider group of clients.

A model for new communication is already at hand in the agricultural sector. The LDD has already made good progress in directly communicating soil information to farmers though trained volunteer farmers in each village using this is known as the "Soil Doctor" program. Each agricultural village $(65,000)$ has a volunteer in direct contact with the regional LDD offices.

For other users, the LDD needs to develop user-friendly products by redesigning soil survey reports to make them more accessible by internet and other media. However, the user requirements must first be known. One way to determine requirements is by starting collaborative projects with different users such as 
academic institutes and government offices outside the Ministry of Agriculture \& Cooperatives.

Reports for specific purposes and users are needed. The use of taxonomic and series maps should be reserved for scientific communication and as a source for interpretation. Maps for planners and farmers should be interpretive, purposespecific maps. Internally, soil information should emphasize geomorphology-soil relationships, allowing better understanding of soil series as they occur on landscapes, rather than presenting series as disconnected sets of polygons with no communication of how they typically occur in the field. Simplified data presentation for users does not imply simplification of the basic soil survey documents. The scientific foundation for interpretive products must be maintained. The visual presentation of soil maps can be shown as "soilscapes", showing the map user the relation between landscape and soil type by draping the soil map over ortho- photography and terrain models, e. g., as hillshades. At the same time, the LDD must prepare well-trained soil surveyors who understand the soils on the landscape and can provide public relations activities, such as marketing and public presentation of survey and interpreted products.

Simplified soil survey products should be used to raise societal awareness of soils; for example, the concepts of soil science, for example, can be included in school textbooks to educate potential users. Another way to reach potential users is, of course, the internet.

At present, soil information is provided as soil series maps, soil property maps for agriculturally-relevant properties, and some interpreted maps ( see previous section). Series maps can be effective information carriers if the clients become familiar with the soil series properties. But most users do not understand the holistic concept of the soil series and prefer soil properties directly relevant to their needs. LDD does not at present provide directly-usable interpretations for the above-mentioned uses and indeed does not have expertise in most of these applications. Therefore, the general-purpose soil survey (series or phase maps) must be interpreted in terms familiar to these new users. This requires new interpretive tables, similar to those published with USA soil series

\subsubsection{Redefining soil series}

The soil series concept as used in Thailand does not correspond to the level of detail of the series as the lowest hierarchical level of Soil Taxonomy, i.e., the basic unit of technology transfer. Actual series are closer to families or even subgroups. In addition, series are not established according to a strict protocol 
(minimum area, modal profiles, range of properties, etc.). Therefore, series are not at a suitable level of detail for interpretations required by farm-level planners or engineers. They are wholly inadequate as the basis (along with phases) for map units for the 1:4,000 series detailed farm maps. Soil series must therefore be redefined to (1) narrow the range to detailed interpretive units; (2) establish natural ranges on the landscape; (3) document the ranges of series properties, competing series (soils are members of the same family), and associated series on the landscape, in the model of the USA's Official Series Descriptions (OSD). Such narrowly-defined series could then serve as the basis for digital soil mapping by expert systems, in particular by the SoLIM approach applied successfully in the USA (Burt et al., 2006). However, to split current series into more detailed series will require a comprehensive pedon database supplemented by field investigation for correlation and differentiation of the new series.

\subsubsection{Organization and human resources}

LDD must work with its current staff, very few of them who have any experience with the new framework. Thus, current staff must be motivated to retrain and reorient their work. Ideally, training should be in cooperation with soil survey organizations which have already implemented DSM methods.

To alleviate constraints, technical and financial supports from different sources are required in both the short and long terms. The Soil Survey and Classification division of the LDD is lobbying the Thai budget bureau to promote soil surveys through financial support for the expansion of soil services, as well as for the improvement of soil survey quality. We hope that demonstrating high-quality digital products will increase the chances of success of this lobbying.

\subsection{Next steps}

The ambitious program outlined in the previous section must be implemented in phases. Our plan for the period $2019-2022$ is to apply DSM technique for (1) updating semi-detailed soil series map $(1: 25,000)$ for 45 sub-watersheds in 20 provinces, totalling 93,600 km2 and (2) mapping very detailed soil series/phases map $(1: 5,000)$ to target farm planning project in 500 sub-districts, totalling 320 $\mathrm{km} 2$. We hope thereby to have it made the first important steps towards modernizing the Thai soil survey and ensuring its continued relevance in service of the Kingdom of Thailand. 


\section{Chapter 6 Synthesis and conclusions}




\subsection{Potential for digital soil mapping in Thailand}

Thailand has a long tradition of using detailed soil information in agriculture and watershed management. Agricultural extension workers (locally named "soil doctors"), give advice on farm level on increasing agricultural production and combat land degradation. Unfortunately, detailed soil information is only available for the flat areas where most of the agriculture used to be concentrated. As more and more of the hilly and mountainous areas are being used there is now a distinct lack of detailed soil data for these services. Also the complexity of the services has increased, dealing with integrated watershed management, addressing sustainability and more complex forms of land degradation. The Thai government cannot afford to do a detailed soil survey for the entire country and other, more efficient forms of soil type and soil property mapping are needed. This research investigates digital soil mapping as an alternative principle.

This focus leads to the following objectives:

1 To investigate which terrain parameters from high- resolution DEMs and digital terrain analysis can be used for fine-scale digital soil mapping $(1: 5,000)$ in the first order watersheds.

2 To investigate the use of airborne gamma-ray data (AGRI) to infer parent material and soil characteristics (in the context of soil forming factors), as an input layer to Digital Soil Mapping.

3 To investigate a combined use of fine resolution DEM and the SoLIM fuzzy logic model as a predictive method for mapping soil series and properties.

The availability of high resolution geo-spatial data, modern tools and methods for application in making soil surveys more efficient and accurate have been discussed in the previous chapters (Chapters 2, 3 and 4). The potential of the proposed digital soil survey framework to operationalize this research for Thailand is outlined in Chapter 5 .

\subsubsection{Using high resolution DEMs and digital terrain analysis for fine-scale soil mapping $(1: 5,000)$}

Terrain variables are created with a neighborhood (window), an analysis window used for the digital elevation in term of raster operations such as calculation of slope, curvature and aspect.

It has been shown that neighborhood size (window size) influences terrain details, as larger neighborhood sizes smooth terrain features; by contrast smaller 
neighborhoods can produce high frequency-noise (Thompson et al., 2001). These results had no consistent relation with models of soil properties or series. In fact the study shows that the accuracy of soil mapping is not always obtained from using the most detailed DEM and smallest neighborhood size. This finding confirms the results of Smith et al. (2006) and Zhu et al. (2008). A higher resolution DEM did not perform better than the degraded DEM for predicting soil properties, and indeed the large neighborhood sizes tended to improve predictions. Thus, although a fine-resolution DEM can give detailed information on the terrain, a coarser horizontal resolution DEM would be adequate for that purpose.

In terms of soil series, a 5-m DEM with $10 \times 10$ neighborhood size cells was well able to predict soil series. This is due to the existence of optimal neighborhood sizes for mapping soil series. Soil series is a scale-dependent concept, or in other words soil series exists at certain spatial scale. When the scale is coarser than the "coarse end" of this optimal range, the details in the terrain, which are needed to pick up the soil series, are averaged out (Smith et al., 2006).

In contrast to soil properties, soil series mapping, using logistic regression, gives satisfactory results for two series ( $\mathrm{Li}$ and and Tha Phon series), of which the definition corresponds well to landscape position. Tn is the "Tha Phon" soil series, an Aeric Endoaquepts developed in recent alluvial plains, consisting of fine material and poorly drained. They occur in vales and are often used for rice production. The Li soil series are Ultic Haplustalfs developed in shallow shales with a clayey skeleton and well drained, which is commonly developed over the sloping area with in-situ material.

Both soil properties and series are better explained by combined terrain attributes (primary and secondary, combined into standardized principal components), rather than single terrain attributes. This may be related to the concept that soil forming processes are complex and not related to one particular terrain characteristic (such as slope or flow accumulation) but the spatial distribution of processes such as radiation, temperature, moisture and accumulation or erosion of materials.

\subsubsection{Investigating the use of airborne gamma-ray data to infer soil characteristics}

In Chapter 3, airborne gamma- ray imagery (AGRI) provided a potential information source for the gamma-ray emitting elements: potassium $(\mathrm{K})$, thorium 
equivalent (eTh) and uranium equivalent (eU) for bed rock and soil mapping, since their abundance is related to the rock and soil geochemistry, specifically the chemical composition of parent materials and their weathering products, which result from geomorphic and pedogenic processes.

The study shows that bedrock and soil parent materials were well explained by AGRI, e.g. sandstone was found in high eU locations. Some high protassic-mica in bedrock gives a high $\% \mathrm{~K}$.

Some soil properties, such as top soil textures were well explained by AGRI, as $\mathrm{eTh} / \mathrm{K}$ is recommended to be a co-variable for defining topsoil texture and its closely related properties, as $\mathrm{K}$ content is readily absorbed in areas with high clay content, and high eTh relates to resistant materials such as sand particles.

For two existing soil maps, the AGRI were well correlated to a geopedologic map (1:100,000) at two higher levels (landscape and lithology), but to a lesser degree at two lower levels (relief and landform), as shown in section 4.3.4. The AGRI showed deficiencies in the soil series map ( $1: 50,000)$, made by conventional aerial photo analysis, as in section 4.3.5, especially in inaccessible areas but also in low-relief terraces and flood plains, which provided a basis for future field sampling to correct these deficiencies. AGRI suggested new boundaries differentiating topsoil properties and the presence of plinthite, despite its coarse resolution.

\subsubsection{Investigate a combined fuzzy logic predictive method with parameters of soil forming factors, and evaluate its success in mapping soil series and properties.}

The study shows that a contextual knowledge-based system using fuzzy logic has the potential to predict soil series and topsoil texture maps effectively. It has the potential to reduce inconsistency and costs associated with the traditional manual processes, relying upon a relatively low density of soil samples. Nevertheless, the basic idea remains the knowledge of soil- landscape relationships and is irreplaceable, as this technique is knowledge-based.

Using lithology and two terrain parameters (wetness index and slope) as soil predictor variables, the SoLIM fuzzy logic model shows advantages in associating them to the expert field knowledge, in order to produce high quality soil maps. The results provide detailed information about spatial variations, and represent realistic spatial patterns of the soil series in the study area. In addition, use of fuzzy logic is worthwhile in view of the added level of detail compared to the very large and poorly defined units of upland soils (such as "slope complex") 
and can be used to support soil series mapping with high accuracy efficiently. The technique can also be used for mapping soil properties (e.g. topsoil texture) but one has to be careful in selecting the predictor variables: these have to have a conceptual link to the soil forming processes or soil properties under investigation. However, apart from the DEM and derivatives and large scale lithology and geology, there are few other independent datasets that cover Thailand. The approach can be applied in other areas in Thailand to improve soil mapping. Revisions of the LDD semi-detailed scale soil maps $(1: 25,000)$ and producing very detailed soil maps are potentially possible, as the study covers all different topographic types of areas of Thailand.

\subsubsection{The state of soil survey, current needs and application perspectives, and establishing a digital soil survey framework for environment}

Soil survey data are well used in Thailand for agricultural purposes and needed for watershed management, but there is a lack of information for sloping areas as there are no detailed soil maps. It is beyond the means of the government to create a soil map by traditional field survey for the entire missing area $(156,800$ $\mathrm{km}^{2}$ ). DSM is a valid alternative. In order to use DSM for that part the following needs to be done in Thailand.

Therefore, chapter 5 reviews current soil survey projects in Thailand, and proposes a future digital framework for implementation into soil survey projects and products. The proposed methods are based upon DSM concepts and procedures in Thailand, and other developing countries. In Thailand, some DSM methods were introduced for soil mapping on medium $(1: 50,000-25,000)$ to very detailed scale $(1: 5,000)$ e.g., airborne gamma-ray images and optical satellite sensor images. Utilization of high resolution digital elevation models was employed for empirical soil- landscape modeling. In addition, pedotransfer functions were also proposed for getting some soil information such as Ksat, upper limit, lower limit and bulk density.

Predictive soil mapping methods in both linear and non-linear modeling were proposed to test such a case of mapping soil in mountainous area in Ang Khan and Hoi Numrin royal project (Moonjun, 2007; Udomsri, 2006) in Thailand since the demand for high accuracy soil information is increasing for farm level planning and for watershed management in the sloping lands. Moreover, the evaluation method needed to be tested after finishing the soil map. In addition, there was also a need for applying modern tools and techniques to increase 
efficiency in line with budget cuts for soil survey activities. To be successful in DSM, the interaction between soil surveyors and their users is necessary. Moreover soil surveyors need to be trained to understand soil and its role in GIS and remote sensing environments, use new mapping methods for optimizing soil sampling, apply database management system and interpret soil data for transfer to multi-users.

In addition, chapter 5 reviews current soil survey projects in Thailand, and proposes a future digital framework for implementation into soil survey projects and products. The proposed methods are based upon DSM concepts and procedures in Thailand, and other developing countries. In Thailand, some DSM methods were introduced for soil mapping on medium $(1: 50,000-25,000)$ to very detailed scale $(1: 5,000)$ e.g., airborne gamma-ray images, optical satellite sensor images and other suitable remotely sensed data (e.g., ground penetrating radar, Thematic Mapper (TM), SPOT Multi Linear Array (MLA), Panchromatic Linear Array (PLA), Indian Remote Sensing Satellite (IRS) Linear Imaging Selfscanning Sensor (LISS- I, - II and - III), Wide Field Sensor (WiFS) and Panchromatic (PAN. Utilization of high resolution digital elevation modeling (DEM) was employed for empirical soil- landscape modeling. In addition, pedotransfer functions were also proposed to translate texture information to soil hydrological properties.

Predictive soil mapping methods in both linear and non-linear modeling were proposed to test such a case in Thailand since the demand for high accuracy soil information is increasing for farm level planning and for watershed management in the sloping lands. Moreover, the evaluation method needed to be tested after finishing the soil map. In addition there was also a need for applying modern tools and techniques to increase efficiency in line with budget cuts for soil survey activities. To be successful for DSM operation, the interaction between soil surveyors and their users is necessary. Moreover soil surveyors need to be trained to understand soil and its role in ecosystem services, use new mapping methods for optimizing soil sampling, apply database management system and interpret soil data for transfer to multi-users.

\subsection{Suggestions for further research}

1. The soil properties investigated in this study are limited to texture or texture classes. However, most models and predictive methods dealing with land and water management, agriculture and fertility, land degradation, or for instance hydrological disasters need soil chemical and hydrological 
properties. Soil texture and organic matter can be translated to these properties by means of pedotransfer functions, but this likely adds uncertainty. It is advisable to start investigating the use of DSM for chemical and hydrological properties, or it could also be a valuable strategy to create pedotransfer functions specific to Thai soils.

2. In Thailand, the LDD has been surveying and mapping over the agricultural areas with slopes less than $35 \%$. Recently, soil maps at scale 1: 50,000 and 1: 25,000 are being used for agricultural planning without taking into consideration the map accuracies. It is essential to access the accuracy of the existing soil maps before they are used for various purposes.

3. A geopedologic approach takes into account soil-landscape relationships as landscape is one of the soil-forming factors (Zinck, 1980) but none of the research in digital soil mapping applies this. High resolution digital elevation models are a valuable data source. Further study should focus on developing methods on the use of DEMs for soil-landscape or landform modeling.

4. The study shows that airborne gamma- ray imagery can be applied for mapping lithology in complex landscapes. Since Thailand lacks lithology maps, airborne gamma- ray imagery can be useful to get information on lithology for mapping soil. It also helps for characterizing topsoil properties. For example, eTh/K is recommended as a co-variable for mapping topsoil texture and closely related properties, as $\mathrm{K}$ content is readily absorbed in areas with high clay content and high $\mathrm{eTh}$ which relates to resistant materials such as sand particle. In this way the quality of traditional soil maps can be improved. 


\section{Appendix 1}

Geopedologic units (Scale 1:100,000)

\begin{tabular}{|c|c|c|c|c|c|}
\hline Map unit & Landscape & Relief & Lithology & Landform & Dominant soil classes \\
\hline Hi111 & Hilllands & Ridge & $\begin{array}{l}\text { Predominantly Ss } \\
\text { and } \mathrm{Sh}(10)\end{array}$ & $\begin{array}{l}\text { Slope facet } \\
\text { complex }\end{array}$ & $\begin{array}{l}\text { Ultic Haplustalfs, } \\
\text { Typic Ustropepts, } \\
\text { Rocks }\end{array}$ \\
\hline Hi211 & Hilllands & Hogback & $\begin{array}{l}\text { Predominantly Ss } \\
\text { and Sh (10) }\end{array}$ & Reversal & $\begin{array}{l}\text { Ultic Haplustalfs, } \\
\text { Typic Haplustalfs, } \\
\text { Lithic Ustorthents }\end{array}$ \\
\hline $\mathrm{Hi} 212$ & Hilllands & Hogback & $\begin{array}{l}\text { Predominantly Ss } \\
\text { and Sh (10) }\end{array}$ & Front & $\begin{array}{l}\text { Ulitc Ustothents, } \\
\text { Typic Ustorthents, } \\
\text { Lithic Haplustalfs }\end{array}$ \\
\hline Hi213 & Hilllands & Hogback & $\begin{array}{l}\text { Predominantly Ss } \\
\text { and } S h(10)\end{array}$ & Talus & $\begin{array}{l}\text { Lithic Ustorthents, } \\
\text { Ultic Haplustalfs, } \\
\text { Typic Haplustalfs }\end{array}$ \\
\hline Hi311 & Hilllands & $\begin{array}{l}\text { Very high } \\
\text { to high hills }\end{array}$ & $\begin{array}{l}\text { Ss, Ads, Sh, Muds, } \\
\text { Si and Gr (14) }\end{array}$ & $\begin{array}{l}\text { Summit } \\
\text { complex } \\
\text { (locally } \\
\text { inside) }\end{array}$ & $\begin{array}{l}\text { Lithic Argiustolls, } \\
\text { Lithic Ustorthents, } \\
\text { Typic Ustropepts }\end{array}$ \\
\hline Hi312 & Hilllands & $\begin{array}{l}\text { Very high } \\
\text { to high hills }\end{array}$ & $\begin{array}{l}\text { Ss, Ads, Sh, Muds, } \\
\text { Si and Gr (14) }\end{array}$ & $\begin{array}{l}\text { Slope facet } \\
\text { complex }\end{array}$ & $\begin{array}{l}\text { Lithic Ustothents, } \\
\text { Vertic Haplustolls, } \\
\text { Ustoxic Dystropepts }\end{array}$ \\
\hline Hi411 & Hilllands & $\begin{array}{l}\text { Moderately } \\
\text { high hills }\end{array}$ & $\begin{array}{l}\text { Ss,Sh, Muds, and } \\
\text { Ads (17) }\end{array}$ & $\begin{array}{l}\text { Slope facet } \\
\text { complex }\end{array}$ & $\begin{array}{l}\text { Typic Ustropepts, } \\
\text { Typic Haplustalfs, } \\
\text { TypicUstorthenents }\end{array}$ \\
\hline Hi511 & Hilllands & Low hills & $\begin{array}{l}\text { Predominantly Sh, } \\
\text { ss, Muds and Qz } \\
\text { veins (8) }\end{array}$ & $\begin{array}{l}\text { Slope facet } \\
\text { complex }\end{array}$ & $\begin{array}{l}\text { Typic Haplustalfs, } \\
\text { Typic Argiustalfs, } \\
\text { Typic Ustropepts }\end{array}$ \\
\hline Hi611 & Hilllands & Escarpment & $\begin{array}{l}\text { Ss, sh, Ads, Muds } \\
\text { and Si (16) }\end{array}$ & $\begin{array}{l}\text { Slope facet } \\
\text { complex }\end{array}$ & $\begin{array}{l}\text { Ultic Haplustolls, } \\
\text { Ultic Haplustalfs, } \\
\text { Lithic Ustorthents }\end{array}$ \\
\hline Hi711 & Hilllands & Vale & $\begin{array}{l}\text { Alluvio-Colluvium } \\
\text { (1) }\end{array}$ & $\begin{array}{l}\text { Bottom/side } \\
\text { complex }\end{array}$ & $\begin{array}{l}\text { Ultic Haplustalfs, } \\
\text { Typic Eutropepts, } \\
\text { Aeric Tropaquepts }\end{array}$ \\
\hline HM111 & $\begin{array}{l}\text { High } \\
\text { Mountain }\end{array}$ & Hills & $\begin{array}{l}\text { Predominantly Ss, } \\
\text { Si and } \mathrm{Sh}(10)\end{array}$ & $\begin{array}{l}\text { Slope facet } \\
\text { complex }\end{array}$ & $\begin{array}{l}\text { Interred-Dystropepts, } \\
\text { Haplustaulfs, Rocks }\end{array}$ \\
\hline HM211 & $\begin{array}{l}\text { High } \\
\text { Mountain }\end{array}$ & Ridge & Ss and Sh (1) & $\begin{array}{l}\text { Slope facet } \\
\text { complex }\end{array}$ & $\begin{array}{l}\text { Interred-Dystropepts, } \\
\text { Haplustaulfs, Rocks }\end{array}$ \\
\hline HM311 & $\begin{array}{l}\text { High } \\
\text { Mountain }\end{array}$ & Hogback & Ss and Sh (1) & Reversal & $\begin{array}{l}\text { Lithic Ustropepts, } \\
\text { Ultic Haplustalfs }\end{array}$ \\
\hline HM312 & $\begin{array}{l}\text { High } \\
\text { Mountain }\end{array}$ & Hogback & Ss and Sh (1) & Front & $\begin{array}{l}\text { Lithic Dystropepts, } \\
\text { Typic Ustropepts, } \\
\text { Typic Argiustolls }\end{array}$ \\
\hline HM313 & $\begin{array}{l}\text { High } \\
\text { Mountain }\end{array}$ & Hogback & Ss and Sh (1) & Talus & $\begin{array}{l}\text { Typic Haplustalfs, } \\
\text { Lithic Ustorhents }\end{array}$ \\
\hline
\end{tabular}




\begin{tabular}{|c|c|c|c|c|c|}
\hline Map unit & Landscape & Relief & Lithology & Landform & Dominant soil classes \\
\hline HM321 & $\begin{array}{l}\text { High } \\
\text { Mountain }\end{array}$ & Hogback & $\begin{array}{l}\text { predominantly Ls, } \\
\text { Si and Chert (6) }\end{array}$ & $\begin{array}{l}\text { Slope facet } \\
\text { complex }\end{array}$ & $\begin{array}{l}\text { Inferred-Haplustalfs, } \\
\text { Ariustolls, Rocks }\end{array}$ \\
\hline$\overline{\text { HM411 }}$ & $\begin{array}{l}\text { High } \\
\text { Mountain }\end{array}$ & Vale & $\begin{array}{l}\text { Alluvio- } \\
\text { colluvium(1) }\end{array}$ & $\begin{array}{l}\text { Bottom/side } \\
\text { complex }\end{array}$ & $\begin{array}{l}\text { Consociation- } \\
\text { Fluventic Ustropepts }\end{array}$ \\
\hline LM111 & $\begin{array}{l}\text { Low } \\
\text { Mountain }\end{array}$ & Hills & $\begin{array}{l}\text { predominantly Sh, } \\
\text { Ss and Ls (7) }\end{array}$ & $\begin{array}{l}\text { Slope facet } \\
\text { complex }\end{array}$ & $\begin{array}{l}\text { Typic Haplustulfs, } \\
\text { Typic Paleustalfs, } \\
\text { Lithic Ustorthens }\end{array}$ \\
\hline LM121 & $\begin{array}{l}\text { Low } \\
\text { Mountain }\end{array}$ & Hills & $\begin{array}{l}\text { Conglomerate, } \\
\text { Ss,Muds and Ls } \\
\text { (5) }\end{array}$ & $\begin{array}{l}\text { Summit } \\
\text { complex }\end{array}$ & $\begin{array}{l}\text { Inferred-Paleustalfs, } \\
\text { Dystropepts }\end{array}$ \\
\hline LM121/122 & $\begin{array}{l}\text { Low } \\
\text { Mountain }\end{array}$ & Hills & $\begin{array}{l}\text { Conglomerate, Ss, } \\
\text { Muds and Ls (5) }\end{array}$ & $\begin{array}{l}\text { Summit/back } \\
\text { slope } \\
\text { complex }\end{array}$ & $\begin{array}{l}\text { Inferred-Paleustalfs, } \\
\text { Dystrpepts, } \\
\text { Haplustulfs }\end{array}$ \\
\hline LM122 & $\begin{array}{l}\text { Low } \\
\text { Mountain }\end{array}$ & Hills & $\begin{array}{l}\text { Conglomerate, Ss, } \\
\text { Muds and Ls (5) }\end{array}$ & Back slope & $\begin{array}{l}\text { Typic Haplustulfs, } \\
\text { Rocks }\end{array}$ \\
\hline LM123 & $\begin{array}{l}\text { Low } \\
\text { Mountain }\end{array}$ & Hills & $\begin{array}{l}\text { Conglomerate, Ss, } \\
\text { Muds and Ls (5) }\end{array}$ & Foot slope & $\begin{array}{l}\text { Consociation-Typic } \\
\text { Haplustalfs }\end{array}$ \\
\hline LM211 & $\begin{array}{l}\text { Low } \\
\text { Mountain }\end{array}$ & Ridge & $\begin{array}{l}\text { Ss, Muds and Ls } \\
\text { (15) }\end{array}$ & $\begin{array}{l}\text { Slope facet } \\
\text { complex }\end{array}$ & $\begin{array}{l}\text { Ustoxic Dystropepts, } \\
\text { Typic Ustropepts }\end{array}$ \\
\hline LM312 & $\begin{array}{l}\text { Low } \\
\text { Mountain }\end{array}$ & Hogback & $\begin{array}{l}\text { Ss, Sh, Muds and } \\
\text { Ls (17) }\end{array}$ & Front & $\begin{array}{l}\text { Inferred-Paleustalfs, } \\
\text { Haplustalfs }\end{array}$ \\
\hline LM313 & $\begin{array}{l}\text { Low } \\
\text { Mountain }\end{array}$ & Hogback & $\begin{array}{l}\text { Ss, Sh, Muds and } \\
\text { Ls (17) }\end{array}$ & Talus & $\begin{array}{l}\text { Consociation-Ultic } \\
\text { Haplustalfs, } \\
\text { Typic Haplustalfs }\end{array}$ \\
\hline LM411 & $\begin{array}{l}\text { Low } \\
\text { Mountain }\end{array}$ & Swale & $\begin{array}{l}\text { Colluvio-alluvium } \\
\text { (4) }\end{array}$ & $\begin{array}{l}\text { Bottom } / \text { side } \\
\text { complex }\end{array}$ & $\begin{array}{l}\text { Aeric Tropaquepts, } \\
\text { Aeric Tropaqualfs, } \\
\text { Fluventic Ustropepts }\end{array}$ \\
\hline LM511 & $\begin{array}{l}\text { Low } \\
\text { Mountain }\end{array}$ & Vale & $\begin{array}{l}\text { Alluvio-Colluvium } \\
\text { (1) }\end{array}$ & $\begin{array}{l}\text { Bottom } / \text { side } \\
\text { complex }\end{array}$ & $\begin{array}{l}\text { Fluventic Ustropepts, } \\
\text { Aquic Ustifluvents, } \\
\text { Aeric Tropaquepts }\end{array}$ \\
\hline Pi111 & Piedmont & Hills & Residual (11) & $\begin{array}{l}\text { Slope facet } \\
\text { complex }\end{array}$ & $\begin{array}{l}\text { Typic Haplustalfs, } \\
\text { Ultic Paleustalfs, } \\
\text { Typic Haplustolls }\end{array}$ \\
\hline Pi211 & Piedmont & High glacis & Residual (11) & $\begin{array}{l}\text { tread-riser } \\
\text { complex } \\
\text { gentle } \\
\text { sloping to } \\
\text { undulating }\end{array}$ & $\begin{array}{l}\text { Typic Haplustults, } \\
\text { Ultic Paleustalfs, } \\
\text { Ultic Haplustalfs }\end{array}$ \\
\hline Pi212 & Piedmont & High glacis & Residual (11) & $\begin{array}{l}\text { tread-riser } \\
\text { complex } \\
\text { gentle } \\
\text { sloping to } \\
\text { undulating }\end{array}$ & $\begin{array}{l}\text { Typic Paleustulfs, } \\
\text { Typic Haplustalfs, } \\
\text { Typic Kandiustults }\end{array}$ \\
\hline Pi311 & Piedmont & $\begin{array}{l}\text { Middle } \\
\text { glacis }\end{array}$ & Residual (11) & $\begin{array}{l}\text { tread-riser } \\
\text { complex }\end{array}$ & $\begin{array}{l}\text { Typic Haplustalfs, } \\
\text { Ultic Haplustalfs, } \\
\text { Typic Ustropepts }\end{array}$ \\
\hline
\end{tabular}




\begin{tabular}{|c|c|c|c|c|c|}
\hline Map unit & Landscape & Relief & Lithology & Landform & Dominant soil classes \\
\hline$\overline{\mathrm{Pi} 311 / 811}$ & Piedmont & $\begin{array}{l}\text { Middle } \\
\text { glacis/Vale } \\
\text { complex }\end{array}$ & $\begin{array}{l}\text { Residual/Alluvio- } \\
\text { colluvium (12) }\end{array}$ & $\begin{array}{l}\text { Tread-riser, } \\
\text { Bottom side } \\
\text { complex }\end{array}$ & $\begin{array}{l}\text { Ultic Haplustalfs, } \\
\text { Typic Ustopepts, } \\
\text { Typic Ustifluvents }\end{array}$ \\
\hline Pi411 & Piedmont & Low glacis & $\begin{array}{l}\text { Residual/AAlluvio- } \\
\text { colluvium-12 }\end{array}$ & $\begin{array}{l}\text { tread-riser } \\
\text { complex }\end{array}$ & $\begin{array}{l}\text { Typic Usttropepts, } \\
\text { Typic Haplustalfs, } \\
\text { Aeric Paleustalfs }\end{array}$ \\
\hline Pi511 & Piedmont & $\begin{array}{l}\text { Spray } \\
\text { glacis }\end{array}$ & $\begin{array}{l}\text { Alluvio-colluvium } \\
\text { (1) }\end{array}$ & $\begin{array}{l}\text { spray glacis } \\
\text { facet } \\
\text { complex }\end{array}$ & $\begin{array}{l}\text { Typic Haplustalfs, } \\
\text { Fluventic Ustropepts, } \\
\text { Typic Ustropepts }\end{array}$ \\
\hline$\overline{P i 611}$ & Piedmont & Fan & Alluvium (2) & Apical & $\begin{array}{l}\text { Typic Haplustalfs, } \\
\text { Typic Haplustults, } \\
\text { Ultic Haplustalf }\end{array}$ \\
\hline Pi612 & Piedmont & Fan & Alluvium (2) & Distal & $\begin{array}{l}\text { Fluventic Ustropepts, } \\
\text { Ustic Dystropepts }\end{array}$ \\
\hline Pi613 & Piedmont & Fan & Alluvium (2) & $\begin{array}{l}\text { Apical-distal } \\
\text { complex }\end{array}$ & $\begin{array}{l}\text { Typic Haplustalfs, } \\
\text { Ultic Paleustalfs, } \\
\text { Utci Dystropepts }\end{array}$ \\
\hline Pi621 & Piedmont & Fan & $\begin{array}{l}\text { Alluvium/Residual- } \\
3\end{array}$ & $\begin{array}{l}\text { Dissected } \\
\text { apical-distal } \\
\text { complex }\end{array}$ & $\begin{array}{l}\text { Fluventic Ustropepts, } \\
\text { Ultic Haplustalfs, } \\
\text { Lithic Argiustolls }\end{array}$ \\
\hline Pi711 & Piedmont & Swale & $\begin{array}{l}\text { Colluvio-alluvium } \\
\text { (4) }\end{array}$ & $\begin{array}{l}\text { Bottom/side } \\
\text { complex }\end{array}$ & $\begin{array}{l}\text { Typic Eutropepts, } \\
\text { Typic Ustropepts, } \\
\text { Aeric Tropaquepts }\end{array}$ \\
\hline Pi811 & Piedmont & Vale & $\begin{array}{l}\text { Alluvio-colluvium } \\
\text { (1) }\end{array}$ & $\begin{array}{l}\text { Bottom } / \text { side } \\
\text { complex }\end{array}$ & $\begin{array}{l}\text { Aeric Tropaquepts, } \\
\text { Fluventics } \\
\text { Ustropepts, } \\
\text { Typic Ustifluents }\end{array}$ \\
\hline Va111 & Valley & Terrace & Alluvium (2) & $\begin{array}{l}\text { Tread-riser } \\
\text { complex }\end{array}$ & $\begin{array}{l}\text { Aeric Tropaquepts, } \\
\text { Fluventic Ustopepts }\end{array}$ \\
\hline Va112 & Valley & Terrace & Alluvium (2) & Levee & $\begin{array}{l}\text { Fluventic Ustropepts, } \\
\text { Typic Ustropepts }\end{array}$ \\
\hline Va113 & Valley & Terrace & Alluvium (2) & $\begin{array}{l}\text { Levee/overfl } \\
\text { ow mantle } \\
\text { complex }\end{array}$ & $\begin{array}{l}\text { Aeric Tropaquepts, } \\
\text { Fluventic Ustropepts }\end{array}$ \\
\hline$\overline{V a 114}$ & Valley & Terrace & Alluvium (2) & $\begin{array}{l}\text { Overflow } \\
\text { mantle }\end{array}$ & $\begin{array}{l}\text { Fluvaquentic } \\
\text { Eutropepts, } \\
\text { Typic Ustropepts, } \\
\text { Fulventic Ustropepts }\end{array}$ \\
\hline Va114/115 & Valley & Terrace & Alluvium (2) & $\begin{array}{l}\text { Overflow } \\
\text { mantle/ } \\
\text { Overflow } \\
\text { basin } \\
\text { complex }\end{array}$ & $\begin{array}{l}\text { Fluvaquentic } \\
\text { Eutropepts, } \\
\text { Fluventic Ustropepts, } \\
\text { Aquic Eutropepts }\end{array}$ \\
\hline Va115 & Valley & Terrace & Alluvium (2) & $\begin{array}{l}\text { Overflow } \\
\text { basin }\end{array}$ & $\begin{array}{l}\text { Fluvaquentic } \\
\text { Eutropepts, } \\
\text { AquicEutropepts, } \\
\text { Typic Tropaquepts }\end{array}$ \\
\hline
\end{tabular}




\begin{tabular}{|c|c|c|c|c|c|}
\hline Map unit & Landscape & Relief & Lithology & Landform & Dominant soil classes \\
\hline Va115/116 & Valley & Terrace & Alluvium (2) & $\begin{array}{l}\text { Overflow } \\
\text { basin/Decant } \\
\text { ation basin } \\
\text { complex }\end{array}$ & $\begin{array}{l}\text { Aquic Eutropepts, } \\
\text { Aeric Tropaquepts, } \\
\text { Fluvaquentic } \\
\text { Eutropepts }\end{array}$ \\
\hline Va116 & Valley & Terrace & Alluvium (2) & $\begin{array}{l}\text { Decantation } \\
\text { basin }\end{array}$ & $\begin{array}{l}\text { Aquic Eutropepts, } \\
\text { Aeric Tropaquepts, } \\
\text { Fluventic Eutropepts }\end{array}$ \\
\hline Va211 & Valley & Flood plain & Alluvium (2) & $\begin{array}{l}\text { Levee/basin } \\
\text { complex }\end{array}$ & $\begin{array}{l}\text { Fluventic Ustropepts, } \\
\text { Aquic Ustropepts, } \\
\text { Fluvaquentic } \\
\text { Eutropepts }\end{array}$ \\
\hline V1111 & $\begin{array}{l}\text { Lateral } \\
\text { Valley }\end{array}$ & $\begin{array}{l}\text { Terrace } \\
\text { complex }\end{array}$ & $\begin{array}{l}\text { Colluvio-alluvium } \\
\text { (4) }\end{array}$ & $\begin{array}{l}\text { Bottom } / \text { side } \\
\text { complex }\end{array}$ & $\begin{array}{l}\text { Aeric Tropaqualfs, } \\
\text { Aeric Haplustalfs }\end{array}$ \\
\hline V1112 & $\begin{array}{l}\text { Lateral } \\
\text { Valley }\end{array}$ & Depression & $\begin{array}{l}\text { Colluvio-alluvium } \\
\text { (4) }\end{array}$ & $\begin{array}{l}\text { Bottom/side } \\
\text { complex }\end{array}$ & $\begin{array}{l}\text { Aeric Tropaquepts, } \\
\text { Aeric Tropaqualfs }\end{array}$ \\
\hline V1112 & $\begin{array}{l}\text { Lateral } \\
\text { Valley }\end{array}$ & Depression & $\begin{array}{l}\text { Colluvio-alluvium } \\
\text { (4) }\end{array}$ & $\begin{array}{l}\text { Bottom/side } \\
\text { complex }\end{array}$ & $\begin{array}{l}\text { Aeric Tropaquepts, } \\
\text { Aeric Tropaqualfs }\end{array}$ \\
\hline Vt111 & $\begin{array}{l}\text { Trench } \\
\text { Valley }\end{array}$ & $\begin{array}{l}\text { Terrace } \\
\text { complex }\end{array}$ & $\begin{array}{l}\text { Alluvium/Residual } \\
\text { (3) }\end{array}$ & $\begin{array}{l}\text { Bottom/side } \\
\text { complex }\end{array}$ & $\begin{array}{l}\text { Typic Ustifluvents, } \\
\text { Typic Haplustalfs, } \\
\text { Ultic Paleustalfs }\end{array}$ \\
\hline Vt112 & $\begin{array}{l}\text { Trench } \\
\text { Valley }\end{array}$ & $\begin{array}{l}\text { High } \\
\text { terrace }\end{array}$ & $\begin{array}{l}\text { Alluvium/Residual } \\
\text { (3) }\end{array}$ & $\begin{array}{l}\text { Bottom } / \text { side } \\
\text { complex }\end{array}$ & $\begin{array}{l}\text { Consociation-Ultic } \\
\text { Paleustalfs, } \\
\text { Ultic Haplustalfs }\end{array}$ \\
\hline
\end{tabular}




\section{Appendix 2}

Table 2: Soil series (Scale 1: 50,000)

\begin{tabular}{|c|c|c|c|c|}
\hline No. & Series & $\begin{array}{l}\text { Lithologic } \\
\text { setting }\end{array}$ & $\begin{array}{l}\text { Soil Taxonomy } \\
\text { Classification }\end{array}$ & $\begin{array}{l}\text { Profile feature relevant to } \\
\text { gamma-rays }\end{array}$ \\
\hline 1 & $\begin{array}{l}\text { Bor Thai } \\
\text { (Bo) }\end{array}$ & $\begin{array}{l}\text { Residuum and } \\
\text { local colluvium } \\
\text { from sandstone }\end{array}$ & $\begin{array}{l}\text { Coarse- loamy, } \\
\text { kaolinitic, } \\
\text { isohyperthermic } \\
\text { Typic Eutrustox }\end{array}$ & $\begin{array}{l}\text { - Eutrustox is fixed on } \\
\text { soils that have a thick } \\
\text { oxen horizon. } \\
\text { - In B horizon is } \\
\text { underlain by loose } \\
\text { laterite gravel } \\
\text {-kaolinite clay resulted in } \\
\text { higher eTh } \\
\text { - Low fertility }\end{array}$ \\
\hline 2 & $\begin{array}{l}\text { Ban Chong } \\
(\mathrm{Bg})\end{array}$ & $\begin{array}{l}\text { Residuum and } \\
\text { local colluvium } \\
\text { from shale and } \\
\text { metamorphic } \\
\text { equivalents, }\end{array}$ & $\begin{array}{l}\text { Fine, kaolinitic, } \\
\text { isohyperthermic } \\
\text { Typic ( Kandic) } \\
\text { Paleustults. }\end{array}$ & $\begin{array}{l}\text { - Highly developed with } \\
\text { deep to very deep soil } \\
\text { - Low fertility }\end{array}$ \\
\hline 3 & $\begin{array}{l}\text { Chai Badan } \\
(\mathrm{Cd})\end{array}$ & $\begin{array}{l}\text { Residuum and } \\
\text { colluvium from } \\
\text { andesite and } \\
\text { occasionally } \\
\text { rhyolite }\end{array}$ & $\begin{array}{l}\text { Fine, smectitic, } \\
\text { isohyperthermic } \\
\text { Leptic Haplusterts }\end{array}$ & $\begin{array}{l}\text { Weathered parent rocks } \\
\text { in } 50 \mathrm{~cm} \text {. and lithic } \\
\text { contact within } 100 \mathrm{~cm} \text {. } \\
\text { - Slickenside } \\
\text { - Medium fertility }\end{array}$ \\
\hline 4 & $\begin{array}{l}\text { Dong Yang } \\
\text { En } \\
\text { (Don) }\end{array}$ & $\begin{array}{lr}\text { Alluvial fans } \\
\text { mostly } & \text { from } \\
\text { shale } & \text { and } \\
\text { siltstone. } & \end{array}$ & $\begin{array}{l}\text { fine- silty, mixed, } \\
\text { active } \\
\text { isohyperthermic } \\
\text { Oxyaquic ( Ultic) } \\
\text { Haplustalfs. }\end{array}$ & $\begin{array}{l}\text { - Moderately developed } \\
\text { sediment from shale and } \\
\text { siltstone } \\
\text { - Medium fertility }\end{array}$ \\
\hline 5 & $\begin{array}{l}\text { Hang Dong } \\
\text { (Hd) }\end{array}$ & $\begin{array}{l}\text { Alluvium and } \\
\text { occur on flood } \\
\text { plain and semi- } \\
\text { recent terraces. }\end{array}$ & $\begin{array}{l}\text { fine, mixed, semi } \\
\text { active } \\
\text { isohyperthermic } \\
\text { Typic Endoaqualfs. }\end{array}$ & $\begin{array}{l}\text { - Recent alluvial } \\
\text { materials developed soils } \\
\text { over alluvial plain }\end{array}$ \\
\hline
\end{tabular}

6 Lom Sak Recent alluvium fine- silty, mixed, - Silty clay loam or silty on the flood superactive, clay textured in the A and plain of the $\mathrm{Pa}$ nonacid, Bhorizons.
Sak River isohyperthermic - Medium to high fertility Fluvaquentic Endoaquepts.




\begin{tabular}{|c|c|c|c|c|}
\hline No. & Series & $\begin{array}{l}\text { Lithologic } \\
\text { setting }\end{array}$ & $\begin{array}{l}\text { Soil Taxonomy } \\
\text { Classification }\end{array}$ & $\begin{array}{l}\text { Profile feature relevant to } \\
\text { gamma-rays }\end{array}$ \\
\hline 7 & $\begin{array}{l}\text { Lom Kao } \\
\text { (Lk) }\end{array}$ & $\begin{array}{lr}\text { Alluvium } & \text { on } \\
\text { level or } & \text { nearly } \\
\text { level } & \text { low } \\
\text { terraces } & \end{array}$ & $\begin{array}{l}\text { fine-loamy, mixed, } \\
\text { semi active } \\
\text { isohyperthermic } \\
\text { Typic ( Aquic) } \\
\text { Paleustults. They } \\
\text { are very deep soils }\end{array}$ & $\begin{array}{l}\text { - Sandy loam texture in A } \\
\text { and B horizons } \\
\text { - Low fertility }\end{array}$ \\
\hline 8 & $\begin{array}{l}\text { Mae Rim } \\
(\mathrm{Mr})\end{array}$ & $\begin{array}{l}\text { Old gravelly and } \\
\text { cobbly alluvium } \\
\text { on undulating to } \\
\text { hilly relief of } \\
\text { dissected older } \\
\text { terraces and } \\
\text { alluvial fans. }\end{array}$ & $\begin{array}{l}\text { loamy- skeletal, } \\
\text { mixed, } \\
\text { isohyperthermic } \\
\text { Typic ( Kandic) } \\
\text { Paleustuults. They } \\
\text { are gravelly and } \\
\text { cobbly soils. }\end{array}$ & $\begin{array}{l}\text { - Loamy sand textured in } \\
\text { topsoil } \\
\text { - They are gravelly and } \\
\text { cobbly soils. Gravels and } \\
\text { cobbles occur within } 50 \\
\text { cm of the soil surface. } \\
\text { - Low fertility }\end{array}$ \\
\hline 9 & $\begin{array}{l}\text { Nam Len } \\
(\mathrm{Nal})\end{array}$ & $\begin{array}{l}\text { Alluvium on the } \\
\text { terrace. Relief is } \\
\text { undulating to } \\
\text { gently rolling }\end{array}$ & $\begin{array}{l}\text { Nam Len series is a } \\
\text { member of very } \\
\text { fine, smectitic, } \\
\text { isohyperthermic } \\
\text { Aquertic } \\
\text { Paleustalfs. }\end{array}$ & $\begin{array}{l}\text { - Clay loam to clay A and } \\
\text { B horizon } \\
\text { - Medium fertility }\end{array}$ \\
\hline 10 & $\mathrm{~Np}$ & $\begin{array}{l}\text { recent alluvial } \\
\text { on the flood } \\
\text { plain or terrace }\end{array}$ & $\begin{array}{l}\text { Fine, mixed, active, } \\
\text { isohyperthermic } \\
\text { Aeric Endoaqualfs }\end{array}$ & $\begin{array}{l}\text { - Clay loam to clay A and } \\
\text { B horizon } \\
\text { - High fertility }\end{array}$ \\
\hline 11 & $\begin{array}{l}\text { Phetchabun } \\
\text { (Pe) }\end{array}$ & $\begin{array}{l}\text { Alluvium on the } \\
\text { terrace. Relief is } \\
\text { undulating to } \\
\text { gently rolling }\end{array}$ & $\begin{array}{l}\text { Phetchabun series } \\
\text { is a member of fine- } \\
\text { loamy, mixed, semi } \\
\text { active, } \\
\text { isohyperthermic } \\
\text { Ultic Paleustalfs. }\end{array}$ & $\begin{array}{l}\text { - Sandy loam or loam } \\
\text { textured in A horizon } \\
\text { - Sandy loam over clayey } \\
\text { skeletal in B horizon } \\
\text { - Low fertility }\end{array}$ \\
\hline 12 & $\begin{array}{l}\text { Phimai } \\
(\mathrm{Pm})\end{array}$ & $\begin{array}{l}\text { Recent alluvium } \\
\text { on flood plain }\end{array}$ & $\begin{array}{l}\text { Very- fine, } \\
\text { semectitic , } \\
\text { isohyperthermic } \\
\text { Ustic Endoaquepts. }\end{array}$ & $\begin{array}{l}\text { - Deep young soils with } \\
\text { clay loam to clay in A } \\
\text { and B horizons } \\
\text { - Slickenside } \\
\text { - Medium fertility }\end{array}$ \\
\hline 13 & $\begin{array}{l}\text { Saraburi } \\
(\mathrm{Sb})\end{array}$ & $\begin{array}{l}\text { Alluvium and on } \\
\text { low- lying parts } \\
\text { of the terrace or } \\
\text { on transitional } \\
\text { parts between }\end{array}$ & $\begin{array}{l}\text { Saraburi series is a } \\
\text { member of the } \\
\text { Very- fine, mixed, } \\
\text { active, non- acid, } \\
\text { isohyperthermic }\end{array}$ & $\begin{array}{l}\text { - Young alluvial soil with } \\
\text { clay or silty clay in A and } \\
\text { B horizons } \\
\text { - Slickensides, pressure } \\
\text { faces, and few, small }\end{array}$ \\
\hline
\end{tabular}




\begin{tabular}{|c|c|c|c|c|}
\hline No. & Series & $\begin{array}{l}\text { Lithologic } \\
\text { setting }\end{array}$ & $\begin{array}{l}\text { Soil Taxonomy } \\
\text { Classification }\end{array}$ & $\begin{array}{l}\text { Profile feature relevant to } \\
\text { gamma-rays }\end{array}$ \\
\hline & & $\begin{array}{l}\text { the terrace and } \\
\text { flood plain }\end{array}$ & $\begin{array}{l}\text { Vertic ( Aeric) } \\
\text { Endoaquepts. }\end{array}$ & $\begin{array}{l}\text { iron/manganese nodules } \\
\text { occur in the B horizon } \\
\text { - Medium fertility }\end{array}$ \\
\hline 14 & $\begin{array}{l}\text { Sakon } \\
\text { (Sk) }\end{array}$ & $\begin{array}{l}\text { Washed deposit } \\
\text { over siltstone } \\
\text { and/ or shale } \\
\text { occurring on the } \\
\text { wash surface. }\end{array}$ & $\begin{array}{l}\text { loamy-skeletal over } \\
\text { fragmental } \\
\text { mixed, sub active, } \\
\text { isohyperthermic, } \\
\text { Petroferric } \\
\text { Haplustults }\end{array}$ & $\begin{array}{l}\text { - They are shallow soil to } \\
\text { sheet of laterite layer } \\
\text { with in } 50 \mathrm{~cm} \text {. } \\
\text { - Low fertility }\end{array}$ \\
\hline 15 & $\begin{array}{l}\text { Sop Prap } \\
\text { (So) }\end{array}$ & $\begin{array}{lr}\text { Residual basalt } \\
\text { occurring } \\
\text { dissected } \\
\text { lava } \\
\text { flows }\end{array}$ & $\begin{array}{l}\text { fine, smectitic, } \\
\text { isohyperthermic, } \\
\text { Lithic Haplustolls. }\end{array}$ & $\begin{array}{l}\text { - A Weathering zone } \\
\text { which grades to bedrock } \\
\text { within } 50 \mathrm{~cm} \text { of the soil } \\
\text { surface } \\
\text { - moderate fertility }\end{array}$ \\
\hline 16 & $\begin{array}{l}\text { Tha Li } \\
\text { (Tl) }\end{array}$ & $\begin{array}{l}\text { Residuum and } \\
\text { colluvium from } \\
\text { andesite and } \\
\text { equivalent } \\
\text { igneous rocks }\end{array}$ & $\begin{array}{l}\text { Gravelly and } \\
\text { moderately deep } \\
\text { soils with clayey- } \\
\text { skeletal, mixed, } \\
\text { semi active } \\
\text { isohyperthermic } \\
\text { Ultic Haplustalfs. }\end{array}$ & $\begin{array}{l}\text { - They are gravelly and } \\
\text { moderately deep soils, } \\
\text { weathered and/ or partly } \\
\text { weathered rock } \\
\text { fragments usually occur } \\
\text { throughout the profile, } \\
\text { increasing with depth } \\
\text { - Medium fertility }\end{array}$ \\
\hline 17 & $\begin{array}{l}\text { Tha Muang } \\
\text { (Tm) }\end{array}$ & $\begin{array}{l}\text { Recent alluvium } \\
\text { occurring on the } \\
\text { floodplains. } \\
\text { higher parts of } \\
\text { river and stream } \\
\text { levees. }\end{array}$ & $\begin{array}{l}\text { coarse- loamy, } \\
\text { mixed, active, } \\
\text { calcareous, } \\
\text { isohyperthermic } \\
\text { Typic Ustifluvents. }\end{array}$ & $\begin{array}{l}\text { - Alluvial young soil } \\
\text { with fine to coarse } \\
\text { textured in } A \text { and } B \\
\text { horizon } \\
\text { - Medium fertility }\end{array}$ \\
\hline 18 & $\begin{array}{l}\text { Tha Phon } \\
\text { (Tn) }\end{array}$ & $\begin{array}{l}\text { Recent alluvium } \\
\text { occurring on the } \\
\text { alluvial fan } \\
\text { mostly from } \\
\text { andesite and } \\
\text { basalt }\end{array}$ & $\begin{array}{l}\text { fine, mixed, } \\
\text { superactive, non- } \\
\text { acid, } \\
\text { isohyperthermic } \\
\text { Aeric Tropaquepts. }\end{array}$ & $\begin{array}{l}\text { - Parent material is recent } \\
\text { alluvium to develop } \\
\text { young soil in Order } \\
\text { Inceptisols } \\
\text { - Medium fertility }\end{array}$ \\
\hline 19 & $\begin{array}{l}\text { Thap } \\
\text { Khwang } \\
\text { (Tw) }\end{array}$ & $\begin{array}{l}\text { Residuum } \\
\text { and/ or } \\
\text { colluvium from } \\
\text { shale and lime } \\
\text { stone }\end{array}$ & $\begin{array}{l}\text { Fine, mixed, } \\
\text { isohyperthermic } \\
\text { Ultic Paleustalfs }\end{array}$ & $\begin{array}{l}\text { - Clay loam to clay in A } \\
\text { and B horizons } \\
\text { - Medium fertility }\end{array}$ \\
\hline
\end{tabular}




\section{References}

Aili, L., 2008. DEM-based analysis of local relief. In: Q. Zhou, B. Lees, G.-a. Tang (Eds.), Advances in Digital Terrain Analysis. Lecture Notes in Geoinformation and Cartography. Springer Berlin Heidelberg, pp. 177192.

An, P., Chung, C.F., Rencz, A.N., 1995. Digital lithology mapping from airborne geophysical and remote sensing data in the Melville Peninsula, Northern Canada, using a neural network approach. Remote Sensing of Environment 53(2), 76-84.

Angsuwathana, P., Chotikanatis, P., 1997. Back ground radiation map of Thailand, Department of Mineral Resources, Ministry of Industry, Bangkok, Thailand.

Anusontpornperm, S., Thanachit, S., Kheoruenromne, I., Suddhiprakarn, A., Wiriyakitnateekul, W., 2012. Soil Degradation in Thailand: the Obstacles to Soil Management Sustainability, Sustainable Land Management to Enhance Food Production of APEC Member, Imperial Mae Ping Hotel, Chiang Mai, Thailand.

Arnold, R.W., 2006. What do we really know about the space-time continuum of soil-landscapes? In: S. Grunwald (Ed.), Environmental soil-landscape modeling : geographic information technologies and pedometrics. Books in soils, plants, and the environment. CRC/Taylor \& Francis, Boca Raton, pp. 38-59.

Arrouays, D., Grundy, M.G., Hartemink, A.E., Hempel, J.W., Heuvelink, G.B.M., Hong, S.Y., Lagacherie, P., Lelyk, G., McBratney, A.B., McKenzie, N.J., Mendonca-Santos, M.d.L., Minasny, B., Montanarella, L., Odeh, I.O.A., Sanchez, P.A., Thompson, J.A., Zhang, G.-L., 2014a. GlobalSoilMap. Advances in Agronomy 125, 93-134.

Arrouays, D., McKenzie, N., Hempel, J., Forges, A.R.d., McBratney, A.B., 2014b. GlobalSoilMap: Basis of the global spatial soil information system. Taylor and Francis.

Beaudette, D., O'Geen, A., Oster, K., Bullard, V., Southard, S., Smith, D.W., Biggam, a.P., 2006. Integrating soil survey, research, and outreach in California's National Parks, 18th World Congress of Soil Science, July 9-15, 2006 - Philadelphia, Pennsylvania, USA.

Beckett, P.H.T., Burrough, P.A., 1971. The Relation between Cost and Utility in Soil Survey. Journal of Soil Science 22(4), 466-480.

Behrens, T., Förster, H., Scholten, T., Steinrücken, U., Spies, E., Goldschmitt, M., 2005a. Digital soil mapping using artificial neural networks. Journal of Plant Nutrition and Soil Science 168(1), 21-33.

Behrens, T., Forster, H., Scholten, T., Steinrucken, U., Spies, E.D., Goldschmitt, M., 2005b. Digital soil mapping using artificial neural networks. Journal 
of Plant Nutrition and Soil Science-Zeitschrift Fur Pflanzenernahrung Und Bodenkunde 168(1), 21-33.

Bell, J.C., Cunningham, R.L., Havens, M.W., 1992. Calibration and validation of a soil-landscape model for predicting soil drainage class. Soil Sci Soc Am J 56(6), 1860-1866.

Bell, J.C., Cunningham, R.L., Havens, M.W., 1994. Soil drainage class probability mapping using a soil-landscape model. Soil Sci Soc Am J 58(2), 464-470.

Bell, J.C., Grigal, D.F., Bates, P.C., 2000. Chapter 12: a soil-terrain model for estimating spatial patterns of soil organic carbon. In: J.P. Wilson, J.C. Gallant (Eds.), Terrain analysis : principles and applications. Wiley, New York, pp. 295.

Bennema, J., Gelens, H.F., 1969. Aerial photo-interpretation for soil surveys, ITC lecture notes. ITC, Enschede, pp. 87.

Bierwirth, P.N., Gessler, P., McKane, D., 1996. Empical investigation of airborne gamma-ray images as an indicator of soil properties - Wagga Wagga, NSW., NSW. 8th Australasian Remote Sensing Conference Proceedings, Canberra.

Bishop, T.F.A., Minasny, B., 2006. Digital Soil-Terrain Modeling: The predictive Potential and Uncertainty. In: S. Grunwald (Ed.), Environmental soil-landscape modeling : geographic information technologies and pedometrics. Books in soils, plants, and the environment. CRC/Taylor \& Francis, Boca Raton, pp. 185-213.

Boer, M., DelBarrio, G., Puigdefabregas, J., 1996. Mapping soil depth classes in dry Mediterranean areas using terrain attributes derived from a digital elevation model. Geoderma 72(1-2), 99-118.

Boettinger, J.L., 2010. Digital soil mapping : Bridgind research, enviroment application and operation. Progress in Soil Science; 2. Springer Science+Business Media B.V., Dordrecht.

Brown, D.J., Clayton, M.K., McSweeney, K., 2004. Potential terrain controls on soil color, texture contrast and grain-size deposition for the original catena landscape in Uganda. Geoderma 122(1), 51-72.

Bui, E., 1999. A soil information strategy for the Murray-Darling Basin (MDBSIS). PROJECT D5038

Burrough, P.A., Beckett, P.H.T., Jarvis, M.G., 1971. Relation between Cost and Utility in Soil Survey. J Soil Sci 22(3), 359-\&.

Burrough, P.A., McDonell, R.A., 1998. Principles of Geographical Information Systems. Oxford University Press, New York).

Burt, J.E., Zhu, Q., Simonson, D., Hunt, T., Zhu, A.X., 2006. High-resolution soil survey using SoLIM based on 1-foot DEM., 18th World Congress of Soil Science, July 9-15, 2006 - Philadelphia, Pennsylvania, USA.

Carrier, F., Bourdon, B., Pili, É., Truffert, C., Wyns, R., 2006. Airborne gammaray spectrometry to quantify chemical erosion processes. Journal of Geochemical Exploration 88(1-3), 266-270. 
Carvalho Junior, W., Fernandes Filho, E.I., Vieira, C.A.O., Schaefer, C.E.G.R., Chagas, C.S., 2008. Chapter 32 Geomorphometric Attributes Applied to Soil-Landscapes Supervised Classification of Mountainous Tropical Areas in Brazil:A Case Study. In: A.E. Hartemink, A.B. McBratney, M.d.L. Mendonça-Santos (Eds.), Digital soil mapping with limited data. Springer, Dordrecht ; London, pp. 357-380.

Chagas, C.D., de Carvalho, W., Bhering, S.B., 2011a. Integration of Quickbird Data and Terrain Attributes for Digital Soil Mapping by Artificial Neural Networks. Rev Bras Cienc Solo 35(3), 693-704.

Chagas, C.D., de Carvalho, W., Bhering, S.B., 2011b. Integration of Quickbird Data and Terrain Attributes for Digital Soil Mapping by Artificial Neural Networks. Revista Brasileira De Ciencia Do Solo 35(3), 693-704.

Chaplot, V., Walter, C., Curmi, P., 2000. Improving soil hydromorphy prediction according to DEM resolution and available pedological data. Geoderma 97(3-4), 405-422.

Choi, M., 2006. A new intensity-hue-Saturation fusion approach to image fusion with a tradeoff parameter. EEE Transactions On Gescience and Remote Sensing 44(6), 11.

Claridge, J., Grundy, M.J., 2004. Prediction of Fine Scale Soil Attribute and Deep Drainage, ISCO 2004 - 13th International Soil Conservation Organisation Conference - Brisbane, July 2004, Conserving Soil and Water for Society: Sharing Solutions, Brisbane.

Cook, S.E., Corner, R.J., Groves, P.R., Grealish, G.J., 1996. Use of airborne gamma radiometric data for soil mapping. Australian Journal of Soil Research 34(1), 183-194.

Dehn, M., Gartner, H., Dikau, R., 2001. Principles of semantic modeling of landform structures. Computers \& Geosciences 27(8), 1005-1010.

Deng, Y.X., Wilson, J.P., Bauer, B.O., 2007. DEM resolution dependencies of terrain attributes across a landscape. International Journal of Geographical Information Science 21(1-2), 187-213.

Department of Mineral Resource, 2005. Geological map of the northern Thailand: Petcha Bun sheet, pp. 1.

Desta, T.F., 2009. Spatial modeling and timely prediction of salinization using SAHYSMOD in GIS environment [Dissertation], Enschede, Netherlands.

Dickson, B.L., Fraser, S.J., Kinsey-Henderson, A., 1996. Interpreting aerial gamma-ray surveys utilising geomorphological and weathering models. Journal of Geochemical Exploration 57(1-3), 75-88.

Dickson, B.L., Scott, K.M., 1997. Interpretation of Aerial Gamma-Ray SurveysAdding The Geochemial Factors. AGSO Journal of Australia Geology\&Geophysics 17(2), 187-200.

Dobos, E., Carr, F., Hengl, T., Reuter, H.I., Tóth, G., 2006. Digital Soil Mapping as a Support to Production of Functional Maps, Office for Official Publications of the European Communities, Luxemburg. 
Dobos, E., Hengl, T., 2009. Soil Mappling Applications. In: T. Hengl, H.I. Reuter (Eds.), Geomorphometry : concept, software, applications : also as ebook.Developments in soil science;33. Elsevier Science, Amsterdam, pp. 461-479.

Dobos, E., Micheli, E., Baumgardner, M.F., Biehl, L., Helt, T., 2000. Use of combined digital elevation model and satellite radiometric data for regional soil mapping. Geoderma 97(3-4), 367-391.

Dobos, E., Montanarella, L., 2007. Chapter 9 The Development of A Quantitative Procedure for Soilscape Delineation Using Digital Elevation Data for Europe. In: P. Lagacherie, A.B. McBratney, M. Voltz (Eds.), Digital soil mapping : an introductory perspective. Developments in soil science. Elsevier, Amsterdam ; Boston, pp. 107-117.

ESRI-Thailand, 2006. DEM producing and processing : Map for natural resources management project of Ministry of Agriculture \& Coorperatives. Ministry of Agriculture \& Coorperatives. (in Thai). Bangkok, Thailand.

Everitt, B., Hothorn, T., 2011. An Introduction to Applied Multivariate Analysis with R. Springer Science+Business Media,. Springer

FAO., 1976. A framework for land evaluation. FAO Soils Bulletin 32. Rome, Italy: Food and Agriculture Organization of the United Nations.

Farshad, A., Udomsri, S., Hansakdi, E., Shrestha, D.P., 2006. Computer-assisted Geopedology, a Way to Predictive Soil Mapping., 18th World Congress of Soil Science, Phildelphia, Pennsylvania, USA.

Federation Univeristy, 2017. Collaboration work space for Australian digitalsoil mapping (OzDSM).

Florinsky, I.V., 2012. Digital terrain analysis in soil science and geology. Elsevier, Oxford.

Foody, G.M., 1996. Fuzzy modelling of vegetation from remotely sensed imagery. Ecological Modelling 85(1), 3-12.

Forbes, T., Rossiter, D.G., van Wambeke, A., 1987. Guidelines for evaluating the adequacy of soil resource inventories. Technical Monograph : Soil management support services 4, p. ISBN: 0-932865-07-0. Cornell University, Department of Agronomy, New York State College of Agriculture and Life Sciences ; U.S. Department of Agriculture, Soil Conservation Service, Soil Management Support Service (SMSS), 1987. SMSS, Ithaca ; Washington, D.C.

Geomorphometry.org, 2009. Geomorphometry.

Gessler, P.E., Chadwick, O.A., Chamran, F., Althouse, L., Holmes, K., 2000. Modeling Soil-Landscape and Ecosystem Properties Using Terrain Attributes. Soil Sci Soc Am J 64(6), 2046-2056.

Gobin, A., Campling, P., Feyen, J., 2001. Soil-landscape modelling to quantify spatial variability of soil texture. Physics and Chemistry of the Earth, Part B: Hydrology, Oceans and Atmosphere 26(1), 41-45. 
Goosen, D., 1967. Aerial photo interpretation in soil survey. Food and agriculture organisation of the United Nations, Rome, pp. 55.

Grasty, R.L., 1993. Environmental monitoring by airborne gamma-ray spectrometry, experience at the geological survey of Canada. IAEATECDOC-827, International Atomic Energy Agency.

Grasty, R.L., 1997. Radon emanation and soil moisture effects on airborne gamma-ray measurements. Geophysics 62(5), 1379-1385.

Grimm, R., Behrens, T., Marker, M., Elsenbeer, H., 2008. Soil organic carbon concentrations and stocks on Barro Colorado Island â€" Digital soil mapping using Random Forests analysis. Geoderma 146(1-2), 102-113.

Grunwald, S., 2006a. Environmental soil-landscape modeling : geographic information technologies and pedometrics. Books in soils, plants, and the environment. CRC/Taylor \& Francis, Boca Raton.

Grunwald, S., 2006b. What Do We Really Know about the Space-Time Continuum of Soil-Landscapes? In: S. Grunwald (Ed.), Environmental soil-landscape modeling : geographic information technologies and pedometrics. Books in soils, plants, and the environment. CRC/Taylor \& Francis, Boca Raton, pp. 4-36.

Gunn, P.J., Minty, B.R.S., Milligan, P.R., 1997. The airborne gamma-ray spectrometric response over arid Australian terranes. In: A.G. Gubins (Ed.), Geophysics and Geochemistry at the Millenium, Proceedings of Exploration 97: Fourth Decennial International Conference on Mineral Exploration, pp. 733-740.

Hansakdi, E., 1998. Soil pattern analysis and the effect of soil variability on land use in the upper Pasak area Phetchabun, Thailand, ITC, Enschede, 139 pp.

Hartemink, A.E., 2008. Soil map density and nation's wealth and income. In: A.B.M. A.E. Hartemink, M.L. Mendonca-Santos (Ed.), Digital Soil Mapping With Limited Data. Springer, Dordrecht, pp. 53-66.

Hengl, T., de Jesus, J.M., MacMillan, R.A., Batjes, N.H., Heuvelink, G.B.M., Ribeiro, E., Samuel-Rosa, A., Kempen, B., Leenaars, J.G.B., Walsh, M.G., Gonzalez, M.R., 2014. SoilGrids1km - Global Soil Information Based on Automated Mapping. PLOS ONE 9(8), e105992.

Hengl, T., Gruber, M., Shrestha, D.P., 2003. Digital terrain analysis in ILWIS : lecture note, ITC, Enschede.

Hengl, T., Husnjak, S., 2006. Evaluating Adequacy and Usability of Soil Maps in Croatia. Soil Sci Soc Am J 70(3), 920-929.

Hengl, T., Mendes de Jesus J, Heuvelink GBM, Ruiperez Gonzalez M, Kilibarda M, Blagotić A, 2017a. SoilGrids250m: Global gridded soil information based on machine learning. PLoS ONE 12(2).

Hengl, T., Mendes de Jesus, J., Heuvelink, G.B.M., Ruiperez Gonzalez, M., Kilibarda, M., Blagotić, A., Shangguan, W., Wright, M.N., Geng, X., Bauer-Marschallinger, B., Guevara, M.A., Vargas, R., MacMillan, R.A., Batjes, N.H., Leenaars, J.G.B., Ribeiro, E., Wheeler, I., Mantel, S., 
Kempen, B., 2017b. SoilGrids250m: Global gridded soil information based on machine learning. PLOS ONE 12(2), e0169748.

Hengl, T., Reuter, H.I., 2009. Geomorphometry : concept, software, applications : also as e-book. Developments in soil science ; 33, 33. Elsevier Science, Amsterdam.

Hengl, T., Toomanian, N., Reuter, H.I., Malakouti, M.J., 2007. Methods to interpolate soil categorical variables from profile observations: Lessons from Iran. Geoderma 140(4), 417-427.

Hosmer, D.W., Lemeshow, S., 2000. Applied Logistic Regression, 2nd Edition. Wiley Series in Probability and Statistics

Texts and References Section. John Wiley \& Sons, Inc., , New York.

Huang, J., Lark, R.M., Robinson, D.A., Lebron, I., Keith, A.M., Rawlins, B., Tye, A., Kuras, O., Raines, M., Triantafilis, J., 2014. Scope to predict soil properties at within-field scale from small samples using proximally sensed $\gamma$-ray spectrometer and EM induction data. Geoderma 232-234, 69-80.

Ibán`ez, J.J., De-Albs, S., Bermúdez, F.F., García-Álvarez, A., 1995. Pedodiversity: concepts and measures. CATENA 24(3), 215-232.

International Atomic Energy Agency, 2003. Guidelines for radioelement mapping using gamma ray spectrometry data Printed by the IAEA in Austria

ITC, I.D., 2001. ILWIS 3.0 Academic user's guide. ENSCHEDE.

Jackson, M.L., 1965 Soil chemical analysis-advanced course. Department of Soils, University of Wisconsin.

Jaques, A.L., Wellman, P., Whitaker, A., Wyborn, D., 1997. High-resolution geophysics in modern geological mapping. AGSO J. Aus. Geol. Geophys 17(2), 159-174.

Jenness, J., 2005. Topographic Position Index (tpi_jen.avx) Extenstion for ArcView 3.x. Jenness Enterprises.

Jenness, J., B. Brost, P. Beier., 2011. Land Facet Corridor Designer: Extension for ArcGIS. Jenness Enterprises. Available at: .

Jenny, H., 1941. Factors of soil formation; a system of quantitative pedology. McGraw-Hill publications in the agricultural sciences L.J. Cole, consulting ed. 1st ed. McGraw-Hill, New York, London.

Kennelly, P.J., 2008. Terrain maps displaying hill-shading with curvature. Geomorphology 102(3â€“4), 567-577.

Kenting Earth Science International limited (KESIL), 1982. The follow-up survey report of the Phetchabun area for airborne geophysical survey, The Mineral resource Department Project of the Department of Mineral Resource, Thailand, contact no.50/2527.

Keskin, H., Grunwald, S., Harris, W.G., 2019. Digital mapping of soil carbon fractions with machine learning. Geoderma 339, 40-58. 
Lacoste, M., Lemercier, B., Walter, C., 2011. Regional mapping of soil parent material by machine learning based on point data. Geomorphology 133(1-2), 90-99.

Lagacherie, P., 2008. Digital Soil Mapping: A State of the Art. In: A. Hartemink, A. McBratney, M.L. Mendonca-Santos (Eds.), Digital Soil Mapping with Limited Data. Springer Netherlands, pp. 3-14.

Land Development Department, 2009a. Development of methodologies for land degradation assessment applied to land use planning in Thailand

Land Development Department, 2009b. Orthophograph and Map Information Survices, Bangkok.

Land Development Department, 2016. Strategies of Land Development Department, For the 12th National Economic and Social Development Plan 2017-2021 (in Thai). In: L.D. Department (Ed.). Land Development Department, Bangkok, pp. 24-28.

Land Development Department, 2017. Land development strategies, Strategies for Land Development under 12th plan Bangkok.

Lark, R.M., 1999. Soil-landform relationships at within-field scales: an investigation using continuous classification. Geoderma 92(3-4), 141165.

Li, Z., Zhu, Q., Gold, C., 2005. Chapter 9: Multi-Scale Representationsof Digital Terrain Models. In: Z. Li, Q. Zhu, C. Gold (Eds.), Digital terrain modeling: principles and methodology. CRC PRESS, Washington, D.C., pp. 200-218.

Logsdon, S.D., Perfect, E., Tarquis, A.M., 2008. Multiscale Soil Investigations: Physical Concepts and Mathematical Techniques. Vadose Zone J. 7(2), 453-455.

Lorenzetti, R., Barbetti, R., Fantappiè, M., L'Abate, G., Costantini, E.A.C., 2015. Comparing data mining and deterministic pedology to assess the frequency of WRB reference soil groups in the legend of small scale maps. Geoderma 237-238, 237-245.

McBratney, A.B., De Gruijter, J.J., Brus, D.J., 1992. Spacial prediction and mapping of continuous soil classes. Geoderma 54(1-4), 39-64.

McBratney, A.B., M.Santos, M.L., Minasny, B., 2003. On digital soil mapping. Geoderma 117(1-2), 3-52.

McBratney, A.B., Odeh, I.O.A., 1997. Application of fuzzy sets in soil science: fuzzy logic, fuzzy measurements and fuzzy decisions. Geoderma 77(2), $85-113$.

McBratney, A.B., Odeh, I.O.A., Bishop, T.F.A., Dunbar, M.S., Shatar, T.M., 2000. An overview of pedometric techniques for use in soil survey. Geoderma 97(3\&4), 293-327.

Mendonça-Santos, M.L., McBratney, A.B., Minasny, B., 2006. Chapter 21 Soil Prediction with Spatially Decomposed Environmental Factors. In: P. Lagacherie, A.B. McBratney, M. Voltz (Eds.), Developments in Soil Science. Elsevier, pp. 269-278. 
Minasny, B., McBratney, A.B., 2006. A conditioned latin hypercube method for sampling in the presence of ancillary information. Computers \&amp; Geosciences 32(9), 1378-1388.

Minty, B.R.S., 1997. Fundanmentals of airborne gamma-ray spectrometry. AGSO Journal of Australia Geology\&Geophysics 17(2), 39-50.

Minty, B.R.S., Luyendyk, A.P.J., Brodie, R.C., 1997. Calibration and data processsing for airborne gamma-ray spectrometry. AGSO Journal of Australia Geology\&Geophysics 17(2), 51-62.

Moonjun, R., 2007. Application of artificial neural network and decision tree in a GIS - based predictive soil mapping for landslide vulnerability study : a case study of Hoi Num Rin sub - watershed, Thailand, ITC, Enschede, $104 \mathrm{pp}$.

Moonjun, R., Farshad, A., Shrestha, D.P., Vaiphasa, C., 2008. Application of artificial neural network and decision tree in a GIS - based predictive soil mapping in sloping areas in Thailand. Presented at the 3rd global workshop on digital soil mapping, 30 September - 3 October, Utah State University, Logan, Utah. 10 p.

Moonjun, R., Shrestha, D.P., Jetten, V.G., van Ruitenbeek, F.J.A., 2017. Application of airborne gamma-ray imagery to assist soil survey: A case study from Thailand. Geoderma 289, 196-212.

Moore, I.D., Gessler, P.E., Nielsen, G.A., Peterson, G.A., 1993. Soil Attribute Prediction Using Terrain Analysis. Soil Sci. Soc. Am. J. 57(2), 443-452.

Moore, I.D., Grayson, R.B., A. R. Ladson, 1991. Digital terrain modelling: A review of hydrological, geomorphological, and biological applications. Hydrological Processes 5(1), 3-30.

Moore, I.D.G., P.E.; Nielsen, G.A.; Petersen, G.A 1993. Terrain attributes: estimation methods and scale effects. In: A.J.B. Jakeman, M.B.; McAleer, M. (Ed.), Modelling Change in Environmental Systems. Wiley, London, pp. 189-214.

Mulder, V.L., de Bruin, S., Schaepman, M.E., Mayr, T.R., 2011a. The use of remote sensing in soil and terrain mapping -- A review. Geoderma 162(12), $1-19$

Mulder, V.L., de Bruin, S., Schaepman, M.E., Mayr, T.R., 2011b. The use of remote sensing in soil and terrain mapping - A review.

Nearinga, M.A., V. Jettenb, C. Baffautc, O. Cerdand, A. Couturierd, M. Hernandeza, Y. Le Bissonnaise, M.H. Nicholsa, J.P. Nunesf, C.S. Renschlerg, V. Souche'reh, K. van Oosti, 2005. Modeling Response of Soil Erosion and Runoff to Changes in Precipitation and Cover, Impacts of Global Climate Change.

Nikhil, S., Venkatesh, M., 2015. A Faster and Economical Approach to Floodplain Mapping Using Soil Information. JAWRA Journal of the American Water Resources Association 51(5), 1286-1304.

Pahlavan-Rad, M.R., Khormali, F., Toomanian, N., Brungard, C.W., Kiani, F., Komaki, C.B., Bogaert, P., 2016. Legacy soil maps as a covariate in 
digital soil mapping: A case study from Northern Iran. Geoderma 279, 141-148.

Paradella, W.R., Bignelli, P.A., Veneziani, P., Pietsch, R.W., Toutin, T., 1997. Airborne and spaceborne Synthetic Aperture Radar (SAR) integration with Landsat TM and gamma ray spectrometry for geological mapping in a tropical rainforest environment, the Carajas Mineral Province, Brazil. International Journal of Remote Sensing 18(7), 1483-1501.

Park, S.J., McSweeney, K., Lowery, B., 2001. Identification of the spatial distribution of soils using a process-based terrain characterization. Geoderma 103(3-4), 249-272.

Park, S.J., van de Giesen, N., 2004. Soil-landscape delineation to define spatial sampling domains for hillslope hydrology. Journal of Hydrology 295(14), 28-46.

Pendleton, R.L., S. Montrakun, 1957. The soils of Thailand. Proc 9th Pacific science cong Vol. 18 : Soil and Land Clasiification.

Petersen, H., Wunderlich, T., al Hagrey, S.A., Rabbel, W., 2012. Characterization of some Middle European soil textures by gamma-spectrometry. Journal of Plant Nutrition and Soil Science 175(5), 651-660.

Pickup, G., Marks, A., 2000. Identifying large-scale erosion and deposition processes from airborne gamma radiometrics and digital elevation models in a weathered landscape. Earth Surface Processes and Landforms 25(5), 535-557.

Pickup, G., Marks, A., 2001. Regional-scale sedimentation process models from airborne gamma ray remote sensing and digital elevation data. Earth Surface Processes and Landforms 26(3), 273-293.

Pike, R.J., 2000. Geomorphometry -diversity in quantitative surface analysis. Progress in Physical Geography 24(1), 1-20.

Pike, R.J., 2002. A bibliography of terrain modeling (geomorphometry): the quantitative representation of topography-Supplement 40 US Geological Survey.

Potichan, A., Wiwatwongwana, P., Watana, S., 2004. Characterization of Established Soil Series in the North and Central Highland Region of Thailand, Reclassified According to Soil Taxonomy 2003, Land Development Department, Bangkok.

R Development Core Team, 2011. R: A Language and Environment for Statistical Computing. In: T.R.F.f.S. Computing (Ed.), Vienna, Austria.

Rawlins, B.G., B. P. Marchant, D. Smyth, C. Scheib, R. M. Lark, C. Jordan, 2009. Airborne radiometric survey data and a DTM as covariates for regional scale mapping of soil organic carbon across Northern Ireland. European Journal of Soil Science 60(1), 44-54.

Rawlins, B.G., Lark, R.M., Webster, R., 2007. Understanding airborne radiometric survey signals across part of eastern England. Earth Surface Processes and Landforms 32(10), 1503-1515. 
Retallack, G.J., 2001. Soils of the Past-An Introduction to paleopedology. 2nd. Blackwell Science.

Sanchez-Moreno, J.F., Jetten, V., Mannaerts, C.M., de Pina Tavares, J., 2014. Selecting best mapping strategies for storm runoff modeling in a mountainous semi-arid area. Earth Surface Processes and Landforms 39(8), 1030-1048.

Sanchez, P.A., Ahamed, S., Carré, F., Hartemink, A.E., Hempel, J., Huising, J., Lagacherie, P., McBratney, A.B., McKenzie, N.J., Mendonça-Santos, M.d.L., Minasny, B., Montanarella, L., Okoth, P., Palm, C.A., Sachs, J.D., Shepherd, K.D., Vågen, T.-G., Vanlauwe, B., Walsh, M.G., Winowiecki, L.A., Zhang, G.-L., 2009. Digital Soil Map of the World. Science 325(5941), 680-681.

Sangchyoswat, C., Russel, S.Y., 2002. Predicting Soil Properties from Landscape Attributes with a Geographic Information System. CMU. Journal 1(3), 257-272.

Schargel, R., 1994. Multipurpose application of soil information. In: J.A. Zinck (Ed.), Soil survey : perspectives and strategies for the 21st century : an international workshop for heads of national soil survey organizations : November 1992, Enschede, Netherlands. ITC Publication;21. ITC, Enschede, pp. 23-29.

Schetselaar, E.M., Chung, C.-J.F., Kim, K.E., 2000. Integration of Landsat TM, Gamma-Ray, Magnetic, and Field Data to Discriminate Lithological Units in Vegetated. Remote Sensing of Environment 71(1), 89-105.

Schoorl, J.M., Veldkamp, A., 2006. Multiscale soil-landscape process modeling. In: S. Grunwald (Ed.), Environmental soil-landscape modeling : geographic information technologies and pedometrics, Books in soils, plants, and the environment. CRC/Taylor \& Francis, Boca Raton, pp. 417 $-435$.

Schuler, U., Erbe, P., Zarei, M., Rangubpit, W., Surinkum, A., Stahr, K., Herrmann3, L., 2010. A gamma-ray spectrometry approach to field separation of illuviation-type, WRB reference soil groups in northern Thailand. J. Plant Nutr. Soil Sci. 000(1-9).

Scull, P., Franklina, J., Chadwickb, O.A., McArthura, D., 2003. Predictive soil mapping: a review. Progress in Physical Geography 27(2), 171-197.

Shi, X., 2013. ArcSIE user's guide. Available in: <http://

www.arcsie.com/index.htm> Acessed on: December, 2017.

Shi, X., Zhu, A.-X., Burt, J.E., Qi, F., Simonson, D., 2004. A Case-based Reasoning Approach to Fuzzy Soil Mapping. Soil Sci Soc Am J 68(3), 885-894.

Shrestha, D.P., Moonjun, R., Farshad, A., Udomsri, S., 2016. Adequacy of Soil Information Resulting from Geopedology-Based Predictive Soil Mapping for Assessing Land Degradation: Case Studies in Thailand. In: J.A. Zinck, G. Metternicht, G. Bocco, H.F. Del Valle (Eds.), Geopedology: An Integration of Geomorphology and Pedology for Soil 
and Landscape Studies. Springer International Publishing, Cham, pp. 457-471.

Simbahan, G.C., Dobermann, A., Goovaerts, P., Ping, J., Haddix, M.L., 2006. Fine-resolution mapping of soil organic carbon based on multivariate secondary data. Geoderma 132(3-4), 471-489.

Sini, M.A., Al-ayasreh, K., Al-Jundi, J., 2007. Determaion of Uranium, Thorium and Potassium Activity Concentration in Soil Cores in Araba Valley, Jordan. Radiation Protection Dosimetry Advance Access published online on June 26.

Smith, M.P., Zhu, A.X., Burt, J.E., Stiles, C., 2006. The effects of DEM resolution and neighborhood size on digital soil survey. Geoderma 137(1-2), 58-69.

Soil Survey and Classification Division, 2005. Soil map for landuse planning, Petchaboon province. 2548/1, Land Development Department, Bangkok.

Soil Survey Staff, 1975. Soil taxonomy: a basic system of soil classification for making and interpreting soil surveys. 2nd ed. U.S. Dept. of Agriculture, Natural Resources Conservation Service, Washington, D.C.

Soil Survey Staff, 1993. Soil Survey Manual, Agricultural Handbook 18,. In: US Department of Agriculture (Ed.), Washington, D.C., USA (1993).

Soil Survey Staff, 2006. Keys to soil taxonomy, 10th ed. 10th ed. U.S. Dept. of Agriculture, Natural Resources Conservation Service, Washington, D.C.

Sørensen, R., Seibert, J., 2007. Effects of DEM resolution on the calculation of topographical indices: TWI and its components. Journal of Hydrology 347(1-2), 79-89.

SPSS, 1999. SPSS. SPSS Inc.

Sreenivas, K., Dadhwal, V.K., Kumar, S., Harsha, G.S., Mitran, T., Sujatha, G., Suresh, G.J.R., Fyzee, M.A., Ravisankar, T., 2016. Digital mapping of soil organic and inorganic carbon status in India. Geoderma 269, 160173.

Tagil, S., Jenness, J., 2008. GIS-based Automated Landform Classification and Topographic, Landcover and Geologic Attributes of Landforms Around the Yazoren Polje, Turkey. Journal of Applied Sciences 8(6), 910-921.

Taylor, M.J., Smettem, K., Pracilio, G., Verboom4, W., 2002. Relationships between soil properties and high-resolution radiometrics, central eastern Wheatbelt, Western Australia. Exploration Geophysics 33(2), 95-102.

Thomas, A.L., King, D., Dambrine, E., Couturier, A., Roque, J., 1999. Predicting soil classes with parameters derived from relief and geologic materials in a sandstone region of the Vosges mountains (Northeastern France). Geoderma 90(3-4), 291-305.

Thompson, J.A., Bell, J.C., Butler, C.A., 2001. Digital elevation model resolution: effects on terrain attribute calculation and quantitative soillandscape modeling. Geoderma 100(1-2), 67-89. 
Thompson, J.A., Pena-Yewtukhiw, E.M., Grove, J.H., 2006. Soil-landscape modeling across a physiographic region: Topographic patterns and model transportability. Geoderma 133(1-2), 57-70.

Thwaites, R.N., 2007. Chapter 20 Conceptual and Digital Soil-landscape Mapping Using Regolith-catenary Units. In: P. Lagacherie, A.B. McBratney, M. Voltz (Eds.), Digital soil mapping : an introductory perspective. Developments in soil science. Elsevier, Amsterdam ; Boston, pp. 257-268.

Trisurat, Y., Alkemade, R., Verburg, P.H., 2010. Projecting Land-Use Change and Its Consequences for Biodiversity in Northern Thailand. Environmental Management 45(3), 626-639.

Tu, T.-M., Su, S.-C., Shyu, H.-C., Huang, P.S., 2001. A new look at IHS-like image fusion methods. Information Fusion 2(3), 177-186.

Tunstall, B., 2003 Use of Radiometrics in Soil Survey. ERIC.

Udomsri, S., 2006. Application of computer assisted geopedologic to predictive soil mapping and its use in assessing soil erosion prone areas : a case study of Doi Ang Khan, Ang Khang Royal agricultural station, Thailand, ITC, Enschede, 119 pp.

USDA., 1996. Soil Survey Laboratory Methods Manual. SSIR 42.

Valladares, G.S., Hott, M.C., 2008. Chapter 31:The use of GIS and digital elevation model in digital soil mapping - a case study from Sao Paulo, Brazil. In: A.E. Hartemink, A.B. McBratney, M.L. Mendonça-Santos (Eds.), Digital soil mapping with limited data, , pp. 349-356.

Vaysse, K., Lagacherie, P., 2017. Using quantile regression forest to estimate uncertainty of digital soil mapping products. Geoderma 291, 55-64.

Walker, P.H., Hall, G.F., Protz, R., 1968. Relation between Landform Parameters and Soil Properties. Soil Sci Soc Am J 32(1), 101-104.

Weiss, A., 2001. Topographic position and landforms analysis, Poster Presentation, ESRI User Conferrence, San Diego, CA.

Whittig, L.D., 1965. X-ray diffraction technique for minerals identification and mineralogical composition. In: C.A. Black (Ed.), Methods of Soil Analysis. Part II.Monograph No. 9. American Society of Agronomy Inc., Madison, Wiscocsin., pp. 671-698.

Wiesmeier, M., Barthold, F., Blank, B., Kogel-Knabner, I., 2011a. Digital mapping of soil organic matter stocks using Random Forest modeling in a semi-arid steppe ecosystem. Plant Soil 340(1-2), 7-24.

Wiesmeier, M., Barthold, F., Blank, B., Kögel-Knabner, I., 2011b. Digital mapping of soil organic matter stocks using Random Forest modeling in a semi-arid steppe ecosystem. Plant and Soil 340(1), 7-24.

Wilford, J., A weathering intensity index for the Australian continent using airborne gamma-ray spectrometry and digital terrain analysis. Geoderma (0).

Wilford, J., 2002. Ariborne Gamma-Ray Spectrometry, CRCLEME Open File Report. 
Wilford, J., 2007. Remote sensing with gamma-ray spectrometry. In: NJ McKenzie, MJ Grundy, R Webster, AJ Ringrose-Voase (Eds.), Guidelines for surveying soil and land resources Australian soil and land survey handbook series. CSIRO, Melbourne, pp. 557.

Wilford, J., 2009. Using airborne geophysics to define the 3D distribution and landscape evolution of Quaternary valley-fill deposits around the Jamestown area, South Australia. Australian Journal of Earth Sciences: An International Geoscience Journal of the Geological Society of Australia 56(1 supp 1), 67 - 88.

Wilford, J., Minty, B., 2007. Chapter 16 The Use of Airborne Gamma-ray Imagery for Mapping Soil and Understanding Landscape Processes. In: P. Lagacherie, A.B. McBratney, M. Voltz (Eds.), Digital Soil Mapping An Introductory Perspective. Elsevier, Amsterdam, pp. 207-218.

Wilford, J.R., P.N. Bierwirth, Craig, M.A., 1997. Application of airborne gammaray spectrometry in soil/regolith mapping and applied geomorphology. AGSO Journal of Australia Geology\&Geophysics 17 (2), 201-216.

Wilson, J.P., Gallant, J.C., 2000. Terrain analysis : principles and applications. Wiley, New York.

Wisedsind, W., Kiatiwongchai, T., Hatch, D., 1994. Airborne Geophysical Survey Interpretation of Phehchabun, Lopburi and Nakorn Sawan, Thailand, Department of Mineral Resources, Thailand, Economic Geology Division.

Wolock, D.M., McCabe, G.J., 2000. Differences in topographic characteristics computed from 100- and 1000-m resolution digital elevation model data. Hydrological Processes 14(6), 987-1002.

Wu, S., Li, J., Huang, G.H., 2008a. A study on DEM-derived primary topographic attributes for hydrologic applications: Sensitivity to elevation data resolution. Applied Geography 28(3), 210-223.

Wu, W., Fan, Y., Wang, Z., Liu, H., 2008b. Assessing effects of digital elevation model resolutions on soil-landscape correlations in a hilly area. Agriculture, Ecosystems \& Environment 126(3-4), 209-216.

Young, F.J., Hammer, R.D., 2000. Soil-Landform Relationships on a LoessMantled Upland Landscape in Missouri. Soil Sci Soc Am J 64(4), 14431454.

Zeraatpisheh, M., Ayoubi, S., Jafari, A., Tajik, S., Finke, P., 2019. Digital mapping of soil properties using multiple machine learning in a semi-arid region, central Iran. Geoderma 338, 445-452.

Zeverbergen, L.W., and C. R. Thorne. . . . 1987. Quantitative Analysis of Land Surface Topography. Earth Surface Processes and Landforms 12, 47-56.

Zhu, A.X., 1997a. Measuring uncertainty in class assignment for natural resource maps under fuzzy logic. Photogramm Eng Rem S 63(10), 1195-1202.

Zhu, A.X., 1997b. Measuring uncertainty in class assignment for natural resource maps using a similarity model. Photogrammetric Engineering Remote Sensing 63, 1195-1202. 
Zhu, A.X., 1997c. A similarity model for representing soil spatial information. Geoderma 77(2-4), 217-242.

Zhu, A.X., 1997d. A similarity model for representing soil spatial information. Geoderma 77, 217-242.

Zhu, A.X., Band, L., Vertessy, R., Dutton, B., 1997. Derivation of soil properties using a soil land inference model (SoLIM). Soil Science Society of America Journal 61(2), 523-533.

Zhu, A.X., Burt, J.E., Smith, M., Rongxun, W., Jing, G.A.O., 2008. The Impact of Neighbourhood Size on Terrain Derivatives and Digital Soil Mapping. In: Q. Zhou, B. Lees, G.-a. Tang (Eds.), Advances in Digital Terrain Analysis. Lecture Notes in Geoinformation and Cartography. Springer Berlin Heidelberg, pp. 333-348.

Zhu, A.X., Hudson, B., Burt, J., Lubich, K., Simonson, D., 2001. Soil Mapping Using GIS, Expert Knowledge, and Fuzzy Logic. Soil Sci Soc Am J 65(5), 1463-1472.

Ziadat, F.M., 2005. Analyzing Digital Terrain Attributes to Predict Soil Attributes for a Relatively Large Area. Soil Sci Soc Am J 69(5), 15901599.

Zinck, J.A., 1988/1989. Physiography and Soil. Lecture-notes for soil students.

Zinck, J.A., 1989. Physiography and soils, ITC lecture notes. ITC, Enschede, pp. 156. 


\section{Summary}

Thailand has a long tradition of using detailed soil information in agriculture and watershed management .Agricultural extension workers ) locally named "soil doctors(", give advice on farm level on increasing agricultural production and combat land degradation. Unfortunately, detailed soil information is only available for the flat areas where most of the agriculture used to be concentrated, with conventional soil mapping methods based on the US Soil Taxonomy classification system . As more and more of the hilly and mountainous areas are being used there is now a distinct lack of detailed soil data for these services . Also the complexity of the services has increased, dealing with integrated watershed management, addressing sustainability and more complex forms of land degradation, soil conservation and infrastructure development.

The Thai government cannot afford to do a detailed soil survey for the entire country as it is prohibitively expensive. Large scale soil survey products are not adequate, either categorically or cartographically, and cannot be easily downscaled for detailed applications This study investigates an .alternative soil survey method, developing a framework as a standard or guidelines to implement soil survey projects efficiently based on digital soil mapping)DSM (techniques . The framework should cope with the generation, maintenance and use of digital soil map products to meet the increasing demand of soil data for multi-purpose use and also offering possibilities for the update of soil information. The purpose of this research, therefore, is to investigate DSM methods for fine- scale soil mapping. The specific objectives include: 1) an investigation of high-resolution DEM and digital terrain modelling techniques, 2) application of airborne gammaray imagery and 3) use of fuzzy logic for fine-scale soil mapping. The study was conducted in Lomsak, Phetchabun province in Thailand, an area characterized by a variable terrain (flat to mountainous) and a large variety in soil types.

Eight terrain attributes were computed from two DEM resolutions (original 5- $\mathrm{m}$. and degraded to $10-\mathrm{m}$.) using three neighborhood sizes $(5 \times 5,10 \times 10$ and $20 \times 20$ cells). These attributes and their standardized principal components were then used as predictive variables for soil series and properties using logistic and linear regression, respectively. The results show that DEM derivatives based on grid resolution alone are not sufficient in analyzing their applicability in soil mapping. The neighborhood size also becomes important. The application of high resolution DEM at $5 \mathrm{~m}$ resolution with neighborhood size of 10x10 pixels gave good result to help map soil series. Single terrain variables could only model about $20 \%$ of the variability in subsoil bulk density and $\mathrm{pH}$, with no clear advantage to either 
resolution or window size. Principal components derived from 5-m DEM with 20x20 neighborhood size and 10-m DEM with 10x10 neighborhood size were moderately successful (20-25\% of variance explained) for these two properties. Probabilities of occurrence for two of three representative soil series were successfully modeled (area under ROC curve about 0.9 ) from the 5-m DEM with 10x10 neighborhood and 10-m DEM with 5x5 pixel of neighborhood. Predictive maps generally conformed to expert knowledge of experienced mappers, but showed large differences in detail among window sizes. No general conclusion can be drawn about appropriate resolution and window size; these must be investigated per-property or series. Further, relief alone is a poor predictor of soil properties in this landscape.

The relationship between gamma-ray data and geological units was examined with box- and-whisker plots, using rock and soil samples. Rock and soil sample classifications were compared with the gamma- ray image and to typical radioelement responses found in the literature. To interpret AGRI data in terms of regolith and soil genesis, we compared AGRI to two existing soil maps: geopedologic and soil series maps. First, the geopedologic map was split into four maps according to the geopedologic hierarchy: landscape, lithology, relief, and landform; at the latter (lowest) level, soil units are also associated. Secondly, soil series and geopedologic soil units were used to examine the distribution of radioelement response to selected soil characteristics: parent material, texture, mineralogy, and thickness. The correlation in both soil maps was interpreted in terms of the radioelement changes during pedogenic and geomorphic process, based on a review of literature and supported by soil samples.

AGRI provided useful information in three forms (single signal, ratio, and so called ternary images enhanced with a hill shaded DEM) by relating these to lithology, material transport, and internal pedogenic processes. AGRI correlated well with the classes of the geopedologic map $(1: 50,000)$ at the two higher levels (landscape and lithology) but to a lesser degree at the two lower levels (relief and landform in geopedologic approach). In the mapping stage, AGRI showed deficiencies in the soil series map $(1: 50,000)$ made by conventional aerial photo analysis and limited field surveys, especially in inaccessible areas but also in low-relief terraces and flood plains, which provided a basis for future field sampling to correct these deficiencies. AGRI suggested new boundaries, differentiating topsoil properties and the presence of plinthite, despite its coarse resolution. Clustering of gamma ray and elevation data (DEM) was carried out using fuzzy logic to generate various classification layers. Class labels were assigned to the one with the largest total 
inverse distance over the entire set of fuzzy classification bands. The result shows relatively higher classification accuracy for soil parent material differentiation (overall accuracy of $72 \%$ ) as compared to the classification for soil types (67\%). Therefore, the result also shows that gamma- ray helps in determining lithology/parent material, weathering index and topsoil texture.

Soil series and topsoil texture mapping in a complex landscape has been carried out using fuzzy logic (SoLIM). An expert system is used whereby rule-based reasoning is applied for mapping soils in which the soil-landscape relationship is taken into account. The accuracies of the fuzzy logic derived soil map and that of conventional soil map are tested using a set of validation data. The results show that a soil series map generated by fuzzy logic has an overall accuracy of $67 \%$, the highest accuracy is found in the $\mathrm{Ct}$ series (88\%) and the lowest in So series (57\%). The results depend on the degree in which a series are related to a landscape position, and the broadness of the definition of the series. Regarding the topsoil texture, three texture classes give the highest accuracy (greater than $80 \%$ ) are Silty Clay, Slightly Gravelly Clay Loam and Rock outcrops, while the lowest accuracy was found in Clay Loam (53\%). The overall accuracy is about $65 \%$. The accuracy of the soil map prepared by the conventional method shows an overall accuracy of $13 \%$. The results confirm that Fuzzy Logic is advantageous in providing detailed information about spatial variations and representing realistic spatial patterns in soil series and topsoil texture maps. It has also the potential for reducing inconsistency associated with the traditional soil mapping processes, and as mapping can be carried out with a relatively low density of soil samples it may also reduce costs.

Soil survey works in Thailand are the responsibility of the Land Development Department (LDD), Ministry of Agriculture \& Cooperatives. Currently, there is an increased demand of soil information not only for farm level planning but also for addressing complex sustainability issues. LDD has adopted geo- information system (GIS) and remote sensing techniques (RS) for digitizing existing soil maps, map visualization and data retrieval, but the LDD has not yet implemented digital soil mapping (DSM) techniques. The research results can be used to support soil survey works in Thailand in developing guidelines and framework for digital soil mapping, also for soil mapping in complex sloping landscapes, based upon specific Thai needs and conditions. 


\section{Samenvatting}

Thailand heeft een lange geschiedenis in het gebruik van bodeminformatie voor landbouw en het beheer van stroomgebieden. Landbouwdeskundigen (lokaal "soil doctors" genaamd) geven advies op aan boeren om de productie te verhogen en land degradatie te voorkomen. Gedetailleerde bodem informatie is niet overal beschikbaar in Thailand, alleen de vlakke gebieden die voor landbouw gebruikt worden zijn in kaart gebracht met een conventionele bodem karteringsmethode, gebaseerd op de US Soil Taxonomy. Recentelijk worden meer en meer de heuvelachtige en bergachtige gebieden in gebruik genomen, waar bodem informatie ontbreekt. Ook is de behoefte aan informatie meer complex, waar bij bodem informatie gebruikt wordt voor duurzame ontwikkeling door middel van integraal gebiedsbeheer en onderzoeken en modelleren van complexe vormen van land degradatie en bodem conservering, en ontwikkeling van infrastructuur.

De Thaise overheid kan zich niet veroorloven om het hele land te karteren met conventionele technieken. Dit is te duur en grootschalige kaarten zijn cartografisch en inhoudelijk niet geschikt voor het neerschalen naar gedetailleerde toepassingen. Deze studie onderzoekt een alternatieve methode Digital Soil Mapping (DSM) ontwikkeld kan worden als standaard methode. Het DSM raamwerk met het maken en beheer en vernieuwen van bodem informatie voor complexe toepassingen. Om dit te realisren moeten de volgende punten onderzocht worden: 1) welke digitale terrein parameters zijn geschikt om te koppelen aan bodem informatie en op welke resolutie, 2) kunnen we Airborne Gamma-Ray data (AGRI) gebruiken als extra informatie, en 3) kunnen we Fuzzy Logic kartering gebruiken voor gedetailleerde bodem kartering. Als laatste is geanalyseerd wat het Thaise Land Devlopment Department van het Ministerie van Landbouw nodig zou hebben om DSM te implementeren. De studie is uitgevoerd in Lomsak in centraal Thailand, een gebied dat gekenmerkt wordt door variabel terrein (vlak tot bergachtig) en een grote afwisseling in bodemtypes kent.

Acht terrein attributen zijn berekend uit DEMs met 2 resoluties ( 5 en $10 \mathrm{~m}$ ) met drie filter groottes ('neighbourhood size' 5, 10 en 20 cellen). Deze attributen en hun gestandaardiseerde principale componenten zijn als voorspellende variabelen voor Soil Series en bodem eigenschappen, met respectievelijk logistische en lineaire regressie. De resultaten laten zien dat niet alleen de resolutie van de DEM maar ook de filter grootte belangrijk zijn. De combinatie $5 \mathrm{~m}$ DEM met een $10 \mathrm{~m}$ filter grootte gaf de beste resultaten. Enkele terrein parameters konden niet meer dan $20 \%$ van de variabiliteit verklaren van de bulk dichtheid en $\mathrm{pH}$ van de 
ondergrond, zonder duidelijke effect van resolutie of filter grootte. Principale componenten afgeleid van de 5m DEM met een 10x10 filter grootte en een $10 \mathrm{~m}$ DEM met een $5 \times 5$ filter grootte waren succesvoller (20-25\% verklaarde variantie) voor bulk dichtheid en $\mathrm{pH}$. het voorspellen van de kans op voorkomen van 2 van de 3 representatieve ' was succesvol (oppervlakte onder de ROC curve ongeveer $0.9)$, met een $5 \mathrm{~m}$ DEM en 10x10 filter grootte en een 10m DEM met een 5x5 filter grootte. De voorspelde kaarten lieten over het algemeen een goede informatie zien beoordeeld door ervaren bodemkundigen, maar er was veel verschil in detail bij de verschillende filter groottes. Er kan geen conclusie getrokken worden met betrekking tot een optimale DEM resolutie en filter grootte, dit is per bodem eigenschap verschillend. Ook blijkt dat reliëf een slechte voorspeller is van bodem eigenschappen in dit landschap.

De relatie tussen Gamma-ray data en geologische eenheden is onderzocht met box-whisker plots, gebruik makend van gesteente en bodem monsters. Geclassificeerde gesteente en bodem monsters zijn vergeleken met het Gammaray beeld en typische respons van radio actieve elementen uit de literatuur. De AGRI data werd geïnterpreteerd in termen van regoliet en bodem genese, door de data te vergelijken met een geo-pedologische en Soil Series kaarten. Eerste werd de geo-pedologische kaart gesplitst in 4 kaarten overeenkomend met de geo=pedologische hiërarchie: landschap, lithologie, reliëf en landchapsvorm. Op dit laatste niveau zijn ook de Soil Series geassocieerd. Ten tweede werden de Soil Series en geo-pedologische eenheden gebruikt om de variabiliteit in respons van radio elementen te onderzoeken in relatie tot de volgende bodem eigenschappen: moeder materiaal, textuur, mineralogie en bodemdikte. De overeenkomsten tussen de kaarten werden geïnterpreteerd in termen van veranderingen in radio elementen gedurende bodemgenese en geomorfologische processen, ondersteund door bodemmonsters en literatuur gegevens.

AGRI geeft nuttige informatie in drie vormen (enkel signal, ratio beelden en zn. "ternary" beelden versterkt met shaded relief), door deze te relateren aan lithologie, materiaal transport en interne geopedologische processen. Op een schaal van 1:50000 correleerde de AGRI informatie goed met de twee hoogste niveaus 'landschap;' en 'lithologie' correleerden redelijk met de AGRI informatie, en in mindere mate met de twee lagere niveaus 'reliëf' en 'landschapsvorm'. Met AGRI is aan te tonen dat de conventionele 1:50000 bodemkaart, geproduceerd met luchtfoto's en beperkt veldonderzoek, tekortkomingen laat zien, die de basis kunnen zijn voor toekomstige planning van aanvullend veld onderzoek, met name in riviervlaktes en reliëfrijke gebieden. 
AGRI geeft mogelijkheden tot het herkennen van nieuwe bodemgrenzen, het onderscheiden van bodemeigenschappen dichtbij het oppervlak en de aanwezigheid van plintiet, ondanks de lage resolutie. Een cluster analyse en classificatie van AGRI en DEM data werd uitgevoerd met fuzzy logic. Het resultaat laat zien dst de moeder materiaal met een nauwkeurigheid van $72 \%$ voorspeld kan worden en bodem type met een nauwkeurigheid van $67 \%$. Hieruit blijkt dat Gamma-ray data bijdraagt aan het bepalen van de litologie/moeder materiaal, de verweringsindex en de textuur van de bovengrond.

Kartering van Soil Series en textuur van de bovengrond in een complex landschap is uitgevoerd met behulp van het Fuzzy Logic systeem SoLIM. Hierbij wordt een expert system gebruikt met regels waarin de relatie tussen bodems en landschap in acht worden genomen. De nauwkeurigheid van de Fuzzy Logic bodemkaart en de conventionele bodemkaart werden getest met een validatie set. De resultaten laten zien dat de nauwkeurigheid $67 \%$ bedraagt met als beste Soil Series de Ct Series (88\%) en de laagste nauwkeurigheid in de Co Series (57\%). De kwaliteit hangt af van de correlatie tussen de Soil Series en de landschappelijke positie en van de breedte van de definitie van de Soil Series. Wat betreft de textuur van de bovengrond werden de beste resultaten bereikt voor drie textuur klassen ( $>80 \%)$ : Silty Clay, Slightly Gravelly Clay Loam en Rock outcrops, terwijl de laagste nauwkeurigheid gevonden wordt voor Clay Loam (53\%). The nauwkeurigheid van de gehele Fuzzy Logic kaart is $65 \%$, terwijl de nauwkeurigheid van de conventionele bodemkaart slechts $13 \%$ is. Dit toont aan dat Fuzzy Logic voordelen biedt in het klaten zien van gedetailleerde informatie over ruimtelijke variabiliteit en patronen in Soil Series en textuur van de bovengrond. Het heeft ook de potentie om tegenstrijdige informatie in bodemkartering te verminderen, en omdat minder bodemmonsters nodig zijn heeft het de potentie om kosten te verminderen.

Bodemkartering in Thailand is de verantwoordelijkheid van de Land Development Department van het Ministerie van Landbouw. Momenteel is er een toenemende vraag naar gedetailleerde bodem informatie, niet alleen voor landbouw op bedrijfsniveau, maar ook voor meer complexe duurzaamheidsvraagstukken. Het LDD gebruikt GIS en RS om de huidige bodem informatie te digitaliseren en de data beschikbaar te maken, maar Digital Soil Mapping is nog niet geïmplementeerd. Dit onderzoek kan gebruikt worden om het bodemkunde onderzoek in Thailand te ondersteunen en een raamwerk te ontwikkelen voor DSM, voor de complexe reliëfrijke gebieden in Thailand. 


\section{Author's biography}

Ruamporn Moonjun was born on 7 June 1976 in Mueang Nan, Nan province, Thailand. She attended primary (1983) and secondary schools (1989) in Mueang Nan, Nan province. In 1995 she moved to Chiang Mai and studied plant science (BSc study) during 1995-1998, and soil science (MSc study) during 1999 to 2002 at Maejo University. In 2005, with the financial support of Agricultural Research Development Agency (ARDA) of Thailand, she attended course at the Department of Earth Systems Analysis, International Institute of Geoinformation Science and Earth Observation where she obtained her second MSc degree (2007) in geo- information science and earth observation with specialization on geo-hazards. Apart from attending regular degree courses, she had also received a number of short duration trainings to improve her skill for work.

After finishing her master degree, she started working on a research project on digital soil mapping, leading to a $\mathrm{PhD}$ degree for which she got once again the financial support from the Thai government (ARDA).

Ruamporn started working in 1999 as an assistant researcher for 2 years in hydroponics at the Royal Project Foundation in Chiang Mai, Thailand. In 2001, she was hired by the Department of Agriculture, Ministry of Agriculture \& Cooperatives, to work for 2 years as an assistant soil scientist in the soil science laboratory located in regional office in Chiang Mai. In 2003, she got employment at the Land Development Department (LDD), Ministry of Agriculture \& Cooperatives to work as a soil surveyor. Since 2003 she has been working at LDD. Her responsibility in the beginning was soil survey and mapping in sloping areas (high land project) at very detailed scale for the purpose of land use planning and soil conservation in 4 provinces in the northern part of Thailand. In 2008, she was also responsible for soil survey and mapping at detailed and semidetailed scale ( $50 \mathrm{k}$ and $25 \mathrm{k}$ ) in 3 provinces covering about $7,200 \mathrm{~km}^{2}$ area. She also did soil survey in saline soil areas in the northeastern part of Thailand. In 2014, she was promoted to senior professional level and became the Director of Soil quality and productivity interpretation group at the Land Development Department. In 2015, she was given an additional responsibility to be a project manager of a Thai development cooperation project for soil survey and mapping in Bhutan. In 2016, she also became the coordinator of a collaboration project of LDD with the French national institute for agriculture research (INRA) and in 2017, the coordinator of a joint Chinese and Thai project on precision agriculture to improve soil quality and suitability for farm management. 


\section{Publications}

\section{Journal articles}

Moonjun, R., Shrestha, D. P., Jetten, V.G., van Ruitenbeek, F. J. A., 2017. Application of airborne gamma-ray imagery to assist soil survey: A case study from Thailand. Geoderma 289, 196-212.

Moonjun, R., Shrestha, D.P., Jetten, V.G., Fuzzy logic for fine scale soil mapping in sub-watersheds. Manuscript submitted for publication in Catena (??).

\section{Book Chapters}

Moonjun, R., Farshad, A., Shrestha, D. P. and Vaiphasa, C., 2010. Artificial neural network and decision tree in predictive soil mapping of Hoi Num Rin sub-watershed, Thailand. J.L. Boettinger et al. (eds.), Digital Soil Mapping, Progress in Soil Science 2, DOI 10.1007/97890-481-8863-5_13, C_Springer Science+Business Media B.V. 2010

Farshad, A., Shrestha, D.P., and Moonjun, R., 2013. Do the emerging methods of digital soil mapping have anything to learn from the geopedologic approach to soil mapping and vice versa? In S.A. Shahid et al. (eds.), Developments in Soil Classification, Land Use Planning and Policy Implications: Innovative Thinking of Soil Inventory for Land Use Planning and Management of Land Resources, DOI 10.1007/978-94-007-5332-7_4, (C) Springer Science+Business Media Dordrecht, p. 109-131

Shrestha, D. P., Moonjun, R., Farshad, A., and Udomsri, S., 2016. Adequacy of soil information resulting from geopedology-based predictive soil mapping for assessing land degradation: case studies in Thailand. In Zinck et al (eds) Geopedology: an integration of geomorphology and pedology for soil and landscape studies, Springer International Publishing Switzerland, p. 457-471

\section{Conferences proceedings}

Moonjun, R, 2017. Digital soil mapping based on airborne gamma-ray imagery and fuzzy logic: a case of upper Pasak watershed, Thailand. Poster presented at the Pedometrics 2017 Conference, 26 June - 1 July 2017, Wageningen, The Netherlands. 
Moonjun, R., 2017. Modernizing the Thai soil survey, poster presented at the Global Soil Map 2017 Conference, 4 - 6 July, 2017, Moscow, Russia.

Moonjun, R. 2012. Application of Airborne Gamma-Ray Imagery to Assist Soil Survey in the Upper Pasak Basin, Thailand. Poster presented at the The 13th International Symposium on River Sedimentation (ISRS2016). 19-22 September 2016, Stuttgart, Germany

R. Moonjun, D.P. Shrestha, V. Jetten, and F.J. A. van Ruitenbeek, 2015. Interpretation of airborne gamma-ray imagery to assist soil survey: case study from Thailand. Oral presentation at the International Soil Conference 2015: Sustainable Uses of Soil in Harmony with Food Security at the (ISC2015), Phetchaburi, Thailand.

R. Moonjun, A. Pinjongsakuldit and A. Phutaso, 2015. Soil property map of Thailand: Soil Quality project. Poster presented at the International Soil Conference 2015: Sustainable Uses of Soil in Harmony with Food Security, Phetchaburi, Thailand. (Oral presentation) (Received the third prize award).

Moonjun, R., 2012. Implementing DSM in the Thai Soil Survey. Poster presented at the 5th Global Workshop on Digital Soil Mapping, 10-13 April 2012, University of Sydney, Australia. (Received the best poster presentation award).

Moonjun, R. Using airborne gamma-ray data and digital terrain modeling for mapping topsoil properties in Upper Pasak watershed, Thailand. Poster presented at the 33rd Asian Conference on Remote Sensing (ACRS 33rd), 26-29 Novemeber 2012, Pattaya Thailand.

Moonjun, R. , Farshad, A., Shrestha, D. P. and Vaiphasa, C. ( 2008) Application of artificial neural network and decision tree in a GIS based predictive soil mapping in sloping areas in Thailand. Oral presentation at the 3rd global workshop on digital soil mapping, 30 September - 3 October, Utah State University, Logan, Utah. 10 p. 